\title{
Genetics of mood disorders : from pharmacogenetics to disease genetics
}

Citation for published version (APA):

Serretti, A. (2008). Genetics of mood disorders : from pharmacogenetics to disease genetics. [Doctoral Thesis, Maastricht University]. Maastricht University. https://doi.org/10.26481/dis.20081126as

Document status and date:

Published: 01/01/2008

DOI:

10.26481/dis.20081126as

Document Version:

Publisher's PDF, also known as Version of record

\section{Please check the document version of this publication:}

- A submitted manuscript is the version of the article upon submission and before peer-review. There can be important differences between the submitted version and the official published version of record.

People interested in the research are advised to contact the author for the final version of the publication, or visit the DOI to the publisher's website.

- The final author version and the galley proof are versions of the publication after peer review.

- The final published version features the final layout of the paper including the volume, issue and page numbers.

Link to publication

\footnotetext{
General rights rights.

- You may freely distribute the URL identifying the publication in the public portal. please follow below link for the End User Agreement:

www.umlib.nl/taverne-license

Take down policy

If you believe that this document breaches copyright please contact us at:

repository@maastrichtuniversity.nl

providing details and we will investigate your claim.
}

Copyright and moral rights for the publications made accessible in the public portal are retained by the authors and/or other copyright owners and it is a condition of accessing publications that users recognise and abide by the legal requirements associated with these

- Users may download and print one copy of any publication from the public portal for the purpose of private study or research.

- You may not further distribute the material or use it for any profit-making activity or commercial gain

If the publication is distributed under the terms of Article $25 \mathrm{fa}$ of the Dutch Copyright Act, indicated by the "Taverne" license above, 
Alessandro Serretti

Genetics of mood disorders: from pharmacogenetics to disease genetics 
Cover illustration: Melancolia I by Albrecht Dürer, 1514. 
Genetics of mood disorders:

from pharmacogenetics to disease genetics

Dissertation:

to obtain the degree of Doctor at the Maastricht University, on the authority of the Rector Magnificus,

Prof. dr. G.P.M.F. Mols

in accordance with the decision of the Board of Deans,

to be defended in public

on Wednesday, the 26 of November 2008, at 4 hours pm

by

Alessandro Serretti 
Supervisor:

Prof. Dr. E.J.L. Griez

Co-supervisor:

Dr. G. Perna, San-Raffaele Turro, Milan, Italy

Degree committee:

Prof.dr. J. Smits, UM (chairman)

Prof.dr. M. Bourin, Université de Nantes, France

Prof.dr. H.M. van Praag

Prof.dr. W. Riedel

Dr. K. Schruers 
During adulthood few men know how they became what they are...

Something acted on them like fly paper on a fly, blocking a hair here, a movement there and slowly enveloping them until they are buried in a thick envelope that hardly resembles their original shape...

but a youthful, unresting, creative and often purposeless force...

may spread and lead to revolutions, progress or simply to the cyclic generation change.

The Man without Qualities Robert Musil, 1942. 
Contents

$\begin{array}{llr}\text { Chapter 1: } & \text { Introduction } & 8\end{array}$

Chapter 2: Influence of tryptophan hydroxylase and serotonin transporter genes on fluvoxamine antidepressant activity 18

Chapter 3: $\quad$ SSRIs antidepressant activity is influenced by Gb3 variants 19

Chapter 4: $\quad$ The C(-1019)G polymorphism of the 5-HT1A gene promoter and antidepressant response in mood disorders: preliminary findings 20

Chapter 5: $\quad$ Neural network analysis in pharmacogenetics of mood disorders $\quad 21$

Chapter 6: Genetic dissection of psychopathological symptoms: Insomnia in mood disorders and CLOCK gene polymorphism

Chapter 7: Insomnia improvement during antidepressant treatment and CLOCK gene polymorphism

Chapter 8: Serotonin transporter gene variants and behavior:

A comprehensive review

Chapter 9: Dissecting the determinants of depressive disorders outcome: an in depth analysis of two clinical cases

Chapter 10: Meta-analysis of serotonin transporter gene promoter polymorphism (5-HTTLPR) association with selective serotonin reuptake inhibitor efficacy in depressed patients

Chapter 11: Association between GSK-3 $\beta$-50T/C polymorphism and personality and psychotic symptoms in mood disorders

Chapter 12: Discussion

Summary and concluding remarks

Samenvatting en conclusies 
Chapter 1: Introduction 
Mental disorders in general, and mood disorders in particular, are leading causes of morbidity which affect human populations around the world. Mood (affective) disorders are the most common severe adult psychiatric disorders. The term 'mood disorder' includes a wide variety of conditions, from mild and close to normal mood variations to some of the most severe episodes of psychotic illness seen in clinical practice (Kendler and Gardner, 1998). The most relevant ones include Bipolar Disorder (BP) and Major Depression (MD).

$\mathrm{BP}$ and MD present a point prevalence of about $1 \%$ and $7-10 \%$ respectively (Alonso and Lepine, 2007; Kessler et al., 2005). These diseases are associated with a high rate of morbidity and mortality, even after taking into account suicide separately (Serretti et al., 1999). Mood disorders are also associated with high direct and indirect costs for the frequent hospitalizations, the high probability of abuse of alcohol and psychotropic drugs, the significant social and professional impairment and the burden on caregivers. It has been estimated that they alone contribute to $11 \%$ of all ICD-9 disabilities, and that only in the USA they cost about 147 billion dollars a year summing both direct and indirect costs (Das Gupta and Guest, 2002; Pincus and Pettit, 2001; Sartorius, 2001; Ustun et al., 2004; Wittchen and Jacobi, 2005).

It is now widely accepted that mood disorders have a genetic liability (McGuffin et al., 2004). This has been demonstrated by decades of family, twin and adoption studies. Estimates of heritability range from $30 \%$ to $80 \%$ with values closer to the higher range for bipolar disorder (Johansson et al., 2001).

In detail, data from more than 40 studies on families over a period of 60 years, show that there is a strong genetic predisposition, with a risk of being affected for relatives of first and second degree affected subjects that ranges from 2 to 15 times compared to the general population (Tsuang and Faraone, 1990). This value is proportional to the number of affected family members, and the results are in favor of a higher genetic component in BP in which the concordance rate for monozygotic twins is $80 \%$, while it is around $59 \%$ for MD (Tsuang and Faraone, 1990). The difference in concordance rate between monozygotic and dizygotic twins allows the calculation of heritability. While if a monozygotic twin is affected, the cotwin has from 60 to $80 \%$ chance of being affected, the dizygote twin of an affected individual has only $10-15 \%$ chance of developing the disease. From this, the heritability estimate of approximately $80 \%$.

Despite the fact that we know that genetic factors play an important role, the pattern of genetic transmission of mood disorders it is not yet established. Segregation analyses rejected a single locus mendelian inheritance, reduced penetrance models have been proposed but also disconfirmed and the most plausible model is a complex interaction between a number of interacting genes, each contributing to a single aspect of the disease and interacting with the environment (Risch, 1990). It is likely that this critical role played by the environment in modulating the genetic susceptibility to mood disorders is the main difficulty in investigating genetics susceptibility factors.

Notwithstanding this strong evidence coming for formal genetic studies, the identification of specific risk gene variants has proven to be quite difficult (Craddock et al., 2001; Johansson et al., 2001; Kato, 2007). After the initial enthusiasm spread by the claim of identification of the gene for bipolar disorder on chromosome 11 (Egeland et al., 1987), 20 years of investigations with more than 2000 published reports failed to identify unequivocal liability genes. In fact, after only 2 years, the same authors re-evaluated the published sample and 2 
subjects out of more than 100 that were not affected at the time of the first report were diagnosed as affected and the association dropped to non significance (Kelsoe et al., 1989). This was the beginning of what has been described a "manic depressive history" (Risch and Botstein, 1996) with enthusiasm for new findings followed by disillusionment for lack of replication in independent samples. The core problem being the original idea that a single gene could be responsible of the disease in a Mendelian inheritance and that the phenotype as described by current classification systems could be adequate (American Psychiatric Association, 1994). The idea that a single gene is responsible for the whole picture of BP or MD has been abandoned also following examples from simpler organisms where each single gene modifies in a subtle but wide way the behavior (Kendler, 2005; Kendler and Greenspan, 2006). Subtle because the variances explained by each variant are in the range of $2-3 \%$ with other gene variants further intervening and wide because each gene variant influences many behavioral traits simultaneously (pleiotropy). This has been clarified by the example of the polymorphism within the serotonin transporter gene (Serretti et al., 2006a), that will be discussed in more detail later. Moreover, the huge number of single nucleotide variations (SNPs, 5-7 millions) is not the only source of genetic variability. Recent reports underline the growing importance of hundred of thousands of small sequence abnormalities (copy number variation) (Rodriguez-Revenga et al., 2007) or of environmentally controlled epigenetic controls (methylation) (Holliday, 2006).

Nevertheless some promising findings have been obtained. A number of risk gene variants for mood disorders have been consistently replicated. A review of published findings is beyond our aim but, as an example, in Figure 1 are reported all the linkage findings in bipolar disorder up to date with in bold the replicated areas. 


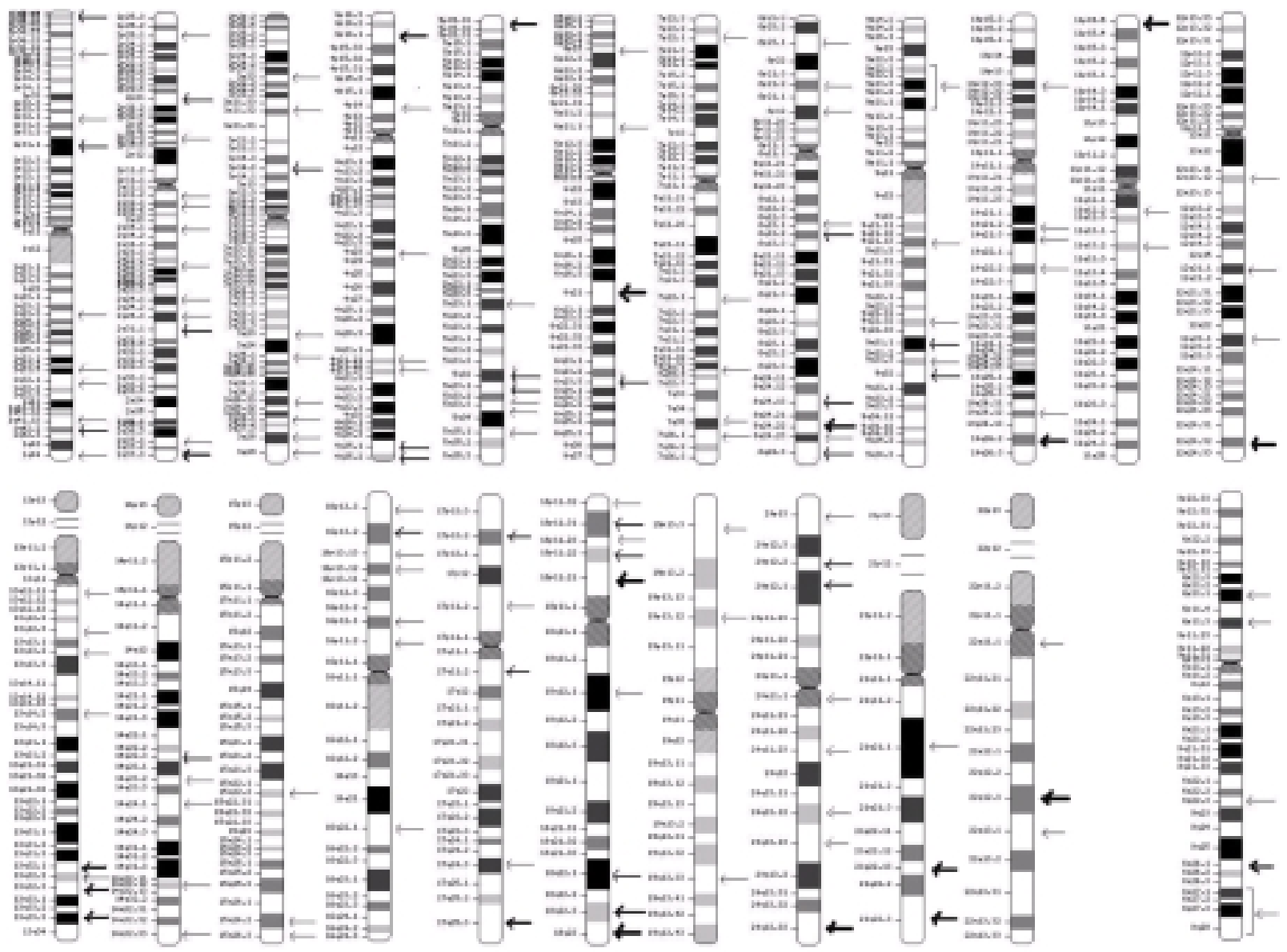

Figure 1. Genome areas where linkage with bipolar disorder has been reported. Bolder arrows indicate stronger evidence.

Some regions are overlapping also with candidate gene studies. Again a huge number of results have been reported and in Table 1 only findings replicated in at least three independent samples are summarized. It is clear from the table that also a number of studies did not confirm the original finding, and this has been related to the complexities abovementioned. 


\begin{tabular}{|c|c|c|c|}
\hline Region & Gene & Positive studies & Negative studies \\
\hline \multicolumn{4}{|c|}{ Chromosome 1} \\
\hline $1 \mathrm{q} 42.1$ & DISC1 & $\begin{array}{l}\text { (Hodgkinson et al., 2004; Maeda et al., } \\
\text { 2006; Thomson et al., 2005; Wellcome } \\
\text { Trust, 2007) }\end{array}$ & (Devon et al., 2001) \\
\hline \multicolumn{4}{|c|}{ Chromosome 5} \\
\hline $5 \mathrm{p} 15.3$ & SLC6A3 & $\begin{array}{l}\text { (Greenwood et al., 2001; Greenwood et } \\
\text { al., 2006; Keikhaee et al., 2005; Ohadi et } \\
\text { al., 2007; Stober et al., 2006; Waldman et } \\
\text { al., 1997) }\end{array}$ & $\begin{array}{l}\text { (Bocchetta et al., 1999; } \\
\text { Georgieva et al., 2002; Gomez- } \\
\text { Casero et al., 1996; Heiden et al., } \\
\text { 2000; Souery et al., 1996) }\end{array}$ \\
\hline $5 \mathrm{q} 35.1 *$ & DRD1 & $\begin{array}{l}\text { (Dmitrzak-Weglarz et al., 2006; Ni et al., } \\
\text { 2002b; Severino et al., 2005) }\end{array}$ & $\begin{array}{l}\text { (Cichon et al., 1994; Cichon et } \\
\text { al., 1996; Jensen et al., 1992; } \\
\text { Mitchell et al., 1992; Nöthen et } \\
\text { al., 1992; Savoye et al., 1998) }\end{array}$ \\
\hline \multicolumn{4}{|c|}{ Chromosome 6} \\
\hline $6 \mathrm{p} 21.3$ & DTNBP1 & $\begin{array}{l}\text { (Breen et al., 2006; Fallin et al., 2005; Joo } \\
\text { et al., 2007; Pae et al., 2006; Pae et al., } \\
\text { 2007; Raybould et al., 2005) }\end{array}$ & \\
\hline \multicolumn{4}{|c|}{ Chromosome 8} \\
\hline $\begin{array}{l}8 \mathrm{p} 22- \\
\mathrm{p} 11^{*}\end{array}$ & NRG1 & $\begin{array}{l}\text { (Green et al., 2005; Thomson et al., 2007; } \\
\text { Walss-Bass et al., 2006) }\end{array}$ & \\
\hline \multicolumn{4}{|c|}{ Chromosome 11} \\
\hline $11 \mathrm{p} 13$ & BDNF & $\begin{array}{l}\text { (Geller et al., 2004; Green et al., 2006; } \\
\text { Kremeyer et al., 2006; Lohoff et al., 2005; } \\
\text { Muller et al., 2006; Neves-Pereira et al., } \\
\text { 2002; Okada et al., 2006; Schumacher et } \\
\text { al., 2005; Sklar et al., 2002; Strauss et al., } \\
\text { 2004) }\end{array}$ & $\begin{array}{l}\text { (Hong et al., 2003; Kanazawa et } \\
\text { al., 2007; Kunugi et al., 2004; } \\
\text { Nakata et al., 2003; Neves- } \\
\text { Pereira et al., 2005; Oswald et } \\
\text { al., 2004; Skibinska et al., 2004) }\end{array}$ \\
\hline \multicolumn{4}{|c|}{ Chromosome 12} \\
\hline $12 \mathrm{q} 21.1$ & TPH2 & $\begin{array}{l}\text { (Harvey et al., 2007; Harvey et al., 2004; } \\
\text { Lopez et al., 2007; Van Den Bogaert et al., } \\
\text { 2006a ) }\end{array}$ & $\begin{array}{l}\text { (De Luca et al., 2004; Mann et } \\
\text { al., 2007) }\end{array}$ \\
\hline \multicolumn{4}{|c|}{ Chromosome 13} \\
\hline $\begin{array}{l}13 \mathrm{q} 14- \\
\mathrm{q} 21^{*}\end{array}$ & HTR2A & $\begin{array}{l}\text { (Arranz et al., 1997; Bonnier et al., 2002; } \\
\text { Chee et al., 2001; Lin et al., 2003; Ranade } \\
\text { et al., 2003) }\end{array}$ & $\begin{array}{l}\text { (Anguelova et al., 2003; Arranz } \\
\text { et al., 1997; Etain et al., 2004; } \\
\text { Gutierrez et al., 1997a; Ni et al., } \\
\text { 2002a; Ohara et al., 1998; } \\
\text { Vincent et al., 1999) } \\
\end{array}$ \\
\hline $13 \mathrm{q} 33.2 *$ & DAOA & $\begin{array}{l}\text { (Chen et al., 2004; Hattori et al., 2003; } \\
\text { Schumacher et al., 2004; Williams et al., } \\
\text { 2006) }\end{array}$ & \\
\hline \multicolumn{4}{|c|}{ Chromosome 17} \\
\hline $\begin{array}{l}17 q 11.1- \\
q 12 *\end{array}$ & SLC6A4 & $\begin{array}{l}\text { (Anguelova et al., 2003; Cho et al., 2005; } \\
\text { Furlong et al., 1998; Lasky-Su et al., } \\
\text { 2005) }\end{array}$ & (Neves et al., 2007) \\
\hline
\end{tabular}




\begin{tabular}{|c|c|c|c|}
\hline \multicolumn{4}{|c|}{ Chromosome 22} \\
\hline $22 q 11.21$ & COMT & $\begin{array}{l}\text { (Burdick et al., 2007; Funke et al., } \\
\text { 2005; Li et al., 1997; Mynett- } \\
\text { Johnson et al., 1998; Rotondo et al., } \\
\text { 2002; Shifman et al., 2004) }\end{array}$ & $\begin{array}{l}\text { (BEBCG, 1997; Gutierrez et al., 1997b; Kunugi } \\
\text { et al., 1997; Lachman et al., 1997; Prata et al., } \\
\text { 2006; Serretti et al., 2003b; Serretti et al., 2006b; } \\
\text { Van Den Bogaert et al., 2006b) }\end{array}$ \\
\hline \multicolumn{4}{|c|}{ Chromosome X } \\
\hline $\mathrm{Xp11.23}$ & MAOA & $\begin{array}{l}\text { Furlong et al., 1999; Lin et al., } \\
\text { 2000; Muller et al., 2007; Preisig et } \\
\text { al., 2000) }\end{array}$ & $\begin{array}{l}\text { (Gutierrez et al., 2004; Kunugi et al., 1999; } \\
\text { Syagailo et al., 2001) }\end{array}$ \\
\hline
\end{tabular}

Table 1. Genes associated with bipolar disorder in at least in three independent samples. The table reports their position and positive and negative studies. Symbol of the gene refer to the OMIM database (http://www.ncbi.nlm.nih.gov/sites/entrez?db=OMIM\&itool=toolbar). Asterisks near the position of the gene indicate that the region have been found in positive linkage with BP. In bold, meta-analysis or large studies on pooled sample.

For MD a smaller number of results have been produced, both for the smaller effort in this direction and for the putatively smaller genetic contribution to the disease (Faraone et al., 1999), however a number of liability gene variants overlap between the two disorders (Kato, 2007; Levinson, 2006).

Converging evidence suggests that this picture is best explained by the fact that each single gene variant exerts some influence on specific behavioral aspects (attention (Egan et al., 2001), temperament (Serretti et al., 2007a), liability to stress (Caspi et al., 2003), etc.) which in turn confers susceptibility to the disease (Flint and Munafo, 2006; Lenox et al., 2002). Therefore the final effect on diagnosis is small and inconsistently replicated. Following this line of evidence, recently research shifted to behavioral aspects more close to the genetic liability, the so called endophenotypes (Flint and Munafo, 2006; Hasler et al., 2006; Lenox et al., 2002). Those may be neuropsychology, symptomatology or brain imaging features. Among the many possible endophenotypes, a particularly interesting one is pharmacogenetics (Weber, 1997). 


\section{Pharmacogenetics}

\section{Historical aspects}

The term "pharmacogenetics" is relatively recent, having been proposed by Friedrich Vogel, German geneticist, in 1959 to describe a discipline dedicated to the study of inheritable differences in the metabolism of pharmacological agents such as exogenous drugs and environmental toxins (Vogel, 1959). However, observations and studies relating to the concept of "pharmacogenetics", as well as phenomena such as interindividual variability of response to a given drug or, in a broader sense, to a given substance, were already known. Between 1850 and 1900 some researchers noticed that most of the drugs were excreted in a different form than the administered one, thus suggesting the existence of chemical modifications prior to the excretion of these substances. Cuenot, Garrod and Bateson first hypothesized that the genetic structure could play a key role in controlling the chemical transformations (Hickman and Cairns, 2003). Garrod realized also that some substances could produce in some people very different reactions, and that these effects could be attributed to toxic substances produced during their metabolic transformations. This is the first time the concept of pharmacokinetics has been proposed.

Around 1930, Snyder showed that the phenomenon of gustatory blindness was inherited as a mendelian autosomal recessive character (Snyder, 1931). This discovery is important because it was the first to suggest the high degree of specificity of the response to chemicals with a genetic influence.

Nearly three decades later, Williams in a series of papers further developed the pharmacokinetic concept putting in evidence the fact that humans are able to transform a large number of chemicals using few metabolic pathways and explained that the metabolism of drugs takes place in two stages, characterized by oxidation reactions, reduction or hydrolysis (Phase I) and conjugation reactions (Phase II) and the involved enzymes were located in the endoplasmic reticulum of the liver or other tissues. Later, the first changes from person to person to be studied were genetic response to succinylcholine, primaquine and isoniazid. Kalow showed the presence of a different enzyme form in some people and their closest relatives with a correlation with hypersensitivity to the drug (Kalow and Gunn, 1957). This study was the first to highlight a link between an heritable enzyme variant and sensitivity to a drug.

Alving then reported that also the administration of the antimalaric primaquine caused in some subjects destruction of red blood cells and correlated this phenomenon to a specific deficiency, associated with sex, to the G6PD enzyme (Alving et al., 1958). Further, isoniazid, widely used in the treatment of tuberculosis, was observed to cause numbness and paresthesia in some patients. Hughes showed that isoniazid had a different level of acetylation in these people (Hughes et al., 1954). Studies on twins and families allowed then to discover that the population could be divided into "slow acetylators" and "rapid acetylators", and that this character was genetically transmitted. Subsequently, molecular studies allowed to establish that this is due to a mutation that makes the enzyme Nacetyltransferase labile and less efficient in its activity.

However it was until late ' 90 that the availability of molecular tools allowed to investigate gene variants linked to the efficacy of antidepressant drugs by our group for the first time (Smeraldi et al., 1998).

Recently, pharmacogenetic aspects have been conceptually divided in pharmacokinetic and pharmacodynamic. Pharmacokinetics is the study of the gene variants responsible of variability in plasma drug concentrations among individuals, on the other hand 
pharmacodynamics focuses on genes influencing variability in sensitivity in drug targets. More specifically, pharmacokinetic describes the way in which a drug is distributed in or cleared from the body and involves absorption of the drug, distribution through hydrophilic and hydrophobic spaces, metabolism, and excretion. Pharmacodynamic examines the drug's interaction with its targets (receptors, transporters or enzymes) and with downstream processes such as second-messenger systems (Perlis, 2007).

Pharmacokinetic genetic controls are important and can influence all antidepressant plasma levels (Kirchheiner et al., 2001), however for the most widely used Selective Serotonin Reuptake Inhibitors (SSRI), the therapeutic range is very large, at times 20-30 times the minimum efficacy level (as an example for Fluvoxamine). Moreover, plasma level has not been linked to therapeutic response, as it was the case for some tricyclic antidepressants (Amsterdam et al., 1997; Kuhs et al., 1992; Normann et al., 2004)

This is the reason why almost all pharmacogenetic studies in mood disorders focused on pharmacodynamic candidate genes. 
We previously outlined the difficulties impairing genetic investigations in psychiatric disorders. Analyses limited to single aspects of the disorder could better elucidate the genetic influence. This, coupled with the need of improving treatments, boosted the recent increase of pharmacogenetic studies in mood disorders.

The need to improve everyday clinical practice comes from the fact that at this moment clinic phenotypes of depression do not allow to select the specific treatment for a specific patient, and when an antidepressant treatment is started, the antidepressant effect does not always lead to complete remission. In fact, even though different classes of antidepressant drugs (AD) have been used to treat depressive syndromes, the antidepressant treatment efficacy is often uncomplete $(60-70 \%$ of patients do not experience remission, $30-40 \%$ do not show significant response) (Moncrieff and Kirsch, 2005), regardless of the initial choice of standard psychiatric medication (Bauer et al., 2002; Entsuah et al., 2001). Moreover, antidepressant response is usually associated with a 2 to 4 weeks lag before improvement takes place, and even though amelioration can occur during the first 2 weeks of treatment, this is uneasy to tell apart from placebo effect (Mitchell, 2006). Accordingly, clinical guidelines still recommend to wait for at least $4-6$ weeks before switching to another $A D$, when an antidepressant response is not achieved. This exposes patients to an un-effective therapy period, higher risk of clinical conditions worsening, higher risk of premature discontinuation, and worse hopelessness feelings, possibly leading to higher suicidal risk (Masand, 2003). As a result, patients run more risk of recurrence of major depressive episodes or worsening of the mental suffering, and possibly have to prolong their hospital stay for longer periods with higher direct and indirect costs. Also, the side effects profiles are not predictable so far, and even though there is a wide interindividual variability, side effects are so common (40\%-90\% (Cramer and Rosenheck, 1998)) that the clinical choice of a specific drug is partially determined by the probability of unwanted effects occurrence. Therefore, in order to reduce the patients' suffering and minimize costs, it would be desirable to know in advance whether a drug is likely to be effective and tolerable: clinic and anamnestic variants were not found to be helpful in this direction (Nierenberg, 2003), whether the genetically determined investigation of pharmacological responses could hold more opportunities (Malhotra et al., 2004; O'Reilly et al., 1994; Perlis, 2007; Serretti and Olgiati, 2007).

The first step to the advance of pharmacogenetic studies is to candidate polymorphic gene variants: there are 5-7 millions of SNPs in the human genome, and even though they usually cosegregate in small groups (tags), the identification of the key variations remains important and difficult to achieve (Drago et al., 2007; Serretti et al., 2007c). The choice of candidate genes is difficult for a number of reasons including the partial knowledge of the pathophysiology mechanisms, the partial knowledge of genetic mechanisms and the almost complete lack of knowledge of systems interactions. In any case candidate genes should be chosen on the basis of variants frequency, functionality, tagging role and coverage of the gene. This last point is almost invariably poorly considered mainly for economical reasons: the genotype of 20-40 variants per gene is more costly than 1-2. However a more complete and commonly accepted investigation of the gene is advised for a list of reasons: to facilitate results' interpretation throughout different studies, to cover important functional areas such as 5'UTR, 3'UTR, promoter, enhancers, silencers, to permit an inductive research approach to the genetic sequence, identifying relevant mutations still far to be hypothesized and to permit the identification of mutations interfering with important functional mechanisms such as: DNA access, reading and trasduction, mRNA stability and translation, mRNA primary 
structure based functions. In all those mechanisms, intronic sequences are as important as exonic ones. Currently, two strategies are available in order to find suitable genes: an inductive approach (genome-wide analysis) based on wide genome association studies of 500,000-1,000,000 SNPs looking for statistical combinations of genetic variations and clinic phenotypes, independently from pharmacological and physiological rational, and a deductive way (candidate gene approach), investigating key variations in genes chosen on the basis of the knowledge of drug therapeutic mechanisms and pathophysiological hypothesis of depression, or based on previous evidence of associations. Those lines of research are mutually dependent: induction of new elements gives more details to improve and criticize previous theoretical models of depression, and deductive efforts stimulate and address new lines of coherent and focused research.

There is a growing interest about the potential of pharmacogenetic in applications for new drug approval and review of existing drugs: the US FDA has began to focus on the near term benefits from such approach (see examples http://www.fda.gov/).

Following this line of research, the present thesis reports 10 recent papers performed within one of the main groups in the field of pharmacogenetics of mood disorders. 
Chapter 2: Influence of tryptophan hydroxylase and serotonin transporter genes on fluvoxamine antidepressant activity 


\title{
Influence of tryptophan hydroxylase and serotonin transporter genes on fluvoxamine antidepressant activity
}

\author{
A Serretti, R Zanardi, D Rossini, C Cusin, R Lilli and E Smeraldi \\ Department of Psychiatry, Vita-Salute University, San Raffaele Institute, Milan, Italy
}

Keywords: tryptophan hydroxylase; serotonin transporter; pindolol; fluvoxamine; mood disorders; antidepressant treatment

The aim of the present study was to test a possible effect of the A218C tryptophan hydroxylase (TPH) gene variant on the antidepressant activity of fluvoxamine in a sample of major and bipolar depressives, with or without psychotic features. Two hundred and seventeen inpatients were treated with fluvoxamine $300 \mathrm{mg}$ and either placebo or pindolol in a double blind design for 6 weeks. The severity of depressive symptoms was weekly assessed with the Hamilton Rating Scale for Depression. TPH allelic variants were determined in each subject by using a PCR-based technique. No significant finding was observed in the overall sample as well as in the pindolol group, while TPH*A/A was associated with a slower response to fluvoxamine treatment in subjects not taking pindolol $(P=0.001)$. This effect was independent from the previously reported influence of 5-HTTLPR polymorphism. If confirmed, these results may shed further light on the genetically determined component of the response to pharmacological treatments, thus helping the clinician to individualize each patient's therapy according to their genetic pattern. Molecular Psychiatry (2001) 6, 586-592.

Antidepressant drugs efficacy for major depression treatment is partly under genetic control. ${ }^{1-7}$ Selective serotonin reuptake inhibitors (SSRIs) exert their activity through a blockade of the neuronal serotonin transporter. The gene encoding for this protein has been shown to have a functional polymorphism in the upstream regulatory region (5-HTTLPR) ${ }^{8,9}$ and recent studies have reported an association between this polymorphism and the antidepressant response to certain SSRIs, such as fluvoxamine ${ }^{10,11}$ and paroxetine. ${ }^{12,13}$ The variance accounted for by this gene was about $7 \%$. This is in accordance with current views on polygenic inheritance, where minor effect genes contribute only $1-10 \%$ to the total phenotypic variance, ${ }^{14,15}$ and the existence of other genes, that contribute with additive, multiplicative or epistatic effects, is very likely. ${ }^{16}$ Further candidate genes may then be identified in the serotonin pathway. Tryptophan (TRP) availability influences 5-HT synthesis in the brain, and TRP has been used both alone $\mathrm{e}^{17}$ and in combination with antidepressant drugs ${ }^{18,19}$ for the treatment of major depressive disorders. Moreover rapid TRP depletion in depressed patients in clinical remission causes a transient depressive relapse. ${ }^{20}$ The tryptophan hydroxylase
(TPH) gene, which codes for the rate-limiting enzyme of serotonin biosynthesis, is therefore a strong candidate for a possible genetic influence on the antidepressant response. This gene has been cloned ${ }^{21}$ and mapped on 11p15.3-p14. ${ }^{22}$ Two biallelic polymorphisms in complete disequilibrium have been identified on position 218 (A218C) and 779 (A779C) of intron $7 .{ }^{23}$ Preliminary evidence suggests that the rarer $\mathrm{TPH}^{*} \mathrm{~A}$ variant influences serotonin turnover as lower CSF 5-HIAA levels were found in male healthy volunteers with the $\mathrm{TPH}^{*} \mathrm{~A}$ allele. ${ }^{24}$ The aim of the present paper is to investigate the possible effect of TPH variants both alone and in interaction with 5-HTTLPR on the outcome of fluvoxamine antidepressant treatment.

A detailed description of the clinical outcome of the sample has been separately reported in previous studies. ${ }^{10,11} \mathrm{~A}$ brief description of the pooled sample is illustrated in Table 1. The time course of fluvoxamine response was investigated using RRM analysis (Table 2). We observed a significant effect of time, indicating an overall symptomatological improvement during the trial. The presence of delusional features was associated with higher HAM-D baseline scores, while the remaining variables were not associated with baseline scores. Following this, we performed an analysis on the effect of independent variables on the HAM-D time course. Gender, education, diagnosis and age at onset did not significantly influence antidepressant outcome. Subjects with psychotic features showed a more rapid decrease of depressive symptomatology independently from treatment $(P=0.014)$. A more rapid improvement was observed in subjects with more severe basal HAMD score $(P<0.001)$. Subjects with pindolol augmentation showed a significantly better response compared to fluvoxamine plus placebo $(P=0.041)$.

Baseline clinical and demographic characteristics of subjects grouped according to TPH variants did not show any significant difference (Table 1). No significant association with time course was observed in the overall sample as well as in the pindolol group, on the other hand the $\mathrm{TPH}^{*} \mathrm{~A} / \mathrm{A}$ variant was significantly associated with a slower response to fluvoxamine treatment in subjects not taking pindolol (see also Figure 1). In fact we observed a significant interaction between $\mathrm{TPH}$ variants and pindolol (interaction term: $\mathrm{Z}=2.82$, $P=0.005$ ), with a much greater effect of TPH variants in subjects without pindolol (TPH effect: $\mathrm{Z}=-3.21, P$ $=0.001)$. We then evaluated the possible confounding 
Table 1 Sample description. Data are expressed as means (standard deviations). No significant difference was found comparing the genotype groups

\begin{tabular}{|c|c|c|c|c|c|}
\hline TPH genotypes & $A / A(n=40)$ & $A / C(n=107)$ & $C / C(n=70)$ & $F$ & $P$ \\
\hline Age (years) & $51.41(13.59)$ & $51.55(12.03)$ & $53.17(11.23)$ & 0.51 & 0.60 \\
\hline Age at onset (years) & $36.26(12.21)$ & $37.73(12.47)$ & $39.64(11.71)$ & 1.09 & 0.34 \\
\hline Education (years) & $10.09(4.19)$ & $8.79(4.27)$ & $8.55(4.27)$ & 1.53 & 0.22 \\
\hline Previous episodes (number) & $4.92(7.24)$ & $4.45(5.25)$ & $4.17(4.64)$ & 0.23 & 0.79 \\
\hline Duration current episode (weeks) & $19.63(19.36)$ & $20.65(17.17)$ & $20.11(21.64)$ & 0.13 & 0.88 \\
\hline Baseline HAM-D score & $31.20(6.14)$ & $30.72(5.62)$ & $30.17(4.68)$ & 0.50 & 0.61 \\
\hline HAM-D score at T6 & $10.18(13.03)$ & $7.06(10.02)$ & $5.77(9.37)$ & 2.26 & 0.11 \\
\hline HAM-D score at T6* & $14.09(13.64)$ & $8.57(10.67)$ & $5.45(8.99)$ & 4.57 & 0.01 \\
\hline \multirow[t]{2}{*}{ Fluvoxamine blood level } & $340.61(140.42)$ & $389.40(231.59)$ & $365.17(226.01)$ & 0.71 & 0.49 \\
\hline & & & & $\chi^{2}$ & $P$ \\
\hline Gender (female/male) & $\begin{array}{c}30 / 10 \\
(75.00 / 25.00 \%)\end{array}$ & $\begin{array}{c}69 / 38 \\
(64.50 / 35.50 \%)\end{array}$ & $\begin{array}{c}45 / 25 \\
(64.30 / 35.70 \%)\end{array}$ & 1.52 & 0.47 \\
\hline Psychotic features (no/yes) & $\begin{array}{c}14 / 26 \\
(35.00 / 65.00 \%)\end{array}$ & $\begin{array}{c}54 / 53 \\
(50.47 / 49.53 \%)\end{array}$ & $\begin{array}{c}38 / 32 \\
(54.29 / 45.71 \%)\end{array}$ & 5.02 & 0.08 \\
\hline Major depressives/bipolar & $\begin{array}{c}27 / 13 \\
(67.50 / 32.50 \%)\end{array}$ & $\begin{array}{c}70 / 37 \\
(65.42 / 34.58 \%)\end{array}$ & $\begin{array}{c}47 / 23 \\
(67.14 / 32.86 \%)\end{array}$ & 0.09 & 0.96 \\
\hline Pindolol augmentation (yes/no) & $\begin{array}{c}19 / 21 \\
(47.50 / 52.50 \%)\end{array}$ & $\begin{array}{c}49 / 58 \\
(45.79 / 54.21 \%)\end{array}$ & $\begin{array}{c}28 / 42 \\
(40.00 / 60.00 \%)\end{array}$ & 0.29 & 0.75 \\
\hline Responders/non responders & $\begin{array}{c}26 / 14 \\
(65.00 / 35.00 \%)\end{array}$ & $\begin{array}{c}81 / 26 \\
(75.70 / 24.30 \%)\end{array}$ & $\begin{array}{c}57 / 13 \\
(81.43 / 18.57 \%)\end{array}$ & 2.93 & 0.23 \\
\hline Responders/non responders* & $\begin{array}{c}11 / 10 \\
(52.38 / 47.62 \%)\end{array}$ & $\begin{array}{c}42 / 16 \\
(72.41 / 27.59 \%)\end{array}$ & $\begin{array}{c}34 / 8 \\
(80.95 / 19.05 \%)\end{array}$ & 5.43 & 0.06 \\
\hline
\end{tabular}

*Subjects not taking pindolol (HAM-D score at T6: $\mathrm{TPH}^{*} \mathrm{~A} / \mathrm{A}$ vs $\mathrm{TPH}{ }^{*} \mathrm{C} / \mathrm{C} P=0.003$ ).

Table 2 RRM results

\begin{tabular}{|c|c|c|c|c|}
\hline Effect & Estimate & SEM & $Z$ & $P$-value \\
\hline Overall improvement rate & -17.197 & 0.811 & -21.212 & $<0.0001$ \\
\hline $\begin{array}{l}\text { Differences in baselines* } \\
\text { Psychotic features }\end{array}$ & 6.457 & 1.306 & 4.946 & $<0.0001$ \\
\hline $\begin{array}{l}\text { Differences in improvement rates (slopes): } \\
\text { Gender } \\
\text { Education } \\
\text { Diagnosis } \\
\text { Age at onset } \\
\text { Pindolol } \\
\text { Psychotic features } \\
\text { Basal HAM-D score } \\
\text { TPH } \\
\text { TPH } \\
\text { 5-HTTLPR } \\
\text { TPH*5-HTTLPR }\end{array}$ & $\begin{array}{r}-0.851 \\
-0.107 \\
0.847 \\
0.043 \\
-2.414 \\
-2.891 \\
-0.379 \\
-1.376 \\
-1.861 \\
-2.752 \\
0.170\end{array}$ & $\begin{array}{l}1.253 \\
0.147 \\
1.238 \\
0.048 \\
1.183 \\
1.179 \\
0.102 \\
0.853 \\
0.579 \\
0.792 \\
0.767\end{array}$ & $\begin{array}{r}-0.679 \\
-0.730 \\
0.684 \\
0.898 \\
-2.039 \\
-2.452 \\
-3.713 \\
-1.613 \\
-3.209 \\
-3.475 \\
0.222\end{array}$ & $\begin{array}{r}0.496 \\
0.465 \\
0.493 \\
0.369 \\
0.041 \\
0.014 \\
<0.001 \\
0.106 \\
0.001 \\
<0.001 \\
0.824\end{array}$ \\
\hline
\end{tabular}

The slope estimate indicates the decrease in HAM-D total score per unit of time due to the variable under analysis. The $P$ values indicate the probability of no association of the variable with HAM-D scores. Pindolol, psychotic features and basal symptomatology were associated with HAM-D total score decrease during treatment while the remaining clinical variables showed no association. TPH": variants were associated with HAM-D total score decrease in the sample not taking pindolol.

*Only significant variables are reported.

effect of clinical variables. In detail, there was a significant interaction between TPH variants and diagnoses $(\mathrm{Z}=2.16, P=0.030)$, with a greater effect of TPH variants when diagnosis was included in the model $(Z$ $=-2.68, P=0.007)$, due to a more marked effect in major depressives. Baseline HAM-D scores, fluvoxamine plasma levels or the presence of psychotic features did not significantly influence the association of TPH with outcome (data not shown). Finally, in order to investigate a possible interaction of $\mathrm{TPH}$ and 5- 
HAM-D DECREASE DURING FLUVOXAMINE TREATMENT

Effect of TPH variants in placebo (121) and pindolol (96) potentiation
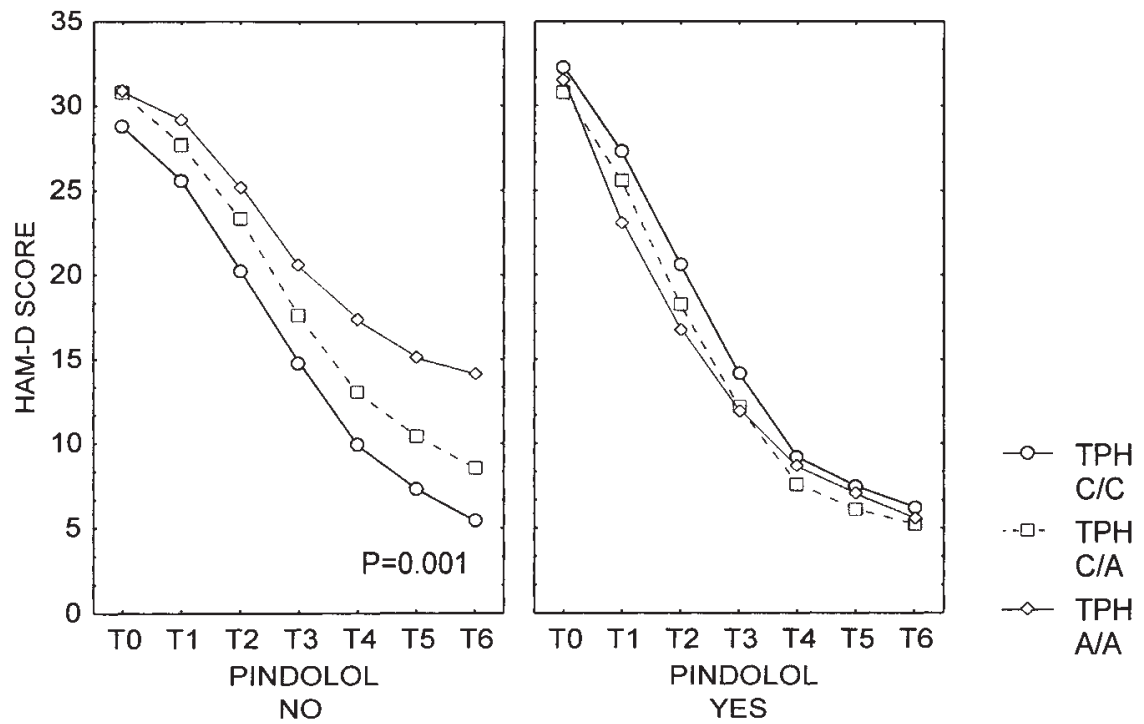

Figure 1 The time course of response divided by TPH variants: subjects with TPH*A/A variant showed a slower decrease of the symptomatology $(P=0.001)$. This effect was not present in subjects on pindolol.

HTTLPR, we included both polymorphisms in the RRM model considering only subjects not taking pindolol. The interaction was not significant (Table 2). In Figure 2 the antidepressant outcome is divided into all possible combinations of the two polymorphisms, the visual inspection suggests an additive effect with independent influences of both polymorphisms. The sample was in Hardy-Weinberg equilibrium $\left(\chi^{2}=0.006, P\right.$ $=0.94)$.
It was previously reported that the 5-HTTLPR short variant was associated with a slower response to various antidepressant treatments ${ }^{10,12,13,25}$ and that the addition of pindolol to fluvoxamine was able to reduce this genotype effect. In the present sample, subjects with the $\mathrm{TPH}^{*} \mathrm{~A} / \mathrm{A}$ variant showed the slowest response, as measured by the HAM-D scores. Also in this case the variant effect was not significant in the group of patients on pindolol augmentation treatment.

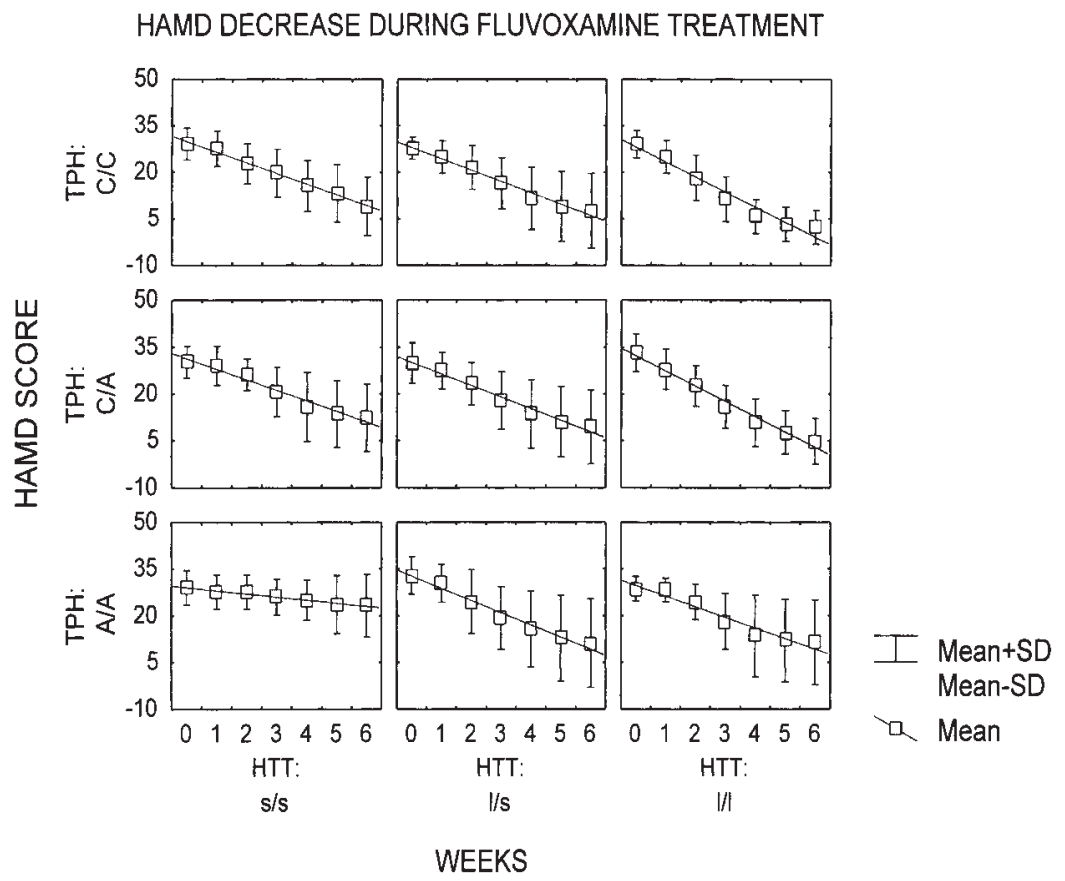

Figure 2 The time course of response divided by TPH and 5-HTTLPR variants in the sample without pindolol: subjects with both $\mathrm{TPH}^{*} \mathrm{~A} / \mathrm{A}$ and $5-\mathrm{HTTLPR}^{*}$ s/s variants showed the slowest decrease of the symptomatology. 
We observed a more marked influence of TPH variants on major depressives response. This could be due to the supposedly different genetic background between the two disorders. ${ }^{26,27}$

Recently Kim et al published a study in which the 5 -HTTLPR * $1 / 1$ was associated with a poor outcome to various SSRIs. ${ }^{28}$ However some differences between this and other studies should be pointed out. Firstly from a genetic point of view, polymorphism frequencies in oriental populations are strongly different from those in Western countries, ${ }^{29}$ a difference reflected in the samples of the aforementioned paper (frequency of 5 -HTTLPR ${ }^{*} 1$ in normals 0.25 vs $0.58-$ 0.68 in Western countries). Subsequently the number of $1 / 1$ patients in the sample was low $(n=5)$. Last but not least the use of a different response criterion (50\% HAM-D score decrease vs a final score of 8) further complicates any comparison. However a more recent paper reported an association between 5-HTTLPR and paroxetine response in the same direction as our original paper. ${ }^{13}$

The frequencies of TPH alleles and genotypes in our sample were similar to those published for Western countries, being 0.57 and 0.43 for the $\mathrm{TPH}^{*} \mathrm{C}$ and $\mathrm{TPH}{ }^{*}$ A allele, respectively. They did not significantly differ from the ones, 0.60 and 0.40 , in Nielsen et al. ${ }^{23,30}$ Ethnic origin is a possible cause of stratification bias since a significant TPH allele frequency variation has been reported among samples of individuals from populations in different parts of the world. ${ }^{31}$ However, Italy being characterized by a substantial genetic homogeneity, ${ }^{32}$ we tend to exclude such bias from our sample. The frequencies in this study were different from those found by Bellivier et al. ${ }^{33}$ This was the only report where an overall association of $\mathrm{TPH}^{*} \mathrm{~A}$ with bipolar disorder was observed while several others failed to confirm this finding. ${ }^{34-40} \mathrm{TPH}$ variants have also been associated with alcoholism, ${ }^{41}$ but further rare variants did not prove to be associated with either mood and anxiety disorders. ${ }^{42-44}$

To date, no definite information is available about the possible functional consequences of the TPH A218C polymorphism. It is located in a potential GATA transcription factor binding site and therefore might affect $\mathrm{TPH}$ gene expression. ${ }^{23}$ Alternatively, it may be in linkage disequilibrium with another nearby functional mutation. Recently, lower CSF 5-HIAA levels were found in male healthy volunteers with the $\mathrm{TPH}^{*} \mathrm{~A}$ allele. ${ }^{24}$ The $\mathrm{TPH}{ }^{*} \mathrm{~A}$ variant was also proposed as a liability factor for suicidal behavior (though not unequivocably), ${ }^{35,39,45-50}$ and anger-related traits. ${ }^{51,52}$

The TPH polymorphism explained about $5 \%$ of the variance (effect size $f=0.235$ ) of the variation in antidepressant efficacy, ${ }^{53}$ an observation that could be in agreement with a supposedly minor effect of the gene coding for the TPH. Moreover, the effect proved to be independent from that of the 5-HTTLPR, thus suggesting an additive effect. The antidepressant drugs activity could be mediated by two limiting steps, one at the level of the TPH and the second at the level of 5-HT transporter function. In conclusion, variants of the TPH polymorphism, as well as those of the 5HTTLPR, may influence the antidepressant response to fluvoxamine, particularly the onset of action. In both cases, pindolol appears to be able to override these genetic effects, therefore it is mainly recommended in those subjects displaying unfavorable variants $\left(\mathrm{TPH}^{*}\right.$ $\mathrm{A} / \mathrm{A}$ and 5 -HTTLPR ${ }^{*}$ s/s). If confirmed by future studies, these results could turn out to be a useful tool for the clinician in choosing a proper pharmacological treatment for each patient.

\section{Methods}

\section{Sample}

Two hundred and seventeen inpatients, consecutively admitted to the Mood Disorder Center, Department of Psychiatry at the Institute H San Raffaele, Milan, were included in this study (age $=52.11 \pm 12.04$ years; onset $=37.97 \pm 12.16$ years; female/male: 144/73; bipolars: delusional/non delusional $=40 / 33$, major depressives: delusional/non delusional $=71 / 73$ ). Lifetime diagnoses were assigned by trained psychiatrists and supervised by an independent senior psychiatrist on the basis of unstructured clinical interviews and medical records, according to DSM-IV criteria ${ }^{54}$ and following a best estimate procedure. ${ }^{55}$ The presence of any concomitant Axis I diagnosis, major depressive single episode, together with somatic or neurological illnesses impairing psychiatric evaluation represented exclusion criteria. Subjects had not taken nonreversible monoamine oxidase inhibitors or slow-release neuroleptics for at least one month before entering the study.

All patients were evaluated at baseline and weekly thereafter until the sixth week using the 21-item Hamilton Rating Scale for Depression (HAM-D-21) ${ }^{56}$ administered by trained senior psychiatrists blind to genetic data and to treatment. Subjects for the present study have been treated in the context of two previous trials under double blind conditions ${ }^{10,11}$ where 5-HTTLPR variants were studied. The procedure was the same in both trials. Briefly, after a 7-day washout period, fluvoxamine was titrated to reach $300 \mathrm{mg}$ daily from day 8 until the end of the trial. Pindolol $2.5 \mathrm{mg}$ three times a day was blindly added to approximately half of the sample randomly selected (96/217). Concomitant psychotropic drugs were not allowed, except flurazepam at bedtime (up to $45 \mathrm{mg}$ ) or lithium maintenance ( $n=$ 26/217). A decrease in HAM-D scores to 8 or less, with Delusion factor equal to 0 (items $2,15,20),{ }^{57-59}$ was considered the response criterion. After the procedure had been fully explained to all subjects, informed consent was obtained.

Plasma fluvoxamine levels were determined by highperformance liquid chromatography after 2 weeks of stable $300 \mathrm{mg}$ daily dose. ${ }^{60}$ Nine patients with fluvoxamine plasma levels exceeding the mean value of the sample \pm 1.96 SD were removed from the study to avoid the possibility that extreme differences in the bioavailability of the drug could influence the clinical response. 
590

DNA analysis

DNA was extracted from leucocytes by $\mathrm{NaCl}$ precipitation. ${ }^{61}$ Genomic DNA was extracted from leucocytes by $\mathrm{NaCl}$ precipitation. ${ }^{61}$ For PCR the $5^{\prime}$-TTC AGA TCC CTT CTA TAC CCC AGA-3' and 5'-GGA CAT GAC CTA AGA GTT CAT GGC A-3' primers were employed. ${ }^{33}$ The PCR reaction was carried out in a 10$\mu \mathrm{l}$ volume containing $150 \mathrm{ng}$ genomic DNA, $1 \mu \mathrm{M}$ of each primer, $200 \mu \mathrm{M}$ each dNTP, $1 \times$ PCR buffer (Perkin Elmer Italia, Monza, Italy), 5\% of DMSO and $0.025 \mathrm{U}$ $\mu \mathrm{l}^{-1}$ of Taq Polymerase (Perkin Elmer Italia). After an initial denaturation step of $4 \mathrm{~min}$ at $99^{\circ} \mathrm{C}, 35$ cycles of amplification $\left(30 \mathrm{~s}\right.$ at $94^{\circ} \mathrm{C}, 30 \mathrm{~s}$ at $60^{\circ} \mathrm{C}, 30 \mathrm{~s}$ at $72^{\circ} \mathrm{C}$ ) and a final extension step of $2 \mathrm{~min}$ at $72^{\circ} \mathrm{C}$ were performed. An aliquot of PCR product was digested using BfaI (New England BioLabs, Beverly, MA, USA) and the fragments obtained were separated in $2.5 \%$ agarose gels. Depending on the presence or absence of the polymorphic BfaI site, either one fragment (allele A) or two fragments (allele C) were produced. 5-HTTLPR polymorphism analysis was carried out with primers and conditions as described elsewhere. ${ }^{10}$

\section{Statistical analysis}

Seven HAM-D scores' measurements (baseline and 6 weeks) were analyzed. Common methods of analysis of longitudinal data imply some level of oversimplification (for a complete review see Gibbons et $a l^{62}$ ). Repeated measures analysis of variance on weekly based mean scores is the most common technique, but two drawbacks are present: first, it does not take into account interindividual variability and second, it is based on an a priori assumption of equal weekly variances. When analyzing longitudinal data, not only the mean trend is of interest, but also the distribution of trends in the sample. To accomplish this analysis, a random regression model (RRM) has been developed, which demonstrates considerably superior flexibility and power when compared to traditional techniques ${ }^{62-64}$ RRM used for the present study was implemented with the computer program MIXREG available at http://www.uic.edu/ hedeker/mix.htm. ${ }^{65}$ In the RRM, we included the HAM-D total scores as dependent variables, time and intercept as random effects, and each independent variable plus the interaction with time as fixed effects. In order to obtain an approximate linearity we used the transformation Ln (time +1$)$. When multiple independent variables were included in the model they were added with the interaction factor with time. The baseline score was included in the model, as well as all the clinical variables that were associated with outcome when investigating TPH variants. An 'intent-to-treat' analysis was carried out for all patients who had a baseline assessment and at least one assessment after randomization, with the last observation carried forward on the HAM-D. A Student's $t$-test and chi-square were used when appropriate. All $P$ values were 2-tailed, and statistical significance was set at $P$ $<0.05$.

\section{Acknowledgements}

This study was supported by Istituto Scientifico Ospedale. San Raffaele (grants M0975 and M2511). The authors acknowledge Cristina Lorenzi for her help with DNA analysis and Enrico Lattuada MD for collecting blood samples.

\section{References}

1 O'Reilly RL, Bouge L, Singh FM. Pharmacogenetic response to antidepressants in a multicase family with affective disorder. Biol Psychiatry 1994; 36: 467-471.

2 Pare CMB, Rees L, Sainsbury MJ. Differentiation of two genetically specific types of depression by the response to antidepressant. Lancet $1962 ; 1340-1343$.

3 Sederer LI. Depression. In: Sederer LI (ed). Inpatients Psychiatry Diagnosis and Treatment. William \& Wilkins: Baltimore, 1986, p 20 .

4 Orsini A. Antidepressant responses and segregation analyses in affective families. In: Racagni G, Smeraldi E (eds). Anxious Depression: Assessment and Treatment. Raven Press: New York 1987.

5 Serretti A, Franchini L, Gasperini M, Rampoldi R, Smeraldi E. Mode of inheritance in mood disorders families according to fluvoxamine response. Acta Psychiatr Scand 1998; 98: 443-450.

6 Franchini L, Serretti A, Gasperini M, Smeraldi E. Familial concordance of fluvoxamine response as a tool for differentiating mood disorder pedigrees. J Psychiatr Res 1998; 32: 255-259.

7 Berrettini W. Progress and pitfalls: bipolar molecular linkage studies. J Affect Disord 1998; 50: 287-297.

8 Lesch K, Bengel D, Heils A, Sabol S, Greenberg B, Petri S et al. Association of anxiety-related traits with a polymorphism in the serotonin transporter gene regulatory region. Science, 1996; 274: 1527-1530.

9 Heils A, Teufel A, Petri S, Stöber G, Riederer P, Bengel D et al. Allelic variation of human serotonin trasporter gene expression. J Neurochem 1996; 66: 2621-2624.

10 Smeraldi E, Zanardi R, Benedetti F, Dibella D, Perez J, Catalano M. Polymorphism within the promoter of the serotonin transporter gene and antidepressant efficacy of fluvoxamine. Mol Psychiatry 1998; 3: 508-511.

11 Zanardi R, Serretti A, Rossini D, Franchini L, Cusin C. Lattuada E et al. Factors affecting fluvoxamine antidepressant activity: influence of pindolol and 5-HTTLPR in delusional and nondelusional depression. Biol Psychiatry (submitted).

12 Zanardi R, Benedetti F, DiBella D, Catalano M, Smeraldi E. Efficacy of paroxetine in depression is influenced by a functional polymorphism within the promoter of serotonin transporter gene. J Clin Psychopharmacol 2000; 20: 105-107.

13 Pollock BG, Ferrell RE, Mulsant BH, Mazumdar S, Miller M, Sweet RA et al. Allelic variation in the serotonin transporter promoter affects onset of paroxetine treatment response in late-life depression. Neuropsychopharmacology 2000; 23: 587-590.

14 Comings D. Polygenic inheritance in psychiatric disorders. In: Blum K, Noble EP (eds). Handbook of Psychiatric Genetics. CRC Press: Boca Raton 1997, pp 235-260.

15 Risch N. Linkage strategies for genetically complex traits: I. Multilocus models. Am J Med Gen 1990; 46: 222-228.

16 Frankel W, Schork N. Who's afraid of epistasis? Nat Genet 1996; 14: $371-373$.

17 Sandyk R. L-tryptophan in neuropsychiatric disorders: a review. Int J Neurosci 1992; 67: 127-144.

18 Walinder J, Skott A, Carlsson A, Nagy A, Bjorn-Erik R. Potentiation of the antidepressant action of clomipramine by tryptophan. Arch Gen Psychiatry 1976; 33: 1384-1389.

19 Young SN. Use of tryptophan in combination with other antidepressant treatments: a review. J Psychiatry Neurosci 1991; 16: 241-246.

20 Smith KA, Fairburn CG, Cowen PJ. Relapse of depression after rapid depletion of tryptophan. Lancet 1997; 349: 915-919.

21 Boularand S, Darmon MC, Ganem Y, Launay JM, Mallet J. Complete coding sequence of human tryptophan hydroxylase. Nucleic Acid Res 1990; 18: 4257. 
22 Craig SP, Boularand S, Darmon MC, Mallet J, Craig IW. Localization of human tryptophan hydroxylase (TPH) to chromosome 11p15.3p14 by in situ hybridization. Cytogenet Cell Genet 1991; 56: $157-$ 159.

23 Nielsen DA, Jenkins GL, Stefanisko KM, Jefferson KK, Goldman D. Sequence, splice site and population frequency distribution analyses of the polymorphic human tryptophan hydroxylase intron 7 . Brain Res Mol Brain Res 1997; 45: 145-148.

24 Jonsson EG, Goldman D, Spurlock G, Gustavsson JP, Nielsen DA, Linnoila $\mathrm{M}$ et al. Tryptophan hydroxylase and catechol-O-methyltransferase gene polymorphisms: relationships to monoamine metabolite concentrations in CSF of healthy volunteers. Eur Arch Psychiatry Clin Neurosci 1997; 247: 297-302.

25 Benedetti F, Serretti A, Colombo C, Campori E, Barbini B, Di Bella $\mathrm{D}$ et al. Influence of a functional polymorphism within the promoter of the serotonin transporter gene on the effects of total sleep deprivation in bipolar depression. Am J Psychiatry 1999; 156: 1450-1452.

26 McGuffin P, Katz R. Nature, nurture and affective disorder. In: Royal College of Psychiatrists (ed). The Biology of Affective Disorders. Gaskell Press: London, 1986.

27 Winokur G, Coryell W, Keller M, Endicott J, Leon A. A family study of manic-depressive (bipolar I) disease. Is it a distinct illness separable from primary unipolar depression? Arch Gen Psychiatry 1995; 52: $367-373$.

28 Kim DK, Lim SW, Lee S, Sohn SE, Kim S, Hahn CG et al. Serotonin transporter gene polymorphism and antidepressant response. Neuroreport 2000; 11: 215-219.

29 Kunugi H, Hattori M, Kato T, Tatsumi M, Sakai T, Sasaki T et al. Serotonin transporter gene polymorphisms: ethnic difference and possible association with bipolar affective disorder. Mol Psychiatry 1997; 2: 457-462.

30 Nielsen DA, Dean M, Goldman D. Genetic mapping of the human tryptophan hydroxylase gene on chromosome 11, using an intronic conformational polymorphism. Am J Hum Genet 1992; 51: 13661371.

31 Gelernter J, Kranzler H, Lacobelle J. Population studies of polymorphisms at loci of neuropsychiatric interest (tryptophan hydroxylase (TPH), dopamine transporter protein (SLC6A3), D3 dopamine receptor (DRD3), apolipoprotein E (APOE), mu opioid receptor (OPRM1), and ciliary neurotrophic factor (CNTF)). Genomics 1998; 52: 289-297.

32 Gasparini P, Estivill X, Volpini V, Totaro A, Castellvi-Bel S, Govea $\mathrm{N}$ et al. Linkage of DFNB1 to non-syndromic neurosensory autosomal-recessive deafness in Mediterranean families. Eur J Hum Genet 1997; 5: 83-88.

33 Bellivier F, Leboyer M, Courtet P, Buresi C, Beaufils B, Samolyk D et al. Association between the tryptophan hydroxylase gene and manic-depressive illness. Arch Gen Psychiatry 1998; 55: 33-37.

34 Frisch A, Postilnick D, Rockah R, Michaelovsky E, Postilnick S, Birman E et al. Association of unipolar major depressive disorder with genes of the serotonergic and dopaminergic pathways. Mol Psychiatry 1999; 4: 389-392.

35 Furlong RA, Ho L, Rubinsztein JS, Walsh C, Paykel ES, Rubinsztein DC. No association of the tryptophan hydroxylase gene with bipolar affective disorder, unipolar affective disorder, or suicidal behaviour in major affective disorder. Am J Med Gen 1998; 81: 245-247.

36 Kunugi H, Ishida S, Kato T, Sakai T, Tatsumi M, Hirose $\mathrm{T}$ et al. No evidence for an association of polymorphisms of the tryptophan hydroxylase gene with affective disorders or attempted suicide among Japanese patients. Am J Psychiatry 1999; 156: 774-776.

37 McQuillin A, Lawrence J, Kalsi G, Gurling H, Curtis D. No allelic association between bipolar affective disorder and the tryptophan hydroxylase gene. Arch Gen Psychiatry 1999; 56: 99-100.

38 Vincent JB, Masellis M, Lawrence J, Choi V, Gurling HM, Parikh SV et al. Genetic association analysis of serotonin system genes in bipolar affective disorder. Am J Psychiatry 1999; 156: 136-138.

39 Tsai SJ, Hong CJ, Wang YC. Tryptophan hydroxylase gene polymorphism (A218C) and suicidal behaviors. Neuroreport 1999; 10: 3773-3775.

40 Rietschel M, Schorr A, Albus M, Franzek E, Kreiner R, Held T et al. Association study of the tryptophan hydroxylase gene and bipolar affective disorder using family-based internal controls. Am J Med Genet 2000; 96: 310-311.

41 Ishiguro H, Saito T, Shibuya H, Toru M, Arinami T. The 5' region of the tryptophan hydroxylase gene: mutation search and association study with alcoholism. J Neural Transm 1999; 106: 1017-1025.

42 Han L, Nielsen DA, Rosenthal NE, Jefferson K, Kaye W, Murphy D et al. No coding variant of tryptophan hydroxylase gene detected in seasonal affective disorder, obsessive-compulsive disorder, anorexia nervosa, and alcoholism. Biol Psychiatry 1999; 45: 615-619.

43 Rotondo A, Schuebel KE, Bergen AW, Aragon R, Virkkunen M, Linnoila $\mathrm{M}$ et al. Identification of four variants in the tryptophan hydroxylase promoter and association to behavior. Mol Psychiatry 1999; 4: 360-368.

44 Frisch A, Michaelovsky E, Rockah R, Amir I, Hermesh H, Laor N et al. Association between obsessive-compulsive disorder and polymorphisms of genes encoding components of the serotonergic and dopaminergic pathways. Eur Neuropsychopharmacol 2000; 10: 205-209.

45 Nielsen DA, Goldman D, Virkkunen M, Tokola R, Rawlings R, Linnoila M. Suicidality and 5-hydroxyindoleacetic acid concentration associated with a tryptophan hydroxylase polymorphism. Arch Gen Psychiatry 1994; 51: 34-38.

46 Mann JJ, Malone KM, Nielsen DA, Goldman D, Erdos J, Gelernter J. Possible association of a polymorphism of the tryptophan hydroxylase gene with suicidal behavior in depressed patients. Am J Psychiatry 1997; 154: 1451-1453.

47 Abbar M, Courtet P, Amadeo S, Caer Y, Mallet J, Baldy-Moulinier $\mathrm{M}$ et al. Suicidal behaviors and the tryptophan hydroxylase gene. Arch Gen Psychiatry 1995; 52: 846-849.

48 Bennett PJ, McMahon WM, Watabe J, Achilles J, Bacon M, Coon H et al. Tryptophan hydroxylase polymorphisms in suicide victims. Psychiatr Genet 2000; 10: 13-17.

49 Paik I, Toh K, Kim J, Lee C. TPH gene may be associated with suicidal behavior, but not with schizophrenia in the Korean population. Hum Hered 2000; 50: 365-369.

50 Geijer T, Frisch A, Persson ML, Wasserman D, Rockah R, Michaelovsky E et al. Search for association between suicide attempt and serotonergic polymorphisms. Psychiatr Genet 2000; 10: 19-26.

51 Manuck SB, Flory JD, Ferrell RE, Dent KM, Mann JJ, Muldoon MF. Aggression and anger-related traits associated with a polymorphism of the tryptophan hydroxylase gene. Biol Psychiatry 1999; 45: $603-614$

52 Evans J, Reeves B, Platt H, Leibenau A, Goldman D, Jefferson K et al. Impulsiveness, serotonin genes and repetition of deliberate selfharm (DSH). Psychol Med 2000; 30: 1327-1334.

53 Cohen J. Statistical Power Analysis for the Behavioral Sciences. Lawrence Erlbaum Associates: Hillsdale, NJ, 1988.

54 American Psychiatric Association. Diagnostic and Statistical Manual of Mental Disorders, 4th edn. American Psychiatric Association: Washington DC, 1994.

55 Leckman JF, Sholomskas D, Thompson WD, Belanger A, Weissman MM. Best estimate of lifetime psychiatric diagnosis: a methodological study. Arch Gen Psychiatry 1982; 39: 879-883.

56 Hamilton M. Development of a rating scale for primary depressive illness. Br J Soc Clin Psychol 1967; 6: 278-296.

57 Bech P, Malt U, Dencker S, Ahlfors U, Elgen K, Lewander T et al. Scales for assessment of diagnosis and severity of mental disorders. Acta Psychiatr Scand 1993; 87 Suppl 372: 37-40.

58 Bellini L, Gatti F, Gasperini M, Smeraldi E. A comparison between delusional and non-delusional depressives. J Affect Disord 1992; 25: 129-138.

59 Sobin CA, Sackeim H. Psychomotor symptoms of depression. Am J Psychiatry 1997; 154: 4-17.

60 Lucca A, Lucini V, Catalano M, Alfano M, Smeraldi E. Plasma tryptophan to large neutral amino acids ratio and therapeutic response to a selective serotonin uptake inhibitor. Neuropsychobiology 1994; 29: 108-111.

61 Lahiri DK, Nurnberger JIJ. A rapid non-enzymatic method for the preparation of HMW DNA from blood for RFLP studies. Nucleic Acid Res 1991; 19: 5444.

62 Gibbons RD, Hedeker D, Elkin I, Waternaux C, Kraemer HC, Greenhouse JB et al. Some conceptual and statistical issues in analysis of longitudinal psychiatric data. Application to the NIMH treat- 
ment of Depression Collaborative Research Program dataset. Arch Gen Psychiatry 1993; 50: 739-750.

63 Elkin I, Gibbons RD, Shea MT, Sotsky SM, Watkins JT, Pilkonis PA et al. Initial severity and differential treatment outcome in the National Institute of Mental Health Treatment of Depression Collaborative Research Program. J Consult Clin Psychol 1995; 63: 841-847.

64 Serretti A, Lattuada E, Zanardi R, Franchini L, Smeraldi E. Patterns of symptom improvement during antidepressant treatment of delusional depression. Psychiatry Res 2000; 94: 185-190.
65 Hedeker D, Gibbons RD. MIXREG: a computer program for mixedeffects regression analysis with autocorrelated errors. Comput Methods Programs Biomed 1996; 49: 229-252.

Correspondence: R Zanardi MD and A Serretti MD, Dept of Psychiatry, Istituto Scientifico H San Raffaele, Vita-Salute University, Via Stamira D’Ancona 20, 20127 Milano, Italy. E-mail: zanardi.raffaella@hsr.it or serretti.alessandro@hsr.it

Received 18 October 2000; revised 8 December 2000; accepted 21 December 2000 
Chapter 3: SSRIs antidepressant activity is influenced by Gb3 variants 


\title{
SSRIs antidepressant activity is influenced by G $\beta 3$ variants
}

\author{
Alessandro Serretti ${ }^{\mathrm{a}, *}$, Cristina Lorenzi ${ }^{\mathrm{a}}$, Cristina Cusin ${ }^{\mathrm{a}}$, Raffaella Zanardi ${ }^{\mathrm{a}}$, Enrico Lattuada ${ }^{\mathrm{a}}$, \\ David Rossini $^{\mathrm{a}}$, Roberta Lilli ${ }^{\mathrm{b}}$, Adele Pirovano ${ }^{\mathrm{a}}$, Marco Catalano ${ }^{\mathrm{a}}$, Enrico Smeraldi ${ }^{\mathrm{a}}$ \\ ${ }^{a}$ Department of Psychiatry, Vita-Salute University, Fondazione Centro San Raffaele del Monte Tabor, Milan, Italy \\ 'Department of Psychiatry "P. Ottonello" Alma Mater Studiorum, University of Bologna, Bologna, Italy
}

Received 8 April 2002; received in revised form 30 October 2002; accepted 30 October 2002

\begin{abstract}
The aim of the present study was to test a possible effect of the G-protein $\beta 3$-subunit (G $\beta 3$ ) C825T gene variant on the antidepressant activity of selective serotonin reuptake inhibitors (SSRIs) in a sample of major and bipolar depressives, with or without psychotic features. Four hundred and ninety inpatients were treated with fluvoxamine $300 \mathrm{mg} /$ day $(n=362)$ or paroxetine $40 \mathrm{mg} / \mathrm{day}(n=128)$ and either placebo or pindolol in a double-blind design for 6 weeks. The severity of depressive symptoms was weekly assessed with the Hamilton Rating Scale for Depression. G $\beta 3$ allelic variants were determined in each subject using a PCR-based technique. Subjects with G $\beta 3$ T/T variants showed better response to treatment $(P=0.009)$ and this effect was independent from analyzed demographic and clinical variables. These results confirm preliminary reports and shed further light on the genetics of the response to antidepressant treatments. (C) 2003 Elsevier Science B.V./ECNP All rights reserved.
\end{abstract}

Keywords: Pharmacogenetics; Paroxetine; Fluvoxamine; Mood disorders; Antidepressant treatment

\section{Introduction}

Antidepressant drugs efficacy in major depression treatment is partly under genetic control (Berrettini, 1998; Franchini et al., 1998; O'Reilly et al., 1994; Orsini, 1987; Pare and Mack, 1971; Sederer, 1986; Serretti et al., 1998). Pharmacogenetic predictors of selective serotonin reuptake inhibitors (SSRIs) efficacy have been postulated and tested over the last few years. The functional polymorphism in the upstream regulatory region of the serotonin transporter (5-HTTLPR) gene has been repeatedly associated with antidepressant response to SSRIs (Pollock et al., 2000; Smeraldi et al., 1998; Zanardi et al., 2000, 2001) even if it has not been replicated in oriental populations (Kim et al., 2000; Yoshid et al., 2002). Preliminary results suggest that the tryptophan hydroxylase (TPH) gene variant (A218C) are also involved in this regulation (Serretti et al., 2001a,b). Pindolol potentiation seems to override the effect

\footnotetext{
*Corresponding author. Tel.: +39-2-2643-3250; fax: +39-2-26433265.

E-mail address: serretti.alessandro@hsr.it (A. Serretti).
}

of both genes, which explain 7 and 5\% of the total variance of antidepressant response, respectively (Serretti et al., 2001b). Other liability genes are therefore possibly involved as antidepressant response is a complex trait (Pickar and Rubinow, 2001) and the existence of other genes, that contribute with additive, multiplicative or epistatic effects, is likely (Frankel and Schork, 1996).

Heterotrimeric guanine nucleotide binding proteins (Gproteins) represent essential regulatory components in the transmembrane coupling system of many receptors involved in SSRIs activity (Birnbaumer et al., 1990; Gilman, 1987). G-proteins are composed by three subunits and, after receptor activation, dissociate into $\mathrm{G} \alpha$ and $\mathrm{G} \beta \gamma$ units (Nestler and Duman, 1994; Simon et al., 1991). It seems therefore possible that mutations in the G-protein $\beta$ or $\gamma$ are responsible for alteration in second messenger pathways (Ram et al., 1997). Levine et al. (1990a,b) mapped the gene for the $\beta 3$ subunit to 12 pter-p12.3. The entire gene spans $7.5 \mathrm{~kb}$ and is composed of 11 exons and 10 introns (Rosskopf et al., 2000). Several polymorphisms has been reported within this gene: an $\mathrm{A}(-350) \mathrm{G}$ substitution in the promoter region, a G814A polymorphism which results 
in the replacement of glycine by serine at position 272 , a C1429T polymorphism in the $3^{\prime}$ untranslated region, a C825T substitution in exon 10. Haplotype analysis indicated an almost complete disequilibrium of C825T with 1429T, and vice versa (Rosskopf et al., 2000; Siffert et al., 1998). The T allele of C825T polymorphism was associated with the occurrence of a splice variants $(\mathrm{G} \beta 3-\mathrm{s})$ in which nucleotides 498-620 of exon 9 were deleted; this in-frame deletion caused the loss of 41 amino acids producing a shortened, more active, splice variant of the $\beta 3$ subunit (Siffert et al., 1998).

Studies about a possible associations between $\mathrm{G}$ proteins subunits variants and mood disorders gave conflicting results (Lin et al., 2001; Ram et al., 1997; Saito et al., 1999; Tsiouris et al., 1996), but, recently, Zill et al. (2000) reported that the C825T G 33 polymorphism was associated with affective disorders and with response to antidepressants treatment in depressive patients (bipolars and unipolars treated with various classes of both pharmacological and non-pharmacological treatments: SSRIs, tricyclic antidepressants, electroconvulsive therapy and others). In detail, they found a statistically significant association between TT homozygosity and better response to antidepressants (Zill et al., 2000).

Therefore we investigated the possible influence of the C825T G 33 polymorphism on antidepressant response to fluvoxamine and paroxetine in a large sample of depressive patients from an Italian population treated with SSRIs with and without pindolol potentiation.

\section{Experimental procedures}

\subsection{Sample}

Four hundred and ninety inpatients, consecutively admitted to the Mood Disorder Center, Department of Psychiatry at the Institute H. San Raffaele, Milan, were included in this study (age, 51.31 \pm 13.07 years; onset, $36.11 \pm 12.92$ years; female/male, 334/156; bipolars/ major depressives, 200/290; delusional/non delusional, 203/287). Lifetime diagnoses were assigned by trained psychiatrists and supervised by an independent senior psychiatrist on the basis of unstructured clinical interviews and medical records, according to DSM-IV criteria (American Psychiatric Association, 1994) and following a best estimate procedure (Leckman et al., 1982). The presence of any concomitant Axis I diagnosis, major depression single episode, together with somatic or neurological illnesses impairing psychiatric evaluation represented exclusion criteria. Subjects had not taken nonreversible monoamine oxidase inhibitors or slow-release neuroleptics for at least 1 month before entering the study.

All patients were evaluated at baseline and weekly thereafter until the sixth week using the 21-item Hamilton Rating Scale for Depression (HAM-D-21) (Hamilton, 1967) administered by trained senior psychiatrists blind to genetic data and to treatment. Subjects for the present study have been treated in the context of previous trials under double-blind conditions (Serretti et al., 2001b; Smeraldi et al., 1998; Zanardi et al., 2000) where 5HTTLPR and TPH variants were studied. The procedure was the same in all trials. Briefly, after a 7-day washout period, fluvoxamine or paroxetine was administered to reach, respectively, 300 and $20-40 \mathrm{mg}$ daily from day 8 until the end of the trial. Pindolol $2.5 \mathrm{mg}$ t.i.d. or placebo was blindly added to approximately one-third of the sample randomly selected $(n=150)$. Concomitant psychotropic drugs were not allowed, except flurazepam at bedtime (up to $45 \mathrm{mg}$ ) or lithium maintenance $(n=84)$. HAMD scores during treatment are the main outcome measure, moreover a decrease in HAM-D scores to 8 or less, with Delusion factor equal to 0 (items 2, 15, 20) (Bech et al., 1993; Bellini et al., 1992; Sobin and Sackeim, 1997), was used to define non-responders. After the procedure had been fully explained to all subjects, written informed consent was obtained. Plasma fluvoxamine and paroxetine levels were determined by high-performance liquid chromatography after 2 weeks of stable daily dose (Lucca et al., 1994). Four patients with fluvoxamine and five with paroxetine plasma levels above or under the mean value of the sample \pm 1.96 S.D. were removed from the study to avoid the possibility that extreme differences in the bioavailability of the drug could influence the clinical response.

\subsection{DNA analysis}

Genomic DNA was extracted from leucocytes by $\mathrm{NaCl}$ precipitation (Lahiri and Nurnberger, 1991). A couple of primers (5'-TGA CCC ACT TGC CAC CCG TGC-3', and 5'-GCA GCA GCC AGG GCT GGC-3') was used to amplify the fragment of interest. Polymerase chain reactions (PCR) were carried out in a $10-\mu l$ volume containing $150 \mathrm{ng}$ genomic DNA, $5 \mathrm{pM}$ of each primer, 200 $\mu \mathrm{M}$ each dNTP, $1 \times \mathrm{PCR}$ Gold Buffer (Applied Biosystems, Monza, Italy), and $0.025 \mathrm{U} / \mu \mathrm{l}$ of Taq Gold Polymerase (Perkin-Elmer). After an initial step of $5 \mathrm{~min}$ at $95^{\circ} \mathrm{C}, 35$ cycles of amplification $\left(1 \mathrm{~min}\right.$ at $95^{\circ} \mathrm{C}, 45 \mathrm{~s}$ at $60{ }^{\circ} \mathrm{C}, 1 \mathrm{~min}$ at $72{ }^{\circ} \mathrm{C}$ ) and a final extension step of $7 \mathrm{~min}$ at $72{ }^{\circ} \mathrm{C}$ were performed. An aliquot of PCR product was digested using BseDI (New England BioLabs) and fragments electrophoresed in agarose gels.

The unrestricted PCR product (TT genotype) has a size of $268 \mathrm{bp}$; complete restriction (CC genotype) produces bands of 116 and $152 \mathrm{bp}$; depending on the presence or absence of the restriction site either two fragments (116 and $152 \mathrm{bp}$ ) or one fragment ( $268 \mathrm{bp}$ ) are produced (Zill et al., 2000).

\subsection{Statistical analysis}

Seven HAM-D scores measurements (baseline and 6 weeks) were analyzed. Repeated measures analysis of 
variance (MANOVA) was used to examine the differences between drug treatments on HAM-D scores. Analysis of covariance (MANCOVA) was used when appropriate. An 'intent-to-treat' analysis was carried out for all patients who had a baseline assessment and at least 1 assessment after randomization, with the last observation carried forward on the HAM-D. Student $t$-test and $\chi^{2}$-test were used to compare demographic data and baseline ratings. All $P$ values are two-tailed, and statistical significance was set at the 5\% level $(P<0.05)$. With these parameters, our sample had a high power (0.80) to detect a medium-small effect size $(d=0.44)$ which corresponded to a difference of approximately 4.2 points on the final HAM-D between two genotypes (Cohen, 1988). The analysis was performed pooling fluvoxamine and paroxetine, given their similarity of action and previous reports suggesting similar genetic influences (Serretti et al., 2001a,b; Smeraldi et al., 1998; Zanardi et al., 2000); in the same way the reported effect of $\mathrm{G} \beta 3$ variants was observed for various antidepressants treatments (Zill et al., 2000).

\section{Results}

A detailed description of the clinical outcome of the sample has been separately reported in previous studies (Serretti et al., 2001b; Smeraldi et al., 1998; Zanardi et al., 2000). A brief description of the pooled sample is summarized in Table 1. Baseline clinical and demographic characteristics of subjects grouped according to $G \beta 3$ variants did not show any significant difference.
G $\beta 3$ genotypes resulted significantly associated with a better response to SSRIs treatment (see also Fig. 1 and Table 1, MANOVA: $F=2.28$; d.f. $=12$, 2922; $P=0.009$ ). We then included the HAMD measurement at baseline as covariant, but the association remained unchanged (MANCOVA: $F=2.22$; d.f. $=10,2435 ; P=0.01)$. Following, we compared mean HAM-D levels at each observation time, and this analysis evidenced that the difference between genotypes was present since week 3 (ANOVA: Week 1, $P=0.13$; Week 2, $P=0.15$; Week 3, $P=0.02$; Week 4, $P=0.02$; Week 5, $P=0.02$; Week 6, $P=0.04$ ). Consideration of clinical and demographic variables, such as sex, diagnosis, presence/absence of delusional features, and treatment (fluvoxamine versus paroxetine, presence versus absence of pindolol augmentation), did not affect this significant genotype effect. Categorical analyses showed a difference in the response rate (55.8 vs. $72 \%$ ) though not reaching the significance level. The sample was in HardyWeinberg equilibrium $\left(\chi^{2}=0.04, P=0.84\right)$.

\section{Discussion}

G $\beta 3$ variants resulted associated with SSRIs treatment outcome, independently from clinical and demographic variables. In detail, subjects with $\mathrm{G} \beta 3 * \mathrm{~T} / \mathrm{T}$ variant showed a significantly better response to antidepressant treatment, as measured by the HAM-D scores, and the variant effect was not significantly influenced by the analysed clinical, demographic and pharmacological variables.

Therefore our finding seems to be in agreement with the

Table 1

Sample description: data are expressed as mean (standard deviations). Significant results are indicated by $*$

\begin{tabular}{|c|c|c|c|c|c|}
\hline Gß3 Genotypes & $\mathrm{C} / \mathrm{C}(n=224)$ & $\mathrm{C} / \mathrm{T}(n=216)$ & $\mathrm{T} / \mathrm{T}(n=50)$ & $F(2,487)$ & $P$ \\
\hline Age (years) & $51.52(13.22)$ & $51.04(13.20)$ & $51.56(12.04)$ & 0.09 & 0.92 \\
\hline Age at onset (years) & $36.44(12.47)$ & $35.74(13.42)$ & $36.29(12.92)$ & 0.16 & 0.85 \\
\hline Education (years) & $9.42(4.32)$ & $8.49(4.36)$ & $9.81(4.64)$ & 2.60 & 0.08 \\
\hline Previous episodes (number) & $5.46(5.82)$ & $4.94(5.28)$ & $4.51(4.15)$ & 0.63 & 0.53 \\
\hline Duration current episode (weeks) & $23.05(25.54)$ & $24.26(42.06)$ & $32.38(25.17)$ & 0.25 & 0.78 \\
\hline Baseline HAM-D score & $30.10(6.32)$ & $30.0(6.04)$ & $29.0(5.08)$ & 0.67 & 0.51 \\
\hline HAM-D score at T6 & $10.37(11.67)$ & $8.83(10.50)$ & $6.22(8.70)$ & 3.27 & 0.04 \\
\hline Fluvoxamine mean blood level & $280.76(124.31)$ & $280.27(120.48)$ & $283.45(101.42)$ & 0.01 & 0.99 \\
\hline Paroxetine mean blood level & $71.48(35.36)$ & $58.32(32.11)$ & $58.63(38.0)$ & $\begin{array}{l}1.08 \\
F(10,2435)\end{array}$ & 0.35 \\
\hline \multirow[t]{2}{*}{ HAM-D score at $\mathrm{T} 1-\mathrm{T} 6 \#$} & - & - & - & 2.22 & $0.01^{*}$ \\
\hline & & & & $\chi^{2}$ & $P$ \\
\hline \multirow[t]{2}{*}{ Gender (female/male) } & $149 / 75$ & $153 / 63$ & $32 / 18$ & & \\
\hline & $(66.5 / 33.5 \%)$ & $(70.8 / 29.2 \%)$ & $(64.0 / 36.0 \%)$ & 1.39 & 0.50 \\
\hline \multirow[t]{2}{*}{ Psychotic features (no/yes) } & $136 / 88$ & $122 / 94$ & $29 / 21$ & & \\
\hline & $(60.7 / 39.3 \%)$ & $(56.5 / 43.5 \%)$ & $(58.0 / 42.0 \%)$ & 0.82 & 0.66 \\
\hline \multirow[t]{2}{*}{ Major depressives/Bipolar } & $136 / 88$ & $124 / 92$ & $30 / 20$ & & \\
\hline & $(60.7 / 39.3 \%)$ & $(57.4 / 42.6 \%)$ & $(60.0 / 40.0 \%)$ & 0.51 & 0.77 \\
\hline \multirow[t]{2}{*}{ Pindolol augmentation (no/yes) } & $150 / 74$ & $158 / 58$ & $32 / 18$ & & \\
\hline & $(67.0 / 33.0 \%)$ & $(73.2 / 26.8 \%)$ & $(64.0 / 36.0 \%)$ & 2.74 & 0.25 \\
\hline \multirow[t]{2}{*}{ Responders/Non-responders } & $125 / 99$ & $132 / 84$ & $36 / 14$ & & \\
\hline & $(55.8 / 44.2 \%)$ & $(61.1 / 38.9 \%)$ & $(72.0 / 28.0 \%)$ & 4.74 & 0.09 \\
\hline
\end{tabular}

\#MANCOVA with HAMD baseline as covariant. 


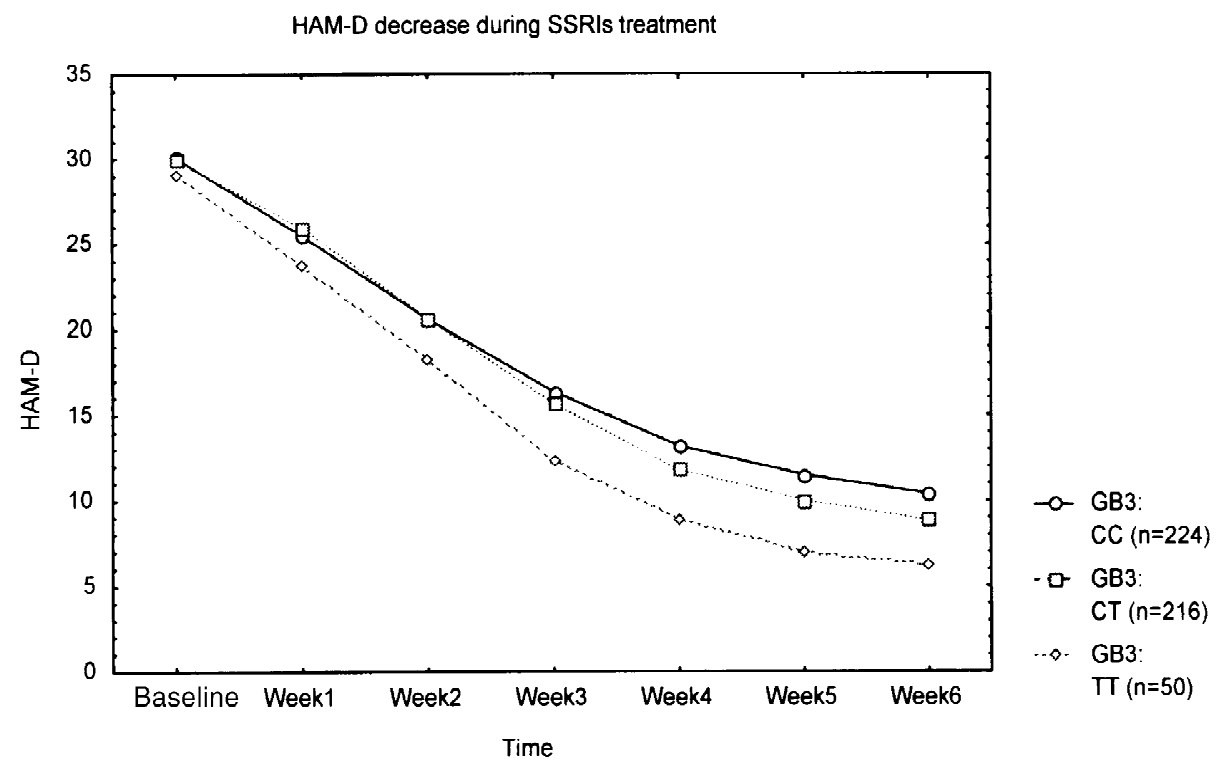

Fig. 1. shows the time course of response divided by G 33 variants: subjects with $G \beta 3 * \mathrm{~T} / \mathrm{T}$ variant showed a faster decrease of the symptomatology compared to other genotypes $(F=2.22 ; \mathrm{df}=12,2922 ; P=0.009)$.

previous study by Zill et al. (2000) which suggested a more favorable outcome of $\mathrm{T} / \mathrm{T}$ homozygotes. It is noteworthy that the observation of a significant effect of $\mathrm{T} / \mathrm{T}$ genotype supports the hypothesis of a recessive effect of G $\beta 3$ variants; however, another study suggested a dominant effect (Siffert et al., 1998).

The C825T G 33 polymorphism has been widely studied because it was primarily associated with hypertension (Pietruck et al., 1996; Siffert et al., 1995, 1998), an association not always confirmed in following papers (Beige et al., 1999; Benjafield et al., 1998; Brand et al., 1999; Dong et al., 1999; Hegele et al., 1998; Jacobi et al., 1999; Jia et al., 1999; Kario et al., 1999; Kato et al., 1998; Schorr et al., 2000; Siffert et al., 2000; Tsai et al., 2000; Wuthrich et al., 2000; Zeltner et al., 2001). However G proteins are extensively implicated also in the pathophysiology and treatment of psychiatric disorders (Avissar et al., 1997a,b, 2001; Young et al., 1994). Its relevance in mood disorders was in fact suggested by studies indicating that abnormalities of the phosphoinositide and $\mathrm{Ca}^{2+}$ signaling systems could influence G-protein-mediated transduction mechanism. In particular, activation of phospholipase beta $\mathrm{C}$ by release of the $\beta \gamma$ subunit from the complex $\mathrm{G} \alpha \beta \gamma$ leads to inositol 1,4,5-triphosphate (IP3) synthesis and to the subsequent release of $\mathrm{Ca}^{2+}$ from the storage pools contained into the endoplasmic reticulum (Camps et al., 1992). In this view, Corson et al. (2001) studied the possible association between the C825T polymorphism in the coding gene for the $\beta 3$ G-protein and calcium basal level in B lymphoblast cell lines in bipolar patients versus control subject. They found no statistically significant association; this study, though, led to the investigation of the possible role of G-proteins and/or intracellular calcium level in mechanism of action of lithium in the treatment of mood disorders (Gerfen et al., 1988; Manji et al., 1995; Rhee et al., 1989). Studies about a possible associations between G-proteins subunits variants and mood disorders gave conflicting results (Lin et al., 2001; Ram et al., 1997; Saito et al., 1999; Tsiouris et al., 1996; Zill et al., 2000), this could be due to the lack of homogeneity in the inclusion criteria of the studies. In fact, hypothesizing that the association of G 33 variants with antidepressant outcome is true, a variable rate of resistant subjects could influence $\mathrm{G} \beta 3$ frequencies.

In our study of the G $\beta 3$ polymorphism explained approximately $2 \%$ of the variance (partial correlationeffect size $f=0.132$ ) of antidepressant efficacy (Cohen, 1988), an observation that could be in agreement with a minor effect of the gene (Pickar and Rubinow, 2001).

We previously reported the influence of 5-HTTLPR and TPH variants on SSRI response and this effect proved to be independent (Serretti et al., 2001b). The present study suggests that also G $\beta 3$ variants influence SSRI efficacy; the complex interaction between polymorphism is a statistically challenging issue (Frankel and Schork, 1996); however, if this finding will be confirmed by future studies, it could accordingly be postulated that the antidepressant drugs efficacy is influenced by different limiting steps. The first could be at TPH level (5-HT biosynthesis) (Serretti et al., 2001a,b), the second at 5-HTT level of the serotonin transporter (Pollock et al., 2000; Smeraldi et al., 1998; Zanardi et al., 2000), and the third at the second messenger cascade level. Interestingly, the effect of G $\beta 3$ genetic variant does not seem influenced by pindolol augmentation.

Ethnicity is often considered a possible source of bias in association studies. However, subjects of Italian descent seem to share a substantial genetic homogeneity (Gasparini 
et al., 1997). Further limitations could be linked to the possibility of spontaneous remissions in our sample (Quitkin et al., 1984); however, the washout period at the beginning of the studies should protect against this bias.

In conclusion, Gß3 genotypes may influence the antidepressant response to SSRI. These results shed further light on the pharmacogenetics of SSRI, and they may contribute to the development of biological tools to help clinicians in more proper therapeutic choices.

\section{Acknowledgements}

This study was supported by Istituto Scientifico Ospedale San Raffaele (grants M0975 and M2511).

\section{References}

American Psychiatric Association, 1994. In: Diagnostic and Statistical Manual of Mental Disorders, 4th Edition. American Psychiatric Association, Washington, DC.

Avissar, S., Barki-Harrington, L., Nechamkin, Y., Roitman, G., Schreiber, G., 2001. Elevated dopamine receptor-coupled G(s) protein measures in mononuclear leukocytes of patients with schizophrenia. Schizophr. Res. 47, 37-47.

Avissar, S., Nechamkin, Y., Barki-Harrington, L., Roitman, G., Schreiber, G., 1997a. Differential G protein measures in mononuclear leukocytes of patients with bipolar mood disorder are state dependent. J. Affect. Disord. 43, 85-93.

Avissar, S., Nechamkin, Y., Roitman, G., Schreiber, G., 1997b. Reduced $\mathrm{G}$ protein functions and immunoreactive levels in mononuclear leukocytes of patients with depression. Am. J. Psychiatry 154, 211217

Bech, P., Malt, U., Dencker, S., Ahlfors, U., Elgen, K., Lewander, T., Lundell, A., Simpson, G., Lingjaerde, O., 1993. Scales for assessment of diagnosis and severity of mental disorders. Acta Psychiatr. Scand. 87 (Suppl. 372), 37-40.

Beige, J., Hohenbleicher, H., Distler, A., Sharma, A.M., 1999. G-Protein beta3 subunit C825T variant and ambulatory blood pressure in essential hypertension. Hypertension 33, 1049-1051.

Bellini, L., Gatti, F., Gasperini, M., Smeraldi, E., 1992. A comparison between delusional and non-delusional depressives. J. Affect. Disord. 25, 129-138.

Benjafield, A.V., Jeyasingam, C.L., Nyholt, D.R., Griffiths, L.R., Morris, B.J., 1998. G-protein beta3 subunit gene (GNB3) variant in causation of essential hypertension. Hypertension 32, 1094-1097.

Berrettini, W., 1998. Progress and pitfalls: bipolar molecular linkage studies. J. Affect. Disord. 50, 287-297.

Birnbaumer, L., Abramowitz, J., Brown, A.M., 1990. Receptor-effector coupling by $\mathrm{G}$ proteins. Biochim. Biophys. Acta 1031, 163-224.

Brand, E., Herrmann, S.M., Nicaud, V., Ruidavets, J.B., Evans, A., Arveiler, D., Luc, G., Plouin, P.F., Tiret, L., Cambien, F., 1999. The $825 \mathrm{C} / \mathrm{T}$ polymorphism of the G-protein subunit beta3 is not related to hypertension. Hypertension 33, 1175-1178.

Camps, M., Carozzi, A., Schnabel, P., Scheer, A., Parker, P.J., Gierschik, P., 1992. Isozyme-selective stimulation of phospholipase C-beta 2 by G protein beta gamma-subunits. Nature 360, 684-686.

Cohen, J., 1988. In: Statistical Power Analysis For the Behavioral Sciences. Lawrence Erlbaum Associates, Hillsdale, NJ, pp. 8-14.

Corson, T.W., Li, P.P., Kennedy, J.L., Macciardi, F., Cooke, R.G., Parikh, S.V., Warsh, J.J., 2001. Association analysis of G-protein beta 3 subunit gene with altered $\mathrm{Ca}(2+)$ homeostasis in bipolar disorder. Mol. Psychiatry 6, 125-126.

Dong, Y., Zhu, H., Sagnella, G.A., Carter, N.D., Cook, D.G., Cappuccio, F.P., 1999. Association between the C825T polymorphism of the G protein beta3-subunit gene and hypertension in blacks. Hypertension 34, 1193-1196.

Franchini, L., Serretti, A., Gasperini, M., Smeraldi, E., 1998. Familial concordance of fluvoxamine response as a tool for differentiating mood disorder pedigrees. J. Psychiatr. Res. 32, 255-259.

Frankel, W., Schork, N., 1996. Who's afraid of epistasis? Nat. Genet. 14, 371-373.

Gasparini, P., Estivill, X., Volpini, V., Totaro, A., Castellvi-Bel, S., Govea, N., Mila, M., Della Monica, M., Ventruto, V., De Benedetto, M., Stanziale, P., Zelante, L., Mansfield, E.S., Sandkuijl, L., Surrey, S., Fortina, P., 1997. Linkage of DFNB1 to non-syndromic neurosensory autosomal-recessive deafness in Mediterranean families. Eur. J. Hum. Genet. 5, 83-88.

Gerfen, C.R., Choi, W.C., Suh, P.G., Rhee, S.G., 1988. Phospholipase C I and II brain isozymes: immunohistochemical localization in neuronal systems in rat brain. Proc. Natl. Acad. Sci. USA 85, 3208-3212.

Gilman, A.G., 1987. G proteins: transducers of receptor-generated signals. Annu. Rev. Biochem. 56, 615-649.

Hamilton, M., 1967. Development of a rating scale for primary depressive illness. Br. J. Soc. Clin. Psychol. 6, 278-296.

Hegele, R.A., Harris, S.B., Hanley, A.J., Cao, H., Zinman, B., 1998. G protein beta3 subunit gene variant and blood pressure variation in Canadian Oji-Cree. Hypertension 32, 688-692.

Jacobi, J., Hilgers, K.F., Schlaich, M.P., Siffert, W., Schmieder, R.E., 1999. 825T allele of the G-protein beta3 subunit gene (GNB3) is associated with impaired left ventricular diastolic filling in essential hypertension. J. Hypertens. 17, 1457-1462.

Jia, H., Hingorani, A.D., Sharma, P., Hopper, R., Dickerson, C., Trutwein, D., Lloyd, D.D., Brown, M.J., 1999. Association of the G(s)alpha gene with essential hypertension and response to beta-blockade. Hypertension 34, 8-14.

Kario, K., Fujiwara, M., Sone, Y., Saiki, K., Hoshide, S., Shimada, K., Schwartz, J.E., Matsuo, M., 1999. G protein beta3 subunit gene variant, twenty-four-hour blood pressure, and hypertensive cerebrovascular disease in a Japanese population. Am. J. Hypertens. 12, 11591160 .

Kato, N., Sugiyama, T., Morita, H., Kurihara, H., Yamori, Y., Yazaki, Y., 1998. G protein beta3 subunit variant and essential hypertension in Japanese. Hypertension 32, 935-938.

Kim, D.K., Lim, S.W., Lee, S., Sohn, S.E., Kim, S., Hahn, C.G., Carroll, B.J., 2000. Serotonin transporter gene polymorphism and antidepressant response. Neuroreport 11, 215-219.

Lahiri, D.K., Nurnberger, J.I.J., 1991. A rapid non-enzymatic method for the preparation of HMW DNA from blood for RFLP studies. Nucleic Acids Res. 19, 5444.

Leckman, J.F., Sholomskas, D., Thompson, W.D., Belanger, A., Weissman, M.M., 1982. Best estimate of lifetime psychiatric diagnosis: a methodological study. Arch. Gen. Psychiatry 39, 879-883.

Levine, M.A., Modi, W.S., O'Brien, S.J., 1990a. Chromosomal localization of the genes encoding two forms of the G-protein beta polypeptide, beta- 1 and beta-3, in man. Genomics 8, 380-386.

Levine, M.A., Smallwood, P.M., Moen, P.T.J., Helman, L.J., Ahn, T.G., 1990b. Molecular cloning of beta-3 subunit, a third form of the $G$ protein beta-subunit polypeptide. Proc. Natl. Acad. Sci. USA 87, 2329-2333.

Lin, C.N., Tsai, S.J., Hong, C.J., 2001. Association analysis of a functional $\mathrm{G}$ protein beta3 subunit gene polymorphism (C825T) in mood disorders. Neuropsychobiology 44, 118-121.

Lucca, A., Lucini, V., Catalano, M., Alfano, M., Smeraldi, E., 1994. Plasma tryptophan to large neutral amino acids ratio and therapeutic response to a selective serotonin uptake inhibitor. Neuropsychobiology 29, 108-111.

Manji, H.K., Potter, W.Z., Lenox, R.H., 1995. Signal transduction pathways. Arch. Gen. Psychiatry 52, 531-543. 
Nestler, E.J., Duman, R.S., 1994. G-proteins and cyclic nucleotides in the nervous system. In: Siegel, G., Agranoff, B., Albers, R.W., Molinoff, P. (Eds.). Basic Neurochemistry, Vol. 1. Raven Press, New York, pp. 449-474.

O’Reilly, R.L., Bogue, L., Singh, S.M., 1994. Pharmacogenetic response to antidepressants in a multicase family with affective disorder. Biol. Psychiatry 36, 467-471.

Orsini, A., 1987. Antidepressant responses and segregation analyses in affective families. In: Racagni, G., Smeraldi, E. (Eds.), Anxious Depression: Assessment and Treatment. Raven Press, New York.

Pare, C.M., Mack, J.W., 1971. Differentiation of two genetically specific types of depression by the response to antidepressant drugs. J. Med. Genet. 8, 306-309.

Pickar, D., Rubinow, K., 2001. Pharmacogenomics of psychiatric disorders. Trends Pharmacol. Sci. 22, 75-83.

Pietruck, F., Moritz, A., Montemurro, M., Sell, A., Busch, S., Rosskopf, D., Virchow, S., Esche, H., Brockmeyer, N., Jakobs, K.H., Siffert, W., 1996. Selectively enhanced cellular signaling by $\mathrm{Gi}$ proteins in essential hypertension. $\mathrm{G}$ alpha i2, $\mathrm{G}$ alpha i3, $\mathrm{G}$ beta 1 , and $\mathrm{G}$ beta 2 are not mutated. Circ. Res. 79, 974-983.

Pollock, B.G., Ferrell, R.E., Mulsant, B.H., Mazumdar, S., Miller, M., Sweet, R.A., Davis, S., Kirshner, M.A., Houck, P.R., Stack, J.A., Reynolds, C.F., Kupfer, D.J., 2000. Allelic variation in the serotonin transporter promoter affects onset of paroxetine treatment response in late-life depression. Neuropsychopharmacology 23, 587-590.

Quitkin, F.M., Rabkin, J.G., Ross, D., Stewart, J.W., 1984. Identification of true drug response to antidepressants. Use of pattern analysis. Arch. Gen. Psychiatry 41, 782-786.

Ram, A., Guedj, F., Cravchik, A., Weinstein, L., Cao, Q., Badner, J.A., Goldin, L.R., Grisaru, N., Manji, H.K., Belmaker, R.H., Gershon, E.S., Gejman, P.V., 1997. No abnormality in the gene for the G protein stimulatory alpha subunit in patients with bipolar disorder. Arch. Gen. Psychiatry 54, 44-48.

Rhee, S.G., Suh, P.G., Ryu, S.H., Lee, S.Y., 1989. Studies of inositol phospholipid-specific phospholipase C. Science 244, 546-550.

Rosskopf, D., Busch, S., Manthey, I., Siffert, W., 2000. G protein beta 3 gene: structure, promoter, and additional polymorphisms. Hypertension 36, 33-41.

Saito, T., Papolos, D.F., Chernak, D., Rapaport, M.H., Kelsoe, J.R., Lachman, H.M., 1999. Analysis of GNAZ gene polymorphism in bipolar affective disorder. Am. J. Med. Genet. 88, 324-328.

Schorr, U., Blaschke, K., Beige, J., Distler, A., Sharma, A.M., 2000. G-protein beta3 subunit $825 \mathrm{~T}$ allele and response to dietary salt in normotensive men. J. Hypertens. 18, 855-859.

Sederer, L.I., 1986. Depression. In: Sederer, L.I. (Ed.), Inpatients Psychiatry Diagnosis and Treatment. William \& Wilkins, Baltimore, MD, p. 20.

Serretti, A., Franchini, L., Gasperini, M., Rampoldi, R., Smeraldi, E., 1998. Mode of inheritance in mood disorders families according to fluvoxamine response. Acta Psychiatr. Scand. 98, 443-450.

Serretti, A., Zanardi, R., Cusin, C., Rossini, D., Lorenzi, C., Smeraldi, E., 2001a. Tryptophan hydroxylase gene associated with paroxetine antidepressant activity. Eur. Neuropsychopharmacol. 11, 375-380.

Serretti, A., Zanardi, R., Rossini, D., Cusin, C., Lilli, R., Smeraldi, E., 2001b. Influence of tryptophan hydroxylase and serotonin transporter genes on fluvoxamine antidepressant activity. Mol. Psychiatry 6, $586-592$.
Siffert, W., Rosskopf, D., Erbel, R., 2000. Genetic polymorphism of the G-protein beta3 subunit, obesity and essential hypertension. Herz 25, 26-33.

Siffert, W., Rosskopf, D., Moritz, A., Wieland, T., Kaldenberg-Stasch, S., Kettler, N., Hartung, K., Beckmann, S., Jakobs, K.H., 1995. Enhanced $\mathrm{G}$ protein activation in immortalized lymphoblasts from patients with essential hypertension. J. Clin. Invest. 96, 759-766.

Siffert, W., Rosskopf, D., Siffert, G., Busch, S., Moritz, A., Erbel, R., Sharma, A.M., Ritz, E., Wichmann, H.E., Jakobs, K.H., Horsthemke, B., 1998. Association of a human G-protein beta3 subunit variant with hypertension. Nat. Genet. 18, 45-48.

Simon, M.I., Strathmann, M.P., Gautam, N., 1991. Diversity of G proteins in signal transduction. Science 252, 802-808.

Smeraldi, E., Zanardi, R., Benedetti, F., Dibella, D., Perez, J., Catalano, M., 1998. Polymorphism within the promoter of the serotonin transporter gene and antidepressant efficacy of fluvoxamine. Mol. Psychiatry $3,508-511$.

Sobin, C.A., Sackeim, H., 1997. Psychomotor symptoms of depression. Am. J. Psychiatry 154, 4-17.

Tsai, C.H., Yeh, H.I., Chou, Y., Liu, H.F., Yang, T.Y., Wang, J.C., Wang, N.M., Chang, J.G., 2000. G protein beta3 subunit variant and essential hypertension in Taiwan-a case-control study. Int. J. Cardiol. 73, 191-195, discussion 197-198.

Tsiouris, S.J., Breschel, T.S., Xu, J., McInnis, M.G., McMahon, F.J., 1996. Linkage disequilibrium analysis of G-olf alpha (GNAL) in bipolar affective disorder. Am. J. Med. Genet. 67, 491-494.

Wuthrich, R.P., Cicvara, S., Booy, C., Widmer, U., Binswanger, U., 2000. The $825 \mathrm{C} / \mathrm{T}$ polymorphism of the G-protein subunit beta3 does not influence blood pressure and renal function in kidney transplant recipients. Nephrol. Dial. Transplant. 15, 1663-1666.

Yoshid, K., Ito, K., Sato, K., Takahashi, H., Kamata, M., Higuchi, H., Shimizu, T., Itoh, K., Inoue, K., Tezuka, T., Suzuki, T., Ohkubo, T., Sugawara, K., Otani, K., 2002. Influence of the serotonin transporter gene-linked polymorphic region on the antidepressant response to fluvoxamine in Japanese depressed patients. Prog. Neuropsychopharmacol. Biol. Psychiatry 26, 383-386.

Young, L.T., Li, P.P., Kamble, A., Siu, K.P., Warsh, J.J., 1994. Mononuclear leukocyte levels of $\mathrm{G}$ proteins in depressed patients with bipolar disorder or major depressive disorder. Am. J. Psychiatry 151, 594596.

Zanardi, R., Benedetti, F., DiBella, D., Catalano, M., Smeraldi, E., 2000. Efficacy of paroxetine in depression is influenced by a functional polymorphism within the promoter of serotonin transporter gene. J. Clin. Psychopharmacol. 20, 105-107.

Zanardi, R., Serretti, A., Rossini, D., Franchini, L., Cusin, C., Lattuada, E., Dotoli, D., Smeraldi, E., 2001. Factors affecting fluvoxamine antidepressant activity: influence of pindolol and 5-HTTLPR in delusional and nondelusional depression. Biol. Psychiatry 50, 323330.

Zeltner, R., Delles, C., Schneider, M., Siffert, W., Schmieder, R.E., 2001. G-protein beta(3) subunit gene (GNB3) $825 \mathrm{~T}$ allele is associated with enhanced renal perfusion in early hypertension. Hypertension 37, 882-886.

Zill, P., Baghai, T.C., Zwanzger, P., Schule, C., Minov, C., Riedel, M., Neumeier, K., Rupprecht, R., Bondy, B., 2000. Evidence for an association between a G-protein beta3-gene variant with depression and response to antidepressant treatment. Neuroreport 11, 1893-1897. 
Chapter 4: $\quad$ The C(-1019)G polymorphism of the 5-HT1A gene promoter and antidepressant response in mood disorders: preliminary findings 


\title{
The C(-1019)G polymorphism of the 5-HT1A gene promoter and antidepressant response in mood disorders: preliminary findings
}

\author{
Alessandro Serretti ${ }^{1}$, Paola Artioli ${ }^{1}$, Cristina Lorenzi ${ }^{1,2}$, Adele Pirovano ${ }^{1}$, Viviana Tubazio ${ }^{1}$ \\ and Raffaella Zanardi ${ }^{1}$ \\ ${ }^{1}$ Department of Psychiatry, School of Medicine, Vita-Salute University San Raffaele, Milan, Italy \\ ${ }^{2}$ Institute of Psychiatry, University of Bologna, Italy
}

\begin{abstract}
Several studies have demonstrated the involvement of 5-HT1A receptors in the pathogenesis of depression and in the antidepressant response to SSRIs. A functional new variant in the promoter region of the 5-HT1A gene was recently reported $(-1019 \mathrm{C}>\mathrm{G})$. The aim of this study is to investigate a possible association between this 5-HT1A receptor variant and antidepressant response to fluvoxamine in a sample of 262 mood-disorder subjects (151 major depressed and 111 bipolars) treated with fluvoxamine for $6 \mathrm{wk}$. The severity of depressive symptoms was assessed weekly with the Hamilton Rating Scale for Depression (HAMD). 5-HT1A variants did not influence antidepressant response in the whole sample and in unipolar subjects. In bipolars, 5-HT1A*C /C genotype carriers showed a better response to fluvoxamine $(p=0.036)$, independently from clinical variables. The 5-HT1A polymorphism effect on antidepressant response was independent from the previously reported effect of the 5-HTTLPR polymorphism. In conclusion, 5-HT1A variants could influence the antidepressant efficacy in bipolar subjects, even if results must be verified on larger samples.
\end{abstract}

Received 24 February 2004; Reviewed 5 May 2004; Revised 19 May 2004; Accepted 26 May 2004

Key words: Antidepressant treatment, bipolar disorder, genetics, major depressive disorder, pharmacogenetics.

\section{Introduction}

The functional polymorphism in the upstream regulatory region of the serotonin transporter (5-HTTLPR) gene was repeatedly associated with antidepressant response to selective serotonin reuptake inhibitors (SSRIs) in mood disorders (Arias et al., 2001; Pollock et al., 2000; Smeraldi et al., 1998; Yu et al., 2002; Zanardi et al., 2000, 2001b). Preliminary results also suggest that the tryptophan hydroxylase (TPH) gene variants (A218C) were involved in the outcome of antidepressant treatment (Peters et al., 2003; Serretti et al., 2001a,b), even if those findings were not univocally confirmed (Kim et al., 2000; Yoshida et al., 2002). Further not univocally replicated positive findings included G-protein beta3-subunit (Gbeta3) and serotonin receptor $2 \mathrm{~A}$ gene polymorphisms (Cusin

Address for correspondence: Dr A. Serretti, Department of Psychiatry, School of Medicine, Vita-Salute University San Raffaele, Via Stamira D'Ancona 20, 20127 Milan, Italy. Tel.: 0039-02-2643 3250 Fax: 0039-02-2643 3265

E-mail : serretti.alessandro@hsr.it et al., 2002 ; Minov et al., 2001; Serretti et al., 2003; Zill et al., 2000).

In the search for further genes influencing response, we focused on the 5-HT1A receptor. Electrophysiological and microdialysis studies performed on animals have shown that administration of SSRIs causes a functional blockade of serotonin (5-HT) feedback onto somatodendritic 5-HT1A receptors. 5-HT neurons therefore continue firing and synthesizing 5-HT, while SSRIs increase synaptic 5-HT concentration through the uptake-pump block (SERT), thus facilitating 5-HT neurotransmission (Bel and Artigas, 1993; Sprouse et al., 2001); this interaction could represent the origin of antidepressant response. A number of partial agonists of the 5-HT1A receptor have been shown to exert a synergic action with 5-HT reuptake blockers in the treatment of depression (Albert et al., 1996; Artigas et al., 1996; Blier and de Montigny, 1994; Mongeau et al., 1997; Zanardi et al., 1997, 1998). Pindolol, a beta adrenoceptor antagonist that also has 5-HT1A receptor antagonist properties, has been used to accelerate the onset of antidepressant action 
by blocking 5-HT1A pre-synaptic receptors (Perez et al., 1997).

Serotonin 1A (5-HT1A) receptors are located both at a post-synaptic and at a pre-synaptic level; in the first case, they mediate the action of 5-HT on cortical and limbic neurons and are thought to play an important role in the pathogenesis of depressive symptomatology, in the second case, they act as serotonergic autoreceptors on serotonergic neurons in the raphe nuclei and prevent the release of 5-HT by a negative feedback (Dubovsky and Thomas, 1995; Kapur and Remington, 1996). 5-HT1A pre-synaptic receptors exert a self-inhibitory function and when they are stimulated by $5-\mathrm{HT}$ the result is a decrease in neuronal firing, and 5-HT synthesis and release.

The 5-HT1A receptor gene was mapped on the long arm of chromosome five (5q11.2-13) and it appears to be intronless (Kobilka et al., 1987). It contains an uninterrupted long open reading frame encoding a $G$ protein-coupled receptor, that acts primarily via inhibition of adenylate cyclase. A functional new variant in the promoter region of the gene was recently reported (Wu and Comings, 1999). This polymorphism consists of a $G$ to $C$ substitution and is located at position $92928 \mathrm{bp}$ (GDB: AC008965) of the human 5-HT1A gene. It is inside a palindromic region of $26 \mathrm{bp}$, which bounds a single repressor, the so-called Nuclear DEAF-1-related (NUDR) protein (Lemonde et al., 2003). This variant was demonstrated to be involved in modulating the rate of transcription of the 5-HT1A gene. When the G-allele is incorporated, it prevents the binding of this putative repressor to DNA, leading, in this way, to an increase of 5-HT1A autoreceptors and a reduction of serotonergic neurotransmission (Stahl, 1994). This C $(-1019) \mathrm{G}$ polymorphism of the 5-HT1A promoter was associated with a number of psychiatric disorders including major depression, suicide and anxiety- related traits (Lemonde et al., 2003; Rothe et al., 2004; Strobel et al., 2003).

To our knowledge, the association between this polymorphism and antidepressant response has not been investigated to date. The aim of our study is to investigate a possible association between these variants of the 5-HT1A receptor and the antidepressant response to fluvoxamine in a sample of 262 depressed subjects treated with fluvoxamine.

\section{Materials and methods}

\section{Sample}

A total of 262 in-patients affected by major recurrent depression and bipolar disorder admitted to the Mood
Disorder Centre at the Department of Psychiatry of San Raffaele Hospital, Milan were included in the study. Lifetime diagnoses were assigned according to DSM-IV criteria (APA, 1994) on the basis of structured clinical interviews, the Schedule for Affective Disorder and Schizophrenia (SADS; Endicott and Spitzer, 1978) and/or the Structured Clinical Interview for DSM-IV (SCID; First et al., 1995), plus all available sources. A first psychiatrist evaluated the retrospective course of illness, by interviewing subjects, family members, previous health professionals and obtaining records where possible (Leckman et al., 1982). A second experienced psychiatrist reviewed the chart and, if no consensus was obtained, a third senior psychiatrist was involved. However, no subject was excluded because of disagreement.

The sample is described in Table 1. Inclusion criteria were described elsewhere (Smeraldi et al., 1998; Zanardi et al., 2000, 2001b). The sample was previously analysed for association between antidepressant treatment and other candidate genes in published studies (Cusin et al., 2002; Serretti et al., 2001b; Smeraldi et al., 1998; Zanardi et al., 2001a); the amount of drop-out patients in those studies was 12 subjects and they have been described previously; the small drop-out rate is due to the in-patient setting of the studies. The presence of any concomitant Axis I diagnosis and somatic or neurological illnesses impairing psychiatric evaluation represented exclusion criteria. All patients were evaluated at baseline and weekly thereafter until the sixth week using the 21-item Hamilton Rating Scale for Depression (HAMD-21; Hamilton, 1967) administered by trained senior psychiatrists blind to genetic data.

Subjects for the present study have been treated as described in our previous antidepressant trials and under double-blind conditions (Smeraldi et al., 1998; Zanardi et al., 2001a). Briefly, after a 7-d washout period, fluvoxamine was titrated to reach $300 \mathrm{mg} / \mathrm{d}$. Concomitant psychotropic drugs were not allowed, except lithium maintenance and flurazepam at bedtime (up to $45 \mathrm{mg}$ ). A decrease in HAMD scores to $\leqslant 8$, with Delusion factor equal to 0 (items $2,15,20$ ) (Bech et al., 1993; Bellini et al., 1992; Sobin and Sackeim, 1997), was considered the response criterion. After the procedure had been fully explained to all subjects, informed consent was obtained.

Plasma fluvoxamine levels were determined by high-performance liquid chromatography after $2 \mathrm{wk}$ of stable daily dose (Lucca et al., 1994). Patients who showed fluvoxamine plasma levels exceeding the mean value of the sample \pm 2 -fold the standard deviation were originally not included to avoid the 
Table 1. Genotype frequencies and clinical and demographic variables (the number of subjects for which the information was available is in parentheses)

\begin{tabular}{|c|c|c|c|c|c|c|}
\hline Variables (5-HT1A) & $\mathrm{C} / \mathrm{C}$ & $\mathrm{C} / \mathrm{G}$ & $\mathrm{G} / \mathrm{G}$ & Total sample & $F$ & $p$ \\
\hline Age (yr) (259) & $48.83 \pm 12.83$ & $52.93 \pm 12.56$ & $49.83 \pm 14.85$ & $51.15 \pm 13.33$ & 2.44 & 0.08 \\
\hline Onset (yr) (257) & $34.72 \pm 11.46$ & $38 \pm 13.40$ & $35.86 \pm 14.58$ & $36.68 \pm 13.30$ & 1.43 & 0.24 \\
\hline $\begin{array}{l}\text { Total no. of } \\
\text { episodes (218) }\end{array}$ & $5.45 \pm 5.32$ & $4.94 \pm 5.29$ & $4.71 \pm 5.49$ & $5.01 \pm 5.33$ & 0.26 & 0.76 \\
\hline $\begin{array}{l}\text { HAMD-21 score at } \\
\text { baseline (262) }\end{array}$ & $29.82 \pm 5.78$ & $30.42 \pm 6.60$ & $29.53 \pm 5.41$ & $30.05 \pm 6.12$ & 0.53 & 0.58 \\
\hline $\begin{array}{l}\text { HAMD-21 score at } \\
\text { week } 6(262)\end{array}$ & $7.93 \pm 10.41$ & $9.64 \pm 12.02$ & $9.35 \pm 10.80$ & $9.15 \pm 11.31$ & 0.47 & 0.61 \\
\hline $\begin{array}{l}\text { Fluvoxamine } \\
\text { plasma level } \\
\text { (mequiv./l) (150) }\end{array}$ & $326.55 \pm 176.20$ & $320.13 \pm 285.78$ & $258.61 \pm 180.22$ & $307.90 \pm 239.06$ & 0.94 & 0.39 \\
\hline Variables (5-HT1A) & $\mathrm{C} / \mathrm{C}$ & $\mathrm{C} / \mathrm{G}$ & $\mathrm{G} / \mathrm{G}$ & Total & $\chi^{2}$ & $p$ \\
\hline $\operatorname{Sex}(F / M)$ & $\begin{array}{l}38 / 24 \\
(61.29 / 38.71 \%)\end{array}$ & $\begin{array}{l}90 / 43 \\
(67.67 / 32.33 \%)\end{array}$ & $\begin{array}{l}45 / 22 \\
(67.16 / 32.84 \%)\end{array}$ & 262 & 0.81 & 0.66 \\
\hline Diagnosis $(\mathrm{MD} / \mathrm{BP})^{*}$ & $\begin{array}{l}32 / 30 \\
(51.61 / 48.39 \%)\end{array}$ & $\begin{array}{l}72 / 61 \\
(54.14 / 45.86 \%)\end{array}$ & $\begin{array}{l}47 / 20 \\
(70.15 / 29.85 \%)\end{array}$ & 262 & 5.88 & 0.05 \\
\hline Responders (yes/no) & $\begin{array}{l}38 / 24 \\
(61.29 / 38.71 \%)\end{array}$ & $\begin{array}{l}80 / 53 \\
(60.15 / 39.85 \%)\end{array}$ & $\begin{array}{l}39 / 28 \\
(58.21 / 41.79 \%)\end{array}$ & 262 & 0.13 & 0.93 \\
\hline $\begin{array}{l}\text { Delusional features } \\
\text { (yes/no) }\end{array}$ & $\begin{array}{l}24 / 30 \\
(44.44 / 55.56 \%)\end{array}$ & $\begin{array}{l}58 / 62 \\
(48.33 / 51.67 \%)\end{array}$ & $\begin{array}{l}26 / 34 \\
(43.33 / 56.67 \%)\end{array}$ & 234 & 0.48 & 0.78 \\
\hline $\begin{array}{l}\text { SERPR genotypes } \\
(1 \mathrm{l} / \mathrm{ls} / \mathrm{ss})\end{array}$ & $\begin{array}{l}21 / 21 / 19 \\
(34.43 / 34.43 / 31.14 \%)\end{array}$ & $\begin{array}{l}50 / 49 / 30 \\
(38.76 / 37.98 / 23.26 \%)\end{array}$ & $\begin{array}{l}16 / 30 / 18 \\
(25 / 46.88 / 28.13 \%)\end{array}$ & 254 & 4.79 & 0.30 \\
\hline Variables (5-HTTLPR) & $1 / 1$ & $1 / \mathrm{s}$ & $\mathrm{s} / \mathrm{s}$ & & $F$ & $p$ \\
\hline $\begin{array}{l}\text { Fluvoxamine } \\
\text { plasma level } \\
\text { (mequiv./l) (150) }\end{array}$ & $283.89 \pm 210.85$ & $314.06 \pm 202.98$ & $325.27 \pm 306.45$ & & 0.36 & 0.69 \\
\hline
\end{tabular}

* MD, Major depression, BP, bipolar.

possibility that extreme differences in the bioavailability of the drug could influence the clinical response. We excluded from our study individuals who reached a HAMD-21 score decrease of more than $50 \%$ of the baseline value after the first week of treatment, to avoid the presence of 'placebo responder' individuals (Quitkin et al., 1984, 1987; Rausch et al., 2002), or of spontaneous remissions. Nineteen subjects were excluded from the analysis for this reason. However, they did not differ from the total sample in terms of clinical characteristics and genotype frequencies (data not shown).

\section{DNA analysis}

Genomic DNA was extracted from leucocytes by $\mathrm{NaCl}$ precipitation (Lahiri and Nurnberger, 1991).
PCR was performed with the following primers: 5'-CCCAGAGTGGCAATAGGAGA-3' and 5'CCGTTTTGTTGTTGTTGTCG-3'. The PCR reaction was carried out in a $10 \mathrm{ml}$ volume containing $150 \mathrm{ng}$ genomic DNA, 5 pmol of each primer, $200 \mathrm{~mm}$ each dNTP, $1 \times$ PCR Gold Buffer (Applied Biosystems, Monza, Italy), and $0.025 \mathrm{U} / \mathrm{ml}$ of Taq Gold Polymerase (Applied Biosystems). After an initial step of $5 \mathrm{~min}$ at $95^{\circ} \mathrm{C}, 35$ cycles of amplification ( $30 \mathrm{~s}$ at $95^{\circ} \mathrm{C}, 30 \mathrm{~s}$ at $62{ }^{\circ} \mathrm{C}, 45 \mathrm{~s}$ at $72^{\circ} \mathrm{C}$ ) and a final extension step of $10 \mathrm{~min}$ at $72{ }^{\circ} \mathrm{C}$ were performed. Then, after purification of PCR product, we performed a SnaPshot ddNTP Primer Extension (kit by Applied Biosystems). The extension reaction was carried out with the 5'-GGAAGAAGACCGAGTGTGTCTTCG-3' primer $(10 \mu \mathrm{M})$ and with the 
Table 2. Clinical and demographical variables according to diagnosis

\begin{tabular}{|c|c|c|c|c|}
\hline Variables & MD & $\mathrm{BP}$ & $t$ & $p$ \\
\hline Age (yr) & $52.20 \pm 12.66$ & $49.74 \pm 14.10$ & 1.47 & 0.14 \\
\hline HAMD-21 score at baseline & $29.46 \pm 5.81$ & $30.86 \pm 6.46$ & -1.83 & 0.07 \\
\hline HAMD-21 score at week 6 & $9.15 \pm 10.85$ & $9.14 \pm 11.95$ & 0.01 & 0.99 \\
\hline Fluvoxamine plasma level (mequiv./l) & $308.03 \pm 273.63$ & $307.70 \pm 181.14$ & 0.008 & 0.99 \\
\hline Variables & UP & $\mathrm{BP}$ & $\chi^{2}$ & $p$ \\
\hline $\operatorname{Sex}(F / M)$ & $\begin{array}{l}107 / 44 \\
(70.86 / 29.14 \%)\end{array}$ & $\begin{array}{l}66 / 45 \\
(59.46 / 40.54 \%)\end{array}$ & 3.70 & 0.05 \\
\hline Responders (yes/no) & $\begin{array}{l}85 / 65 \\
(56.95 / 43.05 \%)\end{array}$ & $\begin{array}{l}71 / 40 \\
(63.96 / 36.04 \%)\end{array}$ & 1.30 & 0.25 \\
\hline
\end{tabular}

MD, Major depression, BP, bipolar, UP, unipolar.

following steps: $10 \mathrm{~s}$ at $96{ }^{\circ} \mathrm{C}, 5 \mathrm{~s}$ at $60^{\circ} \mathrm{C}$ and $30 \mathrm{~s}$ at $60{ }^{\circ} \mathrm{C}$, for 25 cycles. The product was then genotyped by a Genetic Analyser (ABI PRISM ${ }^{\circledR}$ 310, Applied Biosystems), after a denaturation step $\left(95^{\circ} \mathrm{C}\right.$ for $5 \mathrm{~min})$.

5-HTTLPR genotyping was also performed, as described elsewhere (Serretti et al., 2002), producing long (528 bp) and short (484 bp) variants.

\section{Statistical analysis}

Seven HAMD score measurements (at baseline and for $6 \mathrm{wk}$ ) were analysed. Multivariate analysis of variance (MANOVA) for repeated measures was used to examine the differences between genotypes on HAMD scores during the $6 \mathrm{wk}$ of treatment. An 'intent-to-treat' analysis was carried out for all patients who had a baseline assessment and at least one assessment after randomization, with the last observation carried forward on the HAMD. Student's $t$ test, ANOVA and $\chi^{2}$ were used when appropriate. Analysis of covariance (ANCOVA) was used to investigate possible stratification effects. MANOVA for repeated measures including 5-HT1A and 5-HTTLPR variants as main factors was used to investigate a possible interaction between the two polymorphisms. All $p$ values were two-tailed, and statistical significance was set at the $5 \%$ level $(p<0.05)$. With these parameters, for continuous measurements, our sample had a high power (0.80) to detect a small effect size $(d=0.35)$, which corresponded to a difference of approximately 3.7 points on the final HAMD score between two genotypes (Cohen, 1988). Statistical analyses were performed using the STATISTICA package (StatSoft, 2004).

\section{Results}

Genotype frequencies were respectively: C/C 62 (23.67\%), C/G 133 (50.76\%), G/G 67 (25.57\%). They resulted similarly to the frequencies obtained by Lemonde et al. (2003) for their samples of depressed patients [C/C 30 (23.25\%), C/G 63 (48.84\%), G/G 36 $(27.91 \%)]$. The sample resulted in Hardy-Weimberg equilibrium for the analysed polymorphism. The three genotypes did not significantly differ among one another for diagnosis, sex, age, age of onset, presence of psychotic features lifetime, presence of familiarity for mood disorders, number of episodes and Hamilton scores at baseline. Descriptive variables, subdivided according to diagnosis of the subjects are shown in Table 2 .

When analysing the whole sample, the three genotypes did not show any difference in antidepressant response (MANOVA: main effect 5-HT1A, $p=0.88$; time, $p<0.0001$; interaction 5-HT1A $\times$ time, $F=0.31$, d.f. $=12,1548, p=0.98$ ), and the same negative finding was observed when analysing unipolar subjects only (MANOVA: main effect 5-HT1A, $p=0.25$; time, $p<0.0001$; interaction 5-HT1A $\times$ time, $F=1.42$, d.f. $=$ $12,882, p=0.15)$. On the other hand, when analysing bipolar subjects, an association between ${ }^{*} \mathrm{C} / \mathrm{G}$ genotype and a worse antidepressant response was observed, as shown in Figure 1 (MANOVA: main effect 5-HT1A, $p=0.08$; time, $p<0.0001$; interaction 5HT1A $\times$ time, $F=1.86$, d.f. $=12,648, p=0.036$ ). Among bipolars, including age and sex as covariants, the effect remained significant ( $p=0.036$ in both cases), while the significance was marginally decreased when basal HAMD was included as a covariant (MANCOVA with HAMD-21 score at baseline; bipolar only: $F=1.70$, 


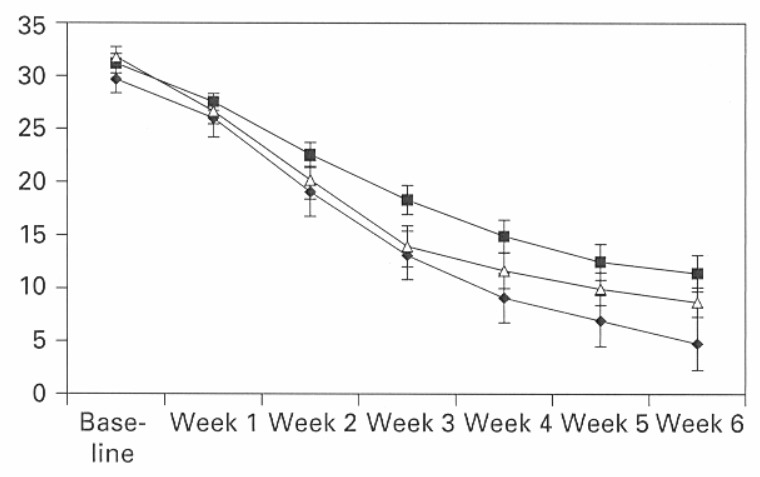

Figure 1. Fluvoxamine responses in terms of HAMD-21 decrease for the three analysed variants of the 5-HT1A receptor in bipolar subjects.,$-- C / C ;-\square-, C / G ;-\triangle-, G / G$.

d.f. $=10,540, p=0.077)$ and it fell to non-significance when plasma levels were also included as a covariant (MANCOVA, bipolar only: $F=0.69$, d.f. $=10,295$, $p=0.60$ ). We then analysed 5-HT1A within responder and non-responder bipolar subjects, and we observed that there was a trend in genotype distribution between responder and non-responder bipolar patients (C/C Resp/Nonresp: $23 / 7, \chi^{2}=3.01, p=0.08$ ).

\section{Interaction with 5-HTTLPR}

We then considered, within our sample, a possible interaction with 5-HTTLPR variants. We performed a MANOVA for repeated measures including 5HT1A and 5-HTTLPR variants as main factors. Given that the inclusion of all the genotypes would incorrectly imply a strict co-dominant effect and that the inclusion of all four of the dummy variables (5-HT1A*C/C，5-HT1A*C/G, 5-HTTLPR*s /s, 5$\mathrm{HTTLPR}^{*} \mathrm{l} / \mathrm{s}$ - the remaining genotypes are implicit) were not feasible for the sample size, we repeated the analysis including two terms in turn. For example we report the results for the $5-\mathrm{HT} 1 \mathrm{~A}^{*} \mathrm{C} / \mathrm{C}$ and 5$\mathrm{HTTLPR}^{*} \mathrm{~s} / \mathrm{s}$ variants which evidenced a slightly higher significance for the 5-HT1A variant (main effect, $p=0.08$; interaction with time, $p=0.018$ ) but no effect of the interaction term ( $p=0.37$ and $p=0.93$ respectively). Similar results were obtained for the other combinations (data not shown).

\section{Discussion}

This is, to our knowledge, the first association study that investigates antidepressant response according to C(-1019)G 5-HT1A variants. Our preliminary findings on the sample of bipolar subjects suggest a liability effect of this polymorphism on antidepressant efficacy. In fact, bipolar disorder is thought to have a heavier genetic load than unipolar depression (Tsuang and Faraone, 1990). According to the molecular hypothesis, we found that *G-allele-containing individuals showed a worse response to fluvoxamine. Following the hypothesis of polygenic inheritance of complex traits, we investigated a possible interaction with 5-HTTLPR variants, but we found no significant effect. We can provisionally regard the 5-HT1A variants' influence as independent from 5-HTTLPR. Obviously, we observed this at a clinical level and we cannot infer possible interactions at the molecular level. We have previously observed that pindolol, a partial 5-HT1A antagonist, influenced the antidepressant response, cancelling the influence of the 5-HTTLPR polymorphism. In fact, with pindolol augmentation, the individuals carrying the *s/s genotype, which was usually associated to a worse response, showed a better outcome and it overwhelmed the differences between genotypes (Smeraldi et al., 1998). In the present paper we excluded subjects treated with pindolol in order to avoid ambiguous interpretation of data (plasma levels of pindolol, rationale of the observed combined effect of pindolol plus antidepressant and so on).

In our sample the 5-HTTLPR frequencies were respectively: $1 / 187(34.25 \%), 1 / \mathrm{s} 100(39.37 \%)$ and s/s $67(26.38 \%)$. They were similar to the frequencies reported in previously published studies in Caucasian patients which, for the s/s genotype, ranged from 21.6 to $28.3 \%$ (Smits et al., 2004). Frequencies were also similar for the other two genotypes.

Other factors associated to mood disorders could hide the effect of genes on antidepressant response, or enhance it. In particular, there is evidence that 5-HT1A receptor density might differ according to gender and age (Cidis Meltzer et al., 2001; Parsey et al., 2002), however, genotype frequencies did not differ according to those two variables in our sample.

The main limitation of this study is the small number of subjects which did not allow detection of small differences between genotypes. A further limitation could be represented by the case-control approach. Genomic control strategies are routinely used in order to detect ethnic stratification biases (Pritchard and Rosenberg, 1999), however, our sample was selected among subjects with northern Italian antecedents for at least two generations, being from north Italy is characterized by a substantial genetic homogeneity (Barbujani and Sokal, 1991). Moreover, our centre is a tertiary care setting and, therefore, we 
cannot exclude a potential bias associated with the severity of illness.

Another issue needs to be considered: the presence of placebo response, which was recently associated to 5-HTTLPR genotype (Walsh et al., 2002). This placebo response could in fact reduce the power to detect the real interaction between gene variants and antidepressant response. However, we tried to avoid this effect with the washout period and the exclusion of early responders (Quitkin et al., 1984).

In conclusion we observed a moderate liability effect of 5-HT1A variants in antidepressant response in bipolar disorder but not in major depressives, this finding adds an important piece of information for the pathway of detecting the genetics of antidepressant response.

\section{Acknowledgements}

The authors thank Anna Colombo for her help with DNA analysis. The present study was partially supported by EC grant no. HPAW-CT-2002-80066.

\section{Statement of Interest}

None.

\section{References}

Albert PR, Lembo P, Storring JM, Charest A, Saucier C (1996). The 5-HT1A receptor: signaling, desensitization, and gene transcription. Neuropsychopharmacology 14, 19-25. APA (1994). Diagnostic and Statistical Manual of Mental Disorders (4th edn). Washington, DC: American Psychiatric Association.

Arias B, Catalan R, Gasto C, Imaz ML, Gutierrez B, Pintor L, Fananas L (2001). Genetic variability in the promoter region of the serotonin transporter gene is associated with clinical remission of major depression after long term treatment with citalopram. World Federation of Societies of Biological Psychiatry, vol. 2 (1). The World Journal of Biological Psychiatry (Berlin, Germany), p. 95.

Artigas F, Romero L, de Montigny C, Blier P (1996). Acceleration of the effect of selected antidepressant drugs in major depression by 5-HT1A antagonists. Trends in Neurosciences 19, 378-383.

Barbujani G, Sokal RR (1991). Genetic population structure of Italy. I. Geographic patterns of gene frequencies. Human Biology 63, 253-272.

Bech P, Malt U, Dencker S, Ahlfors U, Elgen K, Lewander T, Lundell A, Simpson G, Lingjaerde O (1993). Scales for assessment of diagnosis and severity of mental disorders. Acta Psychiatrica Scandinavica 87 (Suppl.) 372, 37-40.

Bel N, Artigas F (1993). Chronic treatment with fluvoxamine increases extracellular serotonin in frontal cortex but not in raphe nuclei. Synapse 15, 243-245.
Bellini L, Gatti F, Gasperini M, Smeraldi E (1992). A comparison between delusional and non-delusional depressives. Journal of Affective Disorders 25, 129-138.

Blier P, de Montigny C (1994). Current advances and trends in the treatment of depression. Trends in Pharmacological Science 15, 220-226.

Cidis Meltzer C, Drevets WC, Price JC, Mathis CA, Lopresti B, Greer PJ, Villemagne VL, Holt D, Mason NS, Houck PR, Reynolds 3rd CF, DeKosky ST (2001). Genderspecific aging effects on the serotonin 1A receptor. Brain Research 895, 9-17.

Cohen J (1988). Statistical Power Analysis for the Behavioral Sciences. Hillsdale, New Jersey: Lawrence Erlbaum Associates.

Cusin C, Serretti A, Zanardi R, Lattuada E, Rossini D, Lilli R, Lorenzi C, Smeraldi E (2002). Influence of monoamine oxydase $\mathrm{A}$ and serotonin receptor $2 \mathrm{~A}$ polymorphisms in SSRIs antidepressant activity. International Journal of Neuropsychopharmacology 5, 27-35.

Dubovsky SL, Thomas M (1995). Serotonergic mechanisms and current and future psychiatric practice. Journal of Clinical Psychiatry 56 (Suppl. 2), 38-48.

Endicott J, Spitzer R (1978). A diagnostic interview : the schedule for affective disorders and schizophrenia. Archives of General Psychiatry 35, 837-844.

First MB, Spitzer RL, Gibbon M, Williams JB (1995). Structured Clinical Interview for DSM-IV Axis I Disorders - Patient Edition (SCID-I/P, Version 2.0). New York: Biometrics Research Department, New York State Psychiatric Institute.

Hamilton M (1967). Development of a rating scale for primary depressive illness. British Journal of Social $\&$ Clinical Psychology 6, 278-296.

Kapur S, Remington G (1996). Serotonin-dopamine interaction and its relevance to schizophrenia. American Journal of Psychiatry 153, 466-476.

Kim DK, Lim SW, Lee S, Sohn SE, Kim S, Hahn CG, Carroll BJ (2000). Serotonin transporter gene polymorphism and antidepressant response. Neuroreport 11, 215-219.

Kobilka BK, Frielle T, Collins S, Yang-Feng T, Kobilka TS, Francke U, Lefkowitz RJ, Caron MG (1987). An intronless gene encoding a potential member of the family of receptors coupled to guanine nucleotide regulatory proteins. Nature 329, 75-79.

Lahiri DK, Nurnberger JIJ (1991). A rapid non-enzymatic method for the preparation of HMW DNA from blood for RFLP studies. Nucleic Acid Research 19, 5444.

Leckman JF, Sholomskas D, Thompson WD, Belanger A, Weissman MM (1982). Best estimate of lifetime psychiatric diagnosis: a methodological study. Archives of General Psychiatry 39, 879-883.

Lemonde S, Turecki G, Bakish D, Du L, Hrdina P, Bown C, Sequeira A, Kushwaha N, Morris S, Basak A, Ou X, Albert P (2003). Impaired trans-repression at a 5-HT1A receptor gene polymorphism associated with major depression and suicide. Journal of Neuroscience 23, 8788-8799. 
Lucca A, Lucini V, Catalano M, Alfano M, Smeraldi E (1994). Plasma tryptophan to large neutral amino acids ratio and therapeutic response to a selective serotonin uptake inhibitor. Neuropsychobiology 29, 108-111.

Minov C, Baghai TC, Schule C, Zwanzger P, Schwarz MJ, Zill P, Rupprecht R, Bondy B (2001). Serotonin-2Areceptor and -transporter polymorphisms : lack of association in patients with major depression. Neuroscience Letters 303, 119-122.

Mongeau R, Blier P, de Montigny C (1997). The serotonergic and noradrenergic systems of the hippocampus: their interactions and the effects of antidepressant treatments. Brain Research. Brain Research Reviews 23, 145-195.

Parsey RV, Oquendo MA, Simpson NR, Ogden RT, Van Heertum R, Arango V, Mann JJ (2002). Effects of sex, age, and aggressive traits in man on brain serotonin 5-HT1A receptor binding potential measured by PET using [C- $\left.{ }^{11}\right]$ WAY-100635. Brain Research 954, 173-182.

Perez V, Gilaberte I, Faries D, Alvarez E, Artigas F (1997). Randomised, double-blind, placebo-controlled trial of pindolol in combination with fluoxetine antidepressant treatment. Lancet 349, 1594-1597.

Peters EJ, Slager SL, McGrath PJ, Knowles JA, Hamilton SP (2003). Pharmacogenomic analysis of five serotonergic pathway genes in antidepressant response. II Annual Pharmacogenetics in Psychiatry Meeting, New York.

Pollock BG, Ferrell RE, Mulsant BH, Mazumdar S, Miller M, Sweet RA, Davis S, Kirshner MA, Houck PR, Stack JA, Reynolds CF, Kupfer DJ (2000). Allelic variation in the serotonin transporter promoter affects onset of paroxetine treatment response in late-life depression. Neuropsychopharmacology 23, 587-590.

Pritchard JK, Rosenberg NA (1999). Use of unlinked genetic markers to detect population stratification in association studies. American Journal of Human Genetics 65, 220-228.

Quitkin FM, Rabkin JD, Markowitz JM, Stewart JW, McGrath PJ, Harrison W (1987). Use of pattern analysis to identify true drug response. A replication. Archives of General Psychiatry 44, 259-264.

Quitkin FM, Rabkin JG, Ross D, Stewart JW (1984). Identification of true drug response to antidepressants. Use of pattern analysis. Archives of General Psychiatry 41, 782-786.

Rausch JL, Johnson ME, Fei Y-J, Li JQ, Shendarkar N, MacHobby H, Ganapathy V, Leibach FH (2002). Initial conditions of serotonin transporter kinetics and genotype: influence on SSRI treatment trial outcome. Biological Psychiatry 51, 723-732.

Rothe C, Gutknecht L, Freitag C, Tauber R, Mossner R, Franke P, Fritze J, Wagner G, Peikert G, Wenda B, Sand P, Jacob C, Rietschel M, Nothen MM, Garritsen H, Fimmers R, Deckert J, Lesch KP (2004). Association of a functional 1019CG 5-HT1A receptor gene polymorphism with panic disorder with agoraphobia. International Journal of Neuropsychopharmacology 7, 189-192.

Serretti A, Lilli R, Lorenzi C, Lattuada E, Cusin C, Smeraldi E (2002). Serotonin transporter gene (5-HTTLPR) and major psychoses. Molecular Psychiatry 7, 95-99.
Serretti A, Lorenzi C, Cusin C, Zanardi R, Lattuada E, Rossini D, Lilli R, Pirovano A, Catalano M, Smeraldi E (2003). SSRIs antidepressant activity is influenced by Gbeta3 variants. European Neuropsychopharmacology 13, 117-122.

Serretti A, Zanardi R, Cusin C, Rossini D, Lorenzi C, Smeraldi E (2001a). Tryptophan hydroxylase gene associated with paroxetine antidepressant activity. European Neuropsychopharmacology 11, 375-380.

Serretti A, Zanardi R, Rossini D, Cusin C, Lilli R, Smeraldi E (2001b). Influence of tryptophan hydroxylase and serotonin transporter genes on fluvoxamine antidepressant activity. Molecular Psychiatry 6, 586-592.

Smeraldi E, Zanardi R, Benedetti F, Dibella D, Perez J, Catalano M (1998). Polymorphism within the promoter of the serotonin transporter gene and antidepressant efficacy of fluvoxamine. Molecular Psychiatry 3, 508-511.

Smits KM, Smits LJ, Schouten JS, Stelma FF, Nelemans P, Prins MH (2004). Influence of SERTPR and STin2 in the serotonin transporter gene on the effect of selective serotonin reuptake inhibitors in depression: a systematic review. Molecular Psychiatry 9, 433-441.

Sobin CA, Sackeim H (1997). Psychomotor symptoms of depression. American Journal of Psychiatry 154, 4-17.

Sprouse J, Braselton J, Reynolds L, Clarke T, Rollema H (2001). Activation of postsynaptic 5-HT(1A) receptors by fluoxetine despite the loss of firing-dependent serotonergic input: electrophysiological and neurochemical studies. Synapse 41, 49-57.

Stahl S (1994). 5HT1A receptors and pharmacotherapy. Is serotonin receptor down-regulation linked to the mechanism of action of antidepressant drugs? Psychopharmacology Bulletin 30, 39-43.

StatSoft (2004). statistica. StatSoft Inc. (http:// www.statsoftinc.com).

Strobel A, Gutknecht L, Rothe C, Reif A, Mossner R, Zeng Y, Brocke B, Lesch KP (2003). Allelic variation in 5-HT1A receptor expression is associated with anxiety- and depression-related personality traits. Journal of Neural Transmission 110, 1445-1453.

Tsuang M, Faraone S (1990). The Genetics of Mood Disorders. Baltimore: The Johns Hopkins University Press.

Walsh BT, Seidman SN, Sysko R, Gould M (2002). Placebo response in studies of major depression: variable, substantial, and growing. Journal of the American Medical. Association 287, 1840-1847.

Wu S, Comings DE (1999). A common C-1018G polymorphism in the human 5-HT1A receptor gene. Psychiatric Genetics 9, 105-106.

Yoshida K, Naito S, Takahashi H, Sato K, Ito K, Kamata M, Higuchi H, Shimizu T, Itoh K, Inoue K, Tezuka T, Suzuki T, Ohkubo T, Sugawara K, Otani K (2002). Monoamine oxidase: a gene polymorphism, tryptophan hydroxylase gene polymorphism and antidepressant response to fluvoxamine in Japanese patients with major depressive disorder. Progress in Neuropsychopharmacology and Biological Psychiatry 26, 1279-1283. 
Yu YW, Tsai SJ, Chen TJ, Lin CH, Hong CJ (2002).

Association study of the serotonin transporter promoter polymorphism and symptomatology and antidepressant response in major depressive disorders. Molecular Psychiatry 7, 1115-1119.

Zanardi R, Artigas F, Franchini L, Sforzini L, Gasperini M, Smeraldi E, Perez J (1997). How long should Pindolol be associated with Paroxetine to improve the antidepressant response? Journal of Clinical Psychopharmacology 17, 446-450.

Zanardi R, Benedetti F, DiBella D, Catalano M, Smeraldi E (2000). Efficacy of paroxetine in depression is influenced by a functional polymorphism within the promoter of serotonin transporter gene. Journal of Clinical Psychopharmacology 20, 105-107.

Zanardi R, Franchini L, Gasperini M, Lucca L, Smeraldi E, Perez J (1998). Faster onset of action of fluvoxamine in combination with pindolol in the treatment of delusional depression: a controlled study. Journal of Clinical Psychopharmacology 18, 441-446.

Zanardi R, Rossini D, Serretti A (2001a). Problems with ensuring double blind - replay. Journal of Clinical Psychiatry 62, 296.

Zanardi R, Serretti A, Rossini D, Franchini L, Cusin C, Lattuada E, Dotoli D, Smeraldi E (2001b). Factors affecting fluvoxamine antidepressant activity: influence of pindolol and 5-HTTLPR in delusional and nondelusional depression. Biological Psychiatry 50, 323-330.

Zill P, Baghai TC, Zwanzger P, Schule C, Minov C, Riedel M, Neumeier K, Rupprecht R, Bondy B (2000). Evidence for an association between a G-protein beta3-gene variant with depression and response to antidepressant treatment. Neuroreport 11, 1893-1897. 
Chapter 5: Neural network analysis in pharmacogenetics of mood disorders 


\title{
Neural network analysis in pharmacogenetics of mood disorders Alessandro Serretti*1,2 and Enrico Smeraldi ${ }^{1,2}$
}

\author{
Address: ${ }^{1}$ Istituto Scientifico Universitario Ospedale San Raffaele, Department of Neuropsychiatric Sciences, Milano, Italy and ${ }^{2}$ Università Vita- \\ Salute San Raffaele, School of Medicine, Milano, Italy \\ Email: Alessandro Serretti* - serretti.alessandro@hsr.it; Enrico Smeraldi - serretti.alessandro@hsr.it \\ * Corresponding author
}

Published: 09 December 2004

BMC Medical Genetics 2004, 5:27 doi:10.1 |86/147|-2350-5-27

This article is available from: http://www.biomedcentral.com/I47/-2350/5/27

(C) 2004 Serretti and Smeraldi; licensee BioMed Central Ltd.

This is an Open Access article distributed under the terms of the Creative Commons Attribution License (http://creativecommons.org/licenses/by/2.0), which permits unrestricted use, distribution, and reproduction in any medium, provided the original work is properly cited.
Received: 23 July 2004

Accepted: 09 December 2004

\begin{abstract}
Background: The increasing number of available genotypes for genetic studies in humans requires more advanced techniques of analysis. We previously reported significant univariate associations between gene polymorphisms and antidepressant response in mood disorders. However the combined analysis of multiple gene polymorphisms and clinical variables requires the use of non linear methods.
\end{abstract}

Methods: In the present study we tested a neural network strategy for a combined analysis of two gene polymorphisms. A Multi Layer Perceptron model showed the best performance and was therefore selected over the other networks. One hundred and twenty one depressed inpatients treated with fluvoxamine in the context of previously reported pharmacogenetic studies were included. The polymorphism in the transcriptional control region upstream of the 5HTT coding sequence (SERTPR) and in the Tryptophan Hydroxylase (TPH) gene were analysed simultaneously.

Results: A multi layer perceptron network composed by I hidden layer with 7 nodes was chosen. $77.5 \%$ of responders and $51.2 \%$ of non responders were correctly classified (ROC area $=0.73 \mathrm{I}-$ empirical $p$ value $=0.0082$ ). Finally, we performed a comparison with traditional techniques. A discriminant function analysis correctly classified $34.1 \%$ of responders and $68.1 \%$ of non responders $(F=8.16 p=0.0005)$.

Conclusions: Overall, our findings suggest that neural networks may be a valid technique for the analysis of gene polymorphisms in pharmacogenetic studies. The complex interactions modelled through NN may be eventually applied at the clinical level for the individualized therapy.

\section{Background}

The increasing number of available genotypes for genetic studies in humans requires more advanced techniques of analysis [1]. Moreover, genes interact in a complex way, with some gene variants acting additively with others, in a multiplicative way or with a compensatory effect $[2,3]$. Traditional statistical techniques are not appropriate for detecting such effects [4], because they rely on the basic assumption of linear combinations only [5]. Investigation in multifactorial disorders in fact evidenced that non linear interactions are not detected by traditional regression analyses [6].

In particular, psychiatric disorders are characterized by a non mendelian, multifactorial genetic contribution with a number of susceptibility genes interacting with each other $[7,8]$. In the process of disentangling the contribution of environment versus genes, it has been recently suggested 
to focus on endophenotypes instead of psychiatric syndromes as a whole $[9,10]$. One interesting endophenotype is drug response, a field that gained much attention due to the possible clinical applications, ranging from individualized therapy to new drug development [11-14]. However, notwithstanding the promising results observed in the pharmacogenetic field, no single major effect gene was identified, but a variable number of polymorphisms in various genes are supposedly involved in modulating the response and/or side effects to drugs [15-20].

Since our initial study [21] we investigated the short term response to Selective Serotonin Reuptake Inhibitors (SSRIs) and a number of candidate genes, observing both positive and negative associations [22].

However, both the increasing number of genes associated with response and the limitations of traditional methods of analysis are factors requiring the use of new techniques of analysis that more closely resemble to the underlying biological process, i.e. that allows for non-linear interactions.

Neural networks (NN) have been proposed for such studies $[1,23,24]$. The main advantage of neural networks is that complex non-linear relationships can be modelled, potentially incorporating high-order interactions between predictive variables. This is of particular importance in a complex phenotype such as antidepressant response $[22,25]$.

NN have been used in other fields of medicine, for example to predict cyclosporine dosage in patients after kidney transplantation [26], perspective outcome in AIDS research [27] but also in a genetic analysis in heart disease analysing 10 candidate genes simultaneously [28]. More complex models including gene-environment interactions have been developed [29].

In fact, neural networks proved to outperform single marker association tests, particularly in the case of a complex mode of inheritance or where multiple mutations result in more than one haplotype associated with the disease $[25,30,31]$.

In the present paper we have re-analysed our sample where polymorphism in the transcriptional control region upstream of the 5HTT coding sequence (SERTPR) and in the Tryptophan Hydroxylase (TPH) gene were analized [32], in that paper we observed an association of both polymorphisms with drug response but we could not evaluate their possible non linear interactions. In the present paper we had the aim of evaluating the validity of $\mathrm{NN}$ models and of comparing them with traditional statistical techniques (multiple regression and discriminant function analysis).

\section{Methods \\ Sample}

The sample was already described in the original paper [32]. Briefly, two hundred and seventeen depressed inpatients were included in this study (age $=52.11 \pm 12.04$; onset $=37.97 \pm 12.16$; female/male: $144 / 73$; bipolars: delusional $/$ non delusional $=40 / 33$, major depressives: delusional/non delusional $=71 / 73$ ). All patients were evaluated at baseline and weekly thereafter until the sixth week using the 21-item Hamilton Rating Scale for Depression (HAM-D-21) [33] administered by trained senior psychiatrists blind to genetic data and to treatment (fluvoxamine $300 \mathrm{mg}$ daily from day 8 plus pindolol $7.5 \mathrm{mg}$ to one third of the sample). A decrease in HAM-D scores to 8 or less was considered the response criterion. After the procedure had been fully explained to all subjects, informed consent was obtained.

Plasma fluvoxamine levels were determined by high-performance liquid chromatography after 2 weeks of stable $300 \mathrm{mg}$ daily dose [34]. Nine patients with extreme plasma levels (more than 2 standard deviations) were removed from the study in order to avoid biases due to side effects that are present at high doses, also subjects with plasma levels below $20 \mathrm{ng} / \mathrm{ml}$ were excluded as this may indicate non compliance, but no cases with such low doses were observed. The influence of both SERTPR and TPH polymorphisms was limited to subjects not taking pindolol [32] therefore we included in the present study the 121 subjects including fluvoxamine alone (81 responders/40 non responders). DNA analysis was performed as described in the original paper [32].

\section{Review of the models used Multilayer Perceptrons}

This is one of the most popular network architecture in use today, though relatively recent [35]. In MLP the units each perform a biased weighted sum of their inputs and pass this activation level through a transfer function to produce their output, and the units are arranged in a layered feedforward topology. The first step of the analysis is the choice of the number of layers and nodes. This is performed searching for a minimum in the error/performance hyperplane. Once the number of layers, and number of units in each layer, have been selected, the weight and threshold of the network must be set so as to minimize the prediction error made by the network. This is the role of the training algorithms. The best-known example of a neural network training algorithm is back propagation. In back propagation, the gradient vector of the error surface is calculated and used to decrease the error. A sequence of such moves (slowing as we near the bottom - epochs) will 
eventually find a minimum. A large number of epochs with no further improvement in the performance suggests that the optimum set of weights has been reached.

\section{Linear Networks}

Originally developed about 60 years ago by Fisher [36], in classification, the hyperplane is positioned to divide the two classes (a linear discriminant function) while in regression, it is positioned to pass through the data. A linear model is typically represented using an $\mathrm{NxN}$ matrix and an Nx1 bias vector. The linear network provides a good benchmark against which to compare the performance of your neural networks.

\section{Radial Basis Function Networks}

In a radial basis function network the response surface of a single radial unit is a Gaussian (bell-shaped) function, peaked at the center, and descending outwards. RBF networks have advantages and disadvantages over MLPs. First, they can model any non-linear function using a single hidden layer, which removes some design-decisions about numbers of layers. Second, the simple linear transformation in the output layer can be optimized fully using traditional linear modelling techniques, which are fast and do not suffer from problems such as local minima which plague MLP training techniques. However the clumpy approach also implies that RBFs are not inclined to extrapolate beyond known data: the response drops off rapidly towards zero if data points far from the training data are used, therefore they are less reliable for clinical samples such our one. Detailed review of the models are reported elsewhere $[24,37]$.

\section{Model development and selection}

An "intent-to-treat" analysis was carried out for all patients who had a baseline assessment and at least 1 assessment after randomization, with the last observation carried forward on the HAM-D. For the current application the inputs to the first layer of the neural network consist of SERTPR and TPH genotypes while the target outputs consist of response status. The network is then trained to attempt to predict response from genotypes. Each node of the input layer of the network is set to a value representing the genotype of each polymorphism. For each polymorphism and for each subject this value is set to genotypes aa, ab or bb. If a marker genotype is missing then the input is assigned a value equal to the average of the values for all subjects in the dataset, however no missing data were present in our sample. The target output for the network is set to 1 or 2 depending on whether the subject is responding or not.

The best network was selected on the basis of its discriminating error and performance, positive and negative predictive values were also reported for each model. This last was expressed as area under the Receiving Operator Characteristic (ROC) Curve. The area under a ROC curve ranges from zero to one, with values close to unity indicating better predictive power; an area of 0.5 indicates that the model is not predicting better than a random choice.

However, one major problem of NN analyses is to establish if the prediction from genotypes is greater than would be expected by chance. If the whole sample is used for training, the network will to some extent "learn to recognise" particular features of each member of the dataset and can use these to predict response in a way which may not reflect any general association between marker genotypes and disease. Generally, this problem is faced by a set of strategies: dividing the dataset (50:50, 80:20...), Jackknife, bootstrapping, cross-validation and so on. However those methods present some disadvantages, in particular if only a part of the data is used to train the network this leads to a loss of power given that subjects in the validating part have different patterns of association between genotypes and drug response.

In order to remedy these problems, in the case of MLP, it has been suggested to perform both training and testing on the entire dataset. The statistical significance of any observed association between outputs and affection status can be estimated using a permutation test [25].

Once the network was defined, a statistic, denoted T, is calculated to compare the outputs for responders and non responders in the same way as an unpaired t statistic, although the statistic is not expected to follow a t distribution under the null hypothesis. Instead, in order to estimate statistical significance a permutation procedure is performed. A large number of replicate data sets are generated from the original data and the obtained network model by randomly permuting genotypes with respect to affection status. For each of these replicate data sets we can then train and test the data set as before, each time calculating $\mathrm{T}$. Since each permuted data set will have only random association between genotype and affection status we obtain $\mathrm{N}$ values of $\mathrm{T}$ which provide a distribution of $\mathrm{T}$ under the null hypothesis. We count the number of times any of these values exceeds the value of $\mathrm{T}$ we obtained for the real dataset and denote this number $R$. Then $(R+1) /$ $(\mathrm{N}+1)$ provides an unbiased estimate of the statistical significance of the association between genotype and affection status in the real dataset.

In order to estimate a p-value of alpha, one should carry out approximately 10/alpha replicates. Typically, in order to detect association at a significance of 0.01 one would 
perform 1000 replicates (including the real dataset and

Table I: Comparison of NN models. PPV = Predictive Positive Value, NPV $=$ Predictive Negative Value, $R O C=$ area under the ROC curve.

\begin{tabular}{lllllllll}
\hline Network type & Error & Performance & sensitivity & specificity & PPV & NPV & ROC & Youden's J \\
\hline Linear & 0.447 & 0.636 & 67.12 & 56.34 & 75.97 & 45.46 & 0.687 & 0.23 \\
RBF & 0.449 & 0.691 & 85.61 & 35.21 & 73.10 & 54.35 & 0.664 & 0.21 \\
MLP (I-7) & 0.439 & 0.682 & 77.50 & 51.20 & 76.35 & 52.17 & 0.731 & 0.28 \\
\hline
\end{tabular}

999 permuted datasets). In the case of the present paper we performed 10000 replicates.

Multiple regression and discriminant function analyses were performed to compare the results obtained with the NN strategy with traditional techniques. Responder status was the dependent variable with SERTPR and TPH as independent variables. Genotypes were scored in the following way according to the hypothesis of codominance $\left(\right.$ SERPR $^{*} \mathrm{l} / \mathrm{l}=1, \mathrm{SERPR}^{*} \mathrm{l} / \mathrm{s}=2, \mathrm{SERPR}^{*} \mathrm{~s} / \mathrm{s}=2, \mathrm{TPH}^{*} \mathrm{C} / \mathrm{C}$ $=1, \mathrm{TPH}^{*} \mathrm{C} / \mathrm{A}=2, \mathrm{TPH}^{*} \mathrm{~A} / \mathrm{A}=2$ ).

Calculations for the NN selection were performed using STATSOFT (Kernel release $5.5 \mathrm{~A}$ ). Evaluation was performed using the NNPERM package [31].

\section{Results}

MLP showed the best performance and was therefore selected over the other networks (see table 1). The MLP selected over the other models on the basis of error and performance was composed by 1 hidden layer with 7 nodes (Figure 1) after testing about 150 different MLP models. The network showed a very good basic performance (Error 0.430, Performance 0.685).

After, we trained the network with the back propagation algorithm. Initially we used a learning rate of 0.1 (momentum 0.3, noise set to 0), after 5000 epochs we reduced it to 0.01 but after 5000 further epochs we observed no improvement and therefore we finished the selection process and retained the network. Both polymorphisms contributed substantially to the model $($ SERTPR error $=0.532$, ratio $=1.21$; TPH error $=0.450$, ratio $=1.02)$. This was expected since both markers were individually associated with response. In detail single marker significance, calculated as simple allelic chisquare, was $\mathrm{p}=0.00058$ for SERTPR and $\mathrm{p}=0.025$ for $\mathrm{TPH}$. The classification of subjects in responders and non responders was $77.5 \%$ for responders and $51.2 \%$ for non responders. Classification may vary depending from the selected threshold, therefore the area under the ROC curve is a better indicator of performance, in this case the area

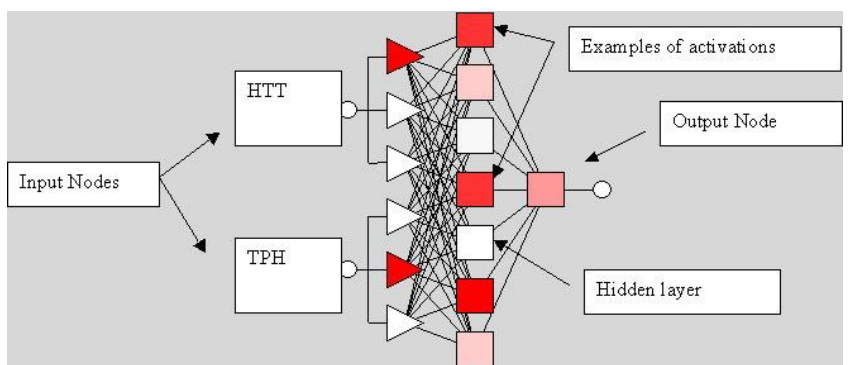

Figure I

MLP composed by I hidden layer with 7 nodes used for the analysis.

was 0.731 . We also evaluated the predictive power of the network with the SERTPR polymorphism only, in this case the area under the ROC curve was 0.698. We may therefore observe that the add of TPH polymorphism increases the predictive power of the system.

In order to evaluate the significance of the network we applied a permutation test with 10000 replicates. The $\mathrm{t}$ statistic for the network was 4.35 , it was achieved in 81 out of 10000 simulations yielding a network p-value $=$ $(81+1) /(10000+1)=0.0082$.

Finally, we performed a comparison with traditional techniques. A multiple regression analysis showed a significant correlation ( $\mathrm{p}=0.0004)$ with a variance explained of $12.5 \%$. The discriminant function analysis correctly classified $34.1 \%$ of responders and $68.1 \%$ of non responders $(\mathrm{F}=8.16 \mathrm{p}=0.0005)$.

Following, we tested the possible impact of clinical variables on response. We included in the model the following variables: Age, age at onset, sex, education, diagnosis, presence of delusional features, recurrence index (defined as number of episodes per year), pindolol augmentation and baseline HAM-D. With those variables no satisfactory network was identified. They were therefore not 
considered as possible confounding factors in the genetic analysis.

\section{Discussion}

This paper reports the first attempt to use NN in pharmacogenetic analyses. We applied this technique to short term antidepressant response in mood disorders. Our analyses suggest that MLP network is the most appropriate for this kind of data, in according with previous observations [25]. The growing number of polymorphisms (about 3.000.000) and the growth of simultaneous techniques such as gene arrays ask for appropriate techniques of analysis. Traditional ones have strong limitations not allowing for non linear interactions and the risk of overfitting in the case of multiple polymorphisms analysed in necessary limited sample sizes. We observed that a relatively simple MLP NN is able to predict response in a way comparable to traditional techniques. The lack of non linear interactions in the simple model we analysed [32] explains why did not observe a marked superiority of NN over traditional analyses. However the most promising result of the strategy we tested in the present paper is the possibility to add a large number of polymorphism to the network and to evaluate the improvement in the prediction, showed by the area under the ROC curve. Moreover the significance of the network can be evaluated with the permutation test [25,31]. Moreover the MLP model we used is quite parsimonious in terms of parameters used (2 input variables, 1 output variable and 1 hidden layer with 7 nodes).

Further developments of this strategy are the inclusion of more detailed information on the phenotypic side. The classification results we obtained are not sufficient in clinical terms were in particular much higher specificities are needed in order to recognize in advance non responders. To reach this target we should consider that we previously observed that some polymorphism influence only part of the whole depressive symptomatology [38]. Further clinical variables should also be considered as reported to influence the short term antidepressant outcome [39], even if previous NN studies failed to identify clinical predictors of antidepressant response [40]. Our analyses are in line with this view, in fact the clinical variables we analysed were not significantly associated with outcome.

The relatively small sample we used does not guarantee against a possible overfitting phenomenon, therefore enlargement of the sample is a priority. Moreover we used the same sample for testing and validating our result, this is not a standard technique [41], this problem is usually faced by a set of strategies such as dividing the dataset, Jackknife, bootstrapping, cross-validation and so on. However those methods present some disadvantages, in particular if only a part of the data is used to train the net- work this leads to a loss of power in the case that subjects in the validating part have different patterns of association between genotypes and drug response. Therefore in the present paper we performed both training and testing on the entire dataset with the use of a permutation test to validate the results [25]. Another limitation of the present paper is that we compared $\mathrm{NN}$ with multiple regression only, other techniques could be tested as well such as set association [30], multifactor dimensionality reduction [42], and logic regression [43].

Differences in allele frequency for different populations have been reported [44]. However our sample was composed of subjects mainly collected in the North of Italy with Italian antecedents for at least two generations, though genetic heterogeneity have been evidenced for some isolate populations (such as Sardinia, not included in our sample) Italy is characterized by a substantial genetic homogeneity [45]. Another caveat is linked to the characteristics of our sample. In fact the Center for Mood Disorders of San Raffaele Hospital is a tertiary structure, therefore we cannot exclude a potential selection bias associated with illness severity and possible extension to outpatients or drug abusers are not warranted [46].

\section{Conclusions}

Overall, our findings suggest that neural networks may be a valid technique for the analysis of gene polymorphisms in pharmacogenetic studies. The complex interactions modelled through NN may be eventually applied at the clinical level for the individualized therapy [47].

\section{Competing interests}

The author(s) declare that they have no competing interests.

\section{Authors' contributions}

AS conceived the study, drafted the manuscript and participated in the design of the study and performed the statistical analysis. ES participated in its design and coordination. All authors read and approved the final manuscript

\section{Acknowledgements}

The authors acknowledge Cristina Lorenzi for the genetic analyses.

\section{References}

I. Ott J: Neural networks and disease association studies. Am J Med Genet 200I, I 05:60-6I.

2. Moore $\mathrm{J}$ : The ubiquitous nature of epistasis in determining susceptibility to common human diseases. Hum Hered 2003, 56:73-82.

3. Frankel WN, Schork NJ: Who's afraid of epistasis? Nature genetics 1996, 14:37I-373.

4. Schaid DJ, Olson JM, Gauderman WJ, Elston RC: Regression models for linkage: issues of traits, covariates, heterogeneity, and interaction. Hum Hered 2003, 55:86-96.

5. Ritchie MD, White BC, Parker JS, Hahn LW, Moore JH: Optimization of neural network architecture using genetic program- 
ming improves detection and modeling of gene-gene interactions in studies of human diseases. BMC Bioinformatics 2003, 4:28.

6. Moore JH, Lamb JM, Brown NJ, Vaughan DE: A comparison of combinatorial partitioning and linear regression for the detection of epistatic effects of the ACE I/D and PAI-I 4G/5G polymorphisms on plasma PAI-I levels. Clin Genet 2002, 62:74-79.

7. Merikangas KR, Risch N: Will the Genomics Revolution Revolutionize Psychiatry? Am J Psychiatry 2003, 160:625-635.

8. Botstein $D$, Risch $N$ : Discovering genotypes underlying human phenotypes: past successes for mendelian disease, future approaches for complex disease. Nat Genet 2003, 33 Suppl:228-237.

9. Lenox RH, Gould TD, Manji HK: Endophenotypes in bipolar disorder. Am J Med Genet 2002, I I 4:391-406.

10. Waterwort DM, Bassett AS, Brzustowicz LM: Recent advances in the genetics of schizophrenia. Cell Mol Life Sci 2002, 59:33I-348.

II. Weber WW: Pharmacogenetics. New York, Oxford University Press; 1997.

12. Lerer B, Macciardi F: Pharmacogenetics of antidepressant and mood-stabilizing drugs: a review of candidate-gene studies and future research directions. Int J Neuropsychopharmacol 2002 , 5:255-275

13. Arranz MJ, Munro J, Birkett J, Bolonna A, Mancama D, Sodhi M, Lesch KP, Meyer JF, Sham P, Collier DA, Murray RM, Kerwin RW: Pharmacogenetic prediction of clozapine response. Lancet 2000, 355:1615-1616.

14. Veenstra-VanderWeele J, Anderson GM, Cook EH: Pharmacogenetics and the serotonin system: initial studies and future directions. Eur J Pharmacol 2000, 41 0:|65-18I.

15. Alda M: Pharmacogenetics of lithium response in bipolar disorder. J Psychiatry Neurosci 1999, 24:154-158.

16. Arranz MJ, Munro J, Osborne S, Collier D, Kerwin RW: Applications of pharmacogenetics in psychiatry: personalisation of treatment. Expert Opin Pharmacother 200I, 2:537-542.

17. Basile VS, Masellis M, McIntyre RS, Meltzer HY, Lieberman JA, Kennedy JL: Genetic dissection of atypical antipsychoticinduced weight gain: novel preliminary data on the pharmacogenetic puzzle. J Clin Psychiatry 200I, 62 Suppl 23:45-66.

18. Segman R, Neeman T, Heresco-Levy U, Finkel B, Karagichev L, Schlafman M, Dorevitch A, Yakir A, Lerner A, Shelevoy A, Lerer B: Genotypic association between the dopamine $D 3$ receptor and tardive dyskinesia in chronic schizophrenia. Mol Psychiatry 1999, 4:247-253.

19. Segman RH, Heresco-Levy U, Finkel B, Goltser T, Shalem R, Schlafman M, Dorevitch A, Yakir A, Greenberg D, Lerner A, Lerer B: Association between the serotonin $2 A$ receptor gene and tardive dyskinesia in chronic schizophrenia. Mol Psychiatry 200I, 6:225-229.

20. Serretti A, Artioli P: Predicting response to lithium in mood disorders: role of genetic polymorphisms. $\mathrm{Am} J$ Pharmacogenomics 2003, 3: 17-30.

21. Smeraldi E, Zanardi R, Benedetti F, Dibella D, Perez J, Catalano M: Polymorphism Within the Promoter of the Serotonin Transporter Gene and Antidepressant Efficacy of Fluvoxamine. Molecular Psychiatry 1998, 3:508-5II.

22. Serretti A, Lilli R, Smeraldi E: Pharmacogenetics in affective disorders. European Journal of Pharmacology 2002, 438: II 17-128.

23. Lucek P, Hanke J, Reich J, Solla SA, Ott J: Multi-locus nonparametric linkage analysis of complex trait loci with neural networks. Human Heredity 1998, 48:275-284.

24. Haykin S: Neural Networks: A Comprehensive Foundation. , Prentice Hall; 1998.

25. Curtis D, North BV, Sham PC: Use of an artificial neural network to detect association between a disease and multiple marker genotypes. Ann Hum Genet 200I, 65:95-107.

26. Camps-Valls G, Porta-Oltra B, Soria-Olivas E, Martin-Guerrero JD, Serrano-Lopez AJ, Perez-Ruixo J], Jimenez-Torres NV: Prediction of cyclosporine dosage in patients after kidney transplantation using neural networks. IEEE Trans Biomed Eng 2003, 50:442-448.

27. Sardari S, Sardari D: Applications of artificial neural network in AIDS research and therapy. Curr Pharm Des 2002, 8:659-670.

28. Yoon Y, Song J, Hong SH, Kim JQ: Analysis of multiple single nucleotide polymorphisms of candidate genes related to cor- onary heart disease susceptibility by using support vector machines. Clin Chem Lab Med 2003, $41: 529-534$.

29. Sing CF, Stengard JH, Kardia SL: Genes, environment, and cardiovascular disease. Arterioscler Thromb Vasc Biol 2003, 23: I I90-I I 96.

30. Hoh J, Ott J: Mathematical multi-locus approaches to localizing complex human trait genes. Nat Rev Genet 2003, 4:70I-709.

31. North BV, Curtis D, Cassell PG, Hitman GA, Sham PC: Assessing Optimal Neural Network Architecture for Identifying Disease-associated Multi-marker Genotypes using a Permutation Test, and Application to Calpain 10 Polymorphisms Associated with Diabetes. Ann Human Genet 2003, 67:348-356.

32. Serretti A, Zanardi R, Rossini D, Cusin C, Lilli R, Smeraldi E: Influence of tryptophan hydroxylase and serotonin transporter genes on fluvoxamine antidepressant activity. Molecular Psychiatry 2001, 6:586-592.

33. Hamilton M: Development of a rating scale for primary depressive illness. British Journal of Social \& Clinical Psychology 1967, 6:278-296.

34. Lucca A, Lucini V, Catalano M, Alfano M, Smeraldi E: Plasma tryptophan to large neutral amino acids ratio and therapeutic response to a selective serotonin uptake inhibitor. Neuropsychobiology 1994, 29: 108-III.

35. Rumelhart DE, McClelland J: Parallel Distributed Processing. Volume I. Cambridge, MA, MIT Press; 1986.

36. Fisher RA: The use of multiple measurements in taxonomic problems. Annals of Eugenics 1936, 7:179-188.

37. Fausett LV: Fundamentals of Neural Networks: Architectures, Algorithms and Applications. , Pearson Higher Education; 1993.

38. Serretti A, Benedetti F, Mandelli L, Lorenzi C, Pirovano A, Colombo C, Smeraldi E: Genetic dissection of psychopathological symptoms: Insomnia in mood disorders and CLOCK gene polymorphism. Am J Med Genet 2003, I 2 I B:39-43.

39. Goodwin FK, Jamison KR: Manic-depressive illness. New York, Oxford University Press; 1990.

40. Winterer G, Ziller M, Linden M: Classification of observational data with artificial neural networks versus discriminant analysis in pharmacoepidemiological studies--can outcome of fluoxetine treatment be predicted? Pharmacopsychiatry 1998, 31:225-231.

4I. Hastie T, Tibshirani R, Friedman J: The Elements of Statistical Learning. Data Mining, Inference, and Prediction. In Springer Series in Statistics New York, Springer-Verlag; 200I.

42. Hahn LW, Ritchie MD, Moore JH: Multifactor dimensionality reduction software for detecting gene-gene and gene-environment interactions. Bioinformatics 2003, 19:376-382.

43. Kooperberg C, Ruczinski I, LeBlanc ML, Hsu L: Sequence analysis using logic regression. Genet Epidemiol 200 I, 2I Suppl I:S626-31.

44. Kunugi H, Hattori M, Kato T, Tatsumi M, Sakai T, Sasaki T, Hirose T, Nanko S: Serotonin transporter gene polymorphisms: ethnic difference and possible association with bipolar affective disorder. Molecular Psychiatry 1997, 2:457-462.

45. Gasparini P, Estivill X, Volpini V, Totaro A, Castellvi-Bel S, Govea N, Mila M, Della Monica M, Ventruto V, De Benedetto M, Stanziale P, Zelante L, Mansfield ES, Sandkuijl L, Surrey S, Fortina P: Linkage of DFNBI to non-syndromic neurosensory autosomal-recessive deafness in Mediterranean families. European Journal of Human Genetics 1997, 5:83-88.

46. Solomon DA, Keller MB, Leon AC, Mueller TI, Lavori PW, Shea T, Coryell W, Warshaw M, Turvey C, Maser JD, Endicott J: Multiple recurrences of major depressive disorder. American Journal of Psychiatry 2000, 157:229-233.

47. Pickar D, Rubinow K: Pharmacogenomics of psychiatric disorders. Trends Pharmacol Sci 200I, 22:75-83.

\section{Pre-publication history}

The pre-publication history for this paper can be accessed here:

http://www.biomedcentral.com/1471-2350/5/27/prepub 
Chapter 6: Genetic dissection of psychopathological symptoms:

Insomnia in mood disorders and CLOCK gene polymorphism 


\title{
Genetic Dissection of Psychopathological Symptoms: Insomnia in Mood Disorders and CLOCK Gene Polymorphism
}

\author{
Alessandro Serretti,* Francesco Benedetti, Laura Mandelli, Cristina Lorenzi, Adele Pirovano, \\ Cristina Colombo, and Enrico Smeraldi \\ Department of Psychiatry, Vita-Salute University, Fondazione Centro San Raffaele del Monte Tabor, Milan, Italy
}

\begin{abstract}
We investigated the possible effect of the 3111 T/C CLOCK gene polymorphism on sleep disorders in a sample of 620 patients affected by major depressive disorder (MDD) and bipolar disorder (BP). We detected a significantly higher recurrence of initial $(P=0.0001)$, middle $(P=0.0009)$, and early $(P=0.0008)$ insomnia in homozygotes for the $C$ variant and a similar trend concerning decreased need of sleep in BP $(P=0.0074)$. Other demographic and clinical features were found not related with CLOCK polymorphisms. This preliminary observation leads to hypothesize a possible involvement of the CLOCK gene polymorphism in the sleep disregulations in MDD and BP. Copyright $\odot 2003$ Wiley-Liss, Inc.
\end{abstract}

KEY WORDS: CLOCK gene; bipolar disorder; major depressive disorder; insomnia; circadian rhythm

\section{INTRODUCTION}

There is substantial evidence that the suprachiasmatic nuclei (SCN) of the anterior hypothalamus contain a central circadian pacemaker that regulates most, if not all, circadian rhythms in mammals [Meijer and Rietveld, 1989; Klein et al., 1991; Moore, 1995]. At a molecular level, several genes interact in intracellular autoregulatory transcriptional-translational feedback loops, with positive and negative components acting to regulate transcriptional events in order to produce

*Correspondence to: Dr. Alessandro Serretti, M.D., Department of Neurosciences, Istituto Scientifico H. San Raffaele, University of Milano, School of Medicine, via Luigi Prinetti 29, 20127 Milano, Italy. E-mail: serretti.alessandro@hsr.it

Received 6 November 2002; Accepted 12 March 2003

DOI 10.1002/ajmg.b.20053 a circadian rhythm (see reviews in [Lowrey and Takahashi, 2000; Reppert and Weaver, 2001]). The genes $C L O C K$ and $B M A L 1$ form the positive regulator of the system, with their protein products driving transcription of other genetic components of the molecular oscillator.

In mice, a mutation of CLOCK has been shown to lead to a lengthened circadian period [Viterna et al., 1994]. In healthy humans, a single nucleotide polymorphism located in the $3^{\prime}$ flanking region of the human CLOCK gene has been investigated as a predictor of diurnal preference. Subjects carrying one of the two CLOCK alleles, 3111C, showed a significantly higher "eveningness" and showed a substantial 10- to 44-min delay in preferred timing for activity or sleep episodes [Katzenberg et al., 1998].

The possible role of $3111 \mathrm{~T} / \mathrm{C}$ CLOCK gene polymorphism in psychiatry is currently under investigation, given the high frequency of circadian rhythms disturbances in psychiatric illnesses, and the proposed role of chronobiological abnormalities in the pathogenesis of mood disorders [Wirz-Justice and Van den Hoofdakker, 1999]. Available data showed that CLOCK alleles were not associated with major depression [Desan et al., 2000]. In a previous study [Benedetti et al., in press] our group could not detect an association between CLOCK genotype and perceived diurnal mood fluctuations during a major depressive episode, but found a significantly higher recurrence rate of illness episodes in bipolar patients homozygotes for the $\mathrm{C}$ variant. To explain this finding, we hypothesized that the eveningness associated with $\mathrm{C}$ allele might result in a prolonged phase delay of sleep and other rhythms in $\mathrm{C} / \mathrm{C}$ patients, a known triggering factor for illness episodes in bipolar disorder (BP) [Wehr et al., 1998; Wirz-Justice and Van den Hoofdakker, 1999].

Following this hypothesis, 3111C CLOCK gene allelic variant should be associated with a delay in sleep onset and could influence the occurrence and the psychopathological features of sleep disturbances in affective illness. In the present study, we investigated the possible effect of CLOCK variants on sleep disturbances in a sample of 620 subjects affected by major depressive disorder (MDD) and BP. 


\section{MATERIALS AND METHODS}

\section{Sample}

Six hundreds and twenty subjects consecutively admitted to the Clinic for Mood Disorders of S. Raffaele Hospital in Milan were included in this study (age $=47.47 \pm 14.23$ years; onset $=32.97 \pm 12.80$ years; female $/$ male $=395 / 225$; bipolars $/$ major depressives $=$ $386 / 234)$. Subjects were mainly inpatients (91.42\%) and few outpatients $(8.58 \%)$ previously included in genetic studies [Serretti et al., 2001]. All patients were evaluated using the Operational Criteria for Psychotic Illness checklist (OPCRIT, [McGuffin et al., 1991]) with a lifetime perspective [Farmer et al., 1994]. Lifetime diagnoses were assigned by two independent psychiatrists on the basis of interviews and medical records, according to DSMIV criteria [American Psychiatric Association, 1994]. Information about the illness before contact with our center were collected following the best estimate procedure interviewing the subjects, family members, previous health professionals, and obtaining records when possible [Leckman et al., 1982]. Mental retardation, drug dependence, or other axis I disorders, together with somatic or neurological illnesses that impaired psychiatric evaluation represented exclusion criteria. OPCRIT comprises a 90 -item checklist of signs and symptoms that cover major psychoses symptomatology. Inter-rater reliability has been evaluated in research centers across Europe and the USA including ours. Each rating was then compared to a standard rating using a kappa statistic. Good levels of reliability were observed within all classifications (e.g., DSM-III-R, kappa $=0.73$ ) and a similar pattern of rating was found in both the European and USA samples [Craddock et al., 1996; Williams et al., 1996].

The OPCRIT items that were used for this study are: reduced need for sleep, initial insomnia, middle insomnia, early morning waking, excessive sleep.

Informed consent was obtained from all probands after the procedure had been fully explained; probands were unrelated and of Italian descent with antecedents from all parts of the country.

\section{DNA Analysis}

Genomic DNA was extracted from leukocytes by $\mathrm{NaCl}$ precipitation [Lahiri and Nurnberger, 1991]. PCR is performed with the following primers: 5 '-TCC AGC AGT TTC ATG AGA TGC-3' 5 '-GAG GTC ATT TCA TAG CTG AGC-3'. The PCR reaction was carried out in a $10 \mathrm{mcl}$ volume containing $150 \mathrm{ng}$ genomic DNA, $1 \mathrm{mcM}$ of each primer, $200 \mathrm{mcM}$ each dNTP, 1× PCR Gold Buffer (Applied Biosystems, Monza, Italy), $0.025 \mathrm{U} / \mathrm{mcl}$ of AmpliTaq Gold Polymerase (Applied Biosystems), and $1.5 \mathrm{mM} \mathrm{MgCl} 2$. DNA was heated at $95^{\circ} \mathrm{C}$ for $5 \mathrm{~min}$; 5 cycles were performed with following steps: $95^{\circ} \mathrm{C}$ for $30 \mathrm{sec}, 58^{\circ} \mathrm{C}$ for $30 \mathrm{sec}$, and $72^{\circ} \mathrm{C}$ for $1 \mathrm{~min}$. This profile was followed by others 30 cycles: $95^{\circ} \mathrm{C}$ for $30 \mathrm{sec}, 57^{\circ} \mathrm{C}$ for $30 \mathrm{sec}$, and $72^{\circ} \mathrm{C}$ for $1 \mathrm{~min}$. The reaction ends with an extension step at $72^{\circ} \mathrm{C}$ for $10 \mathrm{~min}$ [Katzenberg et al., 1998]. Amplified fragments were digested by use of Bsp 1286I restriction enzyme (New England Biolabs, England, UK). The incubation is performed at $37^{\circ} \mathrm{C}$ overnight and fragments are separated in agarose gels. The unrestricted PCR product (TT genotype) has a size of $221 \mathrm{bp}$; complete restriction (CC genotype) produces bands of 125 and $96 \mathrm{bp}$.

\section{Statistical Analysis}

Chi-square was used to investigate differences between groups. Logistic regression analysis was used to include possible confounders. Alpha levels were considered significant when less than 0.05 . The power of our sample to detect differences amongst gene variants was calculated considering an alpha value of $5 \%$ two tailed. With these parameters in our sample we had a high power $(0.80)$ to detect a small effect size $(\mathrm{w}=0.117)$ that corresponded to a difference of approximately $11 \%$ between the two major genotypes or to an Odds Ratio of 1.56 [Cohen, 1988].

\section{RESULTS}

Genotype frequencies are summarized in Table I, the sample is in Hardy-Weinberg equilibrium $\left(\chi^{2}=0.065\right.$, $\mathrm{df}=1, P=0.80$ ). There was no significant difference in genotype frequencies between $\mathrm{MDD}$ and $\mathrm{BP}$.

We observed a strong association between CLOCK genotype variants and initial insomnia, middle insomnia, and early morning waking. Both TC and CC genotypes were associated with a higher occurrence of middle, early, and initial insomnia (Table II). The difference was mainly due to BP, except for initial insomnia where the effect was observed for both groups. Decreased need of sleep in BP was also associated with CLOCK variants, while excessive sleep did not.

No significant differences were observed when controlling for age, sex, age at onset, age at first lifetime treatment, suicide attempts, number and violence of suicide attempts, number of episodes, number of hospitalizations, and positive family history for axis I disorders.

TABLE I. CLOCK Genotype in Subjects Affected by Bipolar Disorder (BP) and Major Depressive Disorder (MDD), Calculated for 620 Subjects

\begin{tabular}{|c|c|c|c|c|c|c|c|}
\hline & \multicolumn{2}{|c|}{$\mathrm{TT}$} & \multicolumn{2}{|c|}{$\mathrm{TC}$} & \multicolumn{2}{|c|}{$\mathrm{CC}$} & \multirow[b]{2}{*}{ Total } \\
\hline & $\mathrm{N}$ & $\%$ & $\mathrm{~N}$ & $\%$ & $\mathrm{~N}$ & $\%$ & \\
\hline BP & 208 & 53.89 & 155 & 40.16 & 23 & 5.96 & 386 \\
\hline MDD & 121 & 51.71 & 92 & 39.32 & 21 & 8.97 & 234 \\
\hline Total & 329 & & 247 & & 44 & & \\
\hline
\end{tabular}


TABLE II. Diurnal Mood Variations and Sleep Dis-Regulations, Calculated for 620 Subjects

\begin{tabular}{|c|c|c|c|c|c|c|c|c|c|}
\hline & \multicolumn{2}{|c|}{$\mathrm{TT}$} & \multicolumn{2}{|c|}{$\mathrm{TC}$} & \multicolumn{2}{|c|}{$\mathrm{CC}$} & \multirow[b]{2}{*}{ Total } & \multirow[b]{2}{*}{$\chi^{2}$} & \multirow[b]{2}{*}{$P$} \\
\hline & $\mathrm{N}$ & $\%$ & $\mathrm{~N}$ & $\%$ & $\mathrm{~N}$ & $\%$ & & & \\
\hline Initial insomnia & & & & & & & & 19.39 & 0.0001 \\
\hline Absent & 72 & 72.73 & 24 & 24.24 & 3 & 3.03 & 99 & & \\
\hline Present & 257 & 49.33 & 223 & 42.80 & 41 & 7.87 & 521 & & \\
\hline Middle insomnia (a) & & & & & & & & 13.99 & 0.0009 \\
\hline Absent & 83 & 66.94 & 37 & 29.84 & 4 & 3.23 & 124 & & \\
\hline Present & 246 & 49.60 & 210 & 42.34 & 40 & 8.06 & 496 & & \\
\hline Early insomnia (b) & & & & & & & & 14.23 & 0.0008 \\
\hline Absent & 60 & 72.29 & 20 & 24.10 & 3 & 3.61 & 83 & & \\
\hline Present & 269 & 50.09 & 227 & 42.27 & 41 & 7.64 & 537 & & \\
\hline Excessive sleep & & & & & & & & 4.1 & n.s. \\
\hline Absent & 273 & 51.80 & 213 & 40.42 & 41 & 7.78 & 527 & & \\
\hline Present & 56 & 60.22 & 34 & 36.56 & 3 & 3.23 & 93 & & \\
\hline $\begin{array}{l}\text { Reduced need of sleep } \\
\text { (bipolars only) }\end{array}$ & & & & & & & & 9.81 & 0.0074 \\
\hline Absent & 28 & 73.68 & 10 & 26.32 & 0 & 0.00 & 38 & & \\
\hline Present & 180 & 51.72 & 145 & 41.67 & 23 & 6.61 & 348 & & \\
\hline
\end{tabular}

Initial insomnia is significant in both groups.

Middle insomnia is significantly different in $\mathrm{BP}\left(\chi^{2}=13.66 ; P=0.0011\right)$; but not in $\mathrm{MDD}(1.93 ; P=0.3801)$

Early insomnia is significantly different in $\mathrm{BP}\left(\chi^{2}=10.39 ; P=0.0055\right)$; but not in MDD $(3.92 ; P=0.1406)$.

\section{DISCUSSION}

We observed a strong association between CLOCK variants and lifetime occurrence of sleep disturbances in a sample of patients affected by mood disorders. In patients affected by recurrent major depression the presence of the $\mathrm{C}$ allele was linked with an higher occurrence of initial insomnia, while in patients affected by BP the same allele was associated with insomnia throughout the whole night and reduced need for sleep.

In MDD, then, the direction of the effect of CLOCK C allele on circadian sleep-wake rhythm was the same described in healthy subjects [Katzenberg et al., 1998], where the $\mathrm{C}$ allele has been reported to be associated with a higher eveningness. This preference for the second half of the day seems to lack clinical relevance in the absence of psychiatric illnesses, since no clinical symptoms were reported in the original work on the relationship between CLOCK and diurnal preference [Katzenberg et al., 1998] and a recent study failed to detect an association between the CLOCK C variant and the presence of delayed sleep phase syndrome [Iwase et al., 2002]. On the other hand, mood disorders are not associated with CLOCK variants, in agreement with previous findings [Desan et al., 2000], in fact in our study we observed genotype frequencies similar to that reported in healthy subjects [Katzenberg et al., 1998]. When both MDD and C alleles are present, the patients complain about initial insomnia. The association of clinical insomnia and CLOCK $\mathrm{C}$ allele in patients affected by mood disorder suggests the presence of a still undefined interaction between CLOCK variants and other variables linked with mood disorders, which may pertain to biological substrates or to environmental stimuli.

In patients affected by BP the effect of CLOCK seemed to be more complex. The presence of the $\mathrm{C}$ variant was associated with higher scores in all sleep disturbance items, except daytime sleepiness. In particular, patients showed a higher lifetime reduced need for sleep. Sleep loss has been shown to trigger and augment mood episodes in patients affected by BP [Wehr et al., 1987; Wehr, 1991; Barbini et al., 1996]: a higher propensity to sleep loss in bipolar patients with the $\mathrm{C}$ allele could explain the finding of more lifetime mood episodes [Benedetti et al., in press]. Again, since the $\mathrm{C}$ allele was not associated with sleep disturbances in healthy subjects, the presence of lifetime sleep disturbances in these patients can only be explained by an interaction between CLOCK variants and mood illness.

A major limitation of our study is its retrospective approach. This could bias data collection towards decreased detection of past episodes and unreliable estimates of clinical variables [Keller et al., 1987]. To limit this bias we used a set of strategies: information about the illness were collected by experienced psychiatrist interviewing subjects, family members, previous health professionals, and obtaining records when possible [Leckman et al., 1982]; a second experienced psychiatrist reviewed the chart, unreliability was assessed and considered an exclusion criteria [Shapira et al., 1996]. The use of hypnotic drugs could bias the observed result, however the lifetime perspective guarantees against this bias. Moreover, the functional significance of the CLOCK polymorphism has not yet been clearly defined at a molecular level. However, polymorphisms in the $3^{\prime}$ flanking region have been shown to affect mRNA stability and half-life [Beelman and Parker, 1995; Ross, 1996], with possible significant effects on the level of protein finally being translated. Finally, differences in allele frequency for different populations have been reported [Desan et al., 2000]. However our sample was composed of subjects mainly collected in the North of Italy with Italian antecedents for at least two generations, though genetic heterogeneity have been evidenced for some isolate populations (such as 
Sardinia, not included in our sample) Italy is characterized by a substantial genetic homogeneity [Gasparini et al., 1997].

Overall our findings support the hypothesis that CLOCK genotype has an effect on sleep disturbances in MDD and BP. By relating this result with previous findings, it is possible to hypothesize a relationship between the eveningness associated with $\mathrm{C}$ allele [Katzenberg et al., 1998] and sleep disregulations in MDD and BP.

\section{REFERENCES}

American Psychiatric Association. 1994. Diagnostic and Statistical Manual of Mental Disorders, 4th edn. Washington DC: American Psychiatric Association.

Barbini B, Bertelli S, Colombo C, Smeraldi E. 1996. Sleep loss, a possible factor in augmenting manic episode. Psychiatry Res 15:121-125.

Beelman CA, Parker R. 1995. Degradation of mRNA in eukaryotes. Cell 81:179-183.

Benedetti F, Serretti A, Colombo C, Barbini B, Fulgosi MC, Lorenzi C, Campori E, Smeraldi E. Influence of CLOCK gene polymorphism on circadian mood fluctuation and illness recurrence in bipolar depression. Am J Med Genet (in press).

Cohen J. 1988. Statistical power analysis for the behavioral sciences. Hillsdale, New Jersey: Lawrence Erlbaum Associates. pp 8-14.

Craddock M, Asherson P, Owen MJ, Williams J, McGuffin P, Farmer AE 1996. Concurrent validity of the OPCRIT diagnostic system. Comparison of OPCRIT diagnoses with consensus best-estimate lifetime diagnoses. Br J Psychiatry 169:58-63.

Desan PH, Oren DA, Malison R, Price LH, Rosenbaum J, Smoller J, Charney DS, Gelernter J. 2000. Genetic polymorphism at the CLOCK gene locus and major depression. Am J Med Genet 96:418-421.

Farmer AE, Williams J, Jones I. 1994. Phenotypic definitions of psychotic illness for molecular genetic research. Am J Med Genet 54:365371.

Gasparini P, Estivill X, Volpini V, Totaro A, Castellvi-Bel S, Govea N, Mila M, Della Monica M, Ventruto V, De Benedetto M, Stanziale P, Zelante L, Mansfield ES, Sandkuijl L, Surrey S, Fortina P. 1997. Linkage of DFNB1 to non-syndromic neurosensory autosomal-recessive deafness in Mediterranean families. Eur J Hum Genet 5:83-88.

Iwase T, Kajimura N, Uchiyama M, Ebisawa T, Yoshimura K, Kamei Y, Shibui K, Kim K, Kudo Y, Katoh M, Watanabe T, Nakajima T, Ozeki Y, Sugishita M, Hori T, Ikeda M, Toyoshima R, Inoue Y, Yamada N, Mishima K, Nomura M, Ozaki N, Okawa M, Takahashi K, Yamauchi T. 2002. Mutation screening of the human Clock gene in circadian rhythm sleep disorders. Psychiatry Res 15:121-128.

Katzenberg D, Young T, Finn L, Lin L, King DP, Takahashi JS, Mignot E. 1998. A CLOCK polymorphism associated with human diurnal preference. Sleep 21:569-576.
Keller MB, Lavori PW, Friedman B, Nielsen E, Endicott J, McDonald-Scott P, Andreasen NC. 1987. The longitudinal interval follow-up evaluation. A comprehensive method for assessing outcome in prospective longitudinal studies. Arch Gen Psychiatry 44:540-548.

Klein DC, Moore RY, Repper SM. 1991. Suprachiasmatic nucleus-The mind's clock. New York: Oxford University Press.

Lahiri DK, Nurnberger JIJ. 1991. A rapid non-enzymatic method for the preparation of HMW DNA from blood for RFLP studies. Nucleic Acid Res 19:5444.

Leckman JF, Sholomskas D, Thompson WD, Belanger A, Weissman MM. 1982. Best estimate of lifetime psychiatric diagnosis: A methodological study. Arch Genet Psychiatry 39:879-883.

Lowrey PL, Takahashi JS. 2000. Genetics of the mammalian circadian system: Photic entrainment, circadian pacemaker mechanisms, and posttranslational regulation. Annu Rev Gen 34:533-562.

McGuffin P, Farmer A, Harvey I. 1991. A polydiagnostic application of operational criteria in studies of psychotic illness. Development and reliability of the OPCRIT system. Arch Gen Psychiatry 48:764-770.

Meijer JH, Rietveld WJ. 1989. Neurophysiology of the suprachiasmatic circadian pacemaker in rodents. Physiol Rev 69:671-707.

Moore RY. 1995. Organization of the mammalian circadian system. In: Chadwick DJ, Ackrill K, editors. Ciba Foundation Symposium on Circadian Clocks and Their Adjustments. West Sussex, England: John Wiley and Sons, pp 88-106.

Reppert S, Weaver D. 2001. Molecular analysis of mammalian circadian rhythms. Annu Rev Physiol 63:647-676.

Ross J. 1996. Control of messenger RNA stability in higher eukariote. Trends Genet 12:171-175.

Serretti A, Lilli R, Lorenzi C, Lattuada E, Smeraldi E. 2001. DRD4 exon 3 variants associated with delusional symptomatology in major psychoses: A study on 2,011 affected subjects. Am J Med Genet 105:283-290.

Shapira B, Lidsky D, Gorfine M, Lerer B. 1996. Electroconvulsive therapy and resistant depression: Clinical implications of seizure threshold. J Clin Psychiatry 57:32-38.

Viterna MH, King DP, Chang AM, Kornhauser JM, Lowrey PL, McDonald JD, Dove WF, Pinto LH, Turkey FW. 1994. Mutagenesis and mapping of a mouse gene, clock, essential for circadian behavior. Science 264: $719-725$.

Wehr TA. 1991. Sleep-loss as a possible mediator of diverse causes of mania. Br J Psychiatry 159:576-578.

Wehr TA, Sack DAN, Norman E. 1987. Sleep reduction as a final common pathway in the genesis of mania. Am J Psychiatry 144:201-204.

Wehr TA, Sack DA, Norman E. 1998. Treatment of rapidly cycling bipolar patient by using extended bed rest and darkness to stabilize the timing and duration of sleep. Biol Psychiatry 43:822-828.

Williams J, Farmer AE, Ackenheil M, Kaufmann CA, McGuffin P. 1996. A multicentre inter-rater reliability study using the OPCRIT computerized diagnostic system. Psychol Med 26:775-783.

Wirz-Justice A, Van den Hoofdakker RH. 1999. Sleep deprivation in depression: What do we know, where do we go? Biol Psychiatry 46: $445-453$. 
Chapter 7: Insomnia improvement during antidepressant treatment and CLOCK gene polymorphism 


\title{
Insomnia Improvement During Antidepressant Treatment and CLOCK Gene Polymorphism
}

\author{
Alessandro Serretti, ${ }^{1,2} *$ Cristina Cusin, ${ }^{1,2}$ Francesco Benedetti, ${ }^{1,3}$ Laura Mandelli, ${ }^{1}$ Adele Pirovano, ${ }^{1}$ \\ Raffaella Zanardi, ${ }^{1,2}$ Cristina Colombo, ${ }^{1,2,3}$ and Enrico Smeraldi ${ }^{1,2,3}$ \\ ${ }^{1}$ Department of Neuropsychiatric Sciences, Istituto Scientifico, Universitario Ospedale San Raffaele, Milano, Italy \\ ${ }^{2}$ School of Medicine, Università Vita-Salute San Raffaele, Milano, Italy \\ ${ }^{3}$ School of Psychology, Università Vita-Salute San Raffaele, Milano, Italy
}

\begin{abstract}
Sleep disturbances are commonly observed in mood disorders, and sleep manipulations can influence the clinical status. In the present study, we investigated the possible effect of the $3111 \mathrm{~T} / \mathrm{C}$ circadian locomotor output cycles kaput (CLOCK) gene polymorphism on insomnia symptomatology during antidepressant treatment. One hundred seventy-eight inpatients were treated with fluvoxamine $300 \mathrm{mg} /$ day $(\mathrm{n}=147)$ or paroxetine 20 $40 \mathrm{mg} /$ day $(\mathrm{n}=31)$, and either placebo or pindolol in a double blind design for 6 weeks. The severity of depressive symptoms was weekly assessed with the Hamilton Rating Scale for Depression (HAMD). We observed a significantly higher presence of insomnia throughout the trial in homozygotes for the $C$ variant $(P=0.026)$. Other demographic and clinical features were found not to be related with CLOCK polymorphisms. Overall, our findings may suggest that CLOCK genotype influences the time course of insomnia during antidepressant treatment. This, together with previous findings on this polymorphism could lead to a further dissection of the complexity of mood disorders.

() 2005 Wiley-Liss, Inc.
\end{abstract}

KEY WORDS: CLOCK gene; pharmacogenetics; bipolar disorder; major depressive disorder; insomnia; circadian rhythm

\section{INTRODUCTION}

Alterations in biological rhythms have been repeatedly observed in subjects affected by mood disorders; for example, circadian mood fluctuations with typical morning worsening and improvement in the evening time have been considered a distinctive trait of those diseases, and they have been also associated with a positive outcome [Reinink et al., 1993]. Further, sleep abnormalities such as failure to fall asleep (initial insomnia), to maintain sleep (middle insomnia), and

*Correspondence to: Alessandro Serretti, M.D., Department of Neurosciences, Istituto Scientifico H San Raffaele, University of Milan, School of Medicine, Via Luigi Prinetti 29-20127 Milano, Italy. E-mail: serretti.alessandro@hsr.it

Received 7 April 2003; Accepted 29 March 2004

DOI 10.1002/ajmg.b.30130 early wakening in the morning (terminal insomnia) are commonly observed. In the manic phase, a general reduction of need of sleep is almost the rule. Besides, in clinical practice, rhythm manipulations have a proven clinical efficacy: in fact, sleep deprivation is an effective treatment for depressed bipolar patients [Smeraldi et al., 1999]; conversely, a prevention of sleep loss could inhibit an early manic phase in patients affected by bipolar disorder [Wehr et al., 1987].

The endogenous control of circadian rhythms is under the control of a central pacemaker localized in the suprachiasmatic nuclei (SCN) of the anterior hypothalamus. Several genes are thought to interact in rhythmic control (see review in Reppert and Weaver, 2001) and they are called "clock" for their function of regulation of timing in biological functions [Bunney and Bunney, 2000]. In particular, the circadian locomotor output cycles kaput $(C L O C K)$ gene was identified in mice [King et al., 1997] and in humans [Steeves et al., 1999].

In the mouse and human orthologs of clock, the high level of sequence conservation suggests a conserved function for the CLOCK protein in the circadian system of mammals. The mRNA of human CLOCK gene (4q12-GDB: 9785615) has been found in the SCN, hippocampus, piriform cortex, and cerebellum [Steeves et al., 1999], all areas involved in biological rhythms.

One polymorphism named $3111 \mathrm{~T} / \mathrm{C}$ located in the $3^{\prime}$ flanking region has been shown to affect mRNA stability and half-life [Mignone et al., 2002]. The $\mathrm{C}$ allele has been associated with significantly higher "eveningness" in healthy subjects and with a delay in preferred timing for activity or sleep episodes, with no changes in sleep architecture [Katzenberg et al., 1998], though this result was not confirmed in a subsequent study [Robilliard et al., 2002]. In patients affected by mood disorders, two studies performed by our research group reported no association between CLOCK $3111 \mathrm{~T} / \mathrm{C}$ polymorphism and diagnosis, and no association with circadian mood fluctuations, but found a significantly higher recurrence rate of illness episodes in bipolar patients homozygotes for the $\mathrm{C}$ variant [Benedetti et al., 2003] and a strong association between the $\mathrm{C}$ variant and an increased lifetime sleep disturbances (in particular, initial and middle insomnia) [Serretti et al., 2003].

Those findings confirmed the clinical relevance of CLOCK $3111 \mathrm{~T} / \mathrm{C}$ polymorphism in mood disorders, raising the possibility of a genetic dissection of psychopathological symptoms associated with depression: the moderate and clinically not relevant phase preference associated with CLOCK C/C genotype in healthy subjects could become symptomatic insomnia in patients affected by mood disorders. We then hypothesized that the efficacy of antidepressant treatments on insomnia symptomatology may vary depending on $3111 \mathrm{~T} / \mathrm{C} C L O C K$ gene variants. 


\section{METHODS}

\section{Sample}

One hundred seventy-eight subjects consecutively admitted to the Mood Disorder Center, Department of Psychiatry at the Institute H. San Raffaele, Milan were included in this study (age $=52.6 \pm 12.6$ years; onset $=37.3 \pm 12.6$ years; female/ male $=113 / 65$; bipolars $/$ major depressives $=88 / 90$; delusional/non-delusional $=70 / 108)$. Assessment methods were previously reported [Smeraldi et al., 1998; Serretti et al., 2001]. All patients were evaluated at baseline and weekly thereafter until the sixth week using the 21-item Hamilton Rating Scale for Depression (HAM-D-21) [Hamilton, 1967] administered by trained senior psychiatrists, blind to genetic data and to treatment. Subjects for the present study are part of a larger sample where we studied the effect of CLOCK variants on lifetime insomnia and periodicity [Serretti et al., 2003]. They have been treated in the context of previous trials under double blind conditions [Smeraldi et al., 1998; Serretti et al., 2001] where 5-HTTLPR and TPH variants were studied. The procedure was the same in all trials. Briefly, after a 7-day washout period, fluvoxamine or paroxetine was administered to reach respectively, $300 \mathrm{mg}$ and $20-40 \mathrm{mg}$ daily from day 8 until the end of the trial. Pindolol was blindly added to approximately one-third of subjects $(n=68)$. Concomitant psychotropic drugs were not allowed except flurazepam at bedtime (up to $45 \mathrm{mg}$ ) or lithium maintenance $(\mathrm{n}=45)$. Detailed data about hypnotics were not available, however, an analysis performed in a subsample of 59 individuals showed that flurazepam was administered to $80 \%$ of patients. The distribution of flurazepam was not significantly different depending on CLOCK variants $\chi^{2}=4.29$; d.f. $=2 ; P=$ n.s.) with a trend of higher use in $\mathrm{C} / \mathrm{C}$ genotype. We also analyzed in this subsample, if the dose was reduced, maintained, or increased during hospitalization, and it was not different across genotypes $\left(\chi^{2}=0.97\right.$; d.f. $=4 ; P=$ n.s. $)$. Therefore, hypnotics were not considered for the calculations. HAM-D scores during treatment are the main outcome measure; insomnia symptomatology was scored based on the actual symptoms of the current week, independent from treatment. A decrease in HAM-D scores to eight or less, with delusion factor equal to zero (items 2, 15, 20) [Bellini et al., 1992; Bech et al., 1993; Sobin and Sackeim, 1997], was used to define responders. After the procedure had been fully explained to all subjects, written informed consent was obtained. Two subjects with extreme $( \pm 1.96 \mathrm{SD})$ plasma fluvoxamine and paroxetine levels were excluded [Lucca et al., 1994].

\section{DNA Analysis}

Genomic DNA was extracted from leukocytes by $\mathrm{NaCl}$ precipitation [Lahiri and Nurnberger, 1991]. PCR was performed according to the methods reported by Katzenberg et al. [1998]. Amplified fragments were digested by use of Bsp 1286I restriction enzyme (New England Biolabs, England, UK). The incubation is performed at $37^{\circ} \mathrm{C}$ overnight and fragments were separated in agarose gels. The unrestricted PCR product (TT genotype) had a size of $221 \mathrm{bp}$; complete restriction (CC genotype) produced bands of 125 and $96 \mathrm{bp}$. The sample was in Hardy-Weinberg equilibrium $\left(\chi^{2}=0.33 ; P=0.56\right)$.

\section{Statistical Analysis}

Seven HAM-D insomnia (items 4-5-6) scores measurements (baseline and 6 weeks) were analyzed. Repeated measures analysis of variance (MANOVA) was used to examine the differences between gene variants on HAM-D scores. Analysis of covariance (MANCOVA) was used when including covariants. An "intent-to-treat" analysis was carried out for all patients who had a baseline assessment and at least one assessment after randomization, with the last observation carried forward on the HAM-D. Variation from baseline was used for all calculations. A Student's $t$-test and $\chi^{2}$ were used to compare demographic data and baseline ratings. All $P$ values are 2 -tailed, and statistical significance was set at the $5 \%$ level $(P<0.05)$

With these parameters, our sample had a high power $(0.80)$ to detect a medium-large effect size $(d=0.74)$, which corresponded to a difference of approximately 0.9 points on the final HAM-D insomnia between the two genotypes [Cohen, 1988]. The analysis was performed, pooling fluvoxamine and paroxetine, given their similarity of action, previous reports suggesting similar genetic influences [Smeraldi et al., 1998; Serretti et al., 2001], and comparing $\mathrm{C} / \mathrm{C}$ variants versus $\mathrm{T} / \mathrm{T}$ and T/C following previous evidences [Katzenberg et al., 1998; Benedetti et al., 2003; Serretti et al., 2003].

\section{RESULTS}

The clinical outcome of the sample has been separately reported in previous studies [Smeraldi et al., 1998; Zanardi et al., 2000; Serretti et al., 2001]. A brief description of demographic and clinical variables is summarized in Table I. Baseline characteristics of subjects grouped according to CLOCK variants did not show any significant difference except for a significant association of the $\mathrm{C} / \mathrm{C}$ genotype with females $\chi^{2}=10.42 ;$ d.f. $=2 ; P=0.0055$ ).

We then analyzed insomnia score (sum of the HAM-D items 4-5-6) during antidepressant treatment with baseline level as a covariant. CLOCK genotypes were not associated with insomnia at baseline, there was a non-significant trend in the direction of higher terminal insomnia in CLOCK C/C genotype. The CLOCK C/C genotype resulted associated with a more severe insomnia symptomatology during SSRIs treatment (see Fig. 1; MANCOVA: $\mathrm{F}=5.04$; d.f. $=1,175 ; P=0.026$; baseline covariant not significant). More in detail, the effect of genotype was greater for middle insomnia $(P=0.02)$ compared to both early and late insomnia respectively, $(P=0.07$ and $P=0.05$ ).

Figure 1 shows that the decrease of insomnia score followed a parallel slope of time course in the $\mathrm{C} / \mathrm{T}$ and $\mathrm{T} / \mathrm{T}$ subjects, but with $\mathrm{C} / \mathrm{C}$ patients maintaining a higher severity throughout the treatment. The whole HAM-D score decrease comparing genotypes $\mathrm{C} / \mathrm{C}$ versus others did not show any significant difference (Table I).

Following, we compared mean insomnia score at each observation time and we observed that the difference between genotypes was present as a trend since week 1 , reaching significance only in week 5 (Student's $t$-test: week 1: $P=0.08$; week $2: P=0.08$; week $3: P=0.2$; week $4: P=0.05$; week 5 : $P=0.02$; week $6: P=0.06)$, but not at baseline $(P=0.9)$. Consideration of sex, presence of delusional features, and drug did not affect the genotype effect, while considering diagnosis, we observed a slightly more marked effect in bipolars subject compared to MDD. Female sex, which was associated with $\mathrm{CLOCK}^{*} \mathrm{C} / \mathrm{C}$ genotype, was associated with higher baseline scores for middle insomnia $(\mathrm{t}=2.64$; d.f. $=169 ; P=0.0092)$.

\section{DISCUSSION}

We observed a significant association between $3111 \mathrm{~T} / \mathrm{C}$ CLOCK polymorphism and sleep disturbances during SSRI treatment in patients affected by a major depressive episode. We previously reported that the same $\mathrm{C} / \mathrm{C}$ variant was associated with lifetime insomnia [Serretti et al., 2003] and mood disorders time course [Benedetti et al., 2003]. In particular, inpatients affected by recurrent major depression, the presence of the $\mathrm{C}$ variant was linked to a higher occurrence of initial insomnia, while inpatients affected by bipolar disorder, 
TABLE I. Demographic and Clinical Features for CLOCK Genotypes

\begin{tabular}{|c|c|c|c|c|c|c|}
\hline & TT number (\%) & TC number $(\%)$ & CC number $(\%)$ & Total* & $\chi^{2}$ & $P$ \\
\hline $\begin{array}{l}\text { Sex } \\
\text { Female } \\
\text { Male }\end{array}$ & $\begin{array}{l}59(52.22 \%) \\
32(49.23 \%)\end{array}$ & $\begin{array}{l}39(34.51 \%) \\
32(49.23 \%)\end{array}$ & $\begin{aligned} 15 & (13.27 \%) \\
1 & (1.54 \%)\end{aligned}$ & $\begin{array}{r}113 \\
65 \\
178\end{array}$ & 10.42 & 0.0055 \\
\hline $\begin{array}{l}\text { Marital status } \\
\text { Single } \\
\text { Married } \\
\text { Separated/divorced } \\
\text { Widowed }\end{array}$ & $\begin{aligned} 17 & (53.13 \%) \\
45 & (47.87 \%) \\
13 & (61.90 \%) \\
3 & (60.00)\end{aligned}$ & $\begin{array}{c}13(40.63 \%) \\
40(42.55 \%) \\
6(28.57) \\
2(40.00)\end{array}$ & $\begin{array}{l}2(6.24 \%) \\
9(9.58 \%) \\
2(9.53 \%) \\
0(0.00 \%)\end{array}$ & $\begin{array}{r}32 \\
94 \\
21 \\
5 \\
152\end{array}$ & 2.86 & 0.8267 \\
\hline $\begin{array}{l}\text { Diagnosis } \\
\text { UP } \\
\text { BP }\end{array}$ & $\begin{array}{l}50(55.56 \%) \\
41(46.59 \%)\end{array}$ & $\begin{array}{l}31(34.44 \%) \\
40(45.46 \%)\end{array}$ & $\begin{array}{l}9(10.00 \%) \\
7(7.95 \%)\end{array}$ & $\begin{array}{r}90 \\
88 \\
178\end{array}$ & 2.26 & 0.3224 \\
\hline $\begin{array}{l}\text { Psychotic features } \\
\text { Absent } \\
\text { Present }\end{array}$ & $\begin{array}{l}39(55.71 \%) \\
52(48.15 \%)\end{array}$ & $\begin{array}{l}23(32.89 \%) \\
48(44.44 \%)\end{array}$ & $\begin{array}{l}8(11.40 \%) \\
8(7.41 \%)\end{array}$ & $\begin{array}{r}70 \\
108 \\
178\end{array}$ & 2.14 & 0.3435 \\
\hline $\begin{array}{l}\text { Personality disorders } \\
\text { Absent } \\
\text { Present }\end{array}$ & $\begin{array}{l}17(48.57 \%) \\
36(49.32 \%)\end{array}$ & $\begin{array}{l}14(40.00 \%) \\
31(42.46 \%)\end{array}$ & $\begin{array}{l}4(11.43 \%) \\
6(8.22 \%)\end{array}$ & $\begin{array}{r}35 \\
73 \\
108\end{array}$ & 0.12 & 0.9401 \\
\hline $\begin{array}{l}\text { Pindolol augmentation } \\
\text { Yes } \\
\text { No }\end{array}$ & $\begin{array}{l}32(46.38 \%) \\
59(54.13 \%)\end{array}$ & $\begin{array}{l}30(43.48 \%) \\
41(37.61 \%)\end{array}$ & $\begin{array}{l}7(10.14 \%) \\
9(8.26 \%)\end{array}$ & $\begin{array}{r}69 \\
109 \\
178\end{array}$ & 0.76 & 0.6832 \\
\hline $\begin{array}{l}\text { Responders } \\
\text { Yes } \\
\text { No }\end{array}$ & $\begin{array}{l}56(53.33 \%) \\
35(47.95 \%)\end{array}$ & $\begin{array}{l}42(40.00 \%) \\
29(39.72 \%)\end{array}$ & $\begin{array}{l}7(6.67 \%) \\
9(12.33 \%)\end{array}$ & $\begin{array}{r}105 \\
73 \\
178\end{array}$ & 1.75 & 0.4168 \\
\hline $\begin{array}{l}\text { Initial insomnia at baseline } \\
\text { Absent } \\
\text { Present }\end{array}$ & $\begin{array}{r}3(50.00 \%) \\
88(51.16 \%)\end{array}$ & $\begin{array}{r}3(50.00 \%) \\
68(39.53 \%)\end{array}$ & $\begin{array}{r}0(0.00 \%) \\
16(9.30 \%)\end{array}$ & $\begin{array}{r}6 \\
172 \\
178\end{array}$ & 1.24 & 0.5362 \\
\hline $\begin{array}{l}\text { Middle insomnia at baseline } \\
\text { Absent } \\
\text { Present }\end{array}$ & $\begin{array}{r}9(60.00 \%) \\
82(50.31 \%)\end{array}$ & $\begin{array}{r}5(33.33 \%) \\
66(40.49 \%)\end{array}$ & $\begin{array}{r}1(6.67 \%) \\
15(9.20 \%)\end{array}$ & $\begin{array}{r}15 \\
163 \\
178\end{array}$ & 0.53 & 0.7659 \\
\hline $\begin{array}{l}\text { Early morning waking insomnia at } \\
\text { baseline } \\
\text { Absent } \\
\text { Present }\end{array}$ & $\begin{array}{r}9(75.00 \%) \\
82(49.40 \%)\end{array}$ & $\begin{array}{r}3(25.00 \%) \\
68(40.96 \%)\end{array}$ & $\begin{array}{r}0(0.00 \%) \\
16(9.64 \%)\end{array}$ & $\begin{array}{r}12 \\
166 \\
178\end{array}$ & 4.32 & 0.1155 \\
\hline & Mean \pm SD & Mean \pm SD & Mean $\pm \mathrm{SD}$ & & $\mathrm{F}$ & $P$ \\
\hline $\begin{array}{l}\text { Age } \\
\text { Education (years) }\end{array}$ & $\begin{array}{l}52.6 \pm 13.16 \\
9.08 \pm 4.05\end{array}$ & $\begin{array}{c}52.04 \pm 12.67 \\
9.23 \pm 3.99\end{array}$ & $\begin{array}{r}54.81 \pm 9.65 \\
7.61 \pm 3.64\end{array}$ & $\begin{array}{l}161 \\
155\end{array}$ & $\begin{array}{l}0.31 \\
0.90\end{array}$ & $\begin{array}{l}0.7347 \\
0.4076\end{array}$ \\
\hline Onset & $35.87 \pm 11.74$ & $38.78 \pm 13.42$ & $39.13 \pm 13.61$ & 161 & 1.13 & 0.3256 \\
\hline Number of episodes & $4.45 \pm 3.71$ & $4.33 \pm 3.23$ & $4.44 \pm 3.36$ & 110 & 0.02 & 0.9842 \\
\hline Age at first lifetime treatment & $38.15 \pm 12.64$ & $40.20 \pm 13.77$ & $40.33 \pm 14.01$ & 142 & 0.44 & 0.6466 \\
\hline Number of hospitalizations & $3.66 \pm 4.15$ & $3.83 \pm 3.50$ & $2.50 \pm 2.11$ & 138 & 0.62 & $\begin{array}{l}0.5416 \\
0.6224\end{array}$ \\
\hline $\begin{array}{l}\text { Duration current episode (weeks) } \\
\text { Baseline HAM-D score }\end{array}$ & $\begin{array}{l}19.04 \pm 21.14 \\
28.67 \pm 6.18\end{array}$ & $\begin{array}{l}16.25 \pm 20.69 \\
30.53 \pm 7.11\end{array}$ & $\begin{array}{l}13.10 \pm 12.40 \\
27.94 \pm 6.43\end{array}$ & $\begin{array}{l}113 \\
178\end{array}$ & $\begin{array}{l}0.48 \\
2.00\end{array}$ & $\begin{array}{l}0.6224 \\
0.1383\end{array}$ \\
\hline $\begin{array}{l}\text { HAM-D score at T6 } \\
\text { Fluvoxamine mean blood level }\end{array}$ & $\begin{aligned} 8.27 & \pm 9.40 \\
370.98 & \pm 201.57\end{aligned}$ & $\begin{aligned} 9.15 & \pm 10.50 \\
300.81 & \pm 175.55\end{aligned}$ & $\begin{array}{c}11.94 \pm 12.74 \\
344.00 \pm 168.03\end{array}$ & $\begin{array}{l}178 \\
147\end{array}$ & $\begin{array}{l}0.90 \\
1.37\end{array}$ & $\begin{array}{l}0.4065 \\
0.2583\end{array}$ \\
\hline Paroxetine mean blood level & $150.00 \pm 92.97$ & $104.50 \pm 89.99$ & - & 31 & 0.43 & 0.5424 \\
\hline
\end{tabular}

*Some data are available for subset of patients.

the same variant was associated with insomnia throughout the whole night and reduced need for sleep.

Interestingly, the present results suggest that part of the clinical picture of acute depressive episodes could be linked to stable trait features, genetically controlled, and relatively resistant to antidepressant treatment. We observed this phenomenon for insomnia, which is a stable lifetime feature in subjects with $3111 \mathrm{~T} / \mathrm{C}$ CLOCK variants and it is significantly less influenced by antidepressant treatment. An early recognition of those subjects could help the clinicians to individualize the treatments, and to avoid the erroneous interpretation of an incomplete remission due to persistence of sleep disturbances. However, we should consider that the present finding was obtained in a relatively small number of subjects (16 with $\mathrm{CLOCK} \mathrm{C} / \mathrm{C}$ ) and with a low significance value.

The use of hypnotic drugs may bias studies on sleep. Unfortunately, in the present sample we do not have reliable data for all subjects. However, we should consider that our analysis in a subgroup of patients did not show any significant 


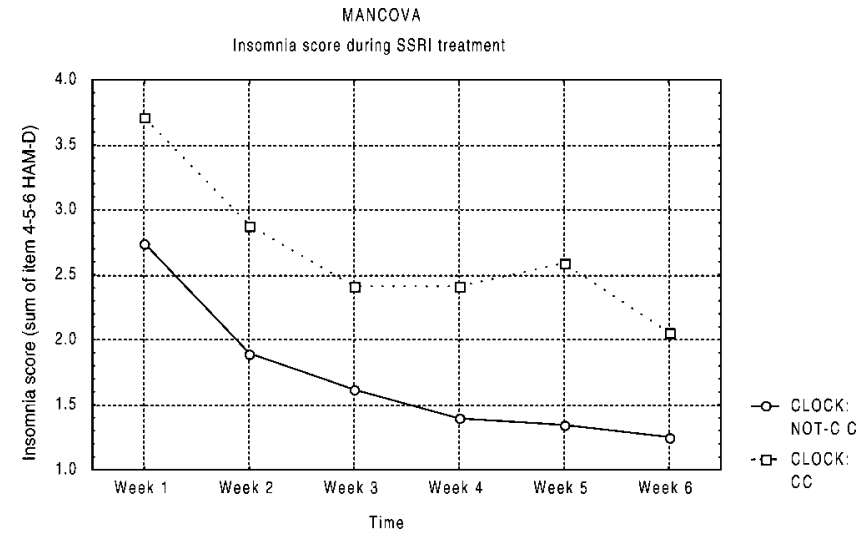

Fig. 1. Shows the time course of response divided by CLOCK variants: subjects with the $\mathrm{C} / \mathrm{C}$ variant showed a constantly higher insomnia score $(\mathrm{F}=5.04 ;$ d.f. $=1,175 ; P=0.026)$.

difference between CLOCK variants. Moreover, a trend toward a heavier use of sleep inducing drugs in $\mathrm{C} / \mathrm{C}$ subjects could bias toward an overtreatment of insomnia in those subjects leading to an effect opposite compared to the one we observed.

We previously investigated the influence of genes of the serotonergic pathway in response to SSRIs, however, we did not observe any association of CLOCK with total HAM-D time course but only with insomnia symptomatology, thus evidencing how polymorphisms may have a different impact on the drug response phenotype. Further, a case-control association study in subjects affected by mood disorders, showed no positive result for CLOCK and major depression [Desan et al., 2000].

The functional significance of the CLOCK polymorphism has not yet been clearly defined at a molecular level. However, it is important to underline that this polymorphism is in a well conserved region between mice and humans, and that in mouse it contains several functional polyadenylation signals [King et al., 1997]. Alternatively, this polymorphism could be in linkage disequilibrium with others, as yet unidentified, but more functionally significant [Savov et al., 1995].

Differences in allele frequency for different populations have been reported [Desan et al., 2000]. However, our sample was genetically homogenous [Gasparini et al., 1997].

Overall, our findings suggest that CLOCK genotype influences the severity of insomnia during antidepressant treatment of a major depressive episode; this together with previous findings on this polymorphism lead to further dissect the complexity of mood disorders.

\section{REFERENCES}

Bech P, Malt U, Dencker S, Ahlfors U, Elgen K, Lewander T, Lundell A, Simpson G, Lingjaerde O. 1993. Scales for assessment of diagnosis and severity of mental disorders. Acta Psychiatr Scand 87(Suppl 372):37-40.

Bellini L, Gatti F, Gasperini M, Smeraldi E. 1992. A comparison between delusional and non-delusional depressives. J Affect Disord 25:129-138.

Benedetti F, Serretti A, Colombo C, Barbini B, Lorenzi C, Campori E, Smeraldi E. 2003. Influence of CLOCK gene polymorphism on circadian mood fluctuation and illness recurrence in bipolar depression. Am J Med Genet 123B:23-26.

Bunney WE, Bunney BG. 2000. Molecular clock genes in man and lower animals: Possible implications for circadian abnormalities in depression. Neuropsychopharmacology 22:335-345.
Cohen J. 1988. Statistical power analysis for the behavioral sciences. Hillsdale, New Jersey: Lawrence Erlbaum Associates. pp 8-14.

Desan PH, Oren DA, Malison R, Price LH, Rosenbaum J, Smoller J, Charney DS, Gelernter J. 2000. Genetic polymorphism at the CLOCK gene locus and major depression. Am J Med Genet 96:418-421.

Gasparini P, Estivill X, Volpini V, Totaro A, Castellvi-Bel S, Govea N, Mila M, Della Monica M, Ventruto V, De Benedetto M, Stanziale P, Zelante L, Mansfield ES, Sandkuijl L, Surrey S, Fortina P. 1997. Linkage of DFNB1 to non-syndromic neurosensory autosomal-recessive deafness in Mediterranean families. Eur J Hum Genet 5:83-88.

Hamilton M. 1967. Development of a rating scale for primary depressive illness. Br J Soc Clin Psychol 6:278-296.

Katzenberg D, Young T, Finn L, Lin L, King DP, Takahashi JS, Mignot E. 1998. A CLOCK polymorphism associated with human diurnal preference. Sleep 21:569-576.

King DP, Vitaterna MH, Chang AM, Dove WF, Pinto LH, Turek FW, Takahashi JS. 1997. The mouse Clock mutation behaves as a antimorph and maps within the W19H deletion, distal of Kit. Genetics 146:10491060.

Lahiri DK, Nurnberger JIJ. 1991. A rapid non-enzimatic method for the preparation of HMW DNA from blood for RFLP studies. Nucleic Acid Res 19:5444.

Lucca A, Lucini V, Catalano M, Alfano M, Smeraldi E. 1994. Plasma tryptophan to large neutral amino acids ratio and therapeutic response to a selective serotonin uptake inhibitor. Neuropsychobiology 29:108111.

Mignone F, Gissi C, Liuni S, Pesole G. 2002. Untranslated regions of mRNAs. Genome Biol 3: REVIEWS0004.

Reinink E, Bouhuys AL, Gordijn MC, Van Den Hoofdakker RH. 1993. Prediction of the antidepressant response to total sleep deprivation of depressed patients: Longitudinal versus single day assessment of diurnal mood variation. Biol Psychiatry 34:471-481.

Reppert S, Weaver D. 2001. Molecular analysis of mammalian circadian rhythms. Annu Rev Physiol 63:647-676.

Robilliard DL, Archer SN, Arendt J, Lockley SW, Hack LM, English J, Leger D, Smits MG, Williams A, Skene DJ, Von Schantz M. 2002. The 3111 Clock gene polymorphism is not associated with sleep and circadian rhythmicity in phenotypically characterized human subjects. J Sleep Res 11:305-312.

Savov A, Angelicheva D, Balassapoulou A, Jordanova A, Noussia-Arvanitakis S, Kalaydjieva L. 1995. Double mutant alleles: Are they rare? Hum Mol Genet 4:1169-1171.

Serretti A, Zanardi R, Rossini D, Cusin C, Lilli R, Smeraldi E. 2001. Influence of tryptophan hydroxylase and serotonin transporter genes on fluvoxamine antidepressant activity. Mol Psychiatry 6:586-592.

Serretti A, Benedetti F, Mandelli L, Lorenzi C, Pirovano A, Colombo C, Smeraldi E. 2003. Genetic dissection of psychopathological symptoms: Insomnia in mood disorders and CLOCK gene polymorphism. Am J Med Genet 121B:39-43.

Smeraldi E, Zanardi R, Benedetti F, Dibella D, Perez J, Catalano M. 1998 Polymorphism within the promoter of the serotonin transporter gene and antidepressant efficacy of fluvoxamine. Mol Psychiatry 3:508-511.

Smeraldi E, Benedetti F, Barbini B, Campori E, Colombo C. 1999. Sustained antidepressant effect of sleep deprivation combined with pindolol in bipolar depression-A placebo-controlled trial. Neuropsychopharmacology $20: 380-385$.

Sobin CA, Sackeim H. 1997. Psychomotor symptoms of depression. Am J Psychiatry 154:4-17.

Steeves TD, King DP, Zhao Y, Sangoram AM, Du F, Bowcock AM, Moore RY, Takahashi JS. 1999. Molecular cloning and characterization of the human clock gene: Expression in the suprachiasmatic nuclei. Genomics 57:198-200.

Wehr TA, Sack DA, Norman E. 1987. Sleep reduction as a final common pathway in the genesis of mania. Am J Psychiatry 144:201-204.

Zanardi R, Benedetti F, DiBella D, Catalano M, Smeraldi E. 2000. Efficacy of paroxetine in depression is influenced by a functional polymorphism within the promoter of serotonin transporter gene. J Clin Psychopharmacol 20:105-107. 
Chapter 8: Serotonin transporter gene variants and behavior: A comprehensive review 


\title{
Serotonin Transporter Gene Variants and Behavior: A Comprehensive Review
}

\author{
Alessandro Serretti*, Raffaella Calati, Laura Mandelli and Diana De Ronchi
}

Institute of Psychiatry, University of Bologna, Bologna, Italy

\begin{abstract}
The serotonin system modulates affective, cognitive and behavioral processes. A key molecular structure of this system, the serotonin transporter (SERT) gene, has been associated with many human behaviors, both normal and pathological. This article aim is a comprehensive overview of the human behavioral features influenced by SERT gene variants and to suggest some comprehensive hypotheses.

In particular, the SERTPR insertion/deletion polymorphism has been related to hippocampal volume and amygdala response and it has been found to influence anxiety-related personality traits and anxiety disorders; in mood disorders it showed some influences on age at onset, periodicity, illness recurrence, rapid cycling, antidepressants response and depressive reaction to stressful life events. Psychosomatic disorders, suicide, alcoholism, smoking, eating disorders, attention deficit hyperactivity disorders and autism have been also found to be related to SERTPR variants.

SERT gene variants seem therefore to modulate a wide range of aspects in both normal and affected individuals, many of which are possibly due to indirect correlations between such human features.
\end{abstract}

Key Words: Serotonin transporter, phenotype, complex disorder, genetics, psychiatry.

\section{INTRODUCTION}

\section{The Serotonin System}

The name "serotonin" is something of a misnomer and it reflects the circumstances of the compound's discovery. It was initially identified as a vasoconstrictor substance in blood serum (hence "serotonin"), a serum agent affecting vascular tone. This agent was later chemically identified as 5-hydroxytryptamine (5HT) and after that the broad range of physiological roles were elucidated, 5-HT became the preferred name in the pharmacological field [1].

Serotonin is synthesized from the aminoacid tryptophan, which is derived from diet; the rate-limiting step is the hydroxylation of tryptophan by tryptophan hydroxylasis.

Serotonin is found in both the brain and the human gastrointestinal tract, or gut, but it is now widely understood that about $98 \%$ of the serotonin in the human body resides in the gut, with only $2 \%$ of serotonin cells in the brain.

Serotoninergic neurons are clustered in midline raphe nuclei of the midbrain, pons and medulla [2]. Raphe nuclei have heavy ascending serotonin projections to cortex, thalamus, hypothalamus and limbic system. Neurons in these regions are involved in circadian rhythms (sleep-wake cycle, hormonal secretion and body temperature), sexual behavior, appetite and mood.

As important as the ascending pathways are fibers that descend from brainstem to spinal cord to modulate the incoming painful stimuli. Serotonin-containing cell bodies more caudal, in the ventral medulla and caudal pons, provide descending projections to dorsal horn of the spinal cord; the lumbosacral section receives a particularly large number of fibers. These neurons are critically involved in pain sensation (anti-nociceptive effect).

The serotonin system has been implicated in almost every conceivable physiologic or behavioral function: affect, aggression, appetite, cognition, emesis, endocrine function, gastrointestinal function, motor function, neurotrophism, perception, sensory function, sex, sleep and vascular function [2-4].

*Address correspondence to this author at the Institute of Psychiatry, University of Bologna, Viale Carlo Pepoli 5, 40123 Bologna, Italy; Tel: +39 051 6584233; Fax: +39051 521030; E-mail: alessandro.serretti@unibo.it
Small lesions or drug injections into the median raphe produce a dramatic behavioral syndrome, characterized by pronounced hyperactivity, aggressiveness, large increases in food and water intake and sexual behavior and a pattern of disturbances in learning and memory [5].

The understanding of the genetic modulation of the serotonin system is therefore crucial in the whole psychiatric genetic field.

\section{The Serotonin Transporter Polymorphisms}

The serotonin transporter (SERT or 5-HTT) is an integral membrane protein, localized in pre-synaptic neuronal membranes, that has the function of taking up serotonin into the pre-synaptic neurons after its release in synaptic spaces, with the purpose of terminating the synaptic action of serotonin and recycle it in a sodium-dependent manner. The SERT is encoded by the single gene SLC6A4, positioned on chromosome 17, in location 17q11.1-q12; the SLC6A4 gene spans $31 \mathrm{~kb}$ and consists of 14 exons [6].

Two polymorphisms have been recognized in this gene: firstly, Ogilvie and colleagues [7] identified the existence of a polymorphism, with three novel alleles of the variable number tandem repeat (VNTR) region, in the second intron, which contains 9 (Stin2.9), 10 (Stin2.10) or 12 (Stin2.12) tandem repeats; they found a significant difference between controls and an affective disorder group, largely explained by an excess of an allele with 9 copies of the VNTR element, that was significantly associated with risk of a depression episode or a major depressive disorder. Secondly, Heils and colleagues [8] reported a polymorphism in the transcriptional control region upstream of the serotonin gene coding sequence (SERTPR); the polymorphism is located approximately $1 \mathrm{~kb}$ upstream of the transcription initiation site of the SLC6A4 gene and is composed of 16 repeat elements. The polymorphism consists of a 44-bp insertion or deletion, involving repeat elements 6 to 8 ; deletion characterizes a short variant (s), while insertion characterizes a long variant (1). The short variant reduces the transcriptional efficiency of the SERT gene promoter, resulting in decreased SERT expression and availability [9].

\section{SEROTONIN TRANSPORTER AND CRITICAL NEURO- ANATOMIC SITES}

\section{Volume of the Hippocampus}

Hippocampus is a part of the limbic system, located inside the temporal lobes. It plays a key part in memory [10]. Frodl and col- 
leagues examined the influence of SERTPR polymorphism on hippocampal volumes in patients with major depression and healthy controls. Patients with the $1 / 1$ genotype had significantly smaller hippocampal gray and white matter volumes than controls with the same genotype, but interestingly they also had significantly smaller hippocampal white matter volumes than patients with the $1 / \mathrm{s}$ or $\mathrm{s} / \mathrm{s}$ genotypes [11].

In a recent study, subjects with the $1 / 1$ genotype and characterized by late-onset depression, exhibited smaller hippocampal volumes than $1 / 1$ non-late onset patients and $1 / 1$ controls. On the other hand, non-late s/s patients had smaller hippocampal volumes in subjects than controls. Authors hypothesized an interaction between the serotonergic system, neurotrophic factors and/or cortisol response to stresses, each of which may have an effect on hippocampal volumes [12].

\section{The Amygdala Response}

The serotonin-containing raphe nuclei have heavy ascending projections to limbic system, which is composed by amygdala, thalamus, hypothalamus, hippocampus, locus coeruleus, cingulate gyrus and pituitary gland. The limbic system modulates emotionally driven behaviors, anxiety, fear and anger, olfaction, taste, sexuality, short-term memory storage (into long-term memory), visual attention and attention span. Amygdala, located in the temporal lobes, is believed to play a key role in the emotional and social behavior [10].

Hariri and collaborators [13], in a functional Magnetic Resonance Imaging (fMRI) study, reported an intriguing result: individuals with one or two copies of the s allele of the SERTPR exhibit greater amygdala neuronal activity in response to fearful stimuli, compared with individuals homozygous for the 1 allele. Thus, differential excitability of the amygdala, mediated by SERTPR, may contribute to increased fear and anxiety, previously associated with the s allele (see below). Recently, the same Authors confirmed their previous finding in a large independent cohort of healthy subjects [14].

Therefore, SERTPR polymorphism may be hypothesized a susceptibility factor for anxiety and affective disorders as it modulates the functional reactivity of the human amygdala in the context of stressful life events and/or deficient cortical regulatory input.

\section{ANXIOUS PERSONALITY TRAITS}

In the field of temperamental anxiety, Lesch and collaborators [9] first reported an association between SERTPR and anxietyrelated personality traits. Personality traits were assessed with three different measures: the Tridimensional Personality Questionnaire (TPQ), which is a former version of the Temperament and Character Inventory (TCI), based on the psychobiological model of Cloninger [15]; the NEO Personality Inventory Revised (NEO-PI-R), a self-report inventory based on the five-factor model of personality [16]; the Sixteen Personality Factor Questionnaire (16PF), based on the factor model by Cattell [17]. Individuals with either 1 or 2 copies of the $\mathrm{s}$ form were found to have higher anxiety related scores compared to individuals homozygous for the 1 variant.

This study caused a huge explosion of researches, both in children and in adults. Children studies reported somewhat conflicting findings. On one hand s variant was found to be related to temperament traits that are perhaps the underpinning of adult neuroticism: Lakatos and his group found that infants at 12 months of age, with at least one copy of both the 1 variant of SERTPR and the 7repeat dopamine D4 receptor (DRD4) allele, responded with significantly less anxiety to the stranger's initiation of interaction than infants with other genotypes [18]; in a second study infants at 2 months with the s/s genotype had higher scores on Negative Emotionality and Distress to Limitations at the Rothbart's Infant Behavior Questionnaire (IBQ) than infants with the 1/s or 1/1 genotypes [19]; finally children shyness was associated with s variant [20].
On the other hand other studies reported the 1 variant associated with the same temperamental traits: Arbelle and colleagues found a significant association between the 1 SERTPR polymorphism and shyness in a non-clinical sample of second-grade children [21]; Auerbach and collaborators, in a sample of infants aged 12 months, found that homozygous for the $\mathrm{s}$ variant showed less fearful distress to stranger approach and less pleasure in a structured play situation than infants with $1 / 1$ or $1 / \mathrm{s}$ [22]; finally, Jorm and his team found that, at ages 13-14 years and 15-16 years, the $1 / 1$ genotype was associated with higher anxiety [23].

Among studies on adult samples, most of them yielded positive results about the association between the s allele and anxiety related temperamental traits [24-32]. Recently, to assess the statistical strength of the relationship between SERTPR gene and anxious personality traits, Schinka and colleagues conducted a metaanalysis of 26 studies of various ethnic groups. They found that the genotype has a small but reliable influence on anxiety traits, but only when measured with a Neuroticism scale based on the fivefactor model of personality [33]. Another meta-analysis on 23 studies achieved the same results: the association between SERTPR $s$ variant and increased Neuroticism scores as measured by the NEO Personality Inventory was found [34].

Gene-gene interaction is a biological mechanism that is poorly considered in psychiatric genetic studies [35]. This is mainly due to the statistical problems that arise when considering more than one polymorphism at time in different loci. However both linear [36] and non linear [37] methods have been proposed to deal with such issue. Using linear methods, Szekely and colleagues observed a significant interaction between the SERTPR and the dopamine D4 receptor gene DRD4 VNTR for the dimension of Harm Avoidance: subjects homozygous for the $\mathrm{s}$ allele and carriers of the 7 repeat DRD4 genotype showed higher Harm Avoidance scores than the other groups [38]. On the other hand, several studies failed to replicate the previous results [39-47].

To our knowledge, there is no evidence for associations between SERT and personality disorders, with the exception of a recent study by Jacob and colleagues in which Authors found differences for SERTPR genotype distribution among patients with a cluster $\mathrm{C}$ diagnosis: as expected, carriers of s allele exhibited higher Neuroticism scores than non-carriers [48].

In conclusion, we can assume the existence of a certain influence of SERTPR short variant on anxiety related traits. The lack of unequivocal results may be due to several factors, such as the sample, for its heterogeneous composition in terms of gender, age and ethnicity, the small number of subjects for each study, the use of different personality scales, like the TPQ, the TCI, the NEO-PI-R, the NEO Five Factor Inventory (NEO-FFI) and the Karolinska Scales of Personality (KSP). Future studies should better investigate homogeneous and large populations and compare different personality scales, pointing out the relationships between the sub-scales of the several tests.

\section{ANXIETY AND MOOD DISORDERS}

Psychiatric disorders are complex diseases with both genetic and environmental components interacting in a complex and unknown way [49]. In the last years we dropped the hypothesis of a single gene causing psychiatric disorders. Complex phenotypes such as Affective Disorders or Schizophrenia recognize multiple susceptibility genes not easy to identify [50,51]. The current approach is represented by the multifactorial inheritance of psychiatric disorders, which also implies that disorders may share susceptibility loci for multiple regions of the genome [52]. Another factor that contributes to increase the complexity of this field is the fact that the genes implicated in psychiatric disorders may predispose to a variety of phenotypical features, not strictly pathological. It has been therefore suggested that the existing data may best fit a model in which different set of genes predispose to overlapping pheno- 
types that are in part both quantitative and dissimilar in nature $[53,54]$. This fact generates a large number of studies in which positive and negative associations followed one another; consequently, having a wide-ranging and comprehensive view is a difficult target.

\section{Anxiety Disorders}

Susceptibility genes findings for anxiety disorder have been recently reviewed. Both genetic and environmental factors are reported to influence normal anxiety traits as well as anxiety disorders $[55,56]$.

Studies on SERTPR knock-out mice showed that behavioral phenotyping function in knock-outs revealed genetic backgroundrelated abnormalities, including increased anxiety-like behaviors, reduced aggression, and exaggerated stress responses [57-60].

To date, researches carried out on humans are controversial regarding the role of SERT in Obsessive Compulsive Disorder (OCD) [61-64], while, for what concerns Panic Disorder (PD), results are mainly negative [65-68], with the exception of a SPECT study, in which patients with current PD showed a significant decrease in SERT binding in the midbrain, in the temporal lobes and in the thalamus, in comparison to controls. These findings allow to hypothesize an involvement of SERT in PD [69]. Further researches are required to investigate this relation.

You and colleagues reported an increased risk for Generalized Anxiety Disorder (GAD) associated with the SERTPR s/s genotype. In their work they found the frequency of the s allele, as well that of the s/s genotype, significantly higher in GAD patients than in control subjects. On the contrary patients and controls were not statistically different for the genotypic and allelic distribution of VNTR polymorphism [70]. However, in a previous Single Photon Emission Computed Tomography (SPECT) study, other Authors did not found positive results regarding differences in binding properties of SERT in brains of patients with GAD, compared to healthy subjects. This negative finding could probably be due to the extremely small sample (7 patients with GAD and 7 matched healthy volunteers) [71].

In a recent study the possible association between Post Traumatic Stress Disorder (PTSD) and SERTPR was examined and the frequency of the $\mathrm{s} / \mathrm{s}$ genotype was found significantly higher in PTSD patients than in normal controls [72].

Finally, in an innovative study the relation between SERTPR and VNTR polymorphisms and compulsive buying was assessed: no significant differences were seen for either polymorphisms among the compulsive buyers [73]. Further studies are required but it should be noted that personality features may also influence the observed associations with anxiety phenotypes.

\section{Psychosomatic Disorders}

The serotonin transporter gene seems to be linked also with several psychosomatic disorders. Park and colleagues, for example, found an excess of the $\mathrm{s}$ allele and $\mathrm{s} / \mathrm{s}$ genotype in patients with Chronic Tension-type Headache (CTH). Moreover, patients with CTH had significantly higher scores on anxiety related personality traits than controls [74].

In another recent study a strong genotypic association was observed between the $\mathrm{s} / \mathrm{s}$ genotype and the diarrhoea predominant Irritable Bowel Syndrome phenotype (dIBS), suggesting that the SERT is a potential candidate gene for dIBS in women [75].

Also Fibromyalgia (FM) seems to be modulated by SERT: in two studies a higher frequency of the s/s genotype in FM patients, compared with healthy controls, was observed. The s/s subgroup exhibited higher mean levels of depression and psychological distress [76,77]. Nevertheless Gursoy did not replicate this finding for both SERTPR and VNTR polymorphisms [78].
All this positive results suggest a connection between the serotonin transporter and psychosomatic disorders. Further studies are required to understand in depth this topic.

\section{Mood Disorders}

Dysfunctions of the serotonin system, in particular a disturbed serotonin transport, have been largely hypothesized in Affective Disorders [79]. Similar results have been achieved in animal samples $[58,80,81]$. The functional SERTPR polymorphism was firstly associated with both Major Depressive (UP) and Bipolar disorders (BP) by Collier and colleagues [82]. These Authors found the frequency of the s variant to be higher in patients than in controls, as well as the frequency of the homozygous s/s genotype.

After this pioneering work, the SERTPR, and also the VNTR polymorphism, were largely studied. However, results of association studies examining UP or BP have been controversial. To sum up the literature status, recent meta-analyses $[83,84]$ and reviews $[85,86]$ focused on this argument. Lotrich and his group carried out a meta-analysis on 48 association studies and 9 Transmission Disequilibrium Tests (TDT) studies. Their primary finding is that the effect of the s/s genotype was significant for the UP patients, even if the association was small. A similar trend was found in BP patients, although the result did not reach statistical significance. No consistent associations for the VNTR polymorphism were found. Lasky-Su and colleagues, in their meta-analysis on case-control studies resulting in four meta-analyses, found the s allele of the SERTPR polymorphism slightly but significantly associated with $\mathrm{BP}$, but not with UP. Regarding the VNTR variants, an increase in the number of tandem repeats had no significant association with any of the disorders.

Different methodologies of analysis may explain those slightly discrepant findings, however the association between the s allele of SERTPR and Mood Disorders is ascertained, although is not clear whether it is more marked in UP or BP affective disorders. On the contrary, the role of VNTR polymorphism remains still unclear.

\section{Symptomatology}

We [87] investigated the potential involvement of SERTPR in depressive symptomatology. Psychiatric inpatients affected by UP and BP disorders were considered. SERTPR variants were not associated with total depressive symptomatology, as measured by the 21 items Hamilton Rating Scale for Depression (HAM-D). However, the s variant was marginally associated with higher psychic anxiety scores, especially among BP patients and those characterized by an early onset. In another study by our group, SERTPR variants were not associated with four symptomatologic factors (Mania, Depression, Delusion and Disorganization) [88], but this analysis did not cover anxiety features.

Thus, the SERTPR gene does not appear to be associated with depressive symptomathology per se, as well as other symptomatologic cluster of Mood Disorders other than anxiety.

\section{Age at onset}

Our groups found BP s/s patients having an earlier age at onset and a lower recurrence of illness than $1 / 1$, with $1 / \mathrm{s}$ patients showing intermediate values. A marginally significant trend toward the same difference in recurrence was observed in UP patients, with no differences in age at onset [89]. Similarly, Bellivier and colleagues found patients carrying the $\mathrm{s} / \mathrm{s}$ genotype to begin their illness slightly earlier than other patients; at the opposite, patients carrying at least one VNTR Stin2.12 allele developed Mood Disorders later [90]. Golimbet and colleagues tested the role of SERT in late-onset depression (LOD) and early-onset depression (EOD). Considering genotype frequency distribution of the two SERT polymorphisms, LOD and EOD patients did not differ from each other and from a control group [91]. 
A recent study seems to confirm the extension of these results to depressed patients [92]: in a children sample, excess of the s allele, as well as the $\mathrm{s} / \mathrm{s}$ genotype, were found among major depressed children. The family-based results suggested that the $\mathrm{s}$ allele was preferentially transmitted to depressed children.

Summing up, the connection between early onset in BP patients and the $\mathrm{s}$ variant of SERTPR seems to be stronger than in UP patients. Other studies are crucial to understand if this link could be extended to UP patients and to replicate the association between SERT variants and illness recurrence.

As previously reviewed, hippocampal volume may be a mediating factor as late-onset $1 / 1$ depressed exhibited smaller hippocampal volumes compared with other groups [12]. Therefore, hippocampal volumes could be considered in future studies on age at onset in Mood Disorders.

\section{Rapid cycling and Antidepressant-Induced Mania}

The rapid cycling pattern, i.e. high depressive and/or manic episodes recurrence, is defined by at least four affective episodes during one year period by the DSM-IV [93].

We observed a significant association of rapid cycling patients with SERTPR 1 allele [94]. On the opposite a French group observed that the s allele was associated with lifetime history of rapid cycling [95]. To our knowledge there are no other studies about rapid cycling and SERTPR. However rapid cycling may also be induced by the use of antidepressant drugs [96], therefore the switch from depression to mania has been studied by some groups.

Mundo and her group originally reported that subjects with at least one manic or hypomanic episode induced by treatment had an excess of the s allele [97]. Though we could not replicate the finding [98], others observed the same excess of s allele in subjects with lifetime history of Antidepressant-Induced Mania (AIM) in bipolar and unipolar patients $[95,99]$.

Another study focused on the relation between the risk of AIM and patient age [100]. The age of patients may modulate the risk of AIM. Treatment with antidepressants is associated with highest conversion hazards among children aged 10 to 14 years. An indirect correlation with age at onset is therefore possible. For that reason the rapid cycling question requires future studies to understand if the association subsists for the $\mathrm{s}$ or the 1 variant and what part patient age plays.

\section{Antidepressant Response}

The serotonin transporter is the site of action of many antidepressants, the so called Selective Serotonin Reuptake Inibitors (SSRIs) antidepressants. A consistent number of studies, recently reviewed by our group, confirmed the association of the SERTPR $\mathrm{s}$ variant with a poorer response to SSRI (fluvoxamine, paroxetine, citalopram, sertraline and fluoxetine) at least in Caucasian samples [101]. Previous studies found that depressed inpatients heterozygous and homozygous for the 1 variant showed a better antidepressant response than homozygous for the s variant to serotoninergic, but not noradrenergic, drug treatments [102-104]. L/l patients also showed a better response to total sleep deprivation, a current nonpharmacological effective treatment for BP [105].

To sum up, consideration of another original study is essential. Hanna and colleagues found SERT-linked polymorphic region having a significant effect on blood serotonin content: a significant interaction between SERTPR and seasonal variation in blood serotonin content was found, with significant seasonal differences in serotonin levels, higher only in subjects with the $1 / 1$ genotype [106]. Consequently, the s allele might lead to a "higher stability" of serotonin function and this stability could manifest both with a lower illness recurrence in s/s patients and with a lower antidepressant response to 5-HT enhancing treatments. If this hypothesis is true, the 1 variant might be related to rapid cycling and a pattern of instability, like stated by our group [94]. Future researches are necessary to solve the matter even because other contradictory evidence has been reported.

\section{Side Effects}

Concerning the role of SERT in side effects of pharmacological treatments, to our knowledge, there are few reports in literature. One study focused on the association between three serotonergic polymorphisms (SERTPR, VNTR in the Stin2 and a polymorphism within the Tryptophan Hydroxylase gene, TPH-A218C), which have all been reported as potentially associated with response to SSRIs, and the occurrence of nausea, which is the most frequent side effect induced by SSRIs, in patients treated with fluvoxamine. The study reported negative finding, suggesting that the incidence of fluvoxamine-induced nausea is not in relation with the considered serotoninergic polymorphisms [107]. Another study, on the other hand, suggested a possible association with side effects of mirtazapine and paroxetine [108].

\section{Life Events}

Recently, a gene-by-environment interaction model has been developed and it postulates that the individual's response to stressful life events is moderated by the individual's genetic makeup.

The SERTPR was found to moderate the influence of stressful life events on depression by Caspi and collaborators [109]. Individuals with one or two copies of the s allele exhibited more depressive symptoms, diagnosable depression and suicidal risk in relation to stressful life events than individuals homozygous for the 1 allele. Eley and colleagues replicated the previous result on a sample of adolescents and found a trend for a similar effect of SERTPR [110]. Gillespie and collaborators were not able to replicate previous results, probably because they used a sample of older subjects than Caspi [111]. Kendler and his group replicated and extended prior findings: they found individuals homozygous for the $\mathrm{s}$ variant more sensitive to the depressogenic effects of stressful life events; moreover, $\mathrm{s} / \mathrm{s}$ individuals had an increased sensitivity to the impact of mild stressors [112]. Finally, we recently replicated the finding in a mood disorder sample with retrospective assessment [113].

This fresh branch of studies needs replication of these intriguing results but the positive outcomes obtained up till now are yet promising.

\section{SUICIDE}

Courtet and his group reviewed the literature on suicide and found a positive association between the $\mathrm{s}$ allele of the SERTPR polymorphism and violent suicidal behavior, possibly mediated by personality aspects. On the contrary, they did not found any positive results about the VNTR polymorphism [114]. Also in another recent review the insertion/deletion polymorphism of the SERTPR did not seem to be involved in general suicidal behaviour but in violent and repeated suicide attempts [115]. After the publication of these works other studies have been carried out, with mainly negative results [116-119]. Further studies are required to better understand this topic.

\section{SUBSTANCE ABUSE DISORDERS \\ Cigarette Smoking}

$\mathrm{Li}$ and collaborators reviewed the genes potentially involved in smoking related behaviors [120] and they asked for further studies investigating SERT gene, to determine whether it plays a significant role in smoking behavior or not. Following the review publication, two other studies still obtained controversial results. Kremer and his group found a significant excess of the SERTPR 1 allele with the 12-repeat VNTR in smokers, compared to participants who had never smoked. Results suggested that this gene influences the initiation of smoking, even independently of Novelty Seeking personality traits, which did not mediate the effect of SERT on smoking in this sample [121]. 
In a second study on adolescents, the s/s genotype frequency was significantly higher among smokers compared with nonsmokers. The $\mathrm{s} / \mathrm{s}$ genotype frequency was significantly higher among heavy smokers with early onset, compared with moderate smokers with late onset [122].

\section{Alcohol}

At present, a bond between alcoholism and the serotoninergic system, in particular the serotonin transporter, is quite established, also in non-human primates sample [123]. In the 1998 a significant reduction in the availability of SERT was found in an alcoholic sample [124]. In alcohol dependent patients, a high frequency of the $\mathrm{s}$ allele was firstly found by Hammoumi [125]. After these pioneering studies, many works followed and currently meta-analyses and reviews are available. In a recent meta-analysis, conducted on 17 published studies, the frequency of the s allele resulted significantly associated with alcohol dependence [126]. Other recent reviews confirm the consistency of this association [127,128]. Nevertheless, a study showed a dissimilar result: alcoholism and low level of response to alcohol (LR), a phenotype that mediates the risk for alcohol abuse, resulted both significantly related to the 1 allele [129].

We previously described some attempt to investigate gene interactions; in this field, Herman and collaborators hypothesized that a significant gene-gene interaction would stratify the risk of binge drinking and assessed both monoamine oxidase type A (MAO-A) VNTR polymorphism and the SERTPR one. Women carrying higher expression MAO-A VNTR allele, homozygous for the $\mathrm{s}$ SERTPR variant, demonstrated the highest rate of binge drinking, while those carrying higher expression MAO-A VNTR allele carrying at least one 1 SERTPR variant had the lowest risk of binge drinking [130].

Therefore, alcoholism seems strongly related to genes involved in the serotonin processing, particularly to s allele of SERTPR; nevertheless, the LR phenotype and its link with the 1 form have to be further investigated.

\section{Ecstasy}

Ecstasy is the colloquial name for 3,4-methylenedioxymethamphetamine (MDMA). Neurotoxic effects of MDMA on the serotonin system have been widely described in humans [131-136]. Functional imaging studies reported decreased availability of the serotonin transporter in different brain regions of MDMA users, supporting the hypothesis of MDMA-induced protracted alterations of the serotonergic system [137-140]. In particular, a recent study found that SERT availability in current MDMA users was significantly reduced in the mesencephalon, thalamus, left caudate, hippocampus, occipital cortex, temporal lobes, and posterior cingulate gyrus compared with all other groups. The reduction resulted more pronounced in female than in male subjects [141].

For what concerns the SERTPR polymorphism, Roiser and colleagues found that MDMA use was associated with higher Beck Depression Inventory score and abnormalities in the Affective Go/No-Go test in individuals with $\mathrm{s} / \mathrm{s}$ and $1 / \mathrm{s}$ genotype but not in those homozygous for the 1 variant. Therefore, MDMA users carrying the s allele showed abnormal emotional processing [142].

In conclusion, it is possible to assume that chronic MDMA use may cause long-term changes to the serotonin system, and that MDMA users carrying the s allele may be at particular risk for emotional dysfunction.

\section{Cocaine}

High affinity binding of the cocaine analogue $\left[{ }^{125}\right.$ I]RTI-55 to the SERT sites in human brain has been demonstrated [143]. Moreover changes in SERT have been reported in neuroimaging and post-mortem studies of cocaine abusers [144,145].
There are relatively limited published data on the relation between cocaine abusers and the SERT polymorphisms. Patkar and colleagues investigated whether SERTPR and VNTR polymorphisms confer susceptibility to cocaine dependence and did not observed any relationship [146,147]. Moreover, the same authors, examining the reduced platelet SERT densities in cocaine dependents, found that allelic variations in the serotonin transporter promoter region do not seem to influence levels of platelet SERT in cocaine-dependent patients or healthy volunteers [148]. Consequently, further studies involving larger samples are required.

\section{Heroin}

There are few and fragmented results in literature about the link between heroin dependence and the SERT polymorphisms. Tan and collaborators found evidence for the association between heroin dependence and the VNTR polymorphism [149]. On the contrary, no association was found between the SERTPR polymorphism and heroin addiction in two further researches $[150,151]$. Nevertheless, in a recent study the $\mathrm{s} / \mathrm{s}$ genotype was significantly higher among heroin dependent individuals, compared with control subjects, and it was significantly higher among violent heroin dependent individuals, compared with addicted individuals without aggressive behavior. These last results suggest that the s variant may be associated with an increased risk for substance use disorders, mostly in subjects with more consistent aggressiveness and impulsiveness [152]. Moreover, Szilagyi and colleagues assessed the interaction between the dopamine receptor DRD4 polymorphism (-521 C/T SNP) and the SERTPR polymorphism and found an interaction between them. Association between the $-521 \mathrm{CC}$ vs. CT or TT genotypes and heroin dependence was enhanced in the presence of SERTPR s allele. This intriguing result emphasizes the importance of combined analysis of polymorphisms in the serotonergic and dopaminergic systems in heroin dependence [153]. However, further studies are necessary to replicate and extend these results.

\section{EATING DISORDERS}

A recent review enlightened the SERT important role in eating disorders: the s allele could represent a moderate but significant risk factor for anorexia nervosa [154].

Following studies obtained positive results and extended the findings to other eating disorders: firstly, the s allele frequency was found significantly higher in subjects with anorexia nervosa than in controls [155]; secondly, in a sample of women with bulimia spectrum syndromes, carriers of the s allele showed significantly more affective instability, behavioral impulsivity, interpersonal insecurity, comorbidity with borderline personality disorder and lower density (Bmax) of paroxetine-binding sites [156].

Finally, in a recent study Urwin and colleagues provided evidence in support of interaction between the MAO-A and SERT genes in anorexia nervosa. The s variant of the SERTPR was preferentially transmitted to children with anorexia nervosa and restricting anorexia nervosa when the more active MAO-A gene variant was also transmitted. The increased risk of developing the disorder is up to eight times greater than the risk imposed by the MAO-A gene variant alone [157].

Consequently, further researches about eating disorders, serotonin transporter polymorphisms and gene-gene interaction are required.

\section{ATTENTION DEFICIT HYPERACTIVITY DISORDER}

The Attention Deficit Hyperactivity Disorder (ADHD), characterized by marked and pervasive inattention, over-reactivity and impulsiveness, is highly heritable but is likely a complex disorder involving multiple genes of moderate effect [158].

Bobb and his team reviewed all ADHD studies and found evidence for association for four genes, including SERT, thought the 
candidate gene approaches continue to face the problem of relatively low power [159]. Evidence for the association between SERT and ADHD was found in another recently published review [160].

\section{AUTISM}

Among candidate genes contributing to Autism Spectrum Disorder (ASD) susceptibility, the serotonin transporter seems to have a role in the modulation of the disorder. In two recent reviews on autism the role of SERTPR gene appears to be consistent, even if studies are far from being complete and further investigation are required $[161,162]$. Nevertheless Bartlett and colleagues stated that the SERTPR may not be the most important of the polymorphisms in SERT and it could be merely in linkage disequilibrium with another risk allele. Authors underlined the need to investigate the role of other proteins capable of transporting serotonin across the membrane, such as the organic cation transporters (OCT1, OCT3 and OCT2) [161].

\section{SCHIZOPHRENIA}

The SERT gene is a candidate for schizophrenia. Nevertheless, association studies have produced conflicting results regarding the association between SERTPR and VNTR polymorphisms and schizophrenia susceptibility. A recent meta-analysis, based on association studies published before April 2004, was performed. The study showed no statistically significant evidence for the connection between the $\mathrm{s}$ variant of the SERTPR and schizophrenia. On the other hand, an association with the Stin2.12 allele of the VNTR polymorphism was observed [163]. Conversely, in a previous review the role of the SERTPR polymorphism was stated [164].

Further association studies obtained conflicting results: Pae and collaborators investigated the potential interaction of the serotonin receptor gene 2A and SERTPR polymorphisms in the development of schizophrenia, as well as in symptomatology, family history, age at onset and antipsychotic response, and they found that SERTPR may not contribute to schizophrenia susceptibility as well as other clinical factors [165]; in a second study an excess of transmission of 1 allele of SERTPR was detected in a sample of schizophrenic patients [166].

Moreover, in a PET study on serotonin transporter availability in patients with schizophrenia and matched controls, no alterations were found in patients with schizophrenia [167].

Therefore, other replication studies are needed to ascertain the association of both SERTPR and VNTR with the susceptibility to schizophrenia.

\section{Symptomatology}

Also the subtypes and the symptomatology features of schizophrenia were analyzed in relation to SERT polymorphisms. Firstly, the schizophrenia subtypes were assessed: patients with schizoparanoid schizophrenia were more frequently homozygous for the Stin2.12 allele than controls and all other schizophrenic patients; on the contrary, the Stin2.9 allele represented a risk factor for residual schizophrenia. Moreover, schizo-affective patients were more frequently homozygous for the 1 allele than other schizophrenic patients and controls [168].

Pae and colleagues found significant differences in the negative score and general psychopathology score of the positive and negative syndrome scale according to SERTPR genotypes in a Korean sample [169].

Patients with the s/s genotype scored significantly higher on "Guilt feelings" and "Depression" items, as compared with homozygous for the 1 genotype [170] and suffered of more distress for auditory hallucinations [171], accordingly with previously described studies on Mood Disorders and anxiety related traits.

In a Korean sample of patients with schizophrenia all episodes of aggression from the last discharge to readmission were rated using the Overt Aggression Scale (OAS). Authors found a statistically significant association between SERTPR 1/1 genotype and higher mean total score of all episodes of aggression [172].

Finally, the $\mathrm{s}$ allele of SERTPR was related to a significant decrease of the scores of delusions, disorganization and negative symptoms among subjects having the TPH genotype AA and was also related to an increase in scores among subjects having the TPH genotype AC, yielding the highest scores for the combinations AA $\mathrm{x} 1 / 1$ and $\mathrm{AC} \times \mathrm{s} / \mathrm{s}$. Schizophrenia subjects had significantly higher frequencies of $\mathrm{AA} \times \mathrm{x} 11$ and of $\mathrm{AC} \mathrm{x}$ ss. Thus, an interaction between TPH and SERTPR genes may constitute susceptibility to schizophrenia, yielding an apparent correlation between symptomatology and genotype [173].

\section{ALZHEIMER AND PARKINSON DISEASES}

The etiology of late onset Alzheimer Disease (AD) and Parkinson Disease (PD) is not known [174]. In both disorders there is an extensive degeneration of serotoninergic neurons, with losses of SERT. A review of association studies on the link between both AD and PD and SERT has been carried out [175]. The studies showed that the low-activity allele of the SERTPR was a risk factor for lateonset AD. Nevertheless, also several negative studies were published [176-179]. On the other hand, the 1 allele and the $1 / 1$ genotype were found to be significantly associated with aggressive behavior in patients with $\mathrm{AD}[180]$ and with the risk for the combined psychotic symptoms and $\mathrm{AD}$ with the aggressive phenotype [181]; also in this case negative studies were published as well $[179,182]$. Finally, in PD, the SERTPR influences the risk of developing depression, a common symptom in PD patients $[175,183]$.

\section{CONCLUSIONS}

This impressive list of effects (summarized in Table 1), some of which widely replicated, suggests that SERT gene variants exert a broad effect on many aspects of the human behavior, in both its normal and pathological expressions. Though at the present time we do not have firm and definitive evidence, as methodological problems and controversies remain and further both biological and behavioral issues are still unexplored, we may provisionally hypothesize a model to combine the several data acquired by the extensive and intensive research on SERTPR in the last decade.

Thus, considering together the main results obtained on SERTPR, a carrier of the short variant may be hypothesized to be iper-reactive to negative stimuli (amygdala iper-reactivity) and thus to be more exposed to Anxiety Disorders and/or to be more likely characterized by anxious personality traits. Being more sensitive to depressogenic effects of stressful life events, as demonstrated, this person would be at risk for Mood Disorders or Alcoholism. In particular, if he/she develop a Mood Disorder, he/she would be young at the onset, he/she subsequently have a low number of episodes, but he/she would show a poor response to pharmacotherapy. It is possible to hypothesize that the amygdala iper-activity represents the origin of the others phenotypes and, consequently, it leads to elevated sensitivity to stressful life events and expose the individual to develop a Mood Disorder early in his/her life, Anxiety Disorders, Psychosomatic Disorders and/or Alcoholism.

Considering all the features modulated by the short allele, the $\mathrm{s}$ allele "high stability" hypothesis would account for the low illness recurrence and the poor antidepressants response.

A person carrier of the long variant is hypothesized to exhibit a more regular amygdala neuronal activity in response to fearful stimuli, to be not particularly anxious and less sensitive to stressful life events. Moreover, he/she would have a lower risk for Mood, Anxiety and Psychosomatic Disorders and Alcoholism than s/s subjects. On the other hand, the $1 / 1$ child would have a higher risk to develop the Attention Deficit Hyperactivity Disorder. Furthermore, if an $1 / 1$ subject develops a Mood Disorder, he/she would probably experience a higher recurrence of affective episodes than $\mathrm{s} / \mathrm{s}$ 
Table 1. Positive and Negative Results About the Features Modulated by SERTPR that have been Cited in the Text, we Followed the Order of Presentation in the Text. SERTPR s Allele or s Containing Genotype is the Risk Factor where not Alternatively Specified

\begin{tabular}{|c|c|}
\hline FEATURES MODULATED BY SERTPR & POSITIVE AND NEGATIVE STUDIES \\
\hline \multicolumn{2}{|l|}{ NEUROANATOMIC SITES } \\
\hline Hippocampal volume & ++ \\
\hline Amygdala response & ++ \\
\hline \multicolumn{2}{|l|}{ ANXIOUS PERSONALITY TRAITS } \\
\hline Infants & +++ \\
\hline Infants $(1 / 1)$ & +++ \\
\hline Adults & $++++++++++* *+\ldots \ldots$ \\
\hline Cluster $\mathrm{C}$ diagnosis & + \\
\hline \multicolumn{2}{|l|}{ ANXIETY DISORDERS } \\
\hline Obsessive Compulsive Disorder & --++ \\
\hline Panic Disorder & - - - - \\
\hline Generalized Anxiety Disorder & + \\
\hline Post Traumatic Stress Disorder & + \\
\hline Compulsive Buying & - \\
\hline \multicolumn{2}{|l|}{ PSYCHOSOMATIC DISORDERS } \\
\hline Chronic Tension-type Headache & + \\
\hline Diarrhoea Irritable Bowel Syndrome phenotype & + \\
\hline Fibromyalgia & ++- \\
\hline \multicolumn{2}{|l|}{ MOOD DISORDERS } \\
\hline Major Depressive Disorder & $+* *$ \\
\hline Bipolar Disorder & $+* * *$ \\
\hline Total depressive symptomatology & - \\
\hline Psychic anxiety symptomatology & + \\
\hline Depression, Mania, Delusion and Disorganization symptomatologic factors & - \\
\hline Early age at onset & ++-+ \\
\hline Lower illness recurrence & + \\
\hline Rapid cycling (1 or s allele) & ++ \\
\hline Antidepressant induced mania & +-++ \\
\hline Better response to serotoninergic treatments ( 1 allele) & $*+++$ \\
\hline Better response to total sleep deprivation (1/1) & + \\
\hline Side effects (nausea) & - \\
\hline Stressful life events & ++-++ \\
\hline SUICIDE & $* * \ldots+$ \\
\hline
\end{tabular}


(Table 1) contd....

\begin{tabular}{|c|c|}
\hline FEATURES MODULATED BY SERTPR & POSITIVE AND NEGATIVE STUDIES \\
\hline \multicolumn{2}{|l|}{ SUBSTANCE ABUSE DISORDERS } \\
\hline Cigarette (1 allele) & $\#+$ \\
\hline Cigarette & $\#+$ \\
\hline Alcohol & $+* * *+$ \\
\hline Alcohol (1 allele) & + \\
\hline Ecstasy & + \\
\hline Cocaine & -- \\
\hline Heroin & +--++ \\
\hline \multicolumn{2}{|l|}{ EATING DISORDERS } \\
\hline Anorexia Nervosa & $*++$ \\
\hline Bulimia Nervosa & + \\
\hline ATTENTION DEFICIT HYPERACTIVITY DISORDER & $* *$ \\
\hline AUTISM & $* *$ \\
\hline \multicolumn{2}{|l|}{ SCHIZOPHRENIA } \\
\hline Diagnosis & $* *_{-}+$ \\
\hline Schizo-affective subtype & + \\
\hline Symptomatology & -++++ \\
\hline ALZHEIMER DISEASE & $* \ldots+\ldots+\ldots$ \\
\hline PARKINSON DISEASE & $*+$ \\
\hline
\end{tabular}

(+: Positive study; - : Negative study; * : Positive results Meta-analysis or Review; \# : Negative results Meta-analysis or Review).

patient, however, he/she would likely gain benefit from pharmacotherapy.

Also for the 1 carrier it is possible to hypothesize a phenotypic model: firstly, the lower amygdala reactivity to negative stimuli would lead to less anxiety, lower sensitivity to stressful life events and, if the person is predisposed to, a postponed development of a Mood Disorder, compared to that of an s/s subject similarly predisposed to Mood Disorders by other means. This lower amygdala reactivity would represent the reason of the lower risk for Anxiety and Psychosomatic Disorders, Alcoholism, Anorexia Nervosa and Suicide. The 1 allele "higher instability" hypothesis explains the high illness recurrence, the rapid cycling pattern and the good response to antidepressants.

But, in an evolutionary perspective, why should short alleles exist given the large number of detrimental effects they cause? A possible answer comes from a recent study which focused on social functioning of s carriers [184]. Though the global adjustment is lower for $\mathrm{s}$ carriers due to their disadvantage, in analogy to other researchers [185], they have a better functioning in family and working areas. This could be due to their more 'anxious' temperament that makes them follow family and working rules more appropriately. In an evolutionary sense, those subjects would have been more keen to the 'team' in ancient human societies, thus favoring their gene transmission.

We should remember to the reader that we here summarized data of literature and we then simply built phenotypic models, basing our observations on the reported results, which are however provided by a large number of studies, often conflicting and methodologically different, each planned for specific aims and each performed employing particular human samples, which are different in each study for a number of features, such as sex rates, age of participants, ethnic origins, psychiatric disorders and more. No mathematical analysis was performed to test our hypothesis. Only a large database with a number of clinical features would allow this to be performed. Moreover, we hypothesized correlations among different phenotypic aspects on the basis of their linear association with the serotonin transporter gene, but we do not have evidence that such phenotypes actually correlated with each other. An intriguing field of research could be focused on this issue, testing cooccurring features influenced by the serotonin transporter gene or other genes that modulate such broad systems.

In conclusion, summarizing the huge amount of studies on a topic could be advantageous, as potentially helpful to gain a comprehensive view of a complex argument, to address innovative investigations and acquire new data. It is in fact now generally believed that only widening the search of liability genes to very broad phenotypes we could understand their effect [54]. We thus here also suggested a simple methodology to resume focused data in complex phenotypic models, as a starting-point for future researches on the role of crucial genes in modulating complex human behaviors.

\section{REFERENCES}

[1] Rang, H.P., Dale, M.M., Ritter, J.M., Moore, P.K. Pharmacology (V ed.). Edinburgh: Churchill Livingstone, 2003. 
[2] Aghajanian, G.K., Sanders-Bush, E. Serotonin, in Neuropsychopharmacology: the fifth generation of progress. Davis, KL, Charney D, Coyle JT, Nemeroff C, eds. Philadelphia: Lippincott Williams \& Wilkins, 2002, pp. 15-34.

[3] Davis, K.L., Charney, D., Coyle, J.T., Nemeroff, C. Neuropsychopharmacology: the fifth generation of progress. Philadelphia: Lippincott Williams \& Wilkins, 2002.

[4] Oquendo, M.A., Placidi, G.P., Malone, K.M., Campbell, C., Keilp, J., Brodsky, B., Kegeles, L.S., Cooper, T.B., Parsey, R.V., van Heertum, R.L., Mann, J.J. (2003) Arch. Gen. Psychiatr., 60(1), 1422.

[5] Clementi, Fumagalli. Farmacologia generale e molecolare: UTET, 1999.

[6] Lesch, K.P., Balling, U., Gross, J., Strauss, K., Wolozin, B.L., Murphy, D.L., Riederer, P. (1994) J. Neural. Transm. Gen. Sect., 95(2), 157-62.

[7] Ogilvie, A.D., Battersby, S., Bubb, V.J., Fink, G., Harmar, A.J., Goodwim, G.M., Smith, C.A. (1996) Lancet, 347(9003), 731-3.

[8] Heils, A., Teufel, A., Petri, S., Stöber, G., Riederer, P., Bengel, D., Lesch, P. (1996) J. Neurochem., 66(6), 2621-2624.

[9] Lesch, K.P., Bengel, D., Heils, A., Sabol, S.Z., Greenberg, B.D., Petri, S., Benjamin, J., Muller, C.R., Hamer, D.H., Murphy, D.L. (1996) Science, 274(5292), 1527-31.

[10] Kandel, E., Schwartz, J.H., Jessell, T.M. Principles of Neural Science. 4th edition ed. New York: McGraw-Hill, 2000.

[11] Frodl, T., Meisenzahl, E.M., Zill, P., Baghai, T., Rujescu, D., Leinsinger, G., Bottlender, R., Schule, C., Zwanzger, P., Engel, R.R., Rupprecht, R., Bondy, B., Reiser, M., Moller, HJ. (2004) Arch. Gen. Psychiatr., 61(2), 177-83.

[12] Taylor, W.D., Steffens, D.C., Payne, M.E., MacFall, J.R., Marchuk, D.A., Svenson, I.K., Krishnan, K.R. (2005) Arch. Gen. Psychiatr., 62(5), 537-44

[13] Hariri, A.R., Mattay, V.S., Tessitore, A., Kolachana, B., Fera, F., Goldman, D., Egan, M.F., Weinberger, DR. (2002) Science, 297(5580), 400-3.

[14] Hariri, A.R., Drabant, E.M., Munoz, K.E., Kolachana, B.S., Mattay, V.S., Egan, M.F., Weinberger, DR. (2005) Arch. Gen. Psychiatr., 62(2), 146-52.

[15] Cloninger, CR, Przybeck, TR, Svrakic, DM, Wetzel, RD. The temperament and character inventory (TCI): a guide to its development and use. St.Louis, Missouri: Center for Psychobiology of Personality Washington University, 1994.

[16] Costa, P., McCrae, R. Revised NEO Personality Inventory and NEO Five Factor Inventory professional manual, 1992

[17] Cattell, R. Handbook for the Sixteen Personality Factor Questionnaire, 1970.

[18] Lakatos, K., Nemoda, Z., Birkas, E., Ronai, Z., Kovacs, E., Ney, K., Toth, I., Sasvari-Szekely, M., Gervai, J. (2003) Mol. Psychiatr., 8(1), 90-7.

[19] Auerbach, J., Geller, V., Lezer, S., Shinwell, E., Belmaker, R.H., Levine, J., Ebstein, R.P. (1999) Mol. Psychiatr., 4(4), 369-373.

[20] Battaglia, M., Ogliari, A., Zanoni, A., Citterio, A., Pozzoli, U., Giorda, R., Maffei, C., Marino, C. (2005) Arch. Gen. Psychiatr., 62(1), 85-94.

[21] Arbelle, S., Benjamin, J., Golin, M., Kremer, I., Belmaker, R.H., Ebstein, R.P. (2003) Am. J. Psychiatr., 160(4), 671-6.

[22] Auerbach, J.G., Faroy, M., Ebstein, R., Kahana, M., Levine, J. (2001) J. Child Psychol. Psychiatr., 42(6), 777-83.

[23] Jorm, A.F., Prior, M., Sanson, A., Smart, D., Zhang, Y., Easteal, S. (2000) Mol. Psychiatr., 5(5), 542-7.

[24] Osher, Y., Hamer, D., Benjamin, J. (2000) Mol. Psychiatr., 5(2), 216-9.

[25] Greenberg, B.D., Li, Q., Lucas, F.R., Hu, S., Sirota, L.A., Benjamin, J., Lesch, K.P., Hamer, D., Murphy, DL. (2000) Am. J. Med. Genet., 96(2), 202-16.

[26] Samochowiec, J., Rybakowski, F., Czerski, P., Zakrzewska, M., Stepien, G., Pelka-Wysiecka, J., Horodnicki, J., Rybakowski, J.K., Hauser, J. (2001) Neuropsychobiology, 43(4), 248-53.

[27] Murakami, F., Shimomura, T., Kotani, K., Ikawa, S., Nanba, E., Adachi, K. (1999) J. Hum. Genet., 44(1), 15-7.

[28] Katsuragi, S., Kunugi, H., Sano, A., Tsutsumi, T., Isogawa, K., Nanko, S., Akiyoshi, J. (1999) Biol. Psychiatr., 45(3), 368-70.

[29] Jang, K.L., Hu, S., Livesley, W.J., Angleitner, A., Riemann, R., Ando, J., Ono, Y., Vernon, P.A., Hamer, DH. (2001) J. Pers. Soc. Psychol., 81(2), 295-304.
[30] Ricketts, M.H., Hamer, R.M., Sage, J.I., Manowitz, P., Feng, F., Menza, MA. (1998) Psychiatr. Genet., 8(2), 41-4.

[31] Melke, J., Landen, M., Baghei, F., Rosmond, R., Holm, G., Bjorntorp, P., Westberg, L., Hellstrand, M., Eriksson, E. (2001) Am. J. Med. Genet., 105(5), 458-63.

[32] Du, L., Bakish, D., Hrdina, P.D. (2000) Psychiatr. Genet., 10(4), 159-64.

[33] Schinka, J.A., Busch, R.M., Robichaux-Keene, N. (2004) Mol. Psychiatr., 9(2), 197-202.

[34] Sen, S., Burmeister, M., Ghosh, D. (2004) Am. J. Med. Genet., 127B(1), 90-3.

[35] Frankel, W., Schork, N. (1996) Nature Genetics, 14371-373

[36] Serretti, A., Cusin, C., Lattuada, E., Lilli, R., Lorenzi, C., Di Bella, D., Catalano, M., Smeraldi, E. (1999) Am. J. Med. Genet., 88(5), 481-5.

[37] Serretti, A., Smeraldi, E. (2004) BMC. Med. Genet., 5(1), 27.

[38] Szekely, A., Ronai, Z., Nemoda, Z., Kolmann, G., Gervai, J., Sasvari-Szekely, M. (2004) Am. J. Med. Genet., 126B(1), 106-10.

[39] Ebstein, R.P., Gritsenko, I., Nemanov, L., Frisch, A., Osher, Y., Belmaker, R.H. (1997) Mol. Psychiatr., 2(3), 224-6.

[40] Jorm, A.F., Henderson, A.S., Jacomb, P.A., Christensen, H., Korten, A.E., Rodgers, B., Tan, X., Easteal, S. (1998) Mol. Psychiatr., 3(5), 449-451.

[41] Flory, J.D., Manuck, S.B., Ferrell, R.E., Dent, K.M., Peters, D.G., Muldoon, MF. (1999) Mol. Psychiatr., 4(1), 93-96.

[42] Gustavsson, J.P., Nothen, M.M., Jonsson, E.G., Neidt, H., Forslund, K., Rylander, G., Mattila-Evenden, M., Sedvall, G.C., Propping, P., Asberg, M. (1999) Am. J. Med. Genet., 88(4), 430-436.

[43] Deary, I.J., Battersby, S., Whiteman, M.C., Connor, J.M., Fowkes, FGR, Harmar, A. (1999) Psychol. Med., 29(3), 735-739.

[44] Golimbet, V.E., Alfimova, V.M., Shcherbatykh, T.V., Abramova, L.I., Kaleda, V.G., Rogaev, E.I. (2001) Mol. Biology, 35(3), 336338.

[45] Brummett, B.H., Siegler, I.C., McQuoid, D.R., Svenson, I.K., Marchuk, D.A., Steffens, D.C. (2003) Psychiatr. Genet., 13(1), 13-8

[46] Gelernter, J., Kranzler, H., Coccaro, E.F., Siever, L.J., New, A.S (1998) Am. J. Psychiatr., 155(10), 1332-8.

[47] Serretti, A., Mandelli, L., Lorenzi, C., Landoni, S., Calati, R., Insacco, C., Cloninger, C.R. (2006) Neuropsychobiology, 53(1), 9-16.

[48] Jacob, C.P., Strobel, A., Hohenberger, K., Ringel, T., Gutknecht, L., Reif, A., Brocke, B., Lesch, K.P. (2004) Am. J. Psychiatr., 161(3), 569-72.

[49] Risch, N. (1990) Am. J. Med. Genet., 46, 222-228.

[50] Tsuang, M. (2000) Biol. Psychiatr., 47(3), 210-20.

[51] Tsuang, M.T., Faraone, S.V. (2000) Am. J. Med. Genet., 97(1), 1-3.

[52] Saugstad, L.F. (2003) Med. Hypotheses, 60(2), 181-7.

[53] Kelsoe, J.R. (2003) J. Affect. Disord., 73(1-2), 183-97.

[54] Kendler, K.S. (2005) Am. J. Psychiatr., 162(7), 1243-52.

[55] Arnold, P.D., Zai, G., Richter, M.A. (2004) Curr. Psychiatr. Rep., 6(4), 243-54.

[56] Gross, C., Hen, R. (2004) Neurotox. Res., 6(6), 493-501.

[57] Holmes, A., Murphy, D.L., Crawley, J.N. (2002) Psychopharmacology (Berl), 161(2), 160-7.

[58] Holmes, A., Murphy, D.L., Crawley, J.N. (2003) Biol. Psychiatr., 54(10), 953-9.

[59] Holmes, A., Lit, Q., Murphy, D.L., Gold, E., Crawley, J.N. (2003) Genes. Brain Behav., 2(6), 365-80.

[60] Gingrich, J.A. (2002) Curr. Drug Targets CNS Neurol. Disord., 1(5), 449-65

[61] Walitza, S., Wewetzer, C., Gerlach, M., Klampfl, K., Geller, F., Barth, N., Hahn, F., Herpertz-Dahlmann, B., Gossler, M., Fleischhaker, C., Schulz, E., Hebebrand, J., Warnke, A., Hinney, A. (2004) J. Neural. Transm., 111(7), 817-25.

[62] Chabane, N., Millet, B., Delorme, R., Lichtermann, D., Mathieu, F., Laplanche, J.L., Roy, I., Mouren, M.C., Hankard, R., Maier, W., Launay, J.M., Leboyer, M. (2004) Neurosci. Lett., 363(2), 154-6.

[63] Meira-Lima, I., Shavitt, R.G., Miguita, K., Ikenaga, E., Miguel, E.C., Vallada, H. (2004) Genes Brain Behav., 3(2), 75-9.

[64] Cavallini, M.C., Di Bella, D., Siliprandi, F., Malchiodi, F., Bellodi, L. (2002) Am. J. Med. Genet., 114(3), 347-53.

[65] Hamilton, S.P., Heiman, G.A., Haghighi, F., Mick, S., Klein, D.F., Hodge, S.E., Weissman, M.M., Fyer, A.J., Knowles, J.A. (1999) Psychiatr. Genet., 9(1), 1-6.

[66] Ishiguro, H., Arinami, T., Yamada, K., Otsuka, Y., Toru, M., Shibuya, H. (1997) Psychiatr. Clin. Neurosci., 51(5), 333-5. 
[67] Matsushita, S., Muramatsu, T., Kimura, M., Shirakawa, O., Mita, T., Nakai, T., Higuchi, S. (1997) Mol. Psychiatr., 2(5), 390-2.

[68] Deckert, J., Catalano, M., Heils, A., Di Bella, D., Friess, F., Politi, E., Franke, P., Nothen, M.M., Maier, W., Bellodi, L., Lesch, K.P. (1997) Psychiatr. Genet., 7(1), 45-7.

[69] Maron, E., Kuikka, JT., Shlik, J., Vasar, V., Vanninen, E., Tiihonen, J. (2004) Psychiatr. Res., 132(2), 173-81.

[70] You, J.S., Hu, S.Y., Chen, B., Zhang, H.G. (2005) Psychiatr Genet., 15(1), 7-11.

[71] Maron, E., Kuikka, J.T., Ulst, K., Tiihonen, J., Vasar, V., Shlik, J. (2004) Eur. Arch. Psychiatr. Clin. Neurosci., 254(6), 392-6.

[72] Lee, H.J., Lee, M.S., Kang, R.H., Kim, H., Kim, S.D., Kee, B.S., Kim, Y.H., Kim, Y.K., Kim, J.B., Yeon, B.K., Oh, K.S., Oh, B.H., Yoon, J.S., Lee, C., Jung, H.Y., Chee, I.S., Paik, I.H. (2005) Depress. Anxiety, 21(3), 135-9.

[73] Devor, E.J., Magee, H.J., Dill-Devor, R.M., Gabel, J., Black, D.W. (1999) Am. J. Med. Genet., 88(2), 123-125.

[74] Park, J.W., Kim, J.S., Lee, H.K., Kim, Y.I., Lee, K.S. (2004) Headache, 44(10), 1005-9.

[75] Yeo, A., Boyd, P., Lumsden, S., Saunders, T., Handley, A., Stubbins, M., Knaggs, A., Asquith, S., Taylor, I., Bahari, B., Crocker, N., Rallan, R., Varsani, S., Montgomery, D., Alpers, D.H., Dukes, G.E., Purvis, I., Hicks, G.A. (2004) Gut, 53(10), 1452-8.

[76] Offenbaecher, M., Bondy, B., de Jonge, S., Glatzeder, K., Kruger, M., Schoeps, P., Ackenheil, M. (1999) Arthritis. Rheum., 42(11), 2482-8.

[77] Cohen, H., Buskila, D., Neumann, L., Ebstein, R.P. (2002) Arthritis. Rheum., 46(3), 845-7.

[78] Gursoy, S. (2002) Clin. Rheumatol., 21(3), 194-7.

[79] Wurtman, R.J. (2005) Metabolism, 54(5 Suppl 1), 16-9.

[80] Lira, A., Zhou, M., Castanon, N., Ansorge, M.S., Gordon, J.A., Francis, J.H., Bradley-Moore, M., Lira, J., Underwood, M.D., Arango, V., Kung, H.F., Hofer, M.A., Hen, R., Gingrich, J.A. (2003) Biol. Psychiatr., 54(10), 960-71.

[81] Holmes, A., Yang, R.J., Lesch, K.P., Crawley, J.N., Murphy, D.L. (2003) Neuropsychopharmacology, 28(12), 2077-88.

[82] Collier, D., Stöber, G., Li , T., Heils, A., Catalano, M., Di Bella , D., Arranz, M., Murray, R., Vallada, H., Bengel, D., Müller-Reible, C., Roberts, G., Smeraldi, E., Kirov, G., Sham, P., Lesh, P. (1996) Mol. Psychiatr., 1(6), 453-460.

[83] Lasky-Su, J.A., Faraone, S.V., Glatt, S.J., Tsuang, M.T. (2005) Am. J. Med. Genet. B. Neuropsychiatr. Genet., 133(1), 110-5.

[84] Lotrich, F.E., Pollock, B.G. (2004) Psychiatr. Genet., 14(3), 121-9.

[85] Cho, H.J., Meira-Lima, I., Cordeiro, Q., Michelon, L., Sham, P., Vallada, H., Collier, D.A. (2005) Mol. Psychiatr., 1212.

[86] Moret, C. (2004) IDrugs, 7(6), 558-62.

[87] Serretti, A., Cusin, C., Lattuada, E., Di Bella, D., Catalano, M., Smeraldi, E. (1999) Mol. Psychiatr., 4(3), 280-283.

[88] Serretti, A., Lilli, R., Lorenzi, C., Lattuada, E., Cusin, C., Smeraldi, E. (2002) Mol. Psychiatr., 795-99.

[89] Smeraldi, E., Benedetti, F., Zanardi, R. (2002) Eur. Neuropsychopharmacol., 12(1), 73-5.

[90] Bellivier, F., Leroux, M., Henry, C., Rayah, F., Rouillon, F., Laplanche, J.L., Leboyer, M. (2002) Neurosci. Lett., 334(1), 17-20.

[91] Golimbet, V.E., Alfimova, M.V., Shcherbatykh, T.V., Rogaev, EI. (2002) Genetika, 38(5), 671-7.

[92] Nobile, M., Cataldo, M.G., Giorda, R., Battaglia, M., Baschirotto, C., Bellina, M., Marino, C., Molteni, M. (2004) Biol. Psychiatr., 56(4), 292-5.

[93] American Psychiatric Association. Diagnostic and Statistical Manual of Mental Disorders, 4th Edition. Washington DC: American Psychiatric Association, 1994.

[94] Cusin, C., Serretti, A., Lattuada, E., Lilli, R., Lorenzi, C., Mandelli, L., Pisati, E., Smeraldi, E. (2001) J. Psychiatric. Res., 35(4), $217-$ 223.

[95] Rousseva, A., Henry, C., Van Den Bulke, D., Fournier, G., Laplanche, J.L., Leboyer, M., Bellivier, F., Aubry, J.M., Baud, P., Boucherie, M., Buresi, C., Ferrero, F., Malafosse, A. (2003) Pharmacogenom. J., 3(2), 101-4.

[96] Papadimitriou, G.N., Calabrese, J.R., Dikeos, D.G., Christodoulou, GN. (2005) Int. J. Neuropsychopharmacol., 1-12.

[97] Mundo, E., Walker, M., Cate, T., Macciardi, F., Kennedy, J.L. (2001) Arch. Gen. Psychiatr., 58539-544.

[98] Serretti, A., Artioli, P., Zanardi, R., Lorenzi, C., Rossini, D., Cusin, C., Arnoldi, A., Catalano, M. (2004) Psychopharmacology (Berl), 174(4), 504-511.
[99] Masoliver, E., Menoyo, A., Perez, V., Volpini, V., Rio, E.D., Perez, J., Alvarez, E., Baiget, M. (2006) Psychiatr. Genet., 16(1), 25-9.

[100] Martin, A., Young, C., Leckman, J.F., Mukonoweshuro, C., Rosenheck, R., Leslie, D. (2004) Arch. Pediatr. Adolesc. Med, 158(8), 773-80.

[101] Serretti, A., Artioli, P., Quartesan, R. (2005) Pharmacogenet. Genomics, 15(2), 61-7.

[102] Smeraldi, E., Zanardi, R., Benedetti, F., Dibella, D., Perez, J., Catalano, M. (1998) Mol. Psychiatr., 3(6), 508-511.

[103] Zanardi, R., Benedetti, F., DiBella, D., Catalano, M., Smeraldi, E. (2000) J. Clin. Psychopharmacol., 20(1), 105-107.

[104] Pollock, B.G., Ferrell, R.E., Mulsant, B.H., Mazumdar, S., Miller, M., Sweet, R.A., Davis, S., Kirshner, M.A., Houck, P.R., Stack, J.A., Reynolds, C.F., Kupfer, D.J. (2000) Neuropsychopharmacology, 23(5), 587-590.

[105] Benedetti, F., Serretti, A., Colombo, C., Campori, E., Barbini, B., Di Bella, D., Smeraldi, E. (1999) Am. J. Psychiatr., 1561450-1452.

[106] Hanna, G.L., Himle, J.A., Curtis, G.C., Koram, D.Q., VanderWeele, J., Leventhal, B.L., Cook, E.H. Jr.. (1998) Neuropsychopharmacology, 18(2), 102-11.

[107] Takahashi, H., Yoshida, K., Ito, K., Sato, K., Kamata, M., Higuchi, H., Shimizu, T., Inoue, K., Tezuka, T., Suzuki, T., Ohkubo, T., Sugawara, K. (2002) Eur. Neuropsychopharmacol., 12(5), 477-81.

[108] Murphy, G., Hollander, S., Rodrigues, H., Schatzberg, A. Effects of the serotonin transporter promoter polymorphism on paroxetine and mirtazapine efficacy and side effects in geriatric major depression. Pharmacogenetics in Psychiatr. meeting 2003, New York: green tab.

[109] Caspi, A., Sugden, K., Moffitt, T.E., Taylor, A., Craig, I.W., Harrington, H., McClay, J., Mill, J., Martin, J., Braithwaite, A., Poulton, R. (2003) Science, 301(5631), 386-9.

[110] Eley, T.C., Sugden, K., Corsico, A., Gregory, A.M., Sham, P., McGuffin, P., Plomin, R., Craig, IW. (2004) Mol. Psychiatr., 9(10), 908-15.

[111] Gillespie, N.A., Whitfield, J.B., Williams, B., Heath, A.C., Martin, NG. (2005) Psychol. Med., 35(1), 101-11.

[112] Kendler, K.S., Kuhn, J.W., Vittum, J., Prescott, C.A., Riley, B. (2005) Arch. Gen. Psychiatr., 62(5), 529-35.

[113] Mandelli, L., Serretti, A., Marino, E., Pirovano, A., Calati, R., Colombo, C. (2006) Int. J. Neuropsychopharmacol., 1-11.

[114] Courtet, P., Jollant, F., Castelnau, D., Buresi, C., Malafosse, A. (2005) Am. J. Med. Genet. C. Semin. Med. Genet., 133(1), 25-33.

[115] Bondy, B., Buettner, A., Zill, P. (2006) Mol. Psychiatr., 11(4), 33651.

[116] Pungercic, G., Videtic, A., Pestotnik, A., Pajnic, I.Z., Zupanc, T., Balazic, J., Tomori, M., Komel, R. (2006) Psychiatr. Genet., 16(5), 187-91.

[117] Mergen, H., Demirel, B., Akar, T., Senol, E. (2006) Psychiatr. Genet., 16(2), 53.

[118] Helbecque, N., Sparks, D.L., Hunsaker, J.C., 3rd, Amouyel, P. (2006) Neurosci. Lett., 400(1-2), 13-5.

[119] Segal, J., Pujol, C., Birck, A., Gus Manfro, G., Leistner-Segal, S (2006) Psychiatr. Res., 143(2-3), 289-291.

[120] Li, M.D., Ma, J.Z., Beuten, J. (2004) Clin. Genet., 66(5), 382-92.

[121] Kremer, I., Bachner-Melman, R., Reshef, A., Broude, L., Nemanov, L., Gritsenko, I., Heresco-Levy, U., Elizur, Y., Ebstein, R.P. (2005) Am. J. Psychiatr., 162(5), 924-30.

[122] Gerra, G., Garofano, L., Zaimovic, A., Moi, G., Branchi, B., Bussandri, M., Brambilla, F., Donnini, C. (2005) Am. J. Med. Genet. B. Neuropsychiatr. Genet., 135(1), 73-8.

[123] Heinz, A., Jones, D.W., Gorey, J.G., Bennet, A., Suomi, S.J., Weinberger, D.R., Higley, J.D. (2003) Mol. Psychiatr., 8(2), 231-4.

[124] Heinz, A., Ragan, P., Jones, D.W., Hommer, D., Williams, W. Knable, M.B., Gorey, J.G., Doty, L., Geyer, C., Lee, K.S., Coppola, R., Weinberger, D.R., Linnoila, M. (1998) Am. J. Psychiatr., 155(11), 1544-9.

[125] Hammoumi, S., Payen, A., Favre, J.D., Balmes, J.L., Benard, J.Y., Husson, M., Ferrand, J.P., Martin, J.P., Daoust, M. (1999) Alcohol, 17(2), 107-112.

[126] Feinn, R., Nellissery, M., Kranzler, H.R. (2005) Am. J. Med. Genet. B. Neuropsychiatr. Genet., 133(1), 79-84.

[127] Oroszi, G., Goldman, D. (2004) Pharmacogenomics, 5(8), 1037 48.

[128] Gorwood, P., Lanfumey, L., Hamon, M. (2004) Med. Sci. (Paris), 20(12), 1132-8. 
[129] Hu, X., Oroszi, G., Chun, J., Smith, T.L., Goldman, D., Schuckit, MA. (2005) Alcohol. Clin. Exp. Res., 29(1), 8-16.

[130] Herman, A.I., Kaiss, K.M., Ma, R., Philbeck, J.W., Hasan, A., Dasti, H., DePetrillo, P.B. (2005) Am. J. Med. Genet. B. Neuropsychiatr. Genet., 133(1), 74-8.

[131] Ricaurte, G.A., Finnegan, K.T., Irwin, I., Langston, J.W. (1990) Ann. N. Y. Acad. Sci., 600, 699-708.

[132] Chang, L., Grob, C.S., Ernst, T., Itti, L., Mishkin, F.S., JoseMelchor, R., Poland, R.E. (2000) Psychiatr. Res., 98(1), 15-28.

[133] Kish, S.J., Furukawa, Y., Ang, L., Vorce, S.P., Kalasinsky, K.S. (2000) Neurology, 55(2), 294-6.

[134] Reneman, L., Booij, J., Schmand, B., van den Brink, W., Gunning, B. (2000) Psychopharmacology (Berl), 148(3), 322-4

[135] Buchert, R., Obrocki, J., Thomasius, R., Vaterlein, O., Petersen, K., Jenicke, L., Bohuslavizki, K.H., Clausen, M. (2001) Nucl. Med. Commun., 22(8), 889-97.

[136] Cole, J.C., Sumnall, H.R. (2003) Pharmacol. Ther., 98(1), 35-58.

[137] McCann, U.D., Szabo, Z., Scheffel, U., Dannals, R.F., Ricaurte, GA. (1998) Lancet, 352(9138), 1433-7.

[138] Reneman, L., Booij, J., de Bruin, K., Reitsma, J.B., de Wolff, F.A., Gunning, W.B., den Heeten, G.J., van den Brink, W. (2001) Lancet, 358(9296), 1864-9.

[139] Reneman, L., Lavalaye, J., Schmand, B., de Wolff, F.A., van den Brink, W., den Heeten, G.J., Booij, J. (2001) Arch. Gen. Psychiatr., 58(10), 901-6.

[140] Buchert, R., Thomasius, R., Nebeling, B., Petersen, K., Obrocki, J., Jenicke, L., Wilke, F., Wartberg, L., Zapletalova, P., Clausen, M. (2003) J. Nucl. Med, 44(3), 375-84

[141] Buchert, R., Thomasius, R., Wilke, F., Petersen, K., Nebeling, B., Obrocki, J., Schulze, O., Schmidt, U., Clausen, M. (2004) Am. J. Psychiatr., 161(7), 1181-9.

[142] Roiser, J.P., Cook, L.J., Cooper, J.D., Rubinsztein, D.C., Sahakian, B.J. (2005) Am. J. Psychiatr., 162(3), 609-12.

[143] Staley, J.K., Basile, M., Flynn, D.D., Mash, D.C. (1994) J. Neurochem., 62(2), 549-56.

[144] Little, K.Y., McLaughlin, D.P., Zhang, L., Livermore, C.S., Dalack, G.W., McFinton, P.R., DelProposto, Z.S., Hill, E., Cassin, B.J., Watson, S.J., Cook, E.H. (1998) Am. J. Psychiatr., 155(2), 207-13.

[145] Jacobsen, L.K., Staley, J.K., Malison, R.T., Zoghbi, S.S., Seibyl, J.P., Kosten, T.R., Innis, R.B. (2000) Am. J. Psychiatr., 157(7), 1134-40.

[146] Patkar, A.A., Berrettini, W.H., Hoehe, M., Hill, K.P., Sterling, R.C., Gottheil, E., Weinstein, S.P. (2001) Addict. Biol., 6(4), 337345.

[147] Patkar, A.A., Berrettini, W.H., Hoehe, M., Hill, K.P., Gottheil, E., Thornton, C.C., Weinstein, S.P. (2002) Psychiatr. Genet., 12(3), 161-4.

[148] Patkar, A.A., Berrettini, W.H., Mannelli, P., Gopalakrishnan, R., Hoehe, M.R., Bilal, L., Weinstein, S., Vergare, M.J. (2004) Psychiatr. Genet., 14(1), 25-32.

[149] Tan, E.C., Yeo, B.K., Ho, B.K., Tay, A.H., Tan, C.H. (1999) Mol. Psychiatr., 4(3), 215-7.

[150] Kotler, M., Cohen, H., Kremer, I., Mel, H., Horowitz, R., Ohel, N., Gritsenko, I., Nemanov, L., Katz, M., Ebstein, R. (1999) Mol. Psychiatr., 4(4), 313-4

[151] Li, T., Liu, X., Zhao, J., Hu, X., Ball, D.M., Lohel, W., Sham, PC., Collier, D.A. (2002) Am. J. Med. Genet., 114(3), 329-35.

[152] Gerra, G., Garofano, L., Santoro, G., Bosari, S., Pellegrini, C., Zaimovic, A., Moi, G., Bussandri, M., Moi, A., Brambilla, F., Donnini, C. (2004) Am. J. Med. Genet. B. Neuropsychiatr. Genet., 126(1), 37-42.

[153] Szilagyi, A., Boor, K., Szekely, A., Gaszner, P., Kalasz, H., Sasvari-Szekely, M., Barta, C. (2005) Neuropsychopharmacol. Hung., 7(1), 28-33.

[154] Gorwood, P. (2004) Am. J. Pharmacogenomics, 4(1), 9-17.

[155] Matsushita, S., Suzuki, K., Murayama, M., Nishiguchi, N., Hishimoto, A., Takeda, A., Shirakawa, O., Higuchi, S. (2004) Am. J. Med. Genet. B. Neuropsychiatr. Genet., 128(1), 114-7.
[156] Steiger, H., Joober, R., Israel, M., Young, S.N., Ng Ying Kin, N.M., Gauvin, L., Bruce, K.R., Joncas, J., Torkaman-Zehi, A. (2005) Int. J. Eat Disord., 37(1), 57-60.

[157] Urwin, R.E., Nunn, KP. (2005) Eur. J. Hum. Genet., 13(3), 370-5.

[158] Smalley, S.L. (1997) Am. J. Hum. Genet., 60(6), 1276-82.

[159] Bobb, A.J., Castellanos, F.X., Addington, A.M., Rapoport, J.L. (2005) Am. J. Med. Genet. B. Neuropsychiatr. Genet., 132(1), 10925.

[160] Faraone, S.V., Khan, S.A. (2006) J. Clin. Psychiatr., 67(Suppl 8), 13-20.

[161] BartLett., C.W., Gharani, N., Millonig, J.H., Brzustowicz, L.M. (2005) Int. J. Dev. Neurosci., 23(2-3), 221-34.

[162] Santangelo, S.L., Tsatsanis, K. (2005) Am. J. Pharmacogenomics, 5(2), 71-92.

[163] Fan, J.B., Sklar, P. (2005) Mol. Psychiatr., 891(10), 928-38.

[164] Seidman, L.J., Wencel, H.E. (2003) Curr. Psychiatr. Rep, 5(2), 135-44.

[165] Pae, C.U., Artioli, P., Serretti, A., Kim, T.S., Kim, J.J., Lee, C.U., Lee, S.J., Lee, C., Paik, I.H. (2005) Neurosci. Res., 52(2), 195-9.

[166] Dubertret, C., Hanoun, N., Ades, J., Hamon, M., Gorwood, P. (2005) Int. J. Neuropsychopharmacol, 8(1), 87-92.

[167] Frankle, W.G., Narendran, R., Huang, Y., Hwang, D.R., Lombardo, I., Cangiano, C., Gil, R., Laruelle, M., Abi-Dargham, A. (2005) Biol. Psychiatr., 57(12), 1510-6.

[168] Kaiser, R., Tremblay, P.B., Schmider, J., Henneken, M., Dettling, M., Muller-Oerlinghausen, B., Uebelhack, R., Roots, I., Brockmoller, J. (2001) Mol. Psychiatr., 6(2), 179-185.

[169] Pae, C.U., Kim, J.J., Lee, S.J., Lee, C.U., Lee, C., Paik, I.H., Park, H.R., Yang, S., Serretti, A. (2003) Neuropsychobiology, 47(4), $182-6$.

[170] Golimbet, V.E., Alfimova, M.V., Shchebatykh, T.V., Abramova, L.I., Kaleda, V.G., Rogaev, E.I. (2004) Am. J. Med. Genet., 126B(1), 1-7.

[171] Sanjuan, J., Rivero, O., Aguilar, E.J., Gonzalez, J.C., Molto, M.D., de Frutos, R., Lesch, K.P., Najera, C. (2005) Int. J. Neuropsychopharmacol., 1-3.

[172] Han, D.H., Park, D.B., Na, C., Kee, B.S., Lee, YS. (2004) Psychiatr. Res., 129(1), 29-37.

[173] Chotai, J., Serretti, A., Lorenzi, C. (2005) Neuropsychobiology, 51(1), 3-9.

[174] Bossy-Wetzel, E., Schwarzenbacher, R., Lipton, SA. (2004) Nat. Med., 10(Suppl), S2-9.

[175] Mossner, R., Schmitt, A., Syagailo, Y., Gerlach, M., Riederer, P., Lesch, K.P. The serotonin transporter in Alzheimer's and Parkinson's disease, 2000

[176] Zill, P., Padberg, F., de Jonge, S., Hampel, H., Burger, K., Stubner, S., Boetsch, T., Jurgen Moller, H., Ackenheil, M., Bondy, B. (2000) Neurosci. Lett., 284(1-2), 113-5.

[177] Kunugi, H., Ueki, A., Otsuka, M., Isse, K., Hirasawa, H., Kato, N., Nabika, T., Kobayashi, S., Nanko, S. (2000) Am. J. Med. Genet., 96(3), 307-9

[178] Tsai, S.J., Hong, C.J., Liu, T.Y., Cheng, C.Y., Liu, H.C. (2001) Neuropsychobiology, 44(1), 27-30.

[179] Rocchi, A., Micheli, D., Ceravolo, R., Manca, M.L., Tognoni, G., Siciliano, G., Murri, L. (2003) Genet. Test, 7(4), 309-14.

[180] Sukonick, D.L., Pollock, B.G., Sweet, R.A., Mulsant, B.H., Rosen, J., Klunk, W.E., Kastango, K.B., DeKosky, S.T., Ferrell, R.E. (2001) Arch. Neurol., 58(9), 1425-8.

[181] Sweet, R.A., Pollock, B.G., Sukonick, D.L., Mulsant, B.H., Rosen, J., Klunk, W.E., Kastango, K.B., DeKosky, S.T., Ferrell, R.E. (2001) Int. Psychogeriatr., 13(4), 401-9.

[182] Assal, F., Alarcon, M., Solomon, E.C., Masterman, D., Geschwind, D.H., Cummings, J.L. (2004) Arch. Neurol., 61(8), 1249-53.

[183] Mossner, R., Henneberg, A., Schmitt, A., Syagailo, Y.V., Grassle, M., Hennig, T., Simantov, R., Gerlach, M., Riederer, P., Lesch, K.P. (2001) Mol. Psychiatr., 6(3), 350-2.

[184] Serretti, A., Mandelli, L., Lorenzi, C., Smeraldi, E. (2005) Psychiatr. Res., 134(2), 191-4.

[185] Manuck, S.B., Flory, J.D., Ferrell, R.E., Muldoon, M.F. (2004) Psychoneuroendocrinology, 29(5), 651-668. 
Chapter 9: Dissecting the determinants of depressive disorders outcome: an in depth analysis of two clinical cases 


\title{
Dissecting the determinants of depressive disorders outcome: an in depth analysis of two clinical cases Alessandro Serretti ${ }^{* 1}$, Raffaella Calati ${ }^{1}$, Osmano Oasi ${ }^{2}$, Diana De Ronchi ${ }^{1}$ and Cristina Colombo ${ }^{3}$
}

\author{
Address: ${ }^{1}$ Institute of Psychiatry, University of Bologna, Italy, ${ }^{2}$ Department of Psychology, Catholic University, Milan, Italy and ${ }^{3}$ Department of \\ Psychiatry, San Raffaele Scientific Institute, Milan, Italy \\ Email: Alessandro Serretti* - alessandro.serretti@unibo.it; Raffaella Calati - raffaella.calati@unibo.it; Osmano Oasi - osmano.oasi@unicatt.it; \\ Diana De Ronchi - deronchi@alma.unibo.it; Cristina Colombo - colombo.cristina@hsr.it \\ * Corresponding author
}

This article is available from: http://www.annals-general-psychiatry.com/content/6/1/5

(C) 2007 Serretti et al; licensee BioMed Central Ltd.

This is an Open Access article distributed under the terms of the Creative Commons Attribution License (http://creativecommons.org/licenses/by/2.0), which permits unrestricted use, distribution, and reproduction in any medium, provided the original work is properly cited.

\begin{abstract}
Clinicians face everyday the complexity of depression. Available pharmacotherapies and psychotherapies improve patients suffering in a large part of subjects, however up to half of patients do not respond to treatment. Clinicians may forecast to a good extent if a given patient will respond or not, based on a number of data and sensations that emerge from face to face assessment. Conversely, clinical predictors of non response emerging from literature are largely unsatisfactory.

Here we try to fill this gap, suggesting a comprehensive assessment of patients that may overcome the limitation of standardized assessments and detecting the factors that plausibly contribute to so marked differences in depressive disorders outcome.

For this aim we present and discuss two clinical cases. Mr. A was an industrial manager who came to psychiatric evaluation with a severe depressive episode. His employment was demanding and the depressive episode undermined his capacity to manage it. Based on standardized assessment, Mr. A condition appeared severe and potentially dramatic. Mrs. B was a housewife who came to psychiatric evaluation with a moderate depressive episode. Literature predictors would suggest Mrs. B state as associated with a more favourable outcome.

However the clinician impression was not converging with the standardized assessment and in fact the outcome will reverse the prediction based on the initial formal standard evaluation.

Although the present report is based on two clinical cases and no generalizability is possible, a more detailed analysis of personality, temperament, defense mechanisms, self esteem, intelligence and social adjustment may allow to formalize the clinical impressions used by clinicians for biologic and pharmacologic studies.
\end{abstract}




\section{Background}

Treatment evaluation and guidelines relies mainly on published clinical trials. Unfortunately clinicians face an everyday clinical practice that can differ in terms of efficacy and prediction of outcome. This leaded to criticize the clinical trial method $[1,2]$. The difference is mainly due to the fact that in the clinical practice a much higher number of variables is taken into account. In fact case reports yield much more information and are closer to clinical practice [3]. This gap is particularly troublesome for biologic and genetic research where effects are subtle and wide $[4,5]$.

As an attempt to fill this gap we are presenting two clinical cases of depressed subjects that are much similar in terms of traditional assessment but substantially differ when a more detailed analysis is applied. This could constitute a suggestion for inclusion of such detailed assessment in clinical trials and biologic analyses.

To pursue this goal we have chosen a battery of tests that explore the whole human complexity, according to the holistic approach of the biopsychosocial model of medicine, which considers patient illness like a combination of a large quantity of biological, psychological and social factors interacting with each other [6], and according to W.H.O. concept of health, like "a complete state of physical, mental and social well-being" [7].

We have therefore considered a number of features that have been suggested, at a variable degree of certainty, as associated with outcome [8-19]. We included in the analysis heredity, intrapsychic aspects (temperament and personality traits, personality disorders, defensive mechanisms, locus of control, coping styles, self esteem), cognitive features and social features. In order to measure those features, we tried to use validated and reliable instruments, when available. Informed consent has been obtained by the two subjects in compliance with the Helsinki Declaration in the context of approval of the local ethical committee for the study.

Although a follow up of a large cohort of depressed subjects investigated at baseline would be the correct strategy to investigate this issue, practical limitations do not allow such a study to be performed. The only comprehensive naturalistic follow up to date is the STAR* D study which, with a large effort and a multicentric approach, only targets resistant depression and it includes only a very limited number of predictive variables [20]. We therefore propose a very preliminary strategy of comprehensive assessment in line with the evidence of the complex pattern of determinants of depressive disorders [21-24].
The use of this wide-ranging assessment is also motivated by the fact that clinical predictors of non response emerging from literature are largely unsatisfactory [25]; so it is currently accepted that the coexistence of a broad number of factors contributes to the resistance to therapy response and in this paper we have tried to investigate this issue.

The double aim of this paper is to suggest a comprehensive assessment of mood disorders patients that may overcome the limitation of standardized assessments and to detect factors that plausibly contribute to the well known marked differences in depressive disorders outcome.

\section{Mr. A}

Mr. A is a fifty-year-old industrial manager. Striking politeness and respectfulness characterize him - he defines himself a "medieval knight". His inclination toward cooperation contributes to the fluency of interviews.

He describes himself like a good planner and his life style reflects it: he got a degree in engineering with full marks at twenty-five years old, something that made him very proud; at twenty-six he did military service, he took the qualifying examination and he began to work in a design laboratory of a small business; at twenty-seven he got married with a woman of the same age and they gave birth to a daughter when he was thirty, an experience that he defined hard but of immeasurable joy.

To spoil these plans several depressive episodes have cropped up. At twenty-six years old, in the period of the first employment, Mr. A began to suffer depressive symptoms: persistent sadness, loss of interest in activities, psychic anxiety, weight loss (3-4 kilograms), sleeping difficulty, especially waking too early, sluggishness, lack of energy, tiredness, inappropriate guilt and loss of confidence, thinking and concentrating difficulties. Mr. A imputed this collapse to difficulties and incomprehensions in the business framework. He came to psychiatric evaluation and he was treated with clinical management and pharmacological therapy (clomipramine, dose unknown). After the therapy response and the symtomatological remission, Mr. A got married and this event, in conjunction with the experience of paternity, helped him to become settled and to pass years of composure.

From the age of forty-five years old other three depressive episodes followed, concomitant with stress in the company context. These three episodes, with similar symptomatology of the first, occurred respectively when he was forty-five, forty-seven and forty-eight years old. Each episode was treated with clinical management and the same pharmacological medication (fluvoxamine 200-300 mg and mirtazapine $15 \mathrm{mg}$ ), with positive response and com- 
plete symtomatological remission. The time course of Hamilton Rating Scale for Depression (HAM-D) scores in the first (index) episode at 45 years was 23 at baseline and in the following 7 weeks was: $23,18,17,16,8,8,2$. The present score of his depressive symptoms assessment, carried out with the use of the HAM-D, is 2 (at the item 6, Late Insomnia, 2 = Unable to fall asleep again if he gets out of bed).

A number of stressful life events were concomitant with the occurrence of depression, besides dissatisfactions in job; Mr. A himself made a list of the "heavy events": the death of his father, several organic diseases of his wife and daughter, the country home devastated by an earthquake, the job burden of his wife.

Moreover, two years ago, Mr. A's daughter began to show marked psychopathology which will be diagnosed as Bipolar Disorder, type I. Nevertheless, in this time, Mr. A did not show other depressive signs. He referred to feel himself changed, capable to consider events with detachment, perhaps thanks both to pharmacological treatment, which is still taking, and self-discipline learned with the help of meditation and physical activity.

So, contrary to all expectations, Mr. A condition, at the beginning apparently severe, has completely recovered and, at the present time, seems to be steady.

\section{Mrs. B}

Mrs. B, a sixty-year-old small looking frightened woman came to psychiatric evaluation after the death of her husband, at fifty-one years. From the first interview her frailty was clear. She had few hopes about her recovery.

She felt deeply depressed and anxious, with symptoms like persistent sadness, inappropriate crying, feelings of worthlessness, hopelessness, complete loss of self esteem, loss of interest in activities, agitation and psychic anxiety, appetite and weight loss, sleeping difficulty, lack of energy, tiredness, thinking difficulty, impaired concentrating and making decisions, fear of the future, difficulties in relationships and social withdrawal.

She lived in an isolated setting, incapable to do anything. Difficulties to find the right pharmacological medication became visible quite early because of the absence of any response (amitryptiline not tolerated, amisulpiride 50 $\mathrm{mg}$, citalopram $60 \mathrm{mg}$, paroxetine $50 \mathrm{mg}$, clomipramine $150 \mathrm{mg}$, pindolol $20 \mathrm{mg}$, mirtazapine $60 \mathrm{mg}$, trazodone $100 \mathrm{mg}$, lithium $600 \mathrm{mg}$, venlafaxine $375 \mathrm{mg}$, olanzapine $10 \mathrm{mg}$, fluoxetine $60 \mathrm{mg}$, all for extended periods and in various combinations).
In truth, the first distress sign came into sight when, at the age of twenty-seven, Mrs. B had an abortion. This awful experience damages her everyday-life and forced her in bed for a long time. Unfortunately, other two subsequent abortions, at twenty-nine and thirty-two years old, shocked Mrs. B. She described this period like characterized by ups and downs: the delighted moments during pregnancy and the deep grief of lost and mourning followed one upon the other without a break. Besides feeling depressed, Mrs. B suffered of panic symptomatology (racing heartbeat, excessive sweating, trembling, breathlessness, chest discomfort, nausea, dizziness, feeling of derealization, fear of losing control), which impaired her life, compelling her to avoid crowded places and circumstances like travel by underground, tram or air.

Providentially, at the age of thirty-four years old, Mrs. B gave birth to a son. She stopped to work (she was a tailor) and devoted herself to her son. The uneasiness feelings considerably diminished, even though anxiety and panic attacks were always present.

Nevertheless, after her husband death, her condition got worse and, at the present time, no treatment, neither clinical management nor pharmacological therapy, has any effects on mood and anxiety symptomatology. The present score of her depressive symptoms assessment, carried out with HAM-D, is 24 . The score is substantially stable over time.

Besides the three abortions and the loss of her husband, the death of both parents and two brothers has contributed to Mrs. B manifestation of depression.

Also regarding Mrs. B condition, expectations based on standard research criteria, in this case of a good response, were misleading.

\section{Hereditary features}

In accordance to the principles of formal genetics, sharing a portion of genetic heritage increases the risk of being affected by the same disease.

Both Mr. A and Mrs. B have other cases of depressive disorders in their families, but with substantial differences: Mr. A mother was affected by depressive disorder and showed an anxious temperament; moreover, the bipolar disorder of Mr. A daughter strengthen the genetic hypothesis. On the contrary, only Mrs. B mother aunt was affected by depression and anxiety, pharmacologically treated. Therefore, the genetic load is more marked in Mr. A compared to Mrs. B. This is usually an indication of more 'typical' mood disorder compared to sporadic cases [26] and it has been described as more responsive to treatments $[27,28]$. 


\section{Intrapsychic features}

Temperament and personality traits

Personality can be defined as a complex of psychological and behavioural dimensions [29,30]. Several theories attempted to define what is personality and descriptions of human personality are so many as theories are. Among these, the bio-social theory of Cloninger gave an original and successful contribution, describing a model that incorporates both biological and socio-cultural influences in the development of human personality [31]. His model was based on the assumption that a part of the individual's personality is heritable. In particular, he hypothesized that personality is composed both by Temperament, the totality of traits which are heritable and stable throughout life, and Character, the whole traits that are influenced by socio-cultural learning and that mature throughout life. Temperament consists of four traits, so called Harm Avoidance, Novelty Seeking, Reward Dependence and Persistence. Harm Avoidance denotes the individual's inclination to behavioral inhibition in front of potentially dangerous stimuli and to anticipate negative effects; Novelty Seeking relates to exploratory behaviors and activation in response to novel stimuli; Reward Dependence concerns relational and affective skills but also other dependencies; finally Persistence characterizes industrious, hard working and stable individuals despite frustration and fatigue. Character consists of three dimensions: Self-Directedness, Cooperativeness and Self-Transcendence. Self-Directedness expresses the individual's competence towards autonomy, reliability and maturity; Cooperativeness is related to social skills, like support, collaboration and partnership; finally, SelfTranscendence denotes the aptitude towards mysticism, religion and idealism.

The Temperament and Character Inventory (TCI), a 240 items tool to assess individuals differences in the seven basic dimensions of Temperament and Character [32], was administered to both Mr. A and Mrs. B (Table 1). Mr. A showed high scores in Harm Avoidance (100), Reward Dependence (104), Persistence (126), Self-Directedness (146) and Cooperativeness (132) and low scores in Novelty Seeking (87) and Self-Transcendence (50). Mrs. B showed similar scores to Mr. A in Reward Dependence (109) and Novelty Seeking (86). In comparison with Mr. A, she had higher scores in Harm Avoidance (128), Cooperativeness (147) and Self-Transcendence (66), even if Self-Transcendence score remains low, and she had lower scores in Self-Directedness (138) and Persistence (103).

So, Mr. A appears quite inhibited and responsible, purposeful, goal-oriented and resolute. Differently, Mrs. B seems to be much more timorous and inhibited toward potentially dangerous stimuli or social circumstances, and less mature and tenacious, although more collaborative.

Numerous studies have found high scores in Harm Avoidance trait in samples of patients affected by mood disorders [32-35]; this fact fortifies the hypothesis of a link between depression and withdrawal like reaction to loss or disappointment [36].

Moreover, also low Novelty Seeking and low Self-Directedness represent trait markers for liability to recurrent major depressive disorder [34,35,37].

Therefore, we can hypothesize that the higher introversion and lower responsibility and maturity of Mrs. B could have contributed to the negative outcome of therapies. Nevertheless, it must be said that Harm Avoidance trait is gender-specific and generally scores are higher in women than men [38-42]. Moreover high Harm Avoidance scores could be directly related to the depressive symptomatology [32].

\section{Personality disorders}

Both Mr. A and Mrs. B were investigated for Axis II diagnoses using the Structured Clinical Interview for the DSMIV (SCID-II) [43].

Mr. A suffers from an Obsessive-Compulsive Personality Disorder, with symptoms like: excessive attention to details, rules, lists, tidiness, organization, plans; excessive conscientiousness, meticulousness, rigorousness and idealism; incapability to get rid of consumed and no value objects; rigidity and obstinacy.

Table I: Mr. A and Mrs. B TCI scores in comparison with minimum and maximum values.

\begin{tabular}{ccccc}
\hline $\begin{array}{c}\text { Temperament and } \\
\text { Character dimensions }\end{array}$ & Minimum Scores & Mr. A & Mrs. B & Maximum Scores \\
\hline Harm Avoidance & 33 & 100 & 128 & 165 \\
Novelty Seeking & 35 & 87 & 86 & 175 \\
Reward Dependence & 30 & 104 & 109 & 150 \\
Persistence & 35 & 126 & 103 & 175 \\
Self-Directedness & 40 & 146 & 138 & 200 \\
Cooperativeness & 36 & 132 & 147 & 180 \\
Self-Transcendence & 26 & 50 & 66 & 130
\end{tabular}


Differently, Mrs. B has an Avoidant Personality Disorder, with traits like: avoidance of job activities that imply significant interpersonal relationships due to the fear of criticism and judgment; avoidance of interpersonal relationships if there is no certainty of being accepted; inhibition in interpersonal relationships and inadequacy feelings; feelings of inferiority; reluctance toward new activities. Moreover, Mrs. B shows a number of traits of Dependent Personality Disorder (like difficulties to express disagreement, difficulty to do things autonomously, fear of being alone and need of support) and several traits of Obsessive-Compulsive Personality Disorder (perfectionism interfering with completing activities, excessive conscientiousness and idealism; incapability to get rid of consumed and no value objects).

In literature, up till now, there is evidence of the fact that the occurrence of a personality disorder is high among depressive disorders [44] and complicates their treatment $[45,46]$, though evidence is not unequivocal [47].

In particular, Cluster C Personality Disorders, including Avoidant, Dependent and Obsessive-Compulsive subtypes, has been largely investigated. Firstly, Cluster C subtypes seem to predominate between personality disorders in mood disorder samples [48-52]. Secondly, it was observed that a Cluster $\mathrm{C}$ diagnosis was associated with significantly higher rates of early-onset depression [49]. Several recent studies have replicated these findings: Nubukpo and colleagues observed that the frequency of personality disorders was higher in patients with earlyonset depression rather than in those with late-onset depression; moreover, between the early-onset depressed patients, the most frequent personality disorders were Avoidant and Dependent [53]. Thirdly, patients with both panic disorder and major depression showed higher Harm Avoidance levels and a greater prevalence of Cluster $\mathrm{C}$ personality disorders, compared to patients with pure disorders [54]. Moreover, Russell and colleagues, in a study previously mentioned, observed that a Cluster C diagnosis was associated with comorbid anxiety disorder [49].

Finally, Cluster C subtypes emerged as robust predictors of slowed remission from major depressive disorder. In two different studies Viinamaki and collaborators investigated whether Cluster $\mathrm{C}$ personality disorder is associated with recovery from depression and found an association between lack of recovery and presence of Cluster $\mathrm{C}$ personality disorder. In detail, among patients with depression alone, 54\% had recovered from the disorder, but only $16 \%$ of those with a Cluster C personality disorder and depression recovered [55,56]. Grilo and colleagues observed that participants with major depressive disorder who had certain forms of coexisting personality disorder psychopathology (Avoidant, Schizotypal or Borderline) had a significantly longer time to remission from depression than did patients without any personality disorder [57]. Moreover, Morse and colleagues observed that Cluster $\mathrm{C}$ was associated with longer time-to-response during acute treatment and non-response in continuation or maintenance treatment. Although not statistically significant, there was evidence of a cumulative negative impact of Cluster $\mathrm{C}$ personality disorder and residual depressive symptoms on instrumental activities of daily living during maintenance treatment [58].

Also negative results were reported: in a sample of depressed patients, one comorbid personality disorder was of limited relevance to the course of the affective illness, especially if it was a Cluster $\mathrm{C}$ personality disorder [59].

Nevertheless, summarizing, the large quantity of positive studies justifies the assumption that the diagnosis of a Cluster $\mathrm{C}$ personality disorder could be associated with early-onset depression and comorbid anxiety disorder and it hinders the alleviation of depressive symptoms in major depression.

Consequently, we can hypothesize that Mrs. B repeated treatment failures was due to the specific structure of her personality, in which coincident traits of three personality disorders have been crystallized in a maladaptive organization. These conclusions could be connected to temperamental considerations: actually, Cluster C personality disorders were found related just with high Harm Avoidance, low Novelty Seeking and low Self-Directedness [60], therefore this fact makes Mrs. B personality profile emblematic.

For what concerns Mr. A, his personality organization appears more adaptive: in fact, he shows only one personality Disorder - Obsessive-Compulsive - which furthermore probably represents an important resource for him, especially in the job field.

\section{Defense mechanisms}

We have also considered the defense mechanisms of Mr. A and Mrs. B, administering them the 88 items Defense Style Questionnaire (DSQ) by M. Bond [61], recently validated on Italian sample [62]. The questionnaire allows the identification of four defensive mechanism styles, representing groups of defenses classified from more immature, and therefore maladaptive, to more mature and adaptive (Table 2).

This questionnaire has consented us to analyze the prevalent defensive styles of Mr. A and Mrs. B (Table 3). Their scores are similar to those of healthy Italian sample [62], 
Table 2: The defensive styles according to Bond [6I].

Style I: Reflects a regressive situation and highlights behavioural disorders. The patient appears incapable of integrating his own impulses in a constructive and responsible action. It includes defenses that are commonly considered immature

Autistic withdrawal, acting-out, inhibition, passive aggression, projection

Style 2: Identifies problems in relationships and includes defenses that "distort the image" more than defenses concerning action. Such a defensive structure disturbs the object relations while it does not interfere with social and work fulfilment; in literature these are defenses associated with borderline and narcissistic disorders

\section{Splitting, primitive idealization, omnipotent devaluation}

Style 3: Includes "self-sacrificing" defenses (for instance the compulsion to "appear good"); it poses problems more on the level of creative capabilities rather than relational ones, allowing in this last field stable object relations even if not necessarily "healthy" ones (i.e. masochistic relations)

\section{Reactive formation, pseudo-altruism}

Style 4: It is also defined as "adaptive"; including defenses associated with a good adjustment and a good integration

\section{Sense of humour, repression, sublimation}

with the exceptions of Mr. A scores in Anticipation and Sublimation and Mrs. B scores in Reactive Formation, Inhibition and Isolation, higher in comparison with those of healthy sample.

Analysing scores different from the control sample, two Mr. A defensive mechanisms are more adaptive. Anticipation and Sublimation, in which he obtained higher scores, are mature defenses. Mr. A usually faces up to emotional conflicts or internal and external stressful life events in two adaptive way: 1) anticipating and prefiguring his affective reactions towards future possible events or anticipating the consequences and the solutions of these events (Anticipation); 2) channeling potentially maladaptive affects and impulses in socially appreciated behaviors, like sport, sculpture and painting (Sublimation). Abraham was the first who underlined the possible link between depression and specific defenses like sublimation: he describes in a brilliant way how the painter Giovanni Segantini recreated in his works the love for his mother [63].

On the contrary, several Mrs. B defensive mechanisms appear maladaptive. Reactive Formation, Inhibition and Isolation are neurotic immature defenses. Mrs. B usually faces up emotional conflicts or internal and external stressful life events in three maladaptive way: 1) with behaviours, thoughts and affects opposite to her own unacceptable thoughts and feelings (Reactive Formation); 2) reducing relational capacity to avoid the anxiety associated to unacceptable internal conflicts (Inhibition); 3) removing affects related to concepts and maintaining only cognitive elements (Isolation). M. Klein, in her first studies about early anxieties, placed two different defense mechanisms like Isolation and Splitting close together: it can suggest that the psychological condition of Mrs. B is nearer to a higher level of loss anxiety and it needs early defenses [64].

We can hypothesize that the maturity of Mr. A defenses has a protective function, while the immaturity of Mrs. B defenses could be a further factor explaining the absence of any therapy response. In fact, in the same line of evidence, Mullen and collaborators, comparing treatment responders and non-responders of a major depressive disorder sample, found that medication responders used significantly less maladaptive defenses than did nonresponders and had a significantly higher or healthier level of overall defensive functioning [65]. Nevertheless, it is essential to underline that the individual defensive style could be also modulated by depressive mood itself. Moreover, in a study over mentioned, immature defenses seemed to be strongly related to low Self-Directedness and both Self-Directedness scores and immature defense scores were predictive of the presence and number of personality disorders [60]. Mrs. B particular profile supports these data.

\section{Locus of control}

We have also considered the locus of control of Mr. A and Mrs. B, administering them the 24 item Internal, Powerful Others and Chance Scales (IPC Scales) by H. Levenson [66]. The scale has been validated on Italian sample [67].

Locus of control refers to an individual's generalized expectations concerning where control over subsequent events resides. Hannah Levenson offered an alternative 
Table 3: Mr. A and Mrs. B DSQ mean scores and healthy sample mean scores. The asterisk indicates deviance from normal values on the basis of standardized distance from the population mean and significance of the mechanism on the basis of the number of items.

\begin{tabular}{|c|c|c|c|c|}
\hline Defense Mechanisms & $\begin{array}{c}\text { Healthy Men Sample Scores } \\
\text { (Mean } \pm \text { SD) }\end{array}$ & Mr. A Scores & $\begin{array}{c}\text { Healthy Women Sample Scores } \\
\text { (Mean } \pm \text { SD) }\end{array}$ & Mrs. B Scores \\
\hline Acting-out & $3.52 \pm 1.77$ & 4.8 & $4.06 \pm 1.66$ & 4.4 \\
\hline Affiliation & $2.79 \pm 2.05$ & 5 & $3.48 \pm 2.24$ & 5 \\
\hline Undoing & $2.67 \pm 1.67$ & 2 & $2.60 \pm 1.80$ & 4.33 \\
\hline Anticipation & $4.86 \pm 2.10$ & $7.5^{*}$ & $4.97 \pm 2.13$ & 6.5 \\
\hline Passive aggressive & $2.74 \pm 1.47$ & 2.8 & $2.81 \pm 1.45$ & 2.4 \\
\hline Consumption & $1.94 \pm 1.67$ & 2.33 & $2.56 \pm 1.70$ & 1.33 \\
\hline Denial & $1.80 \pm 1.29$ & 3.5 & $1.43 \pm 1.32$ & 3 \\
\hline Fantasy & $4.52 \pm 2.87$ & 6 & $4.78 \pm 2.83$ & 5 \\
\hline Reaction formation & $2.80 \pm 1.60$ & 3.8 & $2.93 \pm 1.60$ & $5.2^{*}$ \\
\hline Primitive idealization & $3.14 \pm 2.29$ & 4 & $3.62 \pm 2.58$ & 6.5 \\
\hline Projective identification & $0.98 \pm 1.86$ & I & $1.51 \pm 2.45$ & 5 \\
\hline Inhibition & $2.96 \pm 1.72$ & 3.8 & $3.56 \pm 1.84$ & $7^{*}$ \\
\hline Isolation & $3.10 \pm 1.65$ & 3 & $2.47 \pm 1.59$ & $4.5^{*}$ \\
\hline Help-rejecting complaining & $2.22 \pm 1.97$ & 2 & $2.28 \pm 1.96$ & 4 \\
\hline Omnipotence & $2.71 \pm 1.61$ & 2.5 & $2.27 \pm 1.58$ & 1.33 \\
\hline Task-orientation & $4.87 \pm 2.37$ & 6.5 & $5.18 \pm 2.12$ & 2.5 \\
\hline Projection & $1.62 \pm 1.06$ & 2.44 & $1.79 \pm 1.19$ & 2.44 \\
\hline Pseudo-altruism & $5.69 \pm 2.10$ & 7 & $6.22 \pm 1.91$ & 8 \\
\hline Regression & $2.30 \pm 2.02$ & 5 & $3.31 \pm 2.12$ & 6.5 \\
\hline Suppression & $3.94 \pm 2.08$ & 5 & $3.58 \pm 2.18$ & 3 \\
\hline Withdrawal & $4.56 \pm 2.05$ & 6.33 & $5.47 \pm 1.93$ & 7.33 \\
\hline Splitting & $3.45 \pm 2.09$ & 4 & $3.40 \pm 1.98$ & 4.67 \\
\hline Somatization & $1.97 \pm 2.09$ & 4 & $2.97 \pm 2.28$ & 5.5 \\
\hline Sublimation & $2.05 \pm 2.65$ & $5^{*}$ & $2.60 \pm 2.98$ & 5 \\
\hline Humor & $4.69 \pm 1.84$ & 4.33 & $4.57 \pm 1.93$ & 4.33 \\
\hline
\end{tabular}

model of Rotter's original locus of control formulation [68]. Whereas Rotter's conceptualization viewed locus of control as unidimensional (internal to external), Levenson's model asserts that there are three independent dimensions: Internal, Powerful Others and Chance. According to Levenson's model, one can endorse each of these dimensions of locus of control independently and at the same time. For example, a person might simultaneously believe that both oneself and powerful others influence outcomes, but that chance does not. The IPC Scales allow the identification of the three locus of control dimensions.

Mr. A and Mrs. B scores are similar to those of healthy Italian sample [67] (Table 4).

Nevertheless, Mr. A Internal score is higher than Mrs. B one (40 versus 28) and $\mathrm{Mr}$. A Chance score is lower (18 versus 25). The prominent internal locus of control of $\mathrm{Mr}$. A represents a resource: he is certain to control events of his own life, to obtain success thanks to hard work and to his own capacities and talent. Mrs. B has a less strong internal locus of control and she scarcely believes to the influence of fortune in determining her life.
It is essential to consider that these features could also be altered by the specific disorder outcome: Mr. A positive response and complete stable recover could have contributed to his confidence, while Mrs. B repeated unsuccessful treatments have certainly emphasized her feelings of powerlessness.

\section{Coping styles}

Besides, we have considered the coping styles of Mr. A and Mrs. B, administering them the 28 items Brief COPE by Carver [69] (Table 5). It has not been validated in Italy. The questionnaire allows the identification of fourteen coping styles: Positive Reorganization, Attention Withdraw, Expression, Instrumental Support, Operatively Facing Up, Negation, Religion, Humor, Behavioral Disengagement, Emotional Support, Substance Use, Acceptation, Planning, Self Blaming.

We focused our attention on marked differences between the two patients $(\geq 4)$. Mr. A uses more adaptive and pragmatic coping strategies like Operatively Facing Up, Acceptation and Planning. Nevertheless, Mrs. B seems to have a positive, essential resource too: the support of Religion. Moreover, she usually looks for advices and aids from oth- 
Table 4: Mr. A and Mrs. B IPC Scales mean scores and healthy sample mean scores.

\begin{tabular}{|c|c|c|c|c|}
\hline Locus of Control scales & $\begin{array}{l}\text { Healthy Men Sample Scores } \\
\text { (Mean } \pm \text { SD) }\end{array}$ & Mr. A Scores & $\begin{array}{c}\text { Healthy Women Sample Scores } \\
\text { (Mean } \pm \text { SD) }\end{array}$ & Mrs. B Scores \\
\hline Internal & $32.54 \pm 8.35$ & 40 & $30.35 \pm 9.12$ & 28 \\
\hline Powerful Others & $18.16 \pm 8.59$ & 8 & $17.04 \pm 8.67$ & 9 \\
\hline Chance & $19.16 \pm 8.92$ & 18 & $20.94 \pm 8.40$ & 25 \\
\hline
\end{tabular}

ers (Instrumental Support); this coping style could be the result of Mrs. B dependent personality traits (like difficulties to do things autonomously).

\section{Self esteem}

To assess Mr. A and Mrs. B self esteem we have administered them the 10 items Self Esteem Scale by Rosenberg [70]. We would expect to observe Mrs. B scores lower than Mr. A ones, also considering her depressive symptomatology. Nonetheless, contrary to all expectations, their self esteem level did not differ. This fact is contrasting with the observation of lower self esteem in euthymic depressed subjects [71] and we are unable to explain this other that some contingent factor that could have influenced it.

\section{Cognitive features}

The Wechsler Adult Intelligence Scale - Revised (WAIS-R) [72] was administered to Mr. A and Mrs. B to evaluate their cognitive functioning and their intelligence quotient.

Mr. A Total IQ was 136, Verbal IQ 126 and Performance IQ 138; Mrs. B obtained lower scores: Total IQ was 112, Verbal IQ 104 and Performance IQ 121. Mr. A scores would suggest that he has more cognitive resources than Mrs. B, but, considering that WAIS-R assesses also the

Table 5: Mr. A and Mrs. B Brief COPE mean scores. The asterisk indicates marked differences between the two patients $(\geq 4)$.

\begin{tabular}{lcc}
\hline Coping Styles & Mr. A Scores & Mrs. B Scores \\
\hline Positive Reorganization & 4 & 6 \\
Attention Withdraw & 2 & 5 \\
Expression & 7 & 5 \\
Instrumental Support & 2 & $7^{*}$ \\
Operatively Facing Up & $8^{*}$ & 4 \\
Negation & 2 & 3 \\
Religion & 2 & $8^{*}$ \\
Humor & 4 & 5 \\
Behavioral Disengagement & 2 & 5 \\
Emotional Support & 6 & 5 \\
Substance Use & 2 & 2 \\
Acceptation & $8^{*}$ & 4 \\
Planning & $8^{*}$ & 4 \\
Self Blaming & 7 & 4 \\
\hline
\end{tabular}

individuals education level, we could observe that the differences between the two scores could be due to the disparity of Mr. A and Mrs. B education years (18 in the case of Mr. A versus 5 in the case of Mrs. B). Furthermore, their different occupations, in terms of cognitive involvement, (industrial manager versus housewife) could influence the outcome.

Finally, cognitive function has been found impaired during acute episodes, particularly attention, learning and memory, psychomotor functioning and frontal executive functions [73] and this could be another possible explanation of the difference in the two scores [74]. Considering all these observations, it is possible to state that both patients have good cognitive resources.

\section{Social features}

\section{Social adjustment}

We have also considered the social adjustment of Mr. A and Mrs. B (Table 6), administering them the Social Adjustment Scale Self-Report (SAS-SR) [75]. The questionnaire has been validated in many countries including Italy and it evaluates six adjustment areas: Work, Spare Time, Family, Children, Family Unity, Finance.

Considering the fact that higher scores correspond to higher impairment, we can observe that Mrs. B reported scores that evidence some impairment in the social functioning. This has been previously observed for patients with mood disorder even in their remission phase $[71,76]$. Mr. B functioning, compared with control one, is worse in all areas, with the exception of Family field. Moreover, comparing Mr. A and Mrs. B scores, a relevant divergence could be detected in the Spare Time area (1.8 versus 3.2).

Since social functioning can be evaluated as an outcome of treatment [77], Mrs. B higher social impairment has surely been modulated by the absence of any positive effect.

\section{Morningness-eveningness preference}

Finally, we have evaluated Mr. A and Mrs. B morningness or eveningness preference administering them the Morningness-Eveningness Self-Assessment Questionnaire [78]. 
Table 6: Mr. A and Mrs. B SAS-SR mean scores.

\begin{tabular}{lccc}
\hline Social Adjustment Areas & Healthy Sample Scores (Mean \pm SD) & Mr. A Scores & Mrs. B Scores \\
\hline Work & $1.24 \pm 0.56$ & 1.5 & 1.7 \\
Spare Time & $1.77 \pm 0.43$ & 1.8 & 3.2 \\
Family & $1.56 \pm 0.39$ & 1.2 & 1.4 \\
Children & $0.76 \pm 0.80$ & 1 & 1.5 \\
Family Unity & $1.07 \pm 0.68$ & 1 & 1.7 \\
Finance & $1.25 \pm 0.56$ & 1 \\
\hline
\end{tabular}

Since mood disorders are characterized by circadian rhythm abnormalities [79], we tried to analyze both Mr. A and Mrs. B rhythm profile. Mr. A reported morningness preference scores markedly higher than Mrs. B one (71 versus 47).

Recent studies showed that a single nucleotide polymorphism (T3111C), located in the 3' flanking region of the human CLOCK gene, was associated with diurnal preferences of human healthy subjects, with higher eveningness in subjects carrying at least one copy of the C allele [80]. In another study the possible role of the same polymorphism in the regulation of diurnal mood fluctuations during a major depressive episode was investigated; Authors observed a significantly worse outcome in homozygotes for the $\mathrm{C}$ variant [81].

Consequently, it is possible to hypothesize a link between eveningness and higher recurrence and, also in this case, Mrs. B condition could be representative of this connection.

\section{Conclusion}

This manuscript aimed to analyse in depth the mixture of aspects contributing to depressive disorders outcome. It is interesting to consider that, from the standard assessment point of view, Mr. A and Mrs. B differ one from another only for what concerns therapy response: both are affected by recurrent major depression, no major somatic or neurologic disorder is present, no other DSM-IV axis I comorbidity. Subsequently, patients with so divergent clinical history in standard research terms are similar. On the contrary, the complexity and heterogeneity of the individual case should be meticulously taken into account.

Summarizing, we can consider Mr. A depression like adaptive since it has facilitated detachment and a more balanced involvement in his life. In fact, depressive disorder has long been explored in terms of adaptive and maladaptive functions [82]. Some depressive disorders, at mild levels, can be adaptive if they enable individuals to disengage from aversive environments and to relocate or elicit new resources from the environment [83-85]. Moreover, Mr. A meticulousness and his strict involvement in work- ing area could have an essential protective function for him.

On the contrary, in Mrs. B case depression has maladaptive functions. The impact of prior pharmacological interventions on Mrs. B may have been adversely affected by several factors: 1) personality factors such as high Harm Avoidance and low Novelty Seeking and Self-Directedness; 2) Avoidant Personality Disorder, which prevents Mrs. B from putting her energy in new social situations; 3 ) Dependent Personality traits and their combination with the loss of her husband; 4) immature defensive mechanisms at intrapsychic level; 5) a therapeutic alliance probably based on omnipotence attributions. We can also hypothesize a different way to react to previous losses and aversive environments: Abraham indicates, among the factors of melancholia, the repeating of situations of loss and mourning [86]. This different way can be found in specific personality organization in which is very difficult to promote the change [87].

Subsequently, we could notice that the role of intrapsychic factors as clinical predictors of non response appears fundamental in the cases presented, especially for what concerns the constellation of individual temperament and personality traits, personality disorders, defensive mechanisms and locus of control. Nevertheless, this presentation has only a suggestive aim, given that no formal (statistical) demonstration has been provided of the predictive value of the reported factors. The differences we observed could be due to chance variations, however we observed associations with poor outcome that were in the direction hypothesized by the a-priori knowledge (e.g. dependent personality profile, lack of maturity, lack of social support) but that have never been joined in a comprehensive assessment.

This last point is the main limitation of our paper: as we stated in the introduction section we did not perform a large, prospective, cohort study with a comprehensive assessment. Such a study would require an extraordinary organizational and economic effort. Even the largest funding agency available to date did only organize a much smaller follow up [20]. We are also aware that two sub- 
jects, of different sex, can be only described and no generalizability is possible.

The choice of the test is also a crucial point. A number of features could be measured with a number of instruments. This article is not aimed for a review of all possible predictors $[10,13,14,16,17]$. We followed the guideline of investigating features previously associated with outcome and using validated instruments used in previous studies. The indications we reported may therefore be of use for larger studies where some of the features we propose could be included. This would improve informativeness and generalizability of clinical trial results $[1,88]$.

Further, a more detailed dissection of depressive status could be of benefit for biologic and specifically genetic studies, where the small variances explained by single gene variant require a careful control of environmental confounders [4]. Alternatively genes may themselves control for basic features [89] such as temperament [90,91], drug response [92], IQ [93], or complex combinations of features [5].

In conclusion, we suggest that the inclusion of a set of assessment that more deeply investigate the patient status may help in filling the gap between routine clinical activity and standardized assessments for pharmacologic or biologic studies.

\section{Key points}

- Clinical trial samples are scarcely representative of 'real' patients

- Standardized clinical assessment is very limited and does not take into account many subtle variables that predict antidepressant response in the everyday clinical practice

- Those variables include personality, temperament, defense mechanisms, self esteem and social adjustment

- Inclusion of those variables in the evaluation is costly but increases validity and representativity for clinical and biologic studies

\section{Competing interests}

The author(s) declare that they have no competing interests.

\section{Authors' contributions}

AS conceived of the study, and participated in its design and coordination and helped to draft the manuscript. RC drafted the manuscript. OO drafted and supervised the psychoanalytic sections. DD drafted the personality sections. CC drafted conclusions and supervised the clinical process. All authors read and approved the final manuscript.

\section{Acknowledgements}

none.

\section{References}

I. Posternak MA, Zimmerman M, Keitner GI, Miller IW: A reevaluation of the exclusion criteria used in antidepressant efficacy trials. Am J Psychiatry 2002, I 59:191-200.

2. Seeman MV: Clinical trials in psychiatry: do results apply to practice? Can J Psychiatry 200I, 46:352-355.

3. Steffensmeier JJ, Ernst ME, Kelly M, Hartz AJ: Do randomized controlled trials always trump case reports? A second look at propranolol and depression. Pharmacotherapy 2006, 26:162-167.

4. Kendler KS: "A gene for...": the nature of gene action in psychiatric disorders. Am J Psychiatry 2005, I 62: I 243-1252.

5. Serretti A, Calati R, Mandelli L, De Ronchi D: Serotonin transporter gene variants and behaviour: a comprehensive review. Current Drug Targets 2006, 7:1659-1669.

6. Engel GL: The need for a new medical model: a challenge for biomedicine. Science 1977, 196:129-136.

7. W.H.O.: International Classification of Impairments, Disabilities and Handicaps. 1980.

8. Angst ]: The Prognosis of Antidepressive Treatments: Longitudinal and Genetic Studies. Anglo Ger Med Rev 1965, 2:733-75I.

9. Joyce PR, Paykel ES: Predictors of drug response in depression. Archives of General Psychiatry 1989, 46:89-99.

10. Spillmann M, Borus JS, Davidson KG, Worthington JJ 3rd, Tedlow JR, Fava M: Sociodemographic predictors of response to antidepressant treatment. Int J Psychiatry Med 1997, 27:129-136.

II. Alvarez JC, Gluck N, Fallet A, Gregoire A, Chevalier JF, Advenier C, Spreux-Varoquaux O: Plasma serotonin level after I day of fluoxetine treatment: a biological predictor for antidepressant response? Psychopharmacology 1999, I43:97-I0I.

12. Sato T, Hirano S, Narita T, Kusunoki K, Kato J, Goto M, Sakado K, Uehara $T$ : Temperament and character inventory dimensions as a predictor of response to antidepressant treatment in major depression. J Affect Disord 1999, 56:153-161.

13. Bagby RM, Ryder AG, Cristi C: Psychosocial and clinical predictors of response to pharmacotherapy for depression. J Psychiatry Neurosci 2002, 27:250-257.

14. Esposito K, Goodnick P: Predictors of response in depression. Psychiatr Clin North Am 2003, 26:353-365.

15. Nierenberg AA: Predictors of response to antidepressants general principals and clinical implications. Psychiatr Clin North Am 2003, 26:345-352.

16. Serretti A, Zanardi R, Mandelli L, Smeraldi E, Colombo C: A neural network model for combining clinical predictors of antidepressant response in mood disorders. Journal of Affective Disorders in press.

17. Trivedi MH, Morris DW, Grannemann BD, Mahadi S: Symptom clusters as predictors of late response to antidepressant treatment. J Clin Psychiatry 2005, 66:1064-1070.

18. Perlis RH, Alpert J, Nierenberg AA, Mischoulon D, Yeung A, Rosenbaum JF, Fava M: Clinical and sociodemographic predictors of response to augmentation, or dose increase among depressed outpatients resistant to fluoxetine $\mathbf{2 0} \mathbf{~ m g} /$ day. Acta Psychiatr Scand 2003, 108:432-438.

19. Papakostas GI, Petersen T, Mischoulon D, Hughes ME, Spector AR, Alpert JE, Fava M, Nierenberg AA: Functioning and interpersonal relationships as predictors of response in treatment-resistant depression. Compr Psychiatry 2003, 44:44-50.

20. Fava M, Rush AJ, Trivedi MH, Nierenberg AA, Thase ME, Sackeim HA, Quitkin FM, Wisniewski S, Lavori PW, Rosenbaum JF, Kupfer DJ: Background and rationale for the sequenced treatment alternatives to relieve depression (STAR*D) study. Psychiatr Clin North Am 2003, 26:457-94, x.

21. Kendler KS, Gardner CO, Prescott CA: Toward a comprehensive developmental model for major depression in women. $\mathrm{Am} J$ Psychiatry 2002, I 59: I | 33- I | 45.

22. Kendler KS, Karkowski LM, Prescott CA: Causal relationship between stressful life events and the onset of major depression. American Journal of Psychiatry 1999, I 56:837-84I. 
23. Kendler KS, Gardner CO, Neale MC, Prescott CA: Genetic risk factors for major depression in men and women: similar or different heritabilities and same or partly distinct genes? Psychol Med 200I, $31: 605-616$.

24. Kendler KS, Kessler RC, Walters EE, MacLean C, Neale MC, Heath $A C$, Eaves LJ: Stressful life events, genetic liability, and onset of an episode of major depression in women. Am J Psychiatry 1995, 152:833-842.

25. Winterer G, Ziller M, Linden M: Classification of observational data with artificial neural networks versus discriminant analysis in pharmacoepidemiological studies--can outcome of fluoxetine treatment be predicted? Pharmacopsychiatry 1998, 31:225-23I.

26. Tsuang MT, Faraone SV: The genetics of mood disorders. Baltimore, The Johns Hopkins University Press; 1990: I-3I.

27. Franchini L, Serretti A, Gasperini M, Smeraldi E: Familial concordance of fluvoxamine response as a tool for differentiating mood disorder pedigrees. Journal of Psychiatric Research 1998, 32:255-259.

28. Serretti A, Franchini L, Gasperini M, Rampoldi R, Smeraldi E: Mode of inheritance in mood disorders families according to fluvoxamine response. Acta Psychiatrica Scandinavica 1998, 98:443-450.

29. Millon T, Davis RD: Disorders of Personality: DSM-IV and Beyond. , 2nd Edition edition. , John Wiley \& Sons; 1995.

30. Hall CS, Lindzey G, Loehlin JC, Manosevitz M: Introduction to Theories of Personality. New York, John Wiley and Sons; 1985.

31. Cloninger CR, Svrakic DM, Przybeck TR: A psychobiological model of temperament and character. Arch Gen Psychiatry 1993, 50:975-990.

32. Cloninger CR, Przybeck TR, Svrakic DM, Wetzel RD: The temperament and character inventory (TCl): a guide to its development and use. St.Louis, Missouri, Center for Psychobiology of Personality Washington University; 1994.

33. Abrams KY, Yune SK, Kim SJ, Jeon HJ, Han SJ, Hwang J, Sung YH, Lee $\mathrm{KJ}$, Lyoo IK: Trait and state aspects of harm avoidance and its implication for treatment in major depressive disorder, dysthymic disorder, and depressive personality disorder. Psychiatry Clin Neurosci 2004, 58:240-248.

34. Smith DJ, Duffy L, Stewart ME, Muir WJ, Blackwood DH: High harm avoidance and low self-directedness in euthymic young adults with recurrent, early-onset depression. I Affect Disord 2005, 87:83-89.

35. Jurado D, Gurpegui M, Moreno O, Fernandez MC, Luna JD, Galvez R: Association of personality and work conditions with depressive symptoms. Eur Psychiatry 2005, 20:213-222.

36. Freud S: Lutto e melanconia. In Opere Sigmund Freud Volume 8. Torino, Bollati Boringhieri; 1917.

37. Matsudaira T, Kitamura T: Personality traits as risk factors of depression and anxiety among Japanese students. J Clin Psychol 2005, 62:97-109.

38. Cloninger CR, Przybeck TR, Svrakic DM: The Tridimensional Personality Questionnaire: U.S. normative data. Psychol Rep 1991, 69:1047-1057

39. Young LT, Bagby RM, Cooke RG, Parker JD, Levitt AJ, Joffe RT: A comparison of Tridimensional Personality Questionnaire dimensions in bipolar disorder and unipolar depression. Psychiatry Res 1995, 58:139-143.

40. de la Rie SM, Duijsens IJ, Cloninger CR: Temperament, character, and personality disorders. J Personal Disord I998, I 2:362-372.

4I. Hansenne M, Reggers J, Pinto E, Kjiri K, Ajamier A, Ansseau M: Temperament and character inventory $(\mathrm{TCl})$ and depression. J Psychiatr Res 1999, 33:31-36.

42. Farmer A, Mahmood A, Redman K, Harris T, Sadler S, McGuffin P: A sib-pair study of the temperament and character inventory scales in major depression. Arch Gen Psychiatry 2003, 60:490-496.

43. First MB, Spitzer RL, Gibbon M, Williams BW, Benjamin L: Structured Clinical Interview for DSM-IV Axis II Personality Disorders (SCID-II). , New York: Biometrics Research Department, New York State Psychiatric Institute; 1990.

44. Corruble E, Ginestet D, Guelfi JD: Comorbidity of personality disorders and unipolar major depression: a review. J Affect Disord 1996, 37:157-170.

45. Ilardi SS, Craighead WE, Evans DD: Modeling relapse in unipolar depression: the effects of dysfunctional cognitions and personality disorders. J Consult Clin Psychol 1997, 65:38I-39I.
46. Newton-Howes G, Tyrer P, Johnson T: Personality disorder and the outcome of depression: meta-analysis of published studies. Br J Psychiatry 2006, I88:13-20.

47. Mulder RT: Personality pathology and treatment outcome in major depression: a review. Am J Psychiatry 2002, 159:359-37I.

48. Devanand DP: Comorbid psychiatric disorders in late life depression. Biol Psychiatry 2002, 52:236-242.

49. Russell JM, Kornstein SG, Shea MT, McCullough JP, Harrison WM, Hirschfeld RM, Keller MB: Chronic Depression and Comorbid Personality Disorders: Response to Sertraline Versus Imipramine. J Clin Psychiatry 2003, 64:554-56I.

50. Casey P, Birbeck G, McDonagh C, Horgan A, Dowrick C, Dalgard O Lethinen V, Ayuso-Mateos JL, Dunn G, Page H, Wilkinson C, Wilkinson G, Vazquez-Barquero JL: Personality disorder, depression and functioning: results from the ODIN study. J Affect Disord 2004, 82:277-283.

51. Schiavone P, Dorz S, Conforti D, Scarso C, Borgherini G: Comorbidity of DSM-IV Personality Disorders in unipolar and bipolar affective disorders: a comparative study. Psychol Rep 2004, 95: $121-128$

52. Johnson JG, Cohen P, Kasen S, Brook JS: Personality disorder traits associated with risk for unipolar depression during middle adulthood. Psychiatry Res 2005, 136: |13-121.

53. Nubukpo P, Hartmann J, Clement JP: [Role of personality in depression of the elderly: difference between early and late life depression]. Psychol Neuropsychiatr Vieil 2005, 3:63-69.

54. Ampollini P, Marchesi C, Signifredi R, Ghinaglia E, Scardovi F, Codeluppi $S$, Maggini $C$ : Temperament and personality features in patients with major depression, panic disorder and mixed conditions. J Affect Disord 1999, 52:203-207.

55. Viinamaki $\mathrm{H}$, Hintikka J, Honkalampi $\mathrm{K}$, Koivumaa-Honkanen $\mathrm{H}$, Kuisma S, Antikainen R, Tanskanen A, Lehtonen J: Cluster C personality disorder impedes alleviation of symptoms in major depression. J Affect Disord 2002, 71:35-4I.

56. Viinamaki $H$, Tanskanen A, Koivumaa-Honkanen $H$, Haatainen $K$, Honkalampi K, Antikainen R, Hintikka J: Cluster $\mathbf{C}$ personality disorder and recovery from major depression: 24-month prospective follow-up. J Personal Disord 2003, I 7:34I-350.

57. Grilo CM, Sanislow CA, Shea MT, Skodol AE, Stout RL, Gunderson JG, Yen S, Bender DS, Pagano ME, Zanarini MC, Morey LC, McGlashan TH: Two-year prospective naturalistic study of remission from major depressive disorder as a function of personality disorder comorbidity. J Consult Clin Psychol 2005, 73:78-85.

58. Morse JQ, Pilkonis PA, Houck PR, Frank E, Reynolds CF 3rd: Impact of Cluster C Personality Disorders on Outcomes of Acute and Maintenance Treatment in Late-Life Depression. Am J Geriatr Psychiatry 2005, I3:808-8|4.

59. Brieger P, Ehrt $U$, Bloeink R, Marneros A: Consequences of comorbid personality disorders in major depression. J Nerv Ment Dis 2002, 190:304-309.

60. Mulder RT, Joyce PR, Sullivan PF, Bulik CM, Carter FA: The relationship among three models of personality psychopathology: DSM-III-R personality disorder, $\mathrm{TCl}$ scores and DSQ defences. Psychol Med 1999, 29:943-951.

61. Bond MP, Vaillant JS: An empirical study of the relationship between diagnosis and defense style. Arch Gen Psychiatry 1986, 43:285-288.

62. San Martini P, Roma P, Sarti S, Lingiardi V, Bond M: Italian version of the defense style questionnaire. Compr Psychiatry 2004, 45:483-494.

63. Abraham K: Giovanni Segantini: un saggio psicoanalitico. In Opere Karl Abraham Volume 2. Torino, Bollati Boringhieri; 191 I.

64. Klein M: II complesso edipico alla luce delle angosce primitive. In Scritti 192 I-1958 Torino, Bollati Boringhieri; 1945.

65. Mullen LS, Blanco C, Vaughan SC, Vaughan R, Roose SP: Defense mechanisms and personality in depression. 1999:168-174.

66. Levenson $\mathrm{H}$ : Multidimensional locus of control in psychiatric patients. Journal of Consulting and Clinical Psychology 1973, 41:397-404.

67. Nigro G, Galli I: La fortuna, l'abilità, il caso. Introduzione allo studio del locus of control. Centro Scientifico; 1988.

68. Rotter JB: Generalized expectancies for internal versus external control of reinforcement. Psychological Monographs 1966, 80: 
69. Carver CS: You want to measure coping but your protocol's too long: Consider the Brief COPE. International Journal of Behavioral Medicine 1997, 4:92-100.

70. Rosenberg M: The measurement of self-esteem. In Society and the Adolescent Self-Image, Princeton University Press; 1965:16-36.

7I. Serretti A, Cavallini MC, Macciardi F, Namia C, Franchini L, Souery D, Lipp O, Bauwens F, Smeraldi E, Mendlewicz J: Social adjustment and self-esteem in remitted patients with mood disorders. European Psychiatry 1999, I 4: 137-142.

72. Wechsler D: Manual for the wechsler Intelligence ScaleRevised (WAIS-R). New York, The Psychological Corporation 1981.

73. Quraishi S, Frangou S: Neuropsychology of bipolar disorder: a review. J Affect Disord 2002, 72:209-226.

74. Mandelli L, Serretti A, Colombo C, Florita M, Santoro A, Rossini D, Zanardi R, Smeraldi E: Improvement of cognitive functioning in mood disorder patients with depressive symptomatic recovery during treatment: An exploratory analysis. Psychiatry Clin Neurosci 2006, 60:598-604.

75. Weissman MM, Bothwell S: Assessment of social adjustment by patient self-report. Archives of General Psychiatry 1976, 33:IIII-III5.

76. Pardoen D, Bauwens F, Tracy AS, Martin F, Mendlewicz J: Self esteem in recovered Bipolar and Unipolar outpatients. $\mathrm{Br} J$ Psychiatry 1993, 163:755-762.

77. Weissman MM: Social functioning and the treatment of depression. J Clin Psychiatry 2000, 6 I Suppl I:33-38.

78. Horne JA, Ostberg $O$ : A self-assessment questionnaire to determine morningness-eveningness in human circadian rhythms. International Journal of Chronobiology 1976, 4:97-I I0.

79. Wehr TA, Sack D, Rosenthal N, Duncan W, Gillin JC: Circadian rhythm disturbances in manic-depressive illness. Federation proceedings I983, 42:2809-28I4

80. Katzenberg D, Young T, Finn L, Lin L, King DP, Takahashi JS, Mignot E: A CLOCK polymorphism associated with human diurnal preference. Sleep 1998, $21: 569-576$.

81. Benedetti F, Serretti A, Colombo C, Barbini B, Lorenzi C, Campori E, Smeraldi E: Influence of CLOCK gene polymorphism on circadian mood fluctuation and illness recurrence in bipolar depression. Am J Med Genet 2003, I 23B:23-26.

82. Allen NB, Badcock PB: Darwinian models of depression: a review of evolutionary accounts of mood and mood disorders. Prog Neuropsychopharmacol Biol Psychiatry 2006, 30:8I5-826.

83. Gilbert P: Depression: the evolution of powerlessness. , Psychology Press; 1992:561.

84. Nesse R: Emotional disorders in evolutionary perspective. $\mathrm{Br}$ J Med Psychol 1998, 71:397-415.

85. Keller MC, Nesse RM: Is low mood an adaptation? Evidence for subtypes with symptoms that match precipitants. J Affect Disord 2005, 86:27-35.

86. Abraham K: Tentativo di una storia evolutiva della libido sulla base della psicoanalisi dei disturbi psichici. In Opere Karl Abraham Volume I. Torino, Bollati Boringhieri; 1924.

87. Benjamin LS: Interpersonal Reconstructive Therapy. Promoting Change in Nonresponders. New York, Guilford Press; 2003.

88. Zimmerman M, Mattia JI, Posternak MA: Are subjects in pharmacological treatment trials of depression representative of patients in routine clinical practice? Am J Psychiatry 2002, 159:469-473.

89. Hasler G, Drevets WC, Gould TD, Gottesman, Manji HK: Toward constructing an endophenotype strategy for bipolar disorders. Biol Psychiatry 2006, 60:93-105.

90. Ebstein RP: The molecular genetic architecture of human personality: beyond self-report questionnaires. Mol Psychiatry 2006, I I:427-445.

91. Serretti A, Mandelli L, Lorenzi C, Landoni S, Calati R, Insacco C, Cloninger CR: Temperament and character in mood disorders: influence of DRD4, SERTPR, TPH and MAO-A polymorphisms. Neuropsychobiology 2006, 53:9-16.

92. Serretti A, Artioli P, Quartesan R: Pharmacogenetics in the treatment of depression: pharmacodynamic studies. Pharmacogenet Genomics 2005, 15:6I-67.

93. Toga AW, Thompson PM: Genetics of brain structure and intelligence. Annu Rev Neurosci 2005, 28: 1-23.
Publish with Bio Med Central and every scientist can read your work free of charge

"BioMed Central will be the most significant development for disseminating the results of biomedical research in our lifetime. "

Sir Paul Nurse, Cancer Research UK

Your research papers will be:

- available free of charge to the entire biomedical community

- peer reviewed and published immediately upon acceptance

- cited in PubMed and archived on PubMed Central

- yours - you keep the copyright
BioMedcentral 
Chapter 10: Meta-analysis of serotonin transporter gene promoter polymorphism (5-HTTLPR) association with selective serotonin reuptake inhibitor efficacy in depressed patients 


\title{
Meta-analysis of serotonin transporter gene promoter polymorphism (5-HTTLPR) association with selective serotonin reuptake inhibitor efficacy in depressed patients
}

\author{
A Serretti ${ }^{1}$, M Kato $^{1,2}$, D De Ronchi ${ }^{1}$ and T Kinoshita ${ }^{2}$ \\ ${ }^{1}$ Institute of Psychiatry, University of Bologna, Bologna, Italy and ${ }^{2}$ Department of Neuropsychiatry, Kansai Medical University, \\ Osaka, Japan
}

\begin{abstract}
The serotonin transporter gene promoter polymorphism (5-HTTLPR) has been repeatedly associated with antidepressant response in mood disorder patients, but findings are not consistent across studies. A meta-analysis was performed on 15 studies including data of 1435 subjects. We tested three phenotypes: remission rate, response rate and response rate within 4 weeks using the cochrane review manager. We observed a significant association of the $\mathrm{s} / \mathrm{s}$ variant of 5-HTTLPR with remission rate $(P<0.0001)$ and both $s / s$ and $s / l$ variants with response rate $(P=0.0002)$. Response rate within 4 weeks was associated in both models $(P=0.003-$ $P<0.00001)$. This effect is quite robust to ethnic differences although a significant heterogeneity is present in Asian samples.
\end{abstract}

Molecular Psychiatry (2007) 12, 247-257. doi:10.1038/sj.mp.4001926; published online 5 December 2006

Keywords: depression; meta-analysis; 5-HTTLPR; polymorphism; treatment response; SSRI

\section{Introduction}

Mood disorders have a large impact on social health, with considerable both direct and indirect costs. ${ }^{1-4}$ Selective serotonin reuptake inhibitors (SSRIs) treatment reduced their morbidity with a favorable side effect profile. Unfortunately, not all individuals benefit from treatment, and $30-40 \%$ of patients do not show a complete response to treatment. ${ }^{5,6}$

The first step of SSRIs action is to inhibit the serotonin transporter (5-HTT) and thus modulate the serotonergic activity. The human gene encoding 5HTT is located on chromosome 17q-11.1-q12, it spans $31 \mathrm{~kb}$ and consists of 14 exons. Heils et al. ${ }^{7}$ reported a functional polymorphism in the transcriptional control region upstream of the 5-HTT coding sequence (5-HTTLPR). Since then, this polymorphism has been the most widely studied in psychiatric genetics for its high number of effects. ${ }^{8}$ Of particular interest is the association with SSRI efficacy. Our group performed the first studies, and tested the hypothesis that 5HTTLPR was related to the response to fluvoxamine and/or augmentation with pindolol in 102 inpatients with major depression. ${ }^{9}$ The carriers of the long allele showed a better response to fluvoxamine compared to those who were homozygous for the short allelic variant. Following this pilot study, the association between 5-HTTLPR and response in patients with

Correspondence: Dr A Serretti, Institute of Psychiatry, University of Bologna, Viale Carlo Pepoli 5, 40123 Bologna, Italy.

E-mail: alessandro.serretti@unibo.it

Received 26 July 2006; revised 31 August 2006; accepted 25 September 2006; published online 5 December 2006 mood disorder has been investigated by a large number of studies, but findings are not always consistent. Significant associations between the long variant and a good response have been reported, but other studies did not confirm these findings. ${ }^{10,11}$

Meta-analysis are a powerful and useful tool to investigate discrepant findings ${ }^{12}$ and this method helped also in the possible association between 5HTTLPR and mood disorders. ${ }^{13,14}$

However, no article has pooled and analyzed all the data from studies testing associations of 5-HTTLPR with treatment response. The purpose of this study is the reevaluation of the association between 5HTTLPR and clinical response to SSRIs treatment in patients with mood disorders pooling existing studies through a meta-analysis.

\section{Materials and methods}

To identify studies eligible for this meta-analysis, we searched Medline for all publications available up to July 2006 studying the association between SSRIs treatments and 5-HTTLPR in depressive patients with the key words affective, depression, mood, treatment response, serotonin transporter promoter region (SERTPR) and 5-HTTLPR. We also used reference lists from identified articles and reviews to find additional articles not indexed by MEDLINE. Studies were included in the current meta-analysis if they evaluated the association between clinical response to SSRIs treatments and 5-HTTLPR in patients diagnosed with major depressive disorder or bipolar disorder according to DSM criteria. Studies were 
excluded from the analysis if outcome was not evaluated as response or remission rate on a depression scale, and studies with overlapping patient samples were excluded to only include the study with the large number of patients. Authors were contacted when data were not reported in the article. Hardy-Weinberg equilibrium was examined in studies where genotype frequencies were included. ${ }^{9,15-25}$ Given the lack of unequivocal data for 5-HTTLPR genotype pooling, we tested both dominant and recessive hypotheses: $1 / 1$ versus $1 / s-s / s$ and $1 / 1-1 / s$ versus s/s. Outcome was defined with three phenotypes: remission rate, response rate, and response rate within 4 weeks. Subjects with pindolol augmentation were excluded given the observed influence of pindolol on the 5-HTTLPR effect. ${ }^{9}$

Remission was defined as a final Hamilton Rating Scale for Depression (HAM-D) total score of 7 or less. Response was defined as at least $50 \%$ decrease in HAM-D or Montgomery and Asberg Depression Rating Scale (MADRS) total score. In one study, ${ }^{17}$ response was defined as a $60 \%$ or greater decrease in MADRS. Remission is a quite robust outcome definition but response is more sensitive although quite non-specific. Moreover, the length of evaluation of response varied largely between studies. We therefore investigated separately response within 4 weeks of treatment and response at any length of observation (2-12 weeks). We focused on the response rate within 4 weeks because it is a sensitive measure to evaluate speed of response. Many studies presented the outcome of 4 weeks, while only three studies presented outcome within 2 weeks, and 6 weeks was too a long period to investigate speed of response. ${ }^{26}$

Remission was instead calculated at 6 weeks when possible, and in defect of data we used different observation lengths. When outcome data were not available in the article, we requested data from the author or estimated the number of response and remission from the presented figures. Data were entered into the Cochrane Collaboration review manager software (RevMan version 4.2) and analyzed by RevMan analysis 1.01. Heterogeneity between the studies was assessed with $\chi^{2}$ test. Individual and pooled odds ratio (OR) and associated 95\% CIs were calculated. A fixed-effect model was used in all analyses. We used the fixed-effect despite a moderate heterogeneity across studies given that we had no a priori reason to hypothesize data coming from different populations and because of the main aim of the present analysis being the identification of the best estimate of a single effect size more than the range of effect sizes across populations. ${ }^{12}$

\section{Results}

The literature search and selection produced 19 studies, ${ }^{9,15-25,27-33}$ but only 15 studies were included in current meta-analysis, as listed in Table 1. Studies by Kraft et al. ${ }^{28}$ and Minov et al. ${ }^{30}$ were excluded because they included patients treated by a mixture of antidepressants. The paper by Lee et $a l^{29}$ was not included because it did not use HAM-D or MADRS but Clinical Global Impressions of Improvement (CGI) score. The paper by Murphy et al. ${ }^{31}$ was not included because data were not available. Two studies ${ }^{17,19}$ used the DSM-III-R diagnostic criteria and all the other studies applied the DSM-IV diagnostic criteria.

\section{Analysis in the whole sample}

Figure 1 presents ORs for the individual studies and the pooled analyses in the $1 / 1$ and $1 /$ s genotype versus the s/s genotype subjects for the remission rate, response rate and response rate within 4 weeks. All studies except two showed an OR higher than 1. The pooled OR of seven studies of remission rate including 745 subjects was highly significant (2.21, $\mathrm{CI}=1.53-3.21, P<0.0001)$ and there was no evidence for heterogeneity across studies. Pooled OR of nine studies of response rate including 944 subjects was not significant $(1.20, \mathrm{CI}=0.90-1.60, P=0.21)$ but with a significant heterogeneity across studies $(P=0.001)$. When we considered only the five studies reporting response rate within 4 weeks including 633 subjects the effect of the 5-HTTLPR s/s genotype was again significant (1.72, $\mathrm{CI}=1.20-2.47, P=0.003$ ) with no heterogeneity across studies.

We then pooled the 1/l genotype versus the 1/s and s/s genotype and results were presented in Figure 2. Pooled OR of seven studies of remission rate including 745 subjects was $1.42(\mathrm{CI}=0.98-2.04, P=0.06)$ with no heterogeneity across studies. On the other hand, that of 10 studies of response rate including 1031 subjects was $2.01(\mathrm{CI}=1.39-2.89, P=0.0002)$ with heterogeneity across studies, whereas the effect in seven studies of response rate within 4 weeks including 771 subjects was significant $(\mathrm{OR}=2.57$, $\mathrm{CI}=1.70-3.88, \quad P<0.00001)$ without heterogeneity across studies.

To investigate whether ethnicity played a role in confounding the association between 5-HTTLPR and SSRIs response, we examined studies with Caucasian and Asian subjects separately.

\section{Analysis in Caucasian subjects}

The pooled analyses and OR in the $1 / 1$ and $1 / s$ genotype versus the s/s genotype within Caucasian subjects are presented in Figure 3. There was no evidence for heterogeneity and all OR were higher than 1. Pooled OR of five studies of remission rate including 544 subjects was highly significant $(2.37$, CI $=1.56-3.58, P<0.0001$ ), while the pooled OR of four studies of response rate including 345 subjects (1.53, CI $=0.90-2.59, P=0.11$ ) and the one of two studies of response rate within 4 weeks including 208 subjects $(1.37, \mathrm{CI}=0.65-2.88, P=0.40$ ) were not significant, although greater than 1 . Figure 4 presented the pooled analyses in the l/l genotype versus the $1 / \mathrm{s}$ and $\mathrm{s} / \mathrm{s}$ genotype. Pooled OR of five studies of remission rate including 544 subjects was not significant $(1.37, \mathrm{CI}=0.93-2.00, P=0.11$ ), whereas the pooled OR of five studies of response rate 
Table 1 Characteristics of studies investigating the association between SSRIs treatments and 5-HTTLPR in mood disorder patients

\begin{tabular}{|c|c|c|c|c|c|c|}
\hline Reference & $\begin{array}{l}\text { Type of SSRIs } \\
\text { (dose: } \mathrm{mg} / \text { day) }\end{array}$ & $N($ Male/Female $)$ & $\begin{array}{l}\text { Mean age } \\
\text { (years) }\end{array}$ & Ethnicity & $\begin{array}{l}\text { Inclusion } \\
\text { criteria }\end{array}$ & Evaluation \\
\hline Arias et $a .^{15}$ & $\begin{array}{l}\text { Citalopram } \\
(20-40)\end{array}$ & $131(31 / 100)$ & 40.0 & Caucasian & MD & $\begin{array}{l}\text { Response rate: } 4 \mathrm{w} \\
\text { Remission rate: } 12 \mathrm{w}\end{array}$ \\
\hline Durham et al. ${ }^{27}$ & $\begin{array}{l}\text { Sertraline } \\
(50-100)\end{array}$ & $106(47 / 59)$ & 69.7 & $\begin{array}{l}\text { Mostly } \\
\text { Caucasian }\end{array}$ & $\mathrm{MD}$ & $\begin{array}{l}\text { Response rate: } 2,4,6 \text {, } \\
8 \mathrm{w} \\
\text { Remission rate: } 12 \mathrm{w}\end{array}$ \\
\hline Hong et $a .^{16}$ & $\begin{array}{l}\text { Fluoxetine } \\
(20-40)\end{array}$ & $224(93 / 131)$ & 44.0 & Asian & MD & Response rate: $4 \mathrm{w}$ \\
\hline Joyce et al. ${ }^{17}$ & $\begin{array}{l}\text { Fluoxetine } \\
(10-80)\end{array}$ & 86 (not reported) & $\begin{array}{c}31.8 \\
\text { whole group }\end{array}$ & Caucasian & $\mathrm{MD}+\mathrm{BPII}$ & Response rate: $6 \mathrm{w}$ \\
\hline Kato et al. ${ }^{18}$ & $\begin{array}{l}\text { Fluvoxamine } \\
(50-150) \text { or } \\
\text { paroxetine } \\
(20-40)\end{array}$ & $80(44 / 36)$ & 43.9 & Asian & MD & $\begin{array}{l}\text { Response rate: } 2,4,6 \mathrm{w} \\
\text { Remission rate: } 6 \mathrm{w}\end{array}$ \\
\hline Kim et al. ${ }^{19}$ & $\begin{array}{l}\text { Fluoxetine } \\
(20-50) \text { or } \\
\text { paroxetine } \\
(20-60)\end{array}$ & $120(78 / 42)$ & 54.2 & Asian & $\begin{array}{l}\text { MD + BPI, II, } \\
\text { dysthymia }\end{array}$ & Response rate: 6w \\
\hline $\begin{array}{l}\text { Kirchheiner } \\
\text { et al. }{ }^{20}\end{array}$ & $\begin{array}{l}\text { Citalopram, } \\
\text { fluoxetine, } \\
\text { fluvoxamine, } \\
\text { paroxetine or } \\
\text { sertraline } \\
\text { (common } \\
\text { doses) }\end{array}$ & $77(22 / 55)$ & 44.0 & Caucasian & $\mathrm{MD}+\mathrm{BP}$ & Response rate: $3 w$ \\
\hline Pollock et al. ${ }^{32}$ & $\begin{array}{l}\text { Paroxetine } \\
(20-30)\end{array}$ & 51 (not reported) & $\begin{array}{c}72.0 \\
\text { whole group }\end{array}$ & Caucasian & $\mathrm{MD}$ & Response rate: $2 \mathrm{w}$ \\
\hline Rausch et al. ${ }^{33}$ & $\begin{array}{l}\text { Fluoxetine } \\
(0-40)\end{array}$ & 51 (not reported) & Not reported & Caucasian & MD & Response rate: $12 \mathrm{w}$ \\
\hline Serretti et al. ${ }^{21}$ & $\begin{array}{l}\text { Fluvoxamine } \\
\text { (up to 300) or } \\
\text { paroxetine } \\
\text { (up to } 40 \text { ) }\end{array}$ & $220(75 / 145)$ & 50.6 & Caucasian & $\mathrm{MD}+\mathrm{BP}$ & Remission rate: $6 w$ \\
\hline Smeraldi et $a l^{9}{ }^{9}$ & $\begin{array}{l}\text { Fluvoxamine } \\
(100-300)\end{array}$ & $53(16 / 37)$ & 49.0 & Caucasian & $\mathrm{MD}+\mathrm{BP}$ & Remission rate: $6 \mathrm{w}$ \\
\hline Yoshida et al. ${ }^{22}$ & $\begin{array}{l}\text { Fluvoxamine } \\
(50-200)\end{array}$ & $54(22 / 32)$ & 51.2 & Asian & MD & Response rate: $6 w$ \\
\hline Yu et $a .^{23}$ & $\begin{array}{l}\text { Fluoxetine } \\
(20-60)\end{array}$ & $121(70 / 51)$ & 44.7 & Asian & MD & $\begin{array}{l}\text { Response rate: } 4 \mathrm{w} \\
\text { Remission rate: } 4 \mathrm{w}\end{array}$ \\
\hline Zanardi et al. ${ }^{24}$ & Paroxetine (40) & $58(15 / 43)$ & 47.7 & Caucasian & $\mathrm{MD}+\mathrm{BP}$ & Remission rate: $4 \mathrm{w}$ \\
\hline Zanardi et $a .^{25}$ & $\begin{array}{l}\text { Fluvoxamine } \\
(100-300)\end{array}$ & $88(25 / 63)$ & 52.0 & Caucasian & $\mathrm{MD}+\mathrm{BP}$ & Remission rate: $6 w$ \\
\hline
\end{tabular}

Abbreviations: MD, major depression; BP, bipolar disorder.

including 432 subjects $(1.74, \mathrm{CI}=1.10-2.76, P=0.02)$ and those of four studies of response rate within 4 weeks including 346 subjects $(1.75, \mathrm{CI}=1.07-2.88$, $P=0.03$ ) was significant. Overall in Caucasians, we observed an association of the s/s genotype with nonremission and of the s containing genotype with nonresponse but with some reduction in the significance possibly due to the smaller number of studies included.

\section{Analysis in Asian subjects}

Figure 5 presented results for Asian subjects. Pooled OR of two studies of remission rate including
201 subjects demonstrated a nonsignificant trend of favorable response to SSRIs in the 1/1 or 1/s genotype carrier $(1.70, \mathrm{CI}=0.74-3.93, P=0.21)$ with no evidence for heterogeneity. Pooled OR of the five studies of response rate including 599 subjects was not significant (1.09, CI $=0.78-1.53, P=0.62$ ) but with evidence for large heterogeneity $(P<0.0001)$. In fact the neutral OR of 1.09 is due to the sum of three studies showing a worse response effect of the s/s genotype and two studies reporting a protective effect of the s/s genotype. However, analyzing response rate within 4 weeks there was no evidence for heterogeneity across three studies including 425 subjects 
Remission

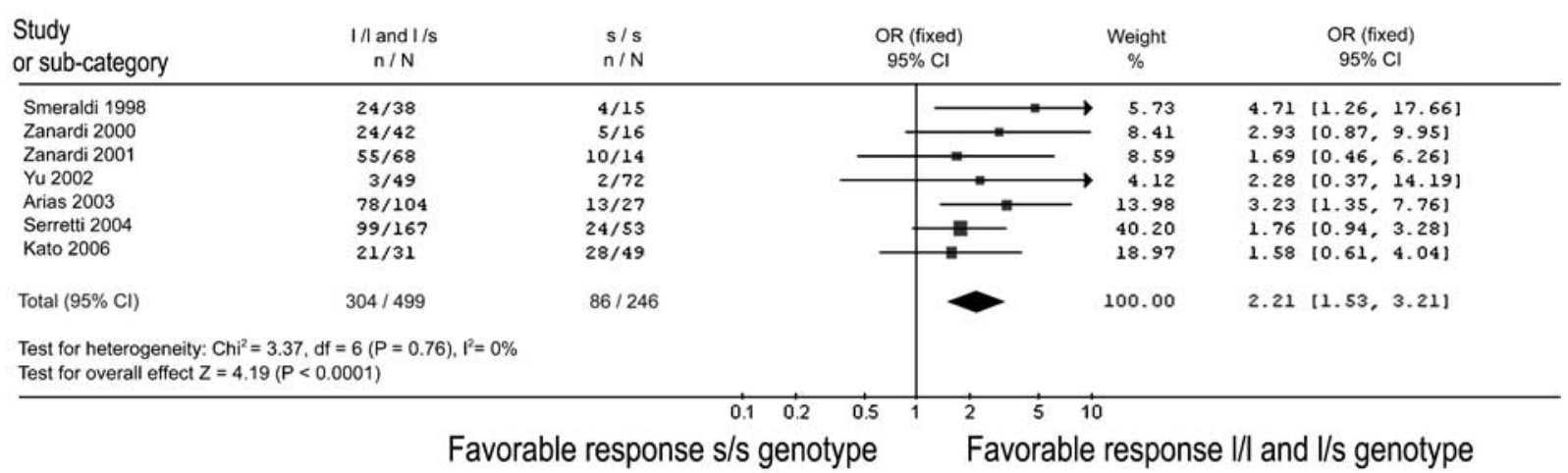

\section{Response}

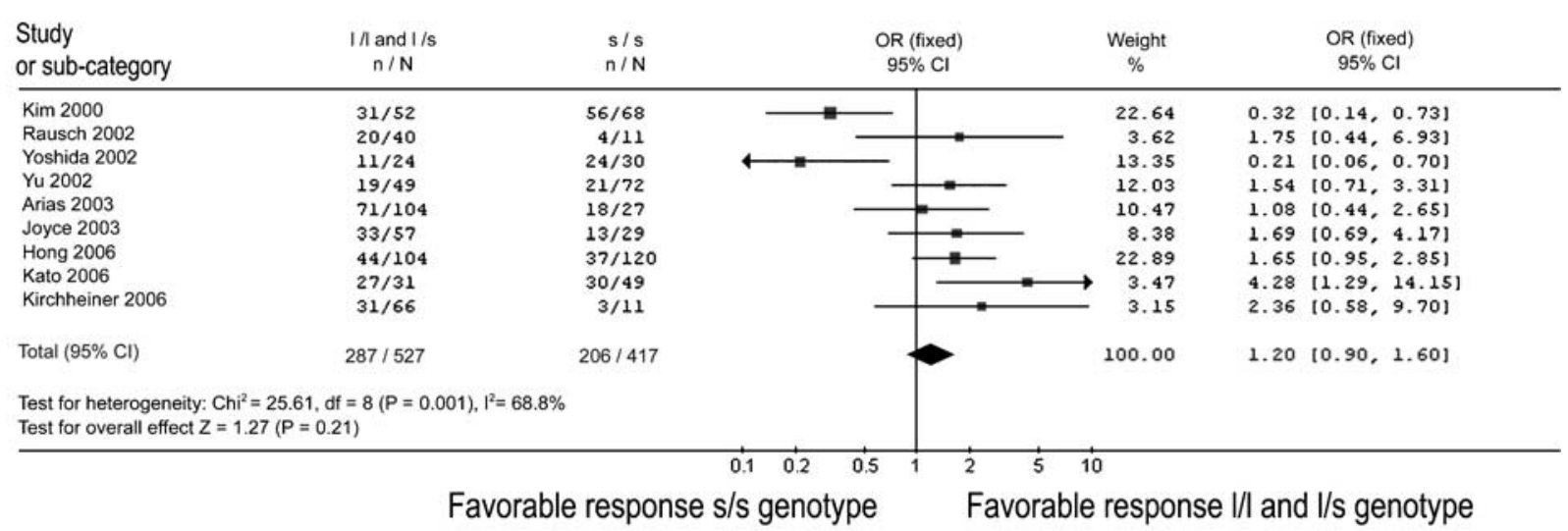

\section{Response within 4 weeks}

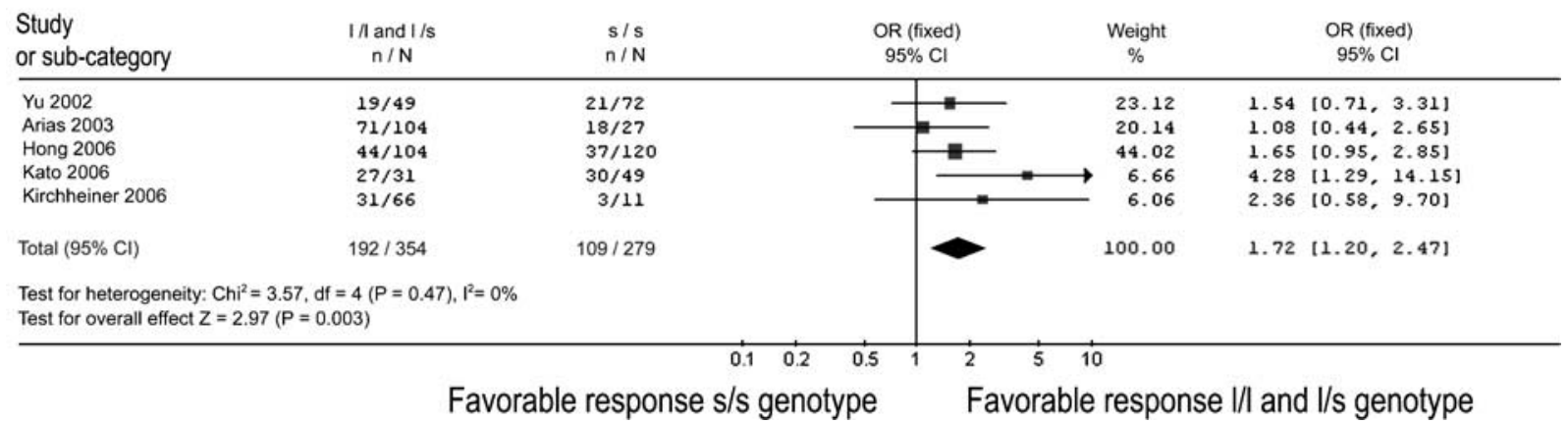

Figure 1 Outcome data for l/l and l/s versus s/s in remission rate, response rate and response rate within 4 weeks in the whole sample.

and pooled OR was significant in the same direction of Caucasians with the s/s genotype associated with poor response $(1.85, \mathrm{CI}=1.22-2.79, P=0.004)$. The alternative pooling of the $1 / 1$ genotype versus the $1 / \mathrm{s}$ and s/s genotype are presented in Figure 6. Pooled OR of the two studies of remission rate including 201 subjects was not significant (2.28, CI=0.59-8.86, $P=0.23$ ). However, pooled OR of the five studies of response rate including 599 was significant $(2.52$, $\mathrm{CI}=1.37-4.62, \quad P=0.003)$ with large heterogeneity, whereas pooled OR of the three studies of response rate within 4 weeks including 425 subjects was highly significant (5.96, CI = 2.70-13.17, $P<0.0001$ ) with no heterogeneity.

\section{Discussion}

In this study, we retrieved 15 studies that included data from 1435 subjects to evaluate the association between 5-HTTLPR and clinical response to SSRIs treatment in patients with mood disorders. The results of our study indicate a significant association between 5-HTTLPR and clinical response in both remission rate and response rate. These findings 
Remission

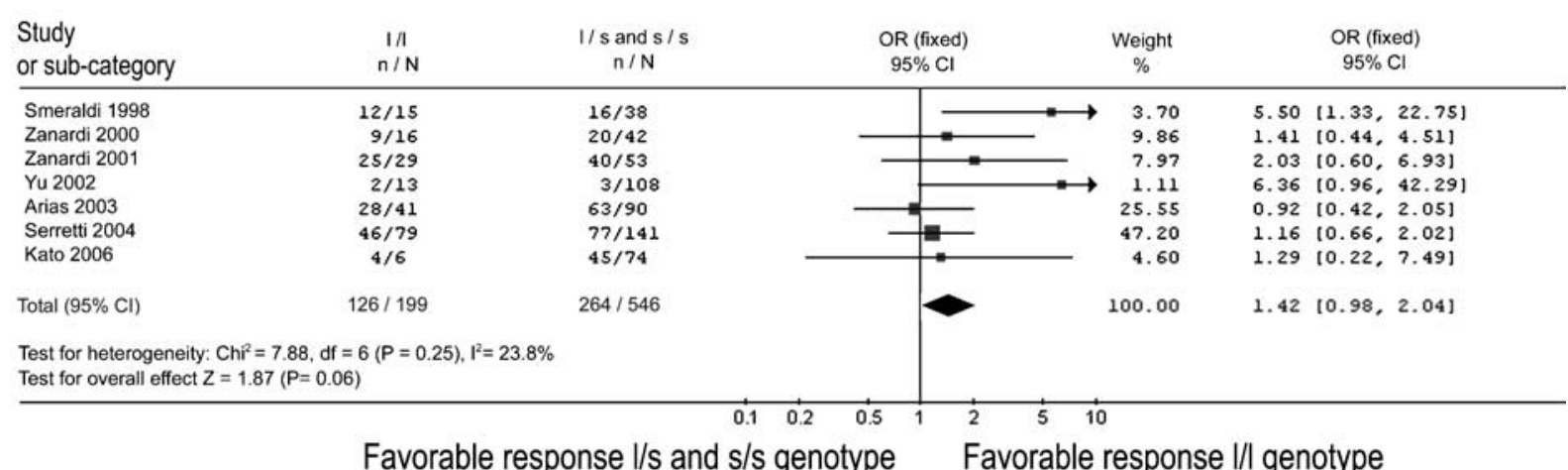

\section{Response}

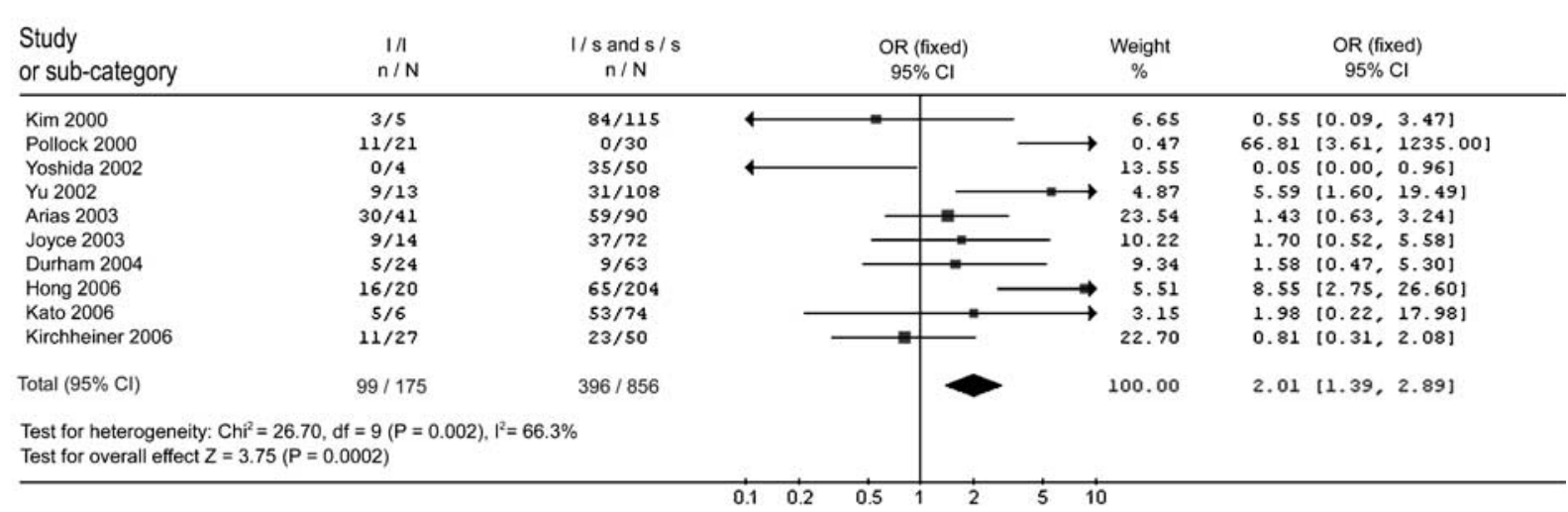

Favorable response $\mathrm{l} / \mathrm{s}$ and $\mathrm{s} / \mathrm{s}$ genotype Favorable response $\mathrm{l} / \mathrm{l}$ genotype

\section{Response within 4 weeks}

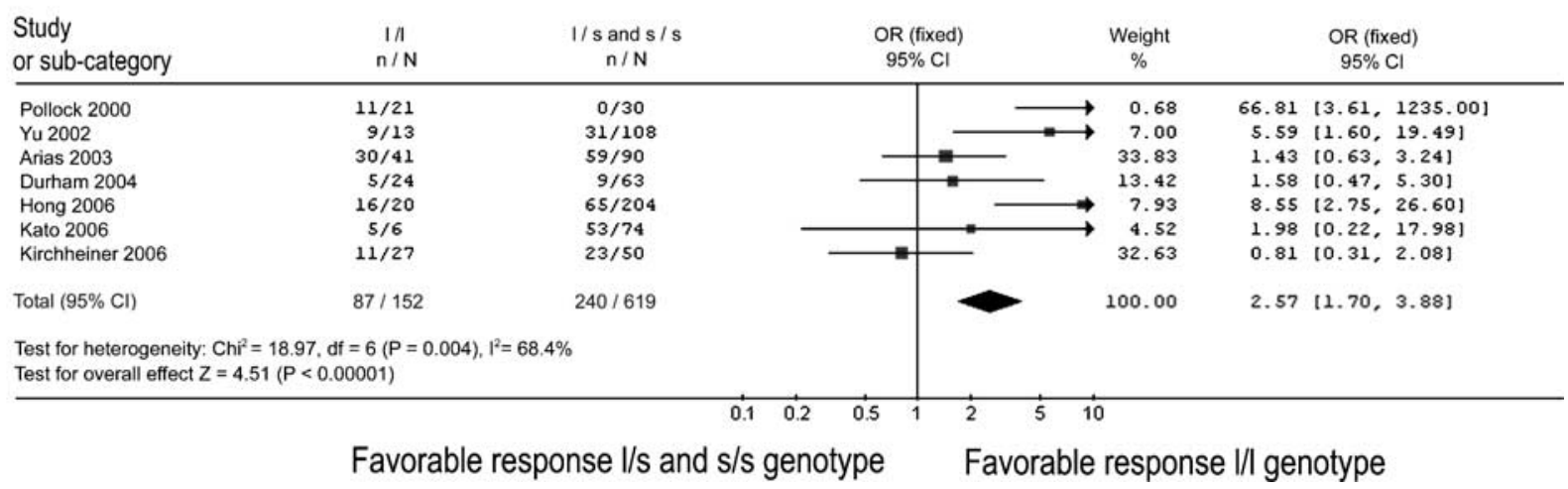

Figure 2 Outcome data for $1 / 1$ versus $1 / \mathrm{s}$ and $\mathrm{s} / \mathrm{s}$ in remission rate, response rate and response rate within 4 weeks in the whole sample.

suggest that 5-HTTLPR could be a predictor of response to SSRIs treatment.

The results also showed a more robust effect of 5-HTTLPR for remission rate when comparing the $1 / 1$ and $1 / s$ versus the s/s and for response rate when comparing the $\mathrm{l} / \mathrm{l}$ versus the $\mathrm{l} / \mathrm{s}$ and $\mathrm{s} / \mathrm{s}$ pooled genotypes. Nevertheless both comparisons showed a similar direction of effect. It is interesting to note that the effect of 5-HTTLPR for response within 4 weeks was the most robust and consistent in all comparisons except one analysis in Caucasian with some reduction in the significance due to the smaller number of studies included. This could suggest a major effect on speed of response of both s/s and s/l genotypes, while only the homozygote s/s effect could influence the overall remission rate. The dominance of 5-HTTLPR 


\section{Remission}

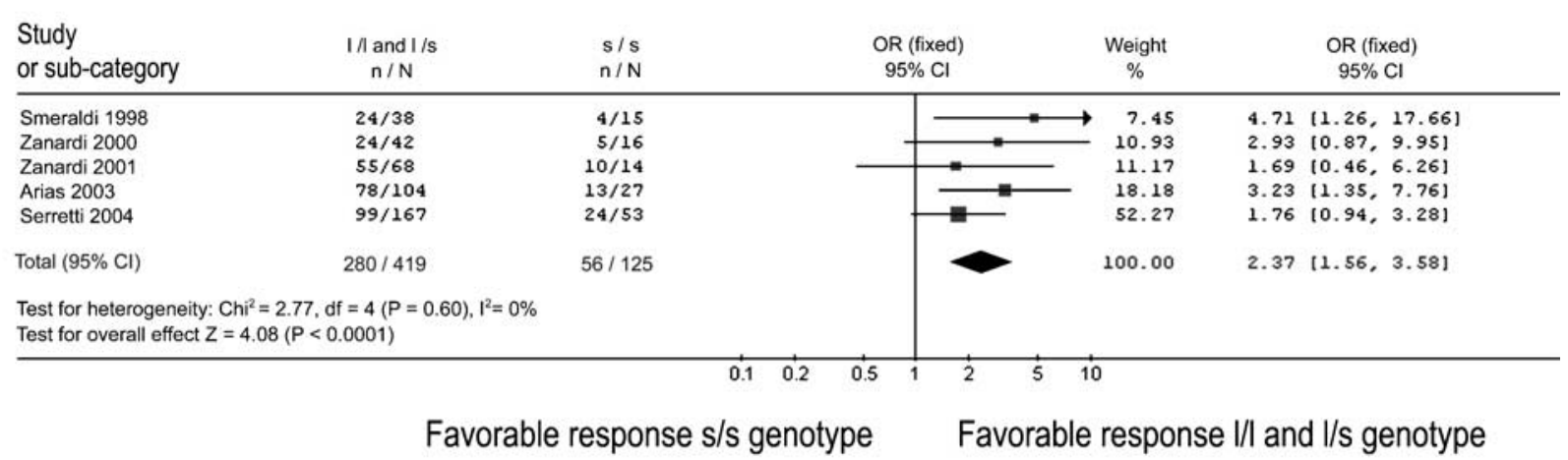

\section{Response}

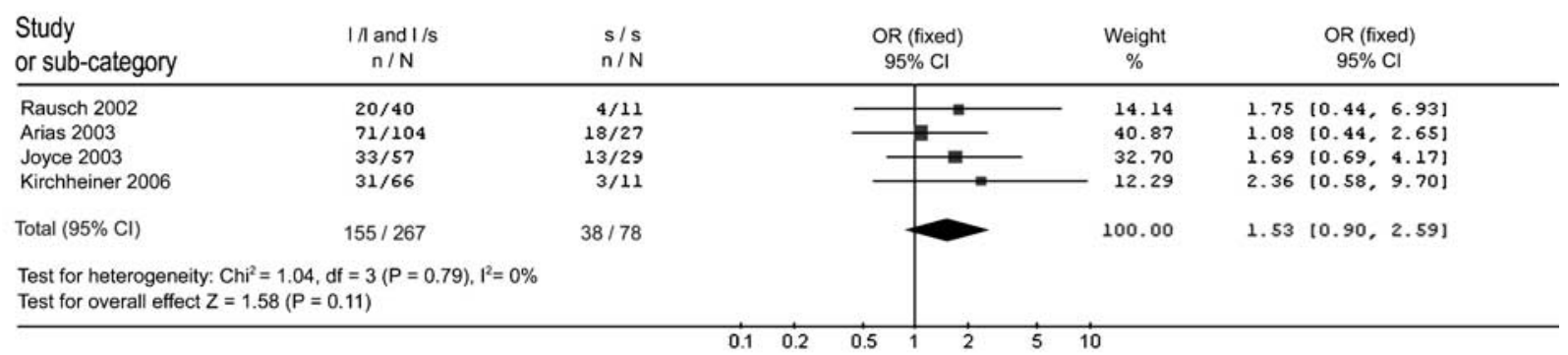

\section{Favorable response s/s genotype Favorable response $\mathrm{I} / \mathrm{l}$ and $\mathrm{I} / \mathrm{s}$ genotype}

\section{Response within 4 weeks}

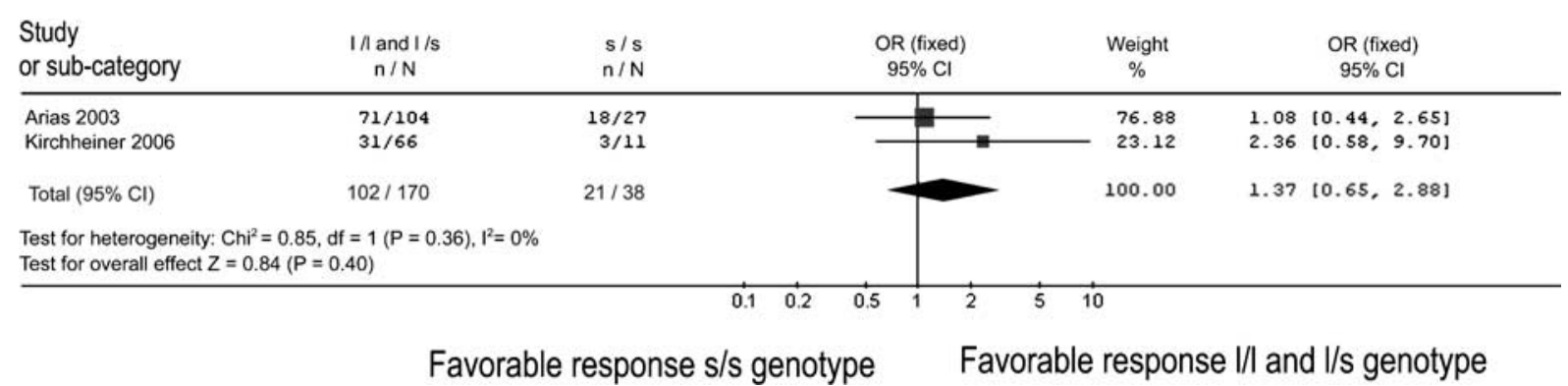

Figure 3 Outcome data for $1 / 1$ and $1 / s$ versus s/s in remission rate, response rate and response rate within 4 weeks in Caucasian subjects.

has not been addressed unequivocally, even though a dominant $s$ allele effect has been repeatedly reported $^{34-36}$ other studies did not confirm this model ${ }^{37}$ and SNPs are usually supposed to have a codominant effect. ${ }^{38}$ Our results favour the view of a dominant $\mathrm{s}$ effect, as indicated on response and early response. However, the remission effect was more clear with both $\mathrm{s}$ allele copies (s/s). We repeated the analysis excluding the first published study, which may inflate the overall estimate of effect to test for publication bias, but the outcome was similar to those with all together. OR in the $1 / 1$ and 1/s genotype versus the $\mathrm{s} / \mathrm{s}$ genotype were $2.06(P=0.0003)$ in the whole population and $2.18(P=0.0005)$ within Caucasian whereas that in the $1 / 1$ versus $1 / \mathrm{s}$ and $\mathrm{s} / \mathrm{s}$ genotype were $1.26(P=0.23)$ in the whole population and $1.20(P=0.38)$ within Caucasian. Consequently, the publication bias should have not influenced our results.

There are several differences among the studies included in this meta-analysis to discuss that could explain the significant heterogeneity we observed in some comparisons: different kind and dose of SSRIs, different subtype of affective disorder, different 
Remission

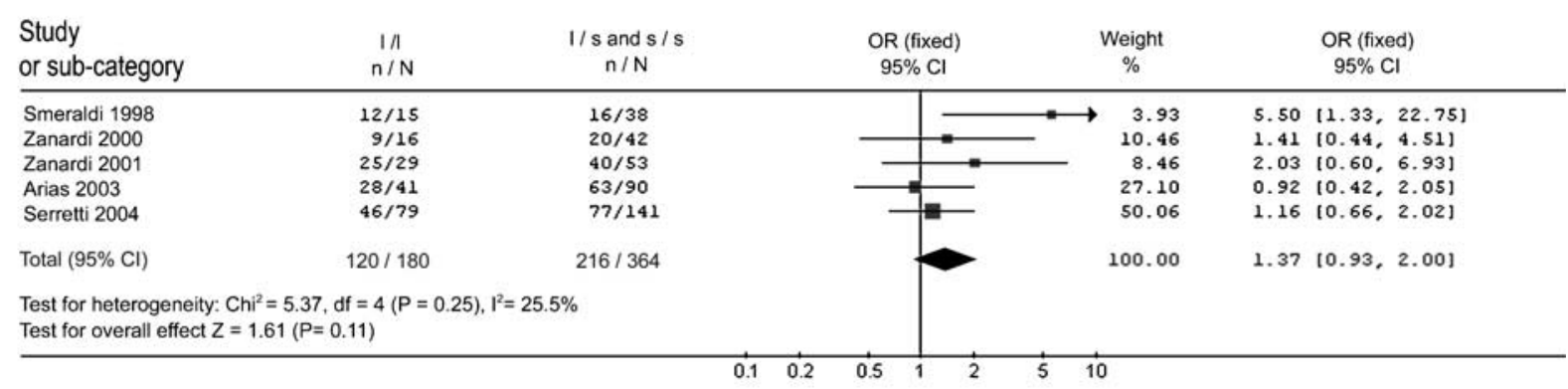

Favorable response $1 / \mathrm{s}$ and s/s genotype Favorable response $1 / /$ genotype

\section{Response}

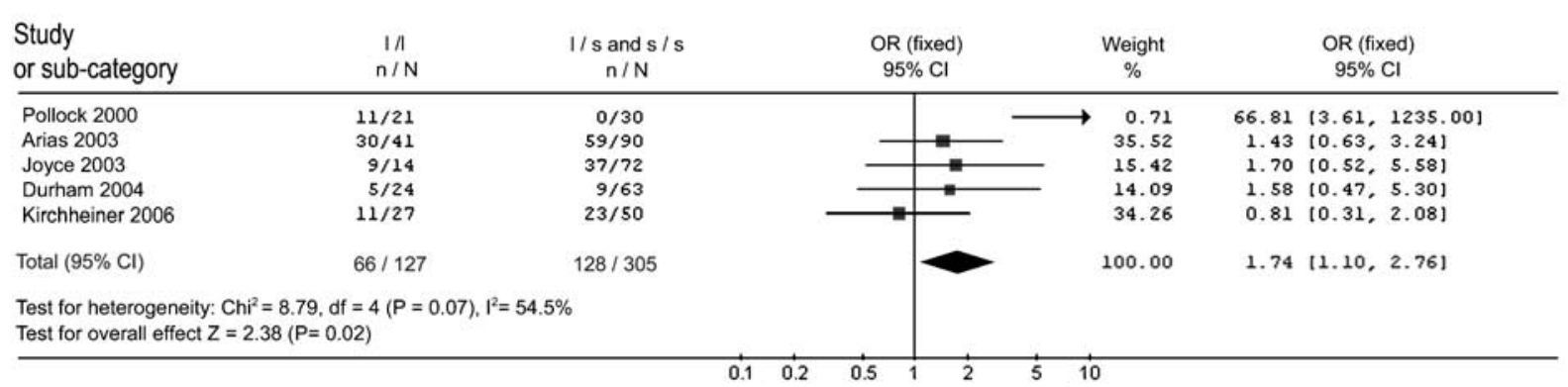

Favorable response $/ / \mathrm{s}$ and s/s genotype Favorable response I// genotype

\section{Response within 4 weeks}

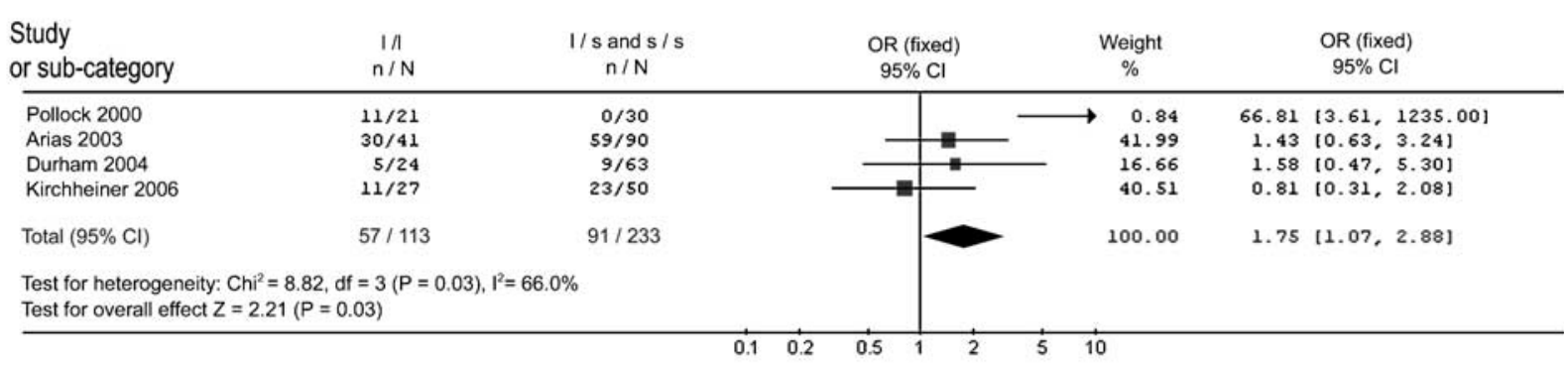

\section{Favorable response l/s and s/s genotype Favorable response I/l genotype}

Figure 4 Outcome data for $1 / 1$ versus $1 / s$ and $s / s$ in remission rate, response rate and response rate within 4 weeks in Caucasian subjects.

ethnic populations, and different lengths of assessment. Moreover other SNPs within the gene could be the causal variant and this might lead to the observed differences. $^{39,40}$ A wider list of polymorphism should be investigated to achieve a better resolution given that other control regions may be present for the 5HTT expression, not to mention possible enhancers or silencers located in other regions far from the gene locus. In fact, Hamilton et al. ${ }^{28,41}$ reported a significant association of a functional SNP (rs25531) $)^{42,43}$ located just upstream of the 5-HTTLPR with antidepressant response to fluoxetine treatment and in linkage disequilibrium (LD) with 5-HTTLPR. In the presence of the $g$ allele of this SNP, the 1 allele of
5-HTTLPR seems to be associated with nonresponse, while this is the case for the s allele in presence of the a allele of the SNP. In partial agreement, we found the same polymorphism influencing response, although in a different direction. ${ }^{44}$ These effects may be one of the sources of heterogeneity between studies.

Ethnicity and length of assessment might have also played a role in determining the heterogeneity among studies. Different allele frequencies between Caucasians and Asians, the s allele being present in $42 \%$ of Caucasians, but in $79 \%$ of Asians, ${ }^{45}$ are a strong cause of heterogeneity. In fact, when Caucasians were analyzed separately, the heterogeneity disappeared but it still remained when Asians were analyzed 


\section{Remission}

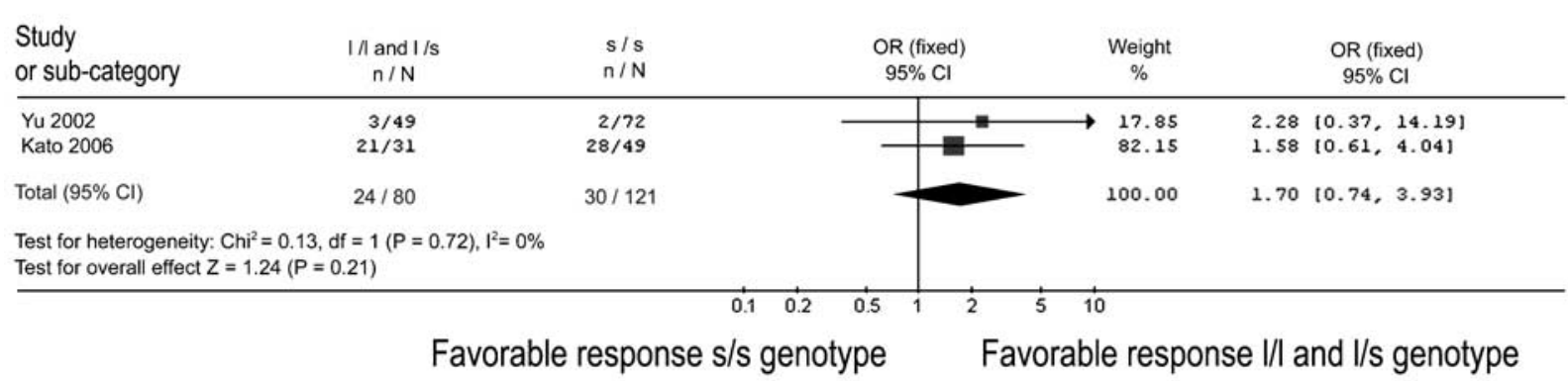

\section{Response}

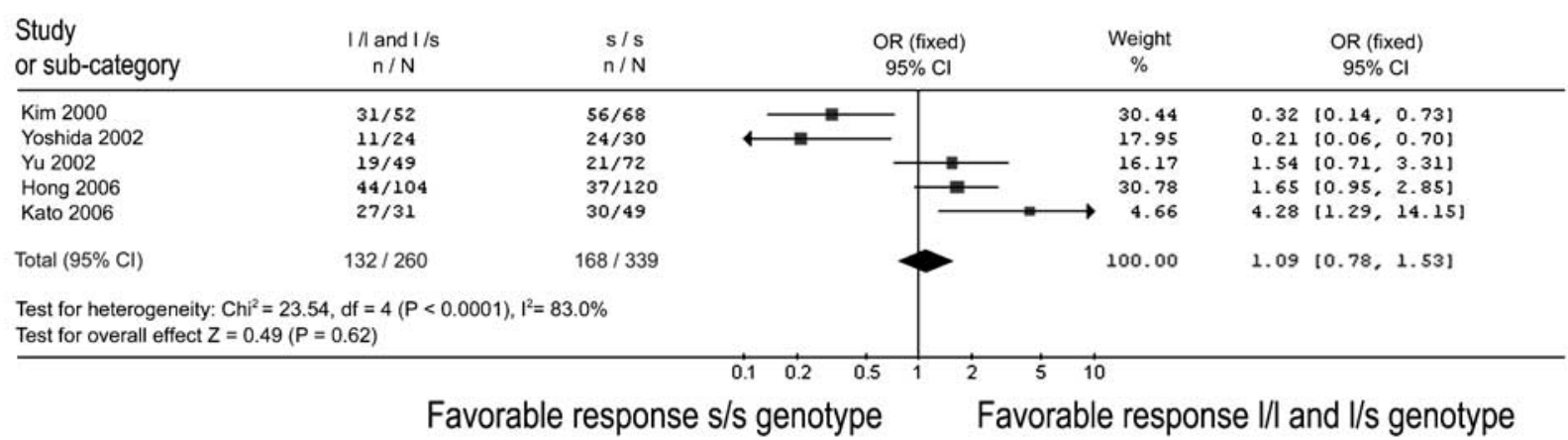

\section{Response within 4 weeks}

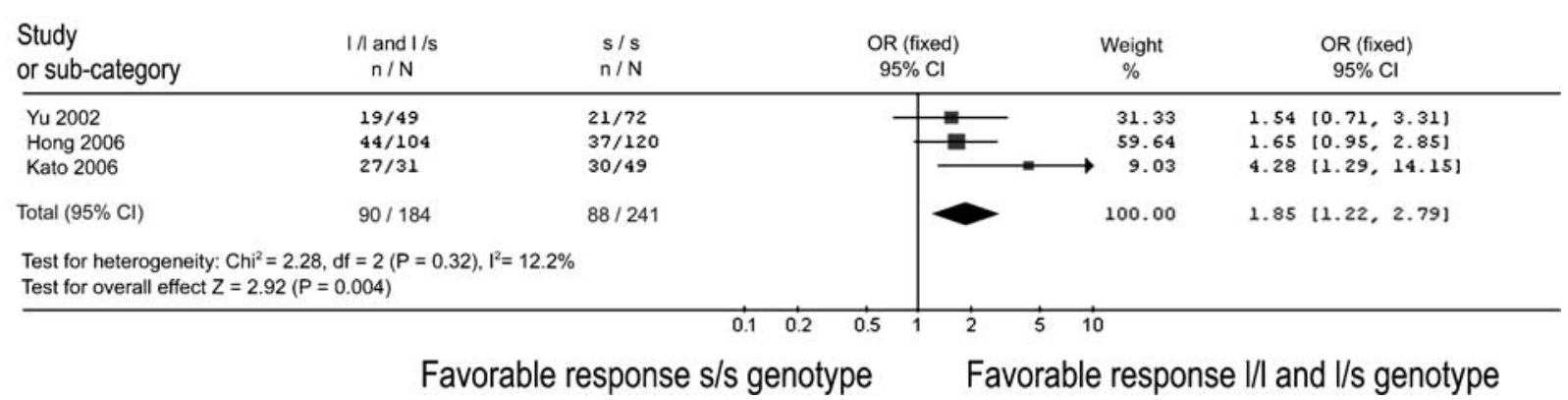

Figure 5 Outcome data for $1 / 1$ and $1 / s$ versus $\mathrm{s} / \mathrm{s}$ in remission rate, response rate and response rate within 4 weeks in Asian subjects.

alone. The reason of this large amount of heterogeneity in Asian population could not be understood well, however, the length of assessment could be one of the sources. Observation length ranged from 2 to 12 weeks, this wide range mostly influences the outcome in term of response given its lower robustness compared to remission. In fact, there was no evidence for heterogeneity among studies that assessed response rate within 4 weeks both in Caucasians and in Asians. Indeed some evidence suggest that the association between 5-HTTLPR and treatment response is due to acceleration, more than overall response rate. ${ }^{24,32,46}$ The results of our study suggest the period of assessment could be an important factor to evaluate the response rate, while on the other hand the remission rate seemed less influenced by the period of assessment because our results showed no heterogeneity in all remission comparison. This could be due to the fact that remission was evaluated in a longer length of observation: only two studies within 4 weeks. ${ }^{23,24}$ Finally, as previously discussed, a causative SNP located nearby the 5-HTTLPR could be the cause for association in the opposite direction in Asians.

We used a fixed-effect model for the meta-analysis. The two populations gene frequency differences may not fully justify the $a$ priori population independence, as well as other minor methodological differences in the studies. Moreover the discrepant Asian results argue against a true population independence from 
Remission

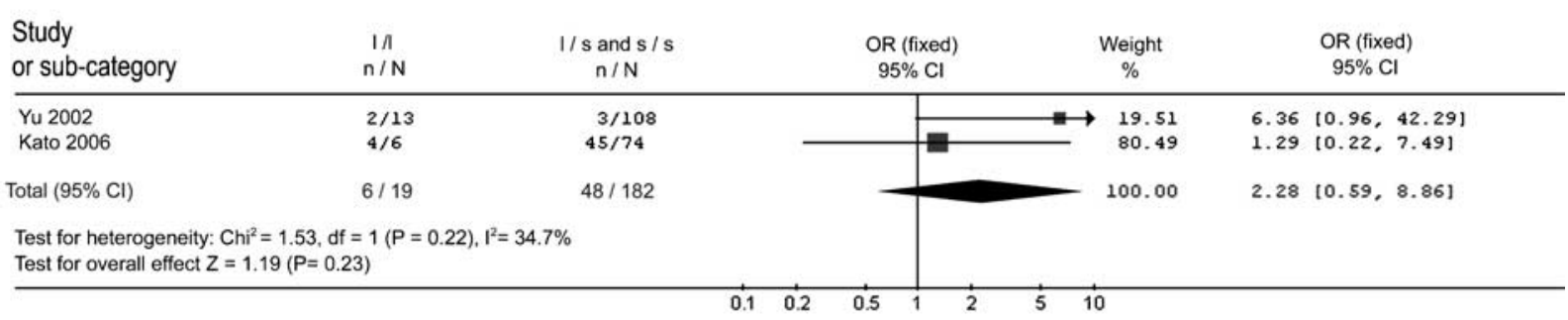

Favorable response l/s and s/s genotype Favorable response I// genotype

\section{Response}

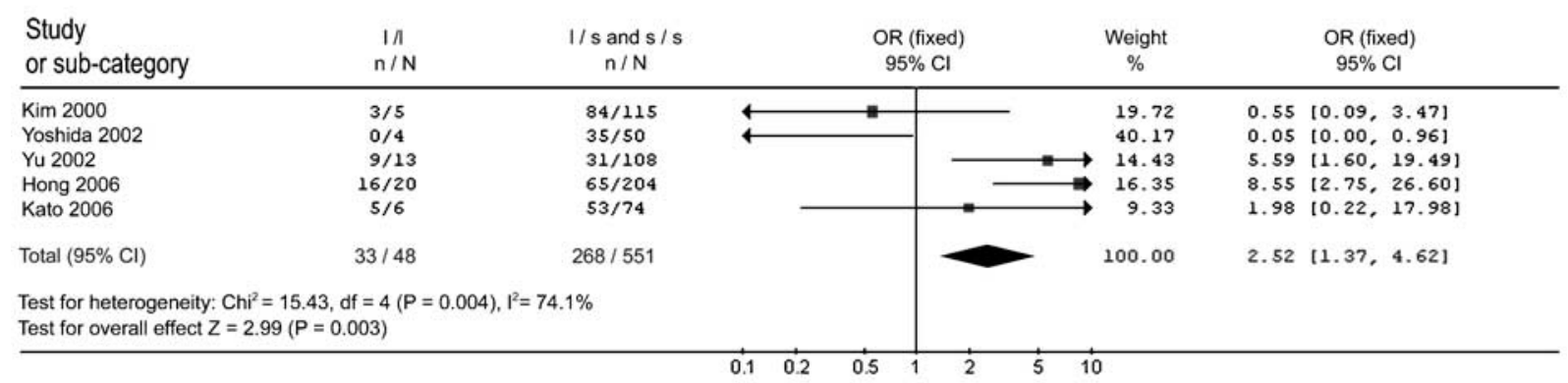

Favorable response l/s and s/s genotype Favorable response I/l genotype

\section{Response within 4 weeks}

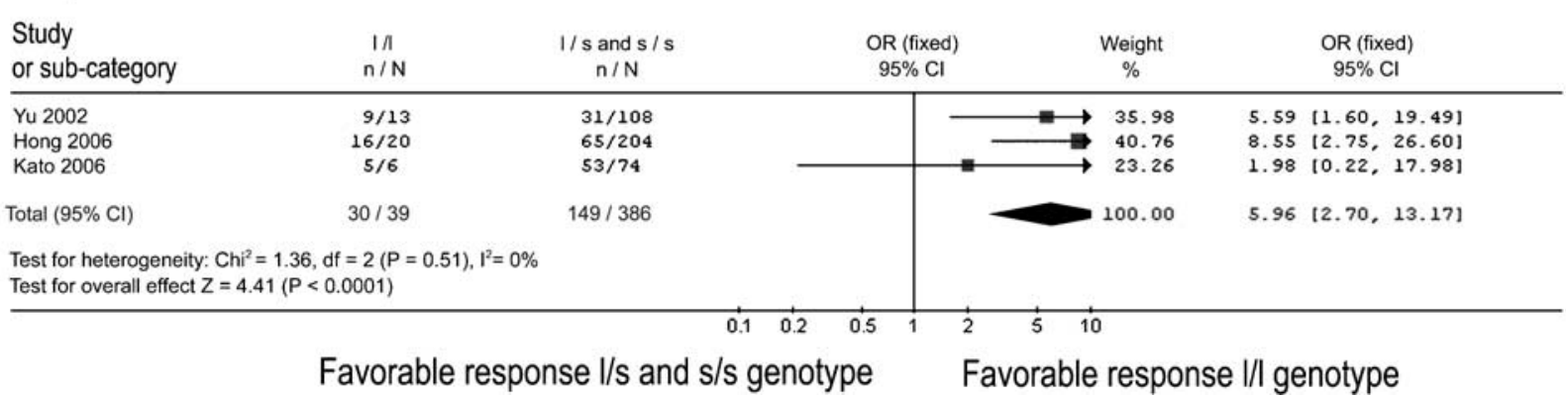

Figure 6 Outcome data for $1 / 1$ versus $1 / s$ and $s / s$ in remission rate, response rate and response rate within 4 weeks in Asian subjects.

Caucasians. Therefore, we presented the fixed-effect model to address the best estimate of a single effect size. However, the differences between the fixedeffects and the random-effects models were minimal in this analysis (data not shown).

To the best of our knowledge, our study is the first article investigating the association of 5-HTTLPR with response to SSRI treatment with a meta-analytic technique. Smits et al. ${ }^{11}$ collected and analyzed studies about association of 5-HTTLPR with treatment in depression. They result in a somewhat less favorable effect of SSRIs among Caucasian population with the s/s variants of the 5-HTTLPR as opposed to those with the $1 / 1$ and $1 / s$ variant and no available evidence in Asian population. Our results were consistent with their ones, the conceivable difference between our study and theirs is that they analyzed a smaller number of studies focusing on the mean decrease in HAM-D and MADRS score. Another partial meta-analysis has been reported but in the context of a wider review and including only a small part of the studies here included and with a large heterogeneity of treatments. ${ }^{47}$

In conclusion, our meta-analysis confirmed the significant association of the 1 variant of 5-HTTLPR with a better response to SSRIs and this effect seemed independent from ethnic differences. The subjects with s/s genotype have difficulties to reach remission, 
and take a long time, over 4 weeks, to respond as well as the subjects with $\mathrm{s}$ allele take a long time to respond. The pooled OR in this meta-analysis resulted in up to 2.57 in all populations that seems a moderate effect and it is in line with minor effect genes. ${ }^{48}$ Other genes are expected to influence this complex trait and a comprehensive knowledge could enable clinical use of a gene profile as predictor to allow identification of the best therapeutic tools and avoid lengthy treatment trials.

\section{References}

1 Greenberg PE, Stiglin LE, Finkelstein SN, Berndt ER. The economic burden of depression in 1990. J Clin Psychiatry 1993; 54: 405-418.

2 Sartorius N. The economic and social burden of depression. J Clin Psychiatry 2001; 62(Suppl 15): 8-11.

3 Wittchen H-U, Jacobi F. Size and burden of mental disorders in Europe - a critical review and appraisal of 27 studies. Eur Neuropsychopharmacol 2005; 15: 357-376.

4 Ustun TB. The worldwide burden of depression in the 21st century. In: Weismann MM (ed). Treatment of Depression: Bridging the 21st Century. American Psichiatric Press: Washington, DC, 2001, pp 35-45.

5 Fava M, Davidson KG. Definition and epidemiology of treatmentresistant depression. Psychiatr Clin North Am 1996; 19: 179-200.

6 Fava M. Diagnosis and definition of treatment-resistant depression. Biol Psychiatry 2003; 53: 649-659.

7 Heils A, Teufel A, Petri S, Stöber G, Riederer P, Bengel D et al. Allelic variation of human serotonin trasporter gene expression. J Neurochem 1996; 66: 2621-2624.

8 Serretti A, Calati R, Mandelli L, De Ronchi D. Serotonin transporter gene variants and behaviour: a comprehensive review. Current Drug Targets, in press.

9 Smeraldi E, Zanardi R, Benedetti F, Dibella D, Perez J, Catalano M. Polymorphism within the promoter of the serotonin transporter gene and antidepressant efficacy of fluvoxamine. Mol Psychiatry 1998; 3: 508-511.

10 Serretti A, Artioli P, Quartesan R. Pharmacogenetics in the treatment of depression: pharmacodynamic studies. Pharmacogenet Genom 2005; 15: 61-67.

11 Smits KM, Smits LJ, Schouten JS, Stelma FF, Nelemans P, Prins MH. Influence of SERTPR and STin2 in the serotonin transporter gene on the effect of selective serotonin reuptake inhibitors in depression: a systematic review. Mol Psychiatry 2004; 9: 433-441.

12 Munafo MR, Flint J. Meta-analysis of genetic association studies. Trends Genet 2004; 20: 439-444.

13 Cho HJ, Meira-Lima I, Cordeiro Q, Michelon L, Sham P, Vallada H et al. Population-based and family-based studies on the serotonin transporter gene polymorphisms and bipolar disorder: a systematic review and meta-analysis. Mol Psychiatry 2005; 12: 12.

14 Lasky-Su JA, Faraone SV, Glatt SJ, Tsuang MT. Meta-analysis of the association between two polymorphisms in the serotonin transporter gene and affective disorders. Am J Med Genet B Neuropsychiatr Genet 2005; 133: 110-115.

15 Arias B, Catalan R, Gasto C, Gutierrez B, Fananas L. 5-HTTLPR polymorphism of the serotonin transporter gene predicts nonremission in major depression patients treated with citalopram in a 12-weeks follow up study. J Clin Psychopharmacol 2003; 23: 563-567.

16 Hong CJ, Chen TJ, Yu YW, Tsai SJ. Response to fluoxetine and serotonin 1A receptor (C-1019G) polymorphism in Taiwan Chinese major depressive disorder. Pharmacogenom $J$ 2006; 6: 27-33.

17 Joyce PR, Mulder RT, Luty SE, McKenzie JM, Miller AL, Rogers GR et al. Age-dependent antidepressant pharmacogenomics: polymorphisms of the serotonin transporter and G protein beta3 subunit as predictors of response to fluoxetine and nortriptyline. Int J Neuropsychopharmacol 2003; 6: 339-346.
18 Kato M, Fukuda T, Wakeno M, Fukuda K, Okugawa G, Ikenaga Y et al. Effects of the serotonin type $2 \mathrm{~A}, 3 \mathrm{~A}$ and $3 \mathrm{~B}$ receptor and the serotonin transporter genes on paroxetine and fluvoxamine efficacy and adverse drug reactions in depressed Japanese patients. Neuropsychobiol 2006; 53: 186-195.

19 Kim DK, Lim SW, Lee S, Sohn SE, Kim S, Hahn CG et al. Serotonin transporter gene polymorphism and antidepressant response. Neuroreport 2000; 11: 215-219.

20 Kirchheiner J, Nickchen K, Sasse J, Bauer M, Roots I, Brockmoller J. A 40-basepair VNTR polymorphism in the dopamine transporter (DAT1) gene and the rapid response to antidepressant treatment. Pharmacogenom J 2006.

21 Serretti A, Artioli P. The pharmacogenomics of selective serotonin reuptake inhibitors. Pharmacogenom $J$ 2004; 4: 233-244.

22 Yoshida K, Ito K, Sato K, Takahashi H, Kamata M, Higuchi H et al. Influence of the serotonin transporter gene-linked polymorphic region on the antidepressant response to fluvoxamine in Japanese depressed patients. Prog Neuropsychopharmacol Biol Psychiatry 2002; 26: 383-386.

23 Yu YW, Tsai SJ, Chen TJ, Lin CH, Hong CJ. Association study of the serotonin transporter promoter polymorphism and symptomatology and antidepressant response in major depressive disorders. Mol Psychiatry 2002; 7: 1115-1119.

24 Zanardi R, Benedetti F, Di Bella D, Catalano M, Smeraldi E. Efficacy of paroxetine in depression is influenced by a functional polymorphism within the promoter of the serotonin transporter gene. J Clin Psychopharmacol 2000; 20: 105-107.

25 Zanardi R, Serretti A, Rossini D, Franchini L, Cusin C, Lattuada E et al. Factors affecting fluvoxamine antidepressant activity: influence of pindolol and 5-HTTLPR in delusional and nondelusional depression. Biol Psychiatry 2001; 50: 323-330.

26 Quitkin FM, Rabkin JG, Ross D, Stewart JW. Identification of true drug response to antidepressants. Use of pattern analysis. Arch Gen Psychiatry 1984; 41: 782-786.

27 Durham LK, Webb SM, Milos PM, Clary CM, Seymour AB. The serotonin transporter polymorphism, 5HTTLPR, is associated with a faster response time to sertraline in an elderly population with major depressive disorder. Psychopharmacology (Berlin) 2004; 174: 525-529.

28 Kraft JB, Slager SL, McGrath PJ, Hamilton SP. Sequence analysis of the serotonin transporter and associations with antidepressant response. Biol Psychiatry 2005; 58: 374-381.

29 Lee MS, Lee HY, Lee HJ, Ryu SH. Serotonin transporter promoter gene polymorphism and long-term outcome of antidepressant treatment. Psychiatr Genet 2004; 14: 111-115.

30 Minov C, Baghai TC, Schule C, Zwanzger P, Schwarz MJ, Zill P et al. Serotonin-2A-receptor and -transporter polymorphisms: lack of association in patients with major depression. Neurosci Lett 2001; 303: 119-122.

31 Murphy Jr GM, Hollander SB, Rodrigues HE, Kremer C, Schatzberg AF. Effects of the serotonin transporter gene promoter polymorphism on mirtazapine and paroxetine efficacy and adverse events in geriatric major depression. Arch Gen Psychiatry 2004; 61: 1163-1169.

32 Pollock BG, Ferrell RE, Mulsant BH, Mazumdar S, Miller M, Sweet RA et al. Allelic variation in the serotonin transporter promoter affects onset of paroxetine treatment response in late-life depression. Neuropsychopharmacology 2000; 23: 587-590.

33 Rausch JL, Johnson ME, Fei YJ, Li JQ, Shendarkar N, Hobby HM et al. Initial conditions of serotonin transporter kinetics and genotype: influence on SSRI treatment trial outcome. Biol Psychiatry 2002; 51: 723-732.

34 Lesch KP. Variation of serotonergic gene expression: neurodevelopment and the complexity of response to psychopharmacologic drugs. Eur Neuropsychopharmacol 2001; 11: 457-474.

35 Hranilovic D, Stefulj J, Schwab S, Borrmann-Hassenbach M, Albus M, Jernej B et al. Serotonin transporter promoter and intron 2 polymorphisms: relationship between allelic variants and gene expression. Biol Psychiatry 2004; 55: 1090-1094.

36 Greenberg BD, Tolliver TJ, Huang SJ, Li Q, Bengel D, Murphy DL. Genetic variation in the serotonin transporter promoter region affects serotonin uptake in human blood platelets. Am J Med Genet 1999; 88: 83-87. 
37 Javors MA, Seneviratne C, Roache JD, Ait-Daoud N, Bergeson SE, Walss-Bass MC et al. Platelet serotonin uptake and paroxetine binding among allelic genotypes of the serotonin transporter in alcoholics. Prog Neuropsychopharmacol Biol Psychiatry 2005; 29: 7-13.

38 Teshima KM, Przeworski M. Directional positive selection on an allele of arbitrary dominance. Genetics 2006; 172: 713-718.

39 Williams NM, O’Donovan MC, Owen MJ. Is the dysbindin gene (DTNBP1) a susceptibility gene for schizophrenia? Schizophr Bull 2005; 31: 800-805.

40 Allison DB. Transmission-disequilibrium tests for quantitative traits. Am J Hum Genet 1997; 60: 676-690.

41 Peters EJ, Slager SL, McGrath PJ, Knowles JA, Hamilton SP. Investigation of serotonin-related genes in antidepressant response. Mol Psychiatry 2004; 9: 879-889.

42 Hu XZ, Lipsky RH, Zhu G, Akhtar LA, Taubman J, Greenberg BD et al. Serotonin transporter promoter gain-of-function genotypes are linked to obsessive-compulsive disorder. Am J Hum Genet 2006; 78: 815-826.

43 Nakamura M, Ueno S, Sano A, Tanabe H. The human serotonin transporter gene linked polymorphism (5-HTTLPR) shows ten novel allelic variants. Mol Psychiatry 2000; 5: 32-38.

44 Smeraldi E, Serretti A, Artioli P, Lorenzi C, Catalano M. Serotonin transporter gene-linked polymorphic region: possible pharmacogenetic implications of rare variants. Psychiatr Genet 2006; 16: 153-158.

45 Kunugi H, Hattori M, Kato T, Tatsumi M, Sakai T, Sasaki T et al. Serotonin transporter gene polymorphisms: ethnic difference and possible association with bipolar affective disorder. Mol Psychiatry 1997; 2: 457-462.

46 Kato M, Ikenaga Y, Wakeno M, Okugawa G, Nobuhara K, Fukuda T et al. Controlled clinical comparison of paroxetine and fluvoxamine considering the serotonin transporter promoter polymorphism. Int Clin Psychopharmacol 2005; 20: 151-156.

47 Kirchheiner J, Nickchen K, Bauer M, Wong ML, Licinio J, Roots I et al. Pharmacogenetics of antidepressants and antipsychotics: the contribution of allelic variations to the phenotype of drug response. Mol Psychiatry 2004; 9: 442-473.

48 Kendler KS. 'A gene for ...': the nature of gene action in psychiatric disorders. Am J Psychiatry 2005; 162: 1243-1252. 
Chapter 11: Association between GSK-3 $\beta$-50T/C polymorphism and personality and psychotic symptoms in mood disorders 


\title{
Association between GSK-3 $\beta$-50T/C polymorphism and personality and psychotic symptoms in mood disorders
}

\author{
Alessandro Serretti*, Francesco Benedetti, Laura Mandelli, Raffaella Calati, \\ Barbara Caneva, Cristina Lorenzi, Valentina Fontana, \\ Cristina Colombo, Enrico Smeraldi \\ Department of Neuropsychiatric Sciences, Scientific Institute and University Vita-Salute San Raffaele, Milan, Italy; \\ "Istituto Nazionale diNeuroscienze", Italy
}

Received 11 August 2006; received in revised form 8 February 2007; accepted 21 June 2007

\begin{abstract}
The exact role of the enzyme glycogen synthase kinase $3 \beta$ (GSK-3 $\beta$ ) in mood disorders is still unknown. GSK-3 $\beta$ has been mapped to chromosome 3q13.3, a potential susceptibility locus for bipolar disorder. The $-50 \mathrm{~T} / \mathrm{C}$ polymorphism, falling within the promoter region of the gene coding for GSK-3 $\beta$, was previously reported to be associated with age at onset, therapeutic response to lithium salts and total sleep deprivation in bipolar patients. In the present study we investigated the association between the $-50 \mathrm{~T} / \mathrm{C}$ polymorphism and both symptomatic and personality features in mood disorders. The sample comprised 365 inpatients affected by major depressive disorder and bipolar disorder, genotyped for the GSK-3 $\beta-50$ polymorphism and assessed with the Operational Criteria Checklist for Psychotic Illness (OPCRIT). Ninety-five subjects were also evaluated with the Temperament and Character Inventory (TCI). The GSK-3 $3-50$ polymorphism showed a positive association with delusional symptomatology and with the personality features linked to Self-Transcendence. Finally, GSK-3ß-50 and personality showed an interactive effect on delusional scores. In conclusion, our findings support the role of GSK-3 $\beta-50$ in both normal and psychopathological aspects of human cognition and further suggest a possible interaction between genes and personality in the liability to psychotic disorders.
\end{abstract}

(C) 2007 Elsevier Ireland Ltd. All rights reserved.

Keywords: Personality; Psychotic symptoms; Delusion; Bipolar disorder; Major depressive disorder; Genetics; GSK-3ß; Personality

\section{Introduction}

The glycogen synthase kinase 3 (GSK-3) enzyme is a proline-directed serine-threonine kinase that was initially identified as a phosphorylating and inactivating

\footnotetext{
* Corresponding author. Institute of Psychiatry, University of Bologna, Viale Carlo Pepoli 5, 40123 Bologna, Italy. Tel.: +39 051 6584233; fax: +39051521030.

E-mail address: alessandro.serretti@unibo.it (A. Serretti).
}

glycogen synthase, which is critical in the regulation of glucose storage (Embi et al., 1980). Two isoforms exist, alpha $(\alpha)$ and beta $(\beta)$, showing a high degree of amino acid homology (Stambolic and Woodgett, 1994).

GSK-3 $\alpha$ is involved in energy metabolism, neuronal cell development and body pattern formation (Plyte et al., 1992); it has a central role in the regulation of neuronal plasticity, gene expression and cell survival; and it may be a key component of neuro-degenerative diseases (Grimes and Jope, 2001). The role of this kinase is well validated in 
Alzheimer's disease (Sperber et al., 1995; Hong and Lee, 1997), and some evidence also exists for an involvement in schizophrenia (Kozlovsky et al., 2000, 2001).

Interesting clues come from mood disorder treatments and their mechanism of action. Lithium, the most widely used mood stabilizer, directly inhibits GSK-3 $\beta$ (Klein and Melton, 1996), and this has been hypothesized as a mechanism underling its action (Salinas and Hall, 1999; Manji et al., 2000; Detera-Wadleigh, 2001). Levels of this kinase in post-mortem brain from bipolar patients did not differ from control subjects; however, differences in level of phosphorylation of protein tau (a target of GSK-3 $\beta$ ) were observed (Lesort et al., 1999; Bijur et al., 2000). In addition, the GSK-3 $\beta$ gene has been mapped to chromosome 3 q13.3, a potential susceptibility locus for bipolar disorder (Bailer et al., 2002).

A large number of polymorphisms exist within the GSK-3 $\beta$ gene. Among those, the GSK-3 $\beta$ single nucleotide polymorphism -50T/C (GSK-3 $\beta-50)$, detected by Russ and collaborators (Russ et al., 2001) has evoked particular interest. It is a common and attention-grabbing Single Nucleotide Polymorphism (SNP) because it falls into the effective promoter region (nt -171 to +29$)$ of the GSK-3 $\beta$ gene.

Association studies with GSK-3 $\beta-50$ and flanking markers have been performed in mood disorders but with conflicting results (Lee et al., 2006; Nishiguchi et al., 2006; Szczepankiewicz et al., 2006b). We previously investigated this variant in different samples. We found an effect of the GSK-3 $\beta-50$ polymorphism on age at onset of bipolar illness (Benedetti et al., 2004a), therapeutic response to lithium salts (Benedetti et al., 2005), though not replicated (Szczepankiewicz et al., 2006a), and efficacy of total sleep deprivation (TSD) treatment (Benedetti et al., 2004b).

Overall, these observations suggest a role for GSK$3 \beta-50$ in respect to bipolar illness, but discrepant findings and associations with specific clinical features suggest that the comprehensive picture of GSK-3 $\beta$ effects could be more complex. In fact, recent genetic analyses in psychiatric disturbances showed that gene variant effects are not limited to single features of the disorder. As an example, the polymorphism in the promoter of the serotonin transporter gene (SERTPR) demonstrated a very broad effect on many features of individuals, both in their normal and abnormal behaviors (Serretti et al., 2006). In fact, if single complex traits are well known to be influenced by many genetic and environmental variables (Glazier et al., 2002), single genes (especially those influencing a complex trait) are probably unlikely to be involved in the determination of a single trait only. For the above-mentioned reasons, any analysis focused on a specific feature may lack sufficient power not only because the genes are interconnected and with reciprocal influences, but also because of the cross-influences exerted on a huge number of features by each single gene (Kendler, 2005).

Recent data suggest new possible roles for GSK-3 $\beta$ in psychiatric diseases, by showing in animal models that antipsychotic and psychotomimetic substances have opposite effects on this enzyme. In particular, in animal models an elevation of GSK-3 $\beta$ has been shown to be shared by repeated administration of antypsychotics of different classes (haloperidol, risperidone, and clozapine), and it has been linked to their antipsychotic effect due to dopamine D2 blockade (Alimohamad et al., 2005a). Conversely, amphetamines were shown to significantly decrease GSK-3 $\beta$ (Alimohamad et al., 2005b), and D-amphetamine, LSD, and PCP shared the ability to regulate the phosphorylation state of GSK-3 $\beta$ (Svenningsson et al., 2003). It should be noted that the abnormalities detected in the levels of GSK-3 $\beta$ in postmortem brains of schizophrenic patients were in the direction elicited, in animal models, by psychotomimetics, and not by antipsychotics, thus suggesting a role for GSK-3 $\beta$ in chronic psychosis (Kozlovsky et al., $2000,2001)$. Following this line of reasoning, it has been suggested that GSK-3 $\beta$ would modulate dopaminergic systems (Castelo-Branco et al., 2004), probably through an indirect effect in circadian rhythm systems (Nestler and Carlezon, 2006).

In the present study: we therefore investigated the involvement of this polymorphism in psychotic symptoms in mood disorders. Moreover, we also controlled for personality features in a sub-sample of subjects.

\section{Materials and methods}

\subsection{Sample}

Three hundred and sixty-five patients affected by recurrent major depressive disorder (MDD) $(N=122)$ and bipolar disorder (BD) $(N=243)$ admitted to the Mood Disorder Center at the Department of Psychiatry of San Raffaele Hospital, Milan, were included in the study. Of the 365 patients, 222 patients were females and 143 were males, with a mean age of 44 years and a mean age at onset of 30 years. Sample's characteristics, stratified for genotypes, are described in Table 1.

Lifetime diagnoses were assigned according to DSM-IV criteria (American Psychiatric Association, 1994) on the basis of the Structured Clinical Interview for DSM-IV (SCID) (First et al., 1995), plus all available sources, such as observed clinical symptomatology, 
Table 1

GSK-3 $\beta-50 \mathrm{~T} / \mathrm{C}$ genotype and demographic and clinical variables (MDD=recurrent major depressive disorder; $\mathrm{BD}=$ bipolar disorder)

\begin{tabular}{|c|c|c|c|c|c|}
\hline & \multicolumn{3}{|l|}{ Genotypes GSK-3 $\beta-50$} & \multirow[t]{2}{*}{$\chi^{2}$} & \multirow[t]{3}{*}{$P$} \\
\hline & $\mathrm{TT}(n=156)$ & TC $(n=159)$ & $\mathrm{CC}(n=50)$ & & \\
\hline & $N(\%)$ & $N(\%)$ & $N(\%)$ & $(d f=2)$ & \\
\hline \multicolumn{6}{|l|}{ Gender } \\
\hline Males & $53(37.06 \%)$ & $75(52.45 \%)$ & $15(10.49 \%)$ & 7.81 & 0.02 \\
\hline Females & $103(46.40 \%)$ & $84(37.84 \%)$ & $35(15.77 \%)$ & & \\
\hline \multicolumn{6}{|l|}{ Diagnosis } \\
\hline MDD & $47(38.52 \%)$ & $61(50.00 \%)$ & $14(11.48 \%)$ & 1.48 & 0.48 \\
\hline \multirow[t]{2}{*}{$\mathrm{BD}$} & $109(44.86 \%)$ & $98(40.33 \%)$ & $36(14.81 \%)$ & & \\
\hline & Mean \pm standard deviation & Mean \pm standard deviation & Mean \pm standard deviation & $F(d f=2,362)$ & $P$ \\
\hline Age & $44.65 \pm 14.35$ & $44.01 \pm 15.85$ & $42.7 \pm 13.08$ & 0.66 & 0.52 \\
\hline Age at onset & $30.34 \pm 11.37$ & $30.15 \pm 11.59$ & $31.51 \pm 12.12$ & 0.50 & 0.60 \\
\hline
\end{tabular}

rating scales administered, family history and previous clinical data. A psychiatrist evaluated the retrospective course of illness, by interviewing subjects, family members, previous health professionals and obtaining records when possible (Leckman et al., 1982). A second experienced psychiatrist reviewed the chart and, if no consensus was obtained, a third senior psychiatrist was involved. However, no subject was excluded because of diagnostic disagreement.

The sample is part of a larger one previously analysed for association between antidepressant treatment and other candidate genes in published studies (Smeraldi et al., 1998; Serretti et al., 2001b, 2004; Zanardi et al., 2001; Cusin et al., 2002; Benedetti et al., 2004a,b, 2005).

The inclusion criteria of the study consisted in the clinical diagnosis of recurrent MDD or BD. The presence of any concomitant Axis I diagnosis and somatic or neurological illnesses limit psychiatric evaluation represented exclusion criteria. All subjects were provided with information about this study and written informed consent was obtained.

\subsection{Evaluation instruments}

Symptomatology of 339 subjects was obtained by the Operational Criteria Checklist for Psychotic Illness (OPCRIT) (McGuffin et al., 1991).

In the present study, we analysed a specific OPCRIT set of items (items 54 to 72) investigating the lifetime psychotic symptomatology. Moreover, we investigated the previously identified five OPCRIT factors: Excitement, Depression, Delusion, Disorganization and Negative Symptomatology (for a description, see Serretti et al., 2001a; Serretti and Olgiati, 2004).
Ninety-five patients included in the study also completed the assessment of temperamental and character features with the Temperament and Character Inventory (TCI) (Cloninger et al., 1994); the questionnaire was administered to subjects only during a euthymic phase of at least 3 months (DSM-IV criteria).

\subsection{DNA analysis}

Blood samples were obtained from 365 subjects. Genomic DNA was extracted from leucocytes by $\mathrm{NaCl}$ precipitation (Lahiri and Nurnberger, 1991). PCR was performed with these primers: 5' GATTCCCAGACGCCTGTTAC $3^{\prime}$ and 5' CTCGCTTCCTTCCTTCCTTT $3^{\prime}$.

The PCR reaction was carried out in a $10 \mu \mathrm{l}$ volume containing $150 \mathrm{ng}$ genomic DNA, $5 \mathrm{pM}$ of each primer, $200 \mu \mathrm{M}$ each dNTP, 1× PCR Gold Buffer (Applied Biosystems, Monza Italy), and $0.025 \mathrm{U} / \mu 1$ of Taq Gold Polymerase (Applied Biosystems, Monza Italy). After an initial step of 5 min at $95^{\circ} \mathrm{C}, 35$ cycles of amplification $\left(30 \mathrm{~s}\right.$ at $95^{\circ} \mathrm{C}, 30 \mathrm{~s}$ at $60{ }^{\circ} \mathrm{C}, 30 \mathrm{~s}$ at $\left.72{ }^{\circ} \mathrm{C}\right)$ and a final extension step of $10 \mathrm{~min}$ at $72{ }^{\circ} \mathrm{C}$ were performed. An aliquot of PCR product was digested using Alu I (New England Biolabs, UK); fragments were separated in agarose gels.

Unrestricted PCR product (CC genotype) had a size of $235 \mathrm{bp}$; complete restriction (TT genotype) produces two bands of $150 \mathrm{bp}$ and $85 \mathrm{bp}$.

\subsection{Statistical analysis}

The Chi-square $\left(\chi^{2}\right)$ test was employed to evaluate the association between GSK-3 $\beta-50$ genotypes and categorical variables. One-way analysis of variance (ANOVA) and Student $t$-test were used for continuous variables. 
Multivariate analysis of variance (MANOVA) was employed to assess the main effect of genotypes and personality on OPCRIT factor scores and to analyse the interaction between the two variables. The relation between OPCRIT factors and TCI dimensions was analysed with the Spearman correlation test. Finally, analysis of covariance (ANCOVA) and linear regression were used to check the effect of potential confounding variables, such as subjects' gender or age, in the statistically significant associations. Statistical analyses were performed using the "Statistica" package (StatSoft, 1995).

The main analysis concerned the association with the OPCRIT delusional factor and personality dimensions of the TCI ( 7 dimensions). To avoid the risk of missing small effects exerted by genetic variants, we applied a reduced Bonferroni correction, setting an alpha level of 0.01 . With these parameters we had a sufficient power $(0.80)$ to detect a medium size effect $(d=0.55)$, corresponding to a difference of 2.7 points on delusional scores for GSK-3 $\beta$ 50 genotypes and to an explained variance of $7 \%$. The effect size was larger $(d=0.73)$ for personality scores, corresponding to a difference of approximately 3.6 points and an explained variance of $12 \%$ (Cohen, 1988).

\section{Results}

Firstly, the association between genotype variants TT, TC and CC of GSK-3 $\beta-50$, demographic factors (gender and age) and clinical features (diagnosis and age at onset) of subjects were investigated. Then, GSK$3 \beta-50$ variants were analysed in relation to symptomatology. Further, since clinical features of affective disorders may be hypothesized to be influenced by some personality features, we controlled for potential associations between personality and symptomatologic clusters, as well as for associations between GSK-3 $\beta-50$ and personality. Finally, we looked for potential interactions between personality, symptomatology and genetic variants.

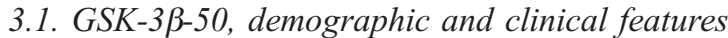

In Table 1, the distribution of the three genotypes TT, TC and CC, stratified for demographic and clinical features of the sample, is reported. GSK-3 $\beta-50$ genotypes were in Hardy-Weinberg equilibrium $\left(\chi^{2}=0.86, d f=1\right.$, $P=0.35$ ); however, we observed a small excess of the heterozygous genotype TC between males. Sex was then systematically controlled in the following analyses by the multivariate analysis of variance (MANOVA) and the linear regression analysis.

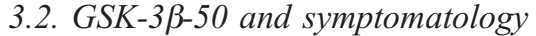

Mean scores of OPCRIT factors in the three groups of subjects (TT, TC and CC) are reported in Table 2. Subjects with the CC genotype showed a trend for higher scores on the Delusion factor, while they did not differ from other patients in the factors of Excitement, Depression, Disorganization and Negative symptoms. We therefore carried out an exploratory analysis, investigating type of single delusions in the three groups of subjects (Table 3) and we observed that delusions of influence occurred more frequently among $\mathrm{CC}$ subjects than in other patients.

\subsection{Personality and symptomatology}

According to the hypothesis of a modulation of some mood disorder manifestations exerted by personality, we found some trends toward association between TCI scores and the delusional factor. Delusion scores were marginally related to Harm Avoidance $(R=-0.23$, $P=0.05)$ and positively related to the Self-Directedness sub-scales of Resourcefulness $(R=0.26, P=0.03)$ and the Self-Transcendence sub-scale of Transpersonal Identification $(R=0.27, P=0.02)$.

Subjects' gender was not associated either with Delusion scores $(t=1.49, d f=1, P=0.14)$ or the Transpersonal Identification dimension $(t=0.83, d f=1, P=0.41)$,

Table 2

Incidence of delusions listed in the OPCRIT, stratified for GSK-3 $\beta-50$ genotypes

\begin{tabular}{|c|c|c|c|c|c|}
\hline & \multicolumn{3}{|l|}{ Genotypes GSK-3 $\beta-50$} & \multirow{3}{*}{$\begin{array}{l}F \\
(d f=2,336)\end{array}$} & \multirow[t]{3}{*}{$P$} \\
\hline & $\mathrm{TT}(n=147)$ & TC $(n=147)$ & $\mathrm{CC}(n=45)$ & & \\
\hline & Mean \pm standard deviation & Mean \pm standard deviation & Mean \pm standard deviation & & \\
\hline Excitement & $0.52 \pm 0.36$ & $0.51 \pm 0.35$ & $0.62 \pm 0.36$ & 2.12 & 0.15 \\
\hline Depression & $0.76 \pm 0.22$ & $0.80 \pm 0.18$ & $0.76 \pm 0.20$ & 0.01 & 0.92 \\
\hline Delusion & $0.11 \pm 0.16$ & $0.11 \pm 0.15$ & $0.18 \pm 0.21$ & 7.15 & 0.008 \\
\hline Disorganization & $0.12 \pm 0.17$ & $0.10 \pm 0.15$ & $0.13 \pm 0.18$ & 0.65 & 0.42 \\
\hline Negative symptomatology & $0.06 \pm 0.15$ & $0.03 \pm 0.09$ & $0.04 \pm 0.11$ & 0.002 & 0.96 \\
\hline
\end{tabular}

Beta and $P$ values obtained by linear regression analysis, controlling for sex, are reported. 
Table 3

OPCRIT factors stratified for the GSK-3 $\beta-50$ genotypes

\begin{tabular}{|c|c|c|c|c|c|}
\hline & \multicolumn{3}{|l|}{ Genotypes GSK-3 $\beta-50$} & \multirow[t]{4}{*}{ Beta } & \multirow[t]{4}{*}{$P$} \\
\hline & TT & $\mathrm{TC}$ & $\mathrm{CC}$ & & \\
\hline & $N(\%)$ & $N(\%)$ & $N(\%)$ & & \\
\hline & No/yes & No/yes & No/yes & & \\
\hline Persecutory delusions & $99 / 48(67.35 / 32.65 \%)$ & $97 / 50(65.99 / 34.01 \%)$ & $23 / 22(51.11 / 48.89 \%)$ & 0.09 & 0.11 \\
\hline Grandiose delusions & $120 / 27(81.63 / 18.37 \%)$ & $126 / 21(85.71 / 14.29 \%)$ & $28 / 17(62.22 / 37.78 \%)$ & 0.10 & 0.06 \\
\hline Delusions of influence & $142 / 5(96.60 / 3.40 \%)$ & 140/7 (95.24/4.76\%) & $38 / 7(84.44 / 15.56 \%)$ & 0.14 & 0.009 \\
\hline Delusions of passivity & $146 / 1(99.32 / 0.68 \%)$ & $146 / 1(99.32 / 0.68 \%)$ & $44 / 1(97.78 / 2.22 \%)$ & 0.04 & 0.45 \\
\hline Thought insertion & 146/1 (99.32/0.68\%) & $147 / 0(100 / 0.00 \%)$ & $43 / 2(95.56 / 4.44 \%)$ & 0.09 & 0.11 \\
\hline Thought withdrawal & $146 / 1(99.32 / 0.68 \%)$ & $146 / 1(99.32 / 0.68 \%)$ & $44 / 1(97.78 / 2.22 \%)$ & 0.04 & 0.47 \\
\hline Thought broadcast & $145 / 2(98.64 / 1.36 \%)$ & $147 / 0(100 / 0.00 \%)$ & $44 / 1(97.78 / 2.225)$ & -0.004 & 0.94 \\
\hline Delusions of guilt & $130 / 17(88.44 / 11.56 \%)$ & $126 / 21(85.71 / 14.29 \%)$ & $43 / 2(95.56 / 4.44 \%)$ & -0.04 & 0.44 \\
\hline Delusions of poverty & $142 / 5(96.60 / 3.40 \%)$ & $141 / 6(95.92 / 4.08 \%)$ & $45 / 0(100 / 0.00 \%)$ & -0.04 & 0.42 \\
\hline Nihilistic delusions & $144 / 3(97.96 / 2.04 \%)$ & $143 / 4(97.28 / 2.72 \%)$ & $45 / 0(100 / 0.00 \%)$ & -0.03 & 0.58 \\
\hline Thought echo & $147 / 0(100 / 0.00 \%)$ & $147 / 0(100 / 0.00 \%)$ & $45 / 0(100 / 0.00 \%)$ & - & - \\
\hline
\end{tabular}

$F$ and $P$ values obtained in multivariate analysis of variance, controlling for sex, are reported.

while females showed higher scores on Harm Avoidance in comparison with males $(t=2.76, d f=1, P=0.007)$, as previously observed (Cloninger et al., 1994).

Analyzing TCI dimensions for each type of delusion, high scores on Transpersonal Identification were significantly associated with Delusion of influence $(t=-2.79$, $d f=1, P=0.007)$. Scores on Harm Avoidance were not significantly related to specific delusion types (data not shown).

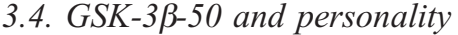

Since we found personality scores moderately associated with delusional symptoms, we investigated whether GSK-3 $\beta-50$ also modulated personality dimensions whether related to delusions or not. We firstly performed an association analysis between GSK-3 $\beta-50$ genotypes and personality traits (Table 4 ) and we found the CC genotype showing a trend of association with low scores on Shyness with Strangers (Harm Avoidance subscale), and a significant association with high scores on Transpersonal Identification (Self-Transcendence subscale). The association between GSK-3 $\beta-50$ and Transpersonal Identification was not influenced by subjects' gender and age (MANCOVA main effect of genotype: $F=5.55, d f=2, P=0.005)$ while gender significantly modulated the association between GSK-3 $\beta-50$ and Harm Avoidance, with females showing higher scores on this sub-scale (Cloninger et al., 1994) (MANCOVA main effect of gender: $F=8.42, d f=1, P=0.005$ ). Diagnosis did not influence the observed association (data not shown).

Table 4

Mean scores in TCI personality dimensions, stratified for GSK-3 $\beta-50$ genotype

\begin{tabular}{|c|c|c|c|c|c|c|}
\hline & & \multicolumn{3}{|l|}{ Genotypes GSK-3 $\beta-50$} & \multirow{3}{*}{$\begin{array}{l}F \\
(d f=2,92)\end{array}$} & \multirow[t]{3}{*}{$P$} \\
\hline & & \multirow{2}{*}{$\frac{\text { TT }(n=39)}{\text { Mean } \pm \text { standard deviation }}$} & \multirow{2}{*}{$\frac{\mathrm{TC}(n=42)}{\text { Mean } \pm \text { standard deviation }}$} & \multirow{2}{*}{$\frac{\mathrm{CC}(n=14)}{\text { Mean } \pm \text { standard deviation }}$} & & \\
\hline & & & & & & \\
\hline Novelty Seeking & NS & $18.85 \pm 5.17$ & $19.58 \pm 6.48$ & $20.21 \pm 5.25$ & 0.38 & 0.68 \\
\hline Harm Avoidance & HA & $20.69 \pm 7.53$ & $18.55 \pm 7.53$ & $18.64 \pm 7.85$ & 2.08 & 0.13 \\
\hline (Shyness with Strangers) & (HA3) & $(4.56 \pm 2.38)$ & $(3.30 \pm 2.22)$ & $(3.93 \pm 1.94)$ & $(3.58)$ & $(0.03)$ \\
\hline Reward Dependence & $\mathrm{RD}$ & $14.54 \pm 3.47$ & $14.65 \pm 3.33$ & $15.28 \pm 3.89$ & 0.19 & 0.83 \\
\hline Persistence & $\mathrm{PE}$ & $3.85 \pm 1.80$ & $4.51 \pm 1.79$ & $3.50 \pm 1.83$ & 1.93 & 0.15 \\
\hline Self-Directedness & SD & $24.69 \pm 17.34$ & $30.35 \pm 7.60$ & $26.57 \pm 10.32$ & 1.40 & 0.25 \\
\hline Cooperativeness & $\mathrm{C}$ & $29.92 \pm 4.95$ & $29.3 \pm 7.03$ & $30.43 \pm 4.64$ & 0.41 & 0.66 \\
\hline Self-Transcendence & ST & $13.33 \pm 6.41$ & $13.53 \pm 7.03$ & $18.36 \pm 5.48$ & 2.38 & 0.098 \\
\hline (Transpersonal Identification) & (ST2) & $(3.38 \pm 1.91)$ & $(3.19 \pm 2.05)$ & $(5.21 \pm 2.01)$ & $(5.11)$ & $(0.008)$ \\
\hline
\end{tabular}

$F$ and value of the multivariate analysis of variance, controlling for sex, are shown. 


\subsection{Interaction between genetics and personality in delusional symptomatology}

Previous analyses evidenced a significant association between the GSK-3 $\beta-50$ CC genotype and Delusional scores. Delusions were also affected by personality traits and GSK-3 $\beta-50$ showed an association with personality as well, in particular with sub-scales of Harm Avoidance and Self-Transcendence. These results allowed us to hypothesize an influence of GSK-3 $\beta-50$ on delusional symptomatology mediated or modulated by personality.

To evaluate the influence of both genetic and individual personality traits on delusional dimensions, we performed a multivariate analysis (MANOVA), including in the model both GSK-3 $\beta-50$ genotypes and personality as independent variables, with OPCRIT Delusion scores as the dependent variable.

Delusions were significantly affected by GSK-3 $\beta-50$ (MANOVA main effect of genotype: $F=10.74, d f=2$, $P=0.0017$ ) and by personality as well (MANOVA effect of interaction between Harm avoidance and SelfTranscendence: $F=8.87, d f=1, P=0.004)$. Moreover, the interaction between GSK-3 $\beta-50$ and personality on Delusion scores was moderately significant (MANOVA interaction between genotype and personality dimensions: $F=6.48, d f=3, P=0.013)$. Results were not influenced either by gender $(P=0.28)$ or age $(P=0.16)$.

\section{Discussion}

In the present study we investigated the relation between genetic aspects, symptomatology dimensions and personality traits, in a sample of patients affected by mood disorders. Our aim was to evaluate the influence of the GSK-3 $\beta$ SNP -50T/C (GSK-3 $\beta-50$ ) on mood disorders, taking into account personality in such illness manifestations. Our results evidenced an association between the GSK-3 $\beta-50 * C$ variant and psychotic symptomatology.

We did not replicate our previous findings concerning age at onset (Benedetti et al., 2004a), but this could be due to the fact that both major depressives and bipolar subjects were included in the present study or to chance fluctuations of associations.

The product of the GSK- $3 \beta$ gene has multiple functions, but this enzyme is particularly involved in cellular degenerative processes. Cellular enzyme capacity may have a remarkable impact on neuronal survival processes, for our interest, in cerebral areas like fronto-temporal cortex (hippocampus and para-hippocampus) and subcortical areas like the thalamus as well.

Confirmation of GSK-3 $\beta$ involvement in neurodegenerative processes came from studies on Alzheimer disease (Sperber et al., 1995; Hong and Lee, 1997); in fact, the protein, responsible of neurofibrillary tangles, is one of the principal targets of the enzyme itself (Lesort et al., 1999; Bijur et al., 2000). Another hypothesis involves the dopaminergic system: GSK-3 $\beta$ action would modulate dopaminergic systems (Castelo-Branco et al., 2004), probably through an indirect effect on circadian rhythm systems (Nestler and Carlezon, 2006), and this would directly influence delusion and personality features.

In the present work we also evaluated personality features, hypothesizing manifestation of the disease as potentially modulated by personality. In accordance with this hypothesis, delusional symptoms were more frequent in patients with higher scores on the Transpersonal Identification sub-scale and, less strongly, on Harm Avoidance.

Transpersonal Identification is characterized by feelings of strong connection with nature and the universe as a whole, feelings of everything as part of one living organism. This inclination towards transcendence is related to a detachment from reality; boundaries between self and the world and between self and other people would be vague and tend to fuse (Houran and Lange, 2004; Lawrence and Peters, 2004).

The GSK-3 $\beta-50$ polymorphism showed a positive association with delusional scores and also with those personality traits related to delusion. We may hypothesize an effect of GSK-3 $\beta-50$ on personality in nonclinical patients as well; however, the lack of a control sample precludes testing of this hypothesis. GSK-3 $\beta-50$ showed a major effect on delusion, but an interaction between genetics and personality was also observed, thus indicating that psychotic aspects may be modulated by personality.

Our investigation had a number of limitations. Firstly, the retrospective approach could bias data collection towards unreliable estimates of clinical variables (Keller et al., 1987). To limit this bias, we used a set of strategies: information about the illness was collected by an experienced psychiatrist who interviewed subjects, family members, and previous health professionals and obtained records when possible (Leckman et al., 1982); a second experienced psychiatrist reviewed the chart, and lack of was assessed and considered an exclusion criterion (Shapira et al., 1996).

Secondly, subjects were mainly inpatients. This could decrease the sample size and impair representativeness for the general population. In fact, our Center is a tertiary care setting, and therefore we cannot exclude a potential bias associated with severity of illness. Third, research was carried out on a sample of patients affected by mood disorders; thus results could not be extended to 
the general population or other psychiatric patients. Further, we can only hypothesize a genetic effect on severity of delusion but not a genetic association, as a control group was not available.

Fourth, the evaluation instruments have some limitations. The OPCRIT has been validated (Williams et al., 1996), but it is not widely employed in both clinical and experimental settings; thus comparison with other studies and observations is difficult. Mood disorders impact patients' personality and thus its evaluation; for example, Harm Avoidance is reported to be higher during a depressive episode and lower with recovery (Cloninger et al., 1994). To limit this bias, the TCI was administered during a euthymic phase, lasting at least 3 months. Nevertheless, Harm Avoidance scores might not return to a standard level after remission (Strakowski et al., 1992; Joffe et al., 1993; Young et al., 1995; Richter et al., 2000; Farmer et al., 2003). Further, sub-clinical symptomatology (Blazer et al., 1994; Blazer, 1997), as well as maintenance antidepressant therapy (Knutson et al., 1998), may impact personality evaluation. From a genetic perspective, we did not control for ethnic stratification (Pritchard and Rosenberg, 1999); however, subjects were recruited in the genetically homogenous area of North Italy (Cavalli Sforza, 1994). Finally, the significance levels were very low (Risch and Merikangas, 1996) and a false positive result is likely considering the large number of analyses performed.

Taking into account the above-mentioned limitations, we observed an association between GSK-3 $\beta$ and both psychotic and personality features in mood disorder patients. Neuro-degenerative processes linked to GSK$3 \beta$ may be in part responsible for delusional symptoms, as well as specific personality dimensions. Finally, we pointed out the interaction between genetic and personality traits in modulating delusional symptoms.

\section{References}

Alimohamad, H., Rajakumar, N., Seah, Y.H., Rushlow, W., 2005a. Antipsychotics alter the protein expression levels of beta-catenin and GSK-3 in the rat medial prefrontal cortex and striatum. Biological Psychiatry 57, 533-542.

Alimohamad, H., Sutton, L., Mouyal, J., Rajakumar, N., Rushlow, W.J., 2005b. The effects of antipsychotics on beta-catenin, glycogen synthase kinase- 3 and dishevelled in the ventral midbrain of rats. Journal of Neurochemistry 95, 513-525.

American Psychiatric Association, 1994. Diagnostic and Statistical Manual of Mental Disorders, 4th edition. APA, Washington, DC.

Bailer, U., Leisch, F., Meszaros, K., Lenzinger, E., Willinger, U., Strobl, R., Heiden, A., Gebhardt, C., Doge, E., Fuchs, K., Sieghart, W., Kasper, S., Hornik, K., Aschauer, H.N., 2002. Genome scan for susceptibility loci for schizophrenia and bipolar disorder. Biological Psychiatry 52, 40-52.
Benedetti, F., Bernasconi, A., Lorenzi, C., Pontiggia, A., Serretti, A., Colombo, C., Smeraldi, E., 2004a. A single nucleotide polymorphism in glycogen synthase kinase 3-beta promoter gene influences onset of illness in patients affected by bipolar disorder. Neuroscience Letters 355, 37-40.

Benedetti, F., Serretti, A., Colombo, C., Lorenzi, C., Tubazio, V., Smeraldi, E., 2004b. A glycogen synthase kinase 3-beta promoter gene single nucleotide polymorphism is associated with age at onset and response to total sleep deprivation in bipolar depression. Neuroscience Letters 368, 123-126.

Benedetti, F., Serretti, A., Pontiggia, A., Bernasconi, A., Lorenzi, C., Colombo, C., Smeraldi, E., 2005. Long-term response to lithium salts in bipolar illness is influenced by the glycogen synthase kinase 3-beta-50 T/C SNP. Neuroscience Letters 376, 51-55.

Bijur, G.N., De Sarno, P., Jope, R.S., 2000. Glycogen synthase kinase-3beta facilitates staurosporine- and heat shock-induced apoptosis. Protection by lithium. Journal of Biological Chemistry 275, 7583-7590.

Blazer, D.G., 1997. Severe episode of depression in late life - the long road to recovery. American Journal of Psychiatry 153, 1620-1623.

Blazer, D.G., Kessler, R.C., McGonagle, K.A., Swartz, M.S., 1994. The prevalence and distribution of major depression in a national community sample: the National Comorbidity Survey. American Journal of Psychiatry 151, 979-986.

Castelo-Branco, G., Rawal, N., Arenas, E., 2004. GSK-3beta inhibition/ beta-catenin stabilization in ventral midbrain precursors increases differentiation into dopamine neurons. Journal of Cellular Science 117, 5731-5737.

Cavalli Sforza, L., 1994. The History and Geography of Human Genes. Princeton University Press, Princeton, NJ, USA.

Cloninger, C.R., Przybeck, T.R., Svrakic, D.M., Wetzel, R.D., 1994. The Temperament and Character Inventory (TCI): A Guide to Its Development and Use. Center for Psychobiology of Personality, Washington University, St. Louis, MO.

Cohen, J., 1988. Statistical Power Analysis for the Behavioral Sciences. Lawrence Erlbaum Associates, Hillsdale, NJ, pp. 8-14.

Cusin, C., Serretti, A., Zanardi, R., Lattuada, E., Rossini, D., Lilli, R., Lorenzi, C., Smeraldi, E., 2002. Influence of monoamine oxydase $\mathrm{A}$ and serotonin receptor $2 \mathrm{~A}$ polymorphisms in SSRIs antidepressant activity. International Journal of Neuropsychopharmacology $5,27-35$.

Detera-Wadleigh, S.D., 2001. Lithium-related genetics of bipolar disorder. Annals of Medicine 33, 272-285.

Embi, N., Rylatt, D.B., Cohen, P., 1980. Glycogen synthase kinase-3 from rabbit skeletal muscle. Separation from cyclic-AMPdependent protein kinase and phosphorylase kinase. European Journal of Biocheminstry 107, 519-527.

Farmer, A., Mahmood, A., Redman, K., Harris, T., Sadler, S., McGuffin, P., 2003. A sib-pair study of the Temperament and Character Inventory scales in major depression. Archives of General Psychiatry 60, 490-496.

First, M.B., Spitzer, R.L., Gibbon, M., Williams, J.B., 1995. Structured Clinical Interview for DSM-IV Axis I Disorders - Patient Edition (SCID - I/P, Version 2.0), Biometrics Research Department, New York State Psychiatric Institute, New York.

Glazier, A.M., Nadeau, J.H., Aitman, T.J., 2002. Finding genes that underlie complex traits. Science 298, 2345-2349.

Grimes, C.A., Jope, R.S., 2001. The multifaceted roles of glycogen synthase kinase 3 beta in cellular signaling. Progress in Neurobiology $65,391-426$.

Hong, M., Lee, V.M., 1997. Insulin and insulin-like growth factor-1 regulate tau phosphorylation in cultured human neurons. Journal of Biological Chemistry 272, 19547-19553. 
Houran, J., Lange, R., 2004. Redefining delusion based on studies of subjective paranormal ideation. Psychological Reports 94, $501-513$.

Joffe, R.T., Bagby, R.M., Levitt, A., 1993. Anxious and nonanxious depression. American Journal of Psychiatry 150, 1257-1258.

Keller, M.B., Lavori, P.W., Friedman, B., Nielsen, E., Endicott, J., McDonald-Scott, P., Andreasen, N.C., 1987. The longitudinal interval follow-up evaluation. A comprehensive method for assessing outcome in prospective longitudinal studies. Archives of General Psychiatry 44, 540-548.

Kendler, K.S., 2005. “A gene for...”: the nature of gene action in psychiatric disorders. American Journal of Psychiatry 162, 1243-1252.

Klein, P.S., Melton, D.A., 1996. A molecular mechanism for the effect of lithium on development. Proceedings of the National Academy of Sciences of the United States of America 93, 8455-8459.

Knutson, B., Wolkowitz, O.M., Cole, S.W., Chan, T., Moore, E.A., Johnson, R.C., Terpstra, J., Turner, R.A., Reus, V.I., 1998. Selective alteration of personality and social behavior by serotonergic intervention. American Journal of Psychiatry 155, 373-379.

Kozlovsky, N., Belmaker, R.H., Agam, G., 2000. Low GSK-3beta immunoreactivity in postmortem frontal cortex of schizophrenic patients. American Journal of Psychiatry 157, 831-833.

Kozlovsky, N., Belmaker, R.H., Agam, G., 2001. Low GSK-3 activity in frontal cortex of schizophrenic patients. Schizophrenia Research 52, 101-105.

Lahiri, D.K., Nurnberger, J.I.J., 1991. A rapid non-enzymatic method for the preparation of HMW DNA from blood for RFLP studies. Nucleic Acids Research 19, 5444.

Lawrence, E., Peters, E., 2004. Reasoning in believers in the paranormal. Journal of Nervous and Mental Disease 192, 727-733.

Leckman, J.F., Sholomskas, D., Thompson, W.D., Belanger, A., Weissman, M.M., 1982. Best estimate of lifetime psychiatric diagnosis: a methodological study. Archives of General Psychiatry 39, 879-883.

Lee, K.Y., Ahn, Y.M., Joo, E.J., Jeong, S.H., Chang, J.S., Kim, S.C., Kim, Y.S., 2006. No association of two common SNPs at position$1727 \mathrm{~A} / \mathrm{T},-50 \mathrm{C} / \mathrm{T}$ of GSK-3 beta polymorphisms with schizophrenia and bipolar disorder of Korean population. Neuroscience Letters 395, 175-178.

Lesort, M., Greendorfer, A., Stockmeier, C., Johnson, G.V., Jope, R.S., 1999. Glycogen synthase kinase-3beta, beta-catenin, and tau in postmortem bipolar brain. Journal of Neural Transmission 106, $1217-1222$.

Manji, H.K., Moore, G.J., Chen, G., 2000. Lithium up-regulates the cytoprotective protein $\mathrm{Bcl}-2$ in the CNS in vivo: a role for neurotrophic and neuroprotective effects in manic depressive illness. Journal of Clinical Psychiatry 61, 82-96.

McGuffin, P., Farmer, A., Harvey, I., 1991. A polydiagnostic application of operational criteria in studies of psychotic illness. Development and reliability of the OPCRIT system. Archives of General Psychiatry 48, 764-770.

Nestler, E.J., Carlezon Jr., W.A., 2006. The mesolimbic dopamine reward circuit in depression. Biological Psychiatry 25, 25.

Nishiguchi, N., Breen, G., Russ, C., St Clair, D., Collier, D., 2006. Association analysis of the glycogen synthase kinase-3beta gene in bipolar disorder. Neuroscience Letters 394, 243-245.

Plyte, S.E., Hughes, K., Nikolakaki, E., Pulverer, B.J., Woodgett, J.R., 1992. Glycogen synthase kinase-3: functions in oncogenesis and development. Biochimica et Biophysica Acta 1114, 147-162.

Pritchard, J.K., Rosenberg, N.A., 1999. Use of unlinked genetic markers to detect population stratification in association studies. American Journal of Human Genetics 65, 220-228.
Richter, J., Eisemann, M., Richter, G., 2000. Temperament and character during the course of unipolar depression among inpatients. European Archives of Psychiatry and Clinical Neuroscience $250,40-47$.

Risch, N., Merikangas, K., 1996. The future of genetic studies of complex human diseases. Science 273, 1516-1517.

Russ, C., Lovestone, S., Powell, J.F., 2001. Identification of sequence variants and analysis of the role of the glycogen synthase kinase 3 beta gene and promoter in late onset Alzheimer's disease. Molecular Psychiatry 6, 320-324.

Salinas, P.C., Hall, A.C., 1999. Lithium and synaptic plasticity. Bipolar Disorders 1, 87-90.

Serretti, A., Olgiati, P., 2004. Dimensions of major psychoses: a confirmatory factor analysis of six competing models. Psychiatry Research 127, 101-109.

Serretti, A., Rietschel, M., Lattuada, E., Krauss, H., Schulze, T., Müller, D., Maier, W., Smeraldi, E., 2001a. Major psychoses symptomatology: factor analysis of 2241 psychotic subjects. European Archives of Psychiatry and Clinical Neuroscience 251, 193-198.

Serretti, A., Zanardi, R., Rossini, D., Cusin, C., Lilli, R., Smeraldi, E., 2001b. Influence of tryptophan hydroxylase and serotonin transporter genes on fluvoxamine antidepressant activity. Molecular Psychiatry 6, 586-592.

Serretti, A., Cusin, C., Rossini, D., Artioli, P., Dotoli, D., Zanardi, R., 2004. Further evidence of a combined effect of SERTPR and TPH on SSRIs response in mood disorders. American Journal of Medical Genetics 129B, 36-40.

Serretti, A., Calati, R., Mandelli, L., De Ronchi, D., 2006. Serotonin transporter gene variants and behaviour: a comprehensive review. Current Drug Targets 7, 1659-1669.

Shapira, B., Lidsky, D., Gorfine, M., Lerer, B., 1996. Electroconvulsive therapy and resistant depression: clinical implications of seizure threshold. Journal of Clinical Psychiatry 57, 32-38.

Smeraldi, E., Zanardi, R., Benedetti, F., Dibella, D., Perez, J., Catalano, M., 1998. Polymorphism within the promoter of the serotonin transporter gene and antidepressant efficacy of fluvoxamine. Molecular Psychiatry 3, 508-511.

Sperber, B.R., Leight, S., Goedert, M., Lee, V.M., 1995. Glycogen synthase kinase-3 beta phosphorylates tau protein at multiple sites in intact cells. Neuroscience Letters 197, 149-153.

Stambolic, V., Woodgett, J.R., 1994. Mitogen inactivation of glycogen synthase kinase- 3 beta in intact cells via serine 9 phosphorylation. Biochemical Journal 303, 701-704.

StatSoft, I., 1995, STATISTICA per Windows, StatSoft Italia srl.

Strakowski, S.M., Faedda, G.L., Tohen, M., Goodwin, D.C., Stoll, A.L., 1992. Possible affective-state dependence of the Tridimensional Personality Questionnaire in first-episode psychosis. Psychiatry Research 41, 215-226.

Svenningsson, P., Tzavara, E.T., Carruthers, R., Rachleff, I., Wattler, S., Nehls, M., McKinzie, D.L., Fienberg, A.A., Nomikos, G.G., Greengard, P., 2003. Diverse psychotomimetics act through a common signaling pathway. Science 302, 1412-1415.

Szczepankiewicz, A., Rybakowski, J.K., Suwalska, A., Skibinska, M., Leszczynska-Rodziewicz, A., Dmitrzak-Weglarz, M., Czerski, P.M., Hauser, J., 2006a. Association study of the glycogen synthase kinase3beta gene polymorphism with prophylactic lithium response in bipolar patients. World Journal of Biological Psychiatry 7, 158-161.

Szczepankiewicz, A., Skibinska, M., Hauser, J., Slopien, A., Leszczynska-Rodziewicz, A., Kapelski, P., Dmitrzak-Weglarz, M., Czerski, P.M., Rybakowski, J.K., 2006b. Association analysis of the GSK-3beta T-50C gene polymorphism with schizophrenia and bipolar disorder. Neuropsychobiology 53, 51-56. 
Williams, J., Farmer, A.E., Ackenheil, M., Kaufmann, C.A., McGuffin, P., 1996. A multicentre inter-rater reliability study using the OPCRIT computerized diagnostic system. Psychological Medicine 26, $775-783$.

Young, L.T., Bagby, R.M., Cooke, R.G., Parker, J.D., Levitt, A.J., Joffe, R.T., 1995. A comparison of Tridimensional Personality Questionnaire dimensions in bipolar disorder and unipolar depression. Psychiatry Research 58, 139-143.
Zanardi, R., Serretti, A., Rossini, D., Franchini, L., Cusin, C., Lattuada, E., Dotoli, D., Smeraldi, E., 2001. Factors affecting fluvoxamine antidepressant activity: influence of pindolol and 5HTTLPR in delusional and nondelusional depression. Biological Psychiatry 50, 323-330. 
Chapter 12: Discussion 


\section{Discussion}

The series of papers reported in the present thesis chapters summarize about 8 years of activity in the field of pharmacogenetics that extend our knowledge also in the broader field of psychiatric genetics.

In fact, while the original effort was directed toward the identification of gene variants influencing the liability to antidepressant response, it was then clear that each gene variant exert an effect that is much broader on the human behavior and extends on many other aspects, as discussed more in detail later.

Coming to the specific chapters, following the first evidence of association of the most plausible candidate, serotonin transporter linked polymorphic region - HTTLPR, with antidepressant response (Smeraldi et al., 1998), we tried to investigate further variants on other genes. The identification of candidate genes must be performed in pathways of the antidepressant response, that, even if not completely known, starts with the initial blockade of serotonin transporter by SSRIs. This increase of serotonin in the synapsis is further modulated by other mechanisms. Notably by the serotonin availability in the presynaptic cleft. The enzyme tryptophan hydroxylase (TPH) is therefore a main candidate as it catalyzes the rate-limiting step in serotonin $(5-\mathrm{HT})$ biosynthesis. TPH has two isoforms: TPH1 and TPH2. Initially TPH1 was considered to be important and this is the reason why we decided o investigate it. After, it has been suggested that it is expressed only in peripheric tissues, while TPH2 is expressed in the central nervous system. But recently it has been suggested that it may exert an important role during development (Nakamura and Hasegawa, 2007; Nakamura et al., 2006). In fact we observed a significant effect on antidepressant response, and for the first time, in the second chapter of this thesis, we demonstrated that it has a contribution on antidepressant response that is independent from the one of HTTLPR (Serretti et al., 2001b). This was the first time that a multigenic control of antidepressant response was observed. This reflects the biological reality, as complex traits are likely controlled by 10-30 gene variants (Kendler, 2005; Kendler and Greenspan, 2006; Risch, 1990). After our initial finding a number of groups alternatively replicated or failed to replicate this finding (Ham et al., 2007; Serretti et al., 2001a; Serretti et al., 2001b), while no significant association could be seen with intolerance as well as treatment response in other studies (Ham et al., 2005; Hong et al., 2006; Kato et al., 2008a; Takahashi et al., 2002; Yoshida et al., 2002). We will discuss later the possible reasons of such discrepancies, that affect also the main field of psychiatric genetics.

In the further search of other gene variants influencing antidepressant response, we focused on post-synaptic candidates. Serotonin receptors are mediated by G protein activities. As in all systems there exist variants genetically controlled. It should be noted that the entire genome contains about 5-7 millions variants (SNPs) spanned approximately every 500 base pairs, therefore each gene has a number of variants depending on its length that can reach several hundreds. We already discussed the issue of the genetic variation and the problems to face in the identification of candidate variants. Therefore we focused on the G protein beta 3 subunit, which gene contains a functional polymorphism influencing the protein activity. Interestingly, in the third chapter of this thesis, we observed a significant correlation with antidepressant response (Serretti et al., 2003c). In the following years some other studies reported significant associations of the same $\mathrm{T}$ variant with better response to various classes of antidepressant (Lee et al., 2004; Zill et al., 2000), to nortriptyline in less than 25 years subjects (Joyce et al., 2003) while other studies found no association of this SNP with SSRIs 
(Hong et al., 2006; Joyce et al., 2003; Kato et al., 2008b) and mirtazapine response (Kang et al., 2007). One study found also opposite results (Wilkie et al., 2007).

During the 1990 decade, a lot of interest focused on the possible modulating influence of serotonin autoreceptors in the serotonin system. Artigas first reported that 5HT1A receptors can modulate via a feedback system the serotonin turnover (Artigas et al., 1994). It was then suggested to add the only available drug having this effect, the beta blocker pindolol, as potentiation to antidepressant treatment to prevent the early negative feedback exerted by 5HT1A with mixed but mainly positive results (Perez et al., 1997). We then candidated 5HT1A gene variants as possible predictors of efficacy hypothesizing that a variation on the protein could modulate the feedback on the serotonin system resulting in a variable clinical effect. In the fourth chapter here presented we reported a significant, though only in bipolar subjects, effect on antidepressant response of 5HT1A gene variants (Serretti et al., 2004). This variant was involved in the regulation of the transcription rate of the HTR1A gene. When the G-allele is present, it prevents the binding of this putative repressor to DNA, leading, in this way, to an increase of 5-HT1A auto receptors and to a reduction of serotonergic neurotransmission (Stahl, 1994). Also for this identification a series of papers followed trying to replicate the finding. One study reported similar findings with less responders in $\mathrm{G} / \mathrm{G}$ carriers but in a small sample (Parsey et al., 2006). While the study by Arias revealed opposite findings to these studies but this significance could be seen only after considering the genetic variation together with the 5-HTTLPR. However most other studies reported negative findings (Arias et al., 2005; Lemonde et al., 2004; Levin et al., 2007; Peters et al., 2004; Serretti et al., 2004). In the Asian population two studies reported significant results with better response for $\mathrm{G} / \mathrm{G}$ compared to $\mathrm{C}$ allele carriers (Hong et al., 2006; Yu et al., 2006). Further variants should be investigated to cover all gene (Drago et al., 2007), this is an aspect that applies to all investigations.

The availability of a number of variants influencing antidepressant response, as it was obtained also for antipsychotic response (Arranz and de Leon, 2007; Arranz et al., 2000), prompted us to investigate possible statistical models that could combine all available genetic effects to reach the final goal of an individualized therapy based on a genetic analysis. This is the topic of the fifth chapter in this thesis. In the paper we developed a neural network model with the aim of testing it versus the more common linear models. In fact it is biologically plausible that gene interactions exert their combined effect in a non linear way. In the paper it is reported that non linear interaction may successfully describe the gene variant effects, this was the first time to investigate and develop such a method that is flexible and can be extended to a much larger number of both genetic and clinical-environmental predictors (Serretti and Smeraldi, 2004), as we further described on other two papers related to clinical and demographic predictors (Serretti et al., 2007f; Serretti et al., 2007g).

Developing this line of research, it was hypothesized that each gene variant may influence a trait that is not reflected by the overall antidepressant response, but only to a part of it. In fact, parallel investigations of our group evidenced that variants on the CLOCK gene (Katzenberg et al., 1998) may influence diurnal preference, sleep pattern (sixth chapter of this thesis) (Serretti et al., 2003a) and this is reflected in higher recurrence of episodes in mood disorder patients (Benedetti et al., 2003). It is in fact well known that if mood disorder patients, particularly bipolars, do not sleep well, they relapse more easily. A gene variant that influences sleep patterns is of great interest for pharmacogenetics, therefore in the seventh chapter of this thesis (Serretti et al., 2005a) we investigated it in our sample and we observed a very interesting finding. Patients carrying the CLOCK CC variant had a peculiar response to treatment evidenced by a normal global response but with persisting insomnia. In other words those patients have a kind of 'structural' insomnia that is not relieved by treatment. If 
confirmed, this finding may have substantial clinical implications because clinicians should not consider the patient as a partial responder, but a full responder with a kind of 'permanent' and genetically determined insomnia. Unfortunately no other group tried to replicate this finding that should be considered as preliminary at this time.

As before mentioned, each gene variant exerts a wide range of effects on human behavior. Scientific investigation is scattered in a number of reports investigating a single aspect each. Therefore, for the first time in literature, we tried to combine all available evidence on the gene that has been most consistently associated with antidepressant response, the HTTLPR variant. In the eight chapter of this thesis we reported the large number of effects of HTTLPR on human behavior (Serretti et al., 2006a). In particular, the 5-HTTLPR short (S) form was found to relate to a higher amygdala response, anxiety-related personality traits but not anxiety disorders, elevated vulnerability in front of stressors, a worse response to selective serotonin reuptake inhibitors in different diagnoses, higher side effects. Moreover, bipolar disorder, alcohol dependence, eating disorders, attention deficit hyperactivity disorder and suicide attempts have also been found to be associated with the $\mathrm{S}$ allele.

If we take the main results obtained on 5-HTTLPR into consideration, a carrier of the short variant may be hypothesized to be strongly hyper-reactive to negative stimuli that, with plausibly other neuroanatomical influences, could lead to a stronger attentional bias for anxious stimuli and to showing more likely anxiety-related personality traits, that could also influence the individual attachment pattern. He or she has higher risk of developing mood disorders, eating disorders, alcohol dependency and of attempting suicide; furthermore, when treated with antidepressants shows a poorer response to pharmacotherapy and higher side effects. As a result, having the $\mathrm{S}$ allele could be erroneously considered as a selection mistake. Nevertheless, being an $\mathrm{S}$ allele carrier has advantages, such as resistance to dementia and more active sexual behaviour with higher number of offsprings. Moreover, $\mathrm{S}$ carriers displayed a better functioning in family and working areas (Serretti et al., 2005b).

This is a further advance that evidences how a single gene variant originally associated with antidepressant response may have this effect via many other interacting pathways.

We previously mentioned that gene variants are important for antidepressant response but clinical and demographic factors are at least equally important. Also previously mentioned is the fact that we tried to combine all clinical-demographical factors in a predictive model but the variance explained in that paper was about $25 \%$, less than half the one expected, that should be in the range of $50 \%$. We therefore hypothesized that other factors should be present but that were not investigated. The clinical practice if of great help in this direction. When a clinician is facing the patient during a consultation a much larger number of variables intervene in the decision of the treatment and prognosis other than age, sex, onset and the limited $\mathrm{n}$ umber of variables collected in pharmacogenetic studies. It was therefore evident a gap between the complexity of the everyday clinical practice and the reductionism of research studies. In the ninth chapter we deeply investigated two clinical cases with the aim of suggesting a more deep and comprehensive assessment for pharmacogenetic studies (Serretti et al., 2007b), that were partially included in another recent paper proposing guidelines in the field (Serretti et al., 2007d). In detail, a more detailed analysis of personality, temperament, defense mechanisms, self esteem, intelligence and social adjustment may allow to formalize the clinical impressions used by clinicians for biologic and pharmacologic studies.

After a decade from our initial report about the HTTLPR influence on antidepressant response a number of other groups tried to replicate the finding, therefore a study summarizing available evidence was greatly needed. This was the aim of the tenth chapter (Serretti et al., 2007e). In a field were independent replications are the exception rather than 
the rule, we observed a significant association of the s/s variant of 5-HTTLPR with remission rate and both $\mathrm{s} / \mathrm{s}$ and $\mathrm{s} / \mathrm{l}$ variants with response. This effect was quite robust to ethnic differences though a significant heterogeneity was present in Asian samples.

The eleventh chapter of this thesis is an application of the finding of the preceding ones, given the pivotal importance of GSK-3beta variants in human physiology, we investigated this variant in a large range of behaviors and we observed that GSK-3 $\beta-50$ polymorphism showed a positive association with delusional symptomatology and with the personality features linked to Self Transcendence. Also, GSK-3 $\beta-50$ and personality showed an interactive effect on delusional scores (Serretti et al., 2008). It also influenced antidepressant response (unpublished data).

The 10 studies here reported show clearly how starting from a relatively simple working hypothesis, results then leaded to a much wider complexity that we are just at the beginning to investigate. Psychiatric genetics is in fact a relatively new field of investigation. A brief historical overview may help in understanding the reasons underlying the present status.

Historically the importance given to hereditary factors in psychiatry has lived synchronous oscillations with the dominance of different pathogenic model of mental illness. A positivist position during the late ' 800 , promoted a biological vision culminated with the race approaches in the first half of the twentieth century that leaded to a rapid decline in genetic research starting from the '50. For three decades, the hegemony of the psycodynamic, phenomenological and psychosocial models (Arieti, 1959; Szaz, 1973) has relegated biological studies to a marginal position. The '80s marked a new reverse route announced by the publication of DSM-III (American Psychiatric Association, 1980). The traditional idiographic method, that is based on the description of individual case studies, is replaced by standardized atheoretical diagnostic criteria. This neo-kraepelinian model marks the rebirth of the biological psychiatry also fostered by the spread of an effective psychopharmacology, although not resolving, in most psychiatric disorders.

Psychiatric genetic research knows at this time an exciting phase of expansion driven by advances in molecular biology. Since the mid-'80s the introduction of genetic markers has made it possible to identify individual parts of the genome and to associate normal or pathological features to it. Human DNA, organized in about 20,000 genes, is $99.9 \%$ the same in all individuals (Venter et al., 2001). The genomic diversity is ensured by the remaining $0.1 \%$. This several million base pairs scattered throughout the genome, constitute the foundation of all genetic interindividual differences. While in previous years genetic association studies were based on phenotypical markers, such as blood group and HLA, they were necessarily limited in number. In this period it become possible for the first time to characterize each subject for hundreds, then millions of variations scattered along the genome. The availability of "reliable" psychiatric diagnosis and techniques for highresolution genotyping represents an extremely favorable conjunction and many authors believed to be able to determine the liability to mental disorders combining one or more gene variants. The enthusiasm for this type of approach has reached its apex at the end of the 80s when particular emphasis was given to the study we previously discussed that seemed to have identified the genetic basis of bipolar disorder (Egeland et al., 1987). It was believed to be on the threshold of an era of profound transformation in the psychiatric classification revolutionized by genetics. We saw later how this vision was overly optimistic (Kendler, 2006). Then started in fact a period characterized by continuous discoveries of susceptibility genes for schizophrenia or mood disorders, followed invariably by lack of confirmations in independent replications (Risch and Botstein, 1996). Although the'90s have been defined 'decade of the brain', it ended without any significant result achieved in the field of 
psychiatric genetics, compared to the amount of studies (over 2000 - source MEDLINE) and the considerable public and private effort put on it. The beginning of the years 2000 features two contrasting trends, on the one hand, the completion of the sequence of the human genome seems to draw a new rebirth of genetics, on the other a public opinion frustrated by the lack of results leaded many agencies to reduce the financing of the sector. This happened at American Institute of Health (NIMH), which in previous years had been one of the main sponsors.

In recent years it takes shape an attitude of the researchers who seems to overcome the difficulties of the past and, perhaps, offer a key interpretation less naive and more profitable.

Which are therefore the real effects of genes in psychiatric disorders? All psychiatric diseases have a genetic component, whose weight varies from $80 \%$ for schizophrenia and bipolar disorder to $30 \%-40 \%$ for anxiety disorders. The effect of individual genes seems to be much more modest, as Kendler clearly described in his work (Kendler, 2005) and we previously outlined.

If the association between a gene variant and the corresponding phenotype following a mendelian mode of transmission is defined by an odds ratio (OR) if 100 or more, depending from the penetrance, the link between psychiatric disorders and most liability genes reported in the literature does not exceed ORs of 5, with a suggested mean value of 1.5 . In the light of these observations the idea prevailing at the end of the'90s and early 2000 was that not one but perhaps 10 or 20 gene variations were necessary to give to a person the liability to develop mood disorder or schizophrenia, along with an equivalent contribution from the environment. In recent years it was clear that each gene variant influences many physiopathological pathways which in turn affect different behavioral characteristics in healthy and affected subjects. This was a change of view from the hypothesis a gene - a disease to multiple genes - a disease and, finally, most genes - various behavioral characteristics.

The complexity of this view can be effectively illustrated by a few examples. In classical mendelian genetics every subject bearing of genotype or pathogen is affected. This is the case for many genetic diseases such as cystic fibrosis, phenylketonuria, or to stay in neuropsychiatric field, the Huntington disease. It is therefore possible for each person to predict the state of the disease on the basis of a simple genetic examination. The so-called complex diseases require the simultaneous presence of several susceptibility genes together with environmental influences, such as diabetes or hypertension. The new concept proposed by the most recent evidence suggests that gene variants are not only responsible for 'part' of susceptibility to the disease, but also has other effects, depending from the condition of the subject. A gene variant may cause slight changes in neuropsychological features of healthy subjects or induce psychotic manifestations in the subject affected by the mood disorder, or influence the choice and pattern of substances of abuse, to influence the response to particular drugs, and so forth. Gene variants thus as factors in susceptibility to behavioural dimensions not only exceeding the nosographic boundaries of psychiatry but also challenging the very concept of psychiatric disorders (Angst and Cassano, 2005).

The paradigmatic example of this understanding of genetics in psychiatry is the variant ' $s$ ' of HTTLPR polymorphism located on promoter gene encoding for the serotonin transporter and analyzed in the seventh chapter of this thesis. This variant is present in just over half the population or, in the homozygous form, in approximately one quarter of the population. This is a functional variant that influences the expression of the serotonin transporter. Subjects homozygous for the s allele have many characteristics: they are characterized by increased anxiety and neuroticism, basic tendency to develop depressive episodes and resistance to 
antidepressant treatment, liability to substance abuse (particularly alcohol) and eating disorders, increased incidence of depressive symptoms in people with schizophrenia and a special presentation of the Alzheimer type dementia (Serretti et al., 2006a). Moreover, in a longitudinal perspective, subjects that express the variation 's' showed greater sensitivity to stressors and anxious stimuli (Caspi et al., 2003), this sensitivity seems to be mediated by temperamental features such as neuroticism (Jacobs et al., 2006). These experimental results appear to outline a scenario different from traditional genetic (Kendler, 2005). An allelic variant on HTTLPR, the physiological effect of which is to reduce by about half the number of serotonin transporters in the brain (Bradley et al., 2005; Lesch et al., 1996), causes a trend to determine slight, but detectable unspecific behaviours of the person, that, in combination with other gene or environmental factors, causes a full disorder. One might ask at this point why these gene variants have been retained by evolution if they are so deleterious to the individual? The answer comes from the cited recent studies showing that the bearers of the $\mathrm{s}$ variant are also (and perhaps because of behavioural trends anxious above mentioned) liable to pay more attention to work and family and with greater cognitive ability (Roiser et al., 2007; Serretti et al., 2005b), further they have a higher sexual activity possibly leading to a higher number of offsprings (Halpern et al., 2007; Krawczak et al., 2005). These features are adaptive in the case of lack of other susceptibility genes or protective factors, but disadaptive in the presence of concurrent genetic or environmental susceptibility factors.

The evidence reported in the literature to support this theory are so substantial that appears difficult doubt of this view. In any case we realized how difficult is to proceed to a full analysis of the interactions occurring in each individual. The variations in the human genome are approximately 5,000,000 of these presumably only 60,000 are functional, namely the ones changing protein expression, and an even smaller number is expressed in the brain. However it is always tens of thousands of possible behavioural modulators whose reciprocal influences and with the environment determine the mental status of the subject. Despite those difficulties, the encouraging results obtained confirm that this is the way forward.

Some authors have raised the question if the traditional scientific method is be best suited to lead us to know of all the factors involved (Woyshville et al., 1999). The complexity of the interaction between genes and environment and their change with time, cannot be analyzed with statistical traditional approaches also considering multivariate or flexible ones such as neural networks (Serretti and Smeraldi, 2004). Probably even more flexible approaches as theories of Chaos or Fuzzy logic could be useful (Ehlers, 1995).

But what could be the future scenario? We could envisage a society based on genetic discrimination in advance of individuals, as proposed by some literary and cinematographic authors (Huxley, 1932; Niccol, 1997)? Or the current historical period characterized by a significant preponderance biological studies will leave the field to a return of humanistic approaches and idiographic ones based on individual cases? The nomothetic and idiographic approaches seem destined to meet when the complexity of each individual is accepted and not reduced within broad nosographic categories. The genetic susceptibility can never be deterministic, it will never be possible to provide each person with a certainty of what will happen, but it will be possible only to furnish a percentage of increase or reduction compared to the general population. Moreover, the detailed knowledge of all possible effects of genetic susceptibility can never create individuals of A or B series - any psychological genetically determined trait also has positive aspects as well as negative ones, as we previously described - but only profiles characterized by specific risks more or less marked in each subject. This will allow to possibly modulate the environment in order to minimize the negative impact of the individual genetic profile.

Even purely psychological aspects such as defense mechanisms and styles of interpersonal 
relationships will be perhaps one day knowable in terms of gene-environment interaction (Mundo, 2006). These acquisitions will enrich the dynamic psychology of new therapeutic tools rather than delete it passing to a biologically based psychiatry. However, premature jumps forward should be avoided, such as that one recently brought to fame by a survey conducted on behalf of the Senate of the United States (July 2006 http://www.gao.gov/new.items/d06977t.pdf). Some Internet sites offered to pay the analysis of the genetic profile of each individual providing a summary that highlighted the possible risks of disease (stroke, hypertension, etc.), followed by prescription of custom packages of integrators aimed at counteracting the genetic susceptibility, this also available on payment. The government survey underscored how, despite there were some scientific basis for the allegation, they were totally insufficient to justify such a behavior by companies.

Finally, the variable part of our genome that makes us different from one another predisposes us so thin but broad trends of specific psychological and psychiatric traits interacting with the environmental stimuli. Knowledge of these effects can realistically be achieved in order to outline a profile of individual vulnerability, according to a bio-psycho-social model really focused on the needs of the patient. 


\section{References}

Alonso J, Lepine JP (2007): Overview of key data from the European Study of the Epidemiology of Mental Disorders (ESEMeD). J Clin Psychiatry 68 Suppl 2:3-9.

Alving AS, Kellermeyer RW, Tarlov A, Schrier S, Carson PE (1958): Biochemical and genetic aspects of primaquine-sensitive hemolytic anemia. Ann Intern Med 49:240-8.

American Psychiatric Association (1980): Diagnostic and Statistical Manual of Mental Disorders, 3rd Edition. American Psychiatric Association, Washington DC.

American Psychiatric Association (1994): Diagnostic and Statistical Manual of Mental Disorders, 4th Edition. American Psychiatric Association, Washington DC.

Amsterdam JD, Fawcett J, Quitkin FM, Reimherr FW, Rosenbaum JF, Michelson D, Hornig-Rohan M, Beasley CM (1997): Fluoxetine and norfluoxetine plasma concentrations in major depression: a multicenter study. Am J Psychiatry 154:963-9.

Angst J, Cassano G (2005): The mood spectrum: improving the diagnosis of bipolar disorder. Bipolar Disord 7 Suppl 4:4-12.

Anguelova M, Benkelfat C, Turecki G (2003): A systematic review of association studies investigating genes coding for serotonin receptors and the serotonin transporter: I. Affective disorders. Mol Psychiatry 8:592-610.

Arias B, Catalan R, Gasto C, Gutierrez B, Fananas L (2005): Evidence for a combined genetic effect of the 5HT1A receptor and serotonin transporter genes in the clinical outcome of major depressive patients treated with citalopram. J Psychopharmacol 19:166-172.

Arieti S (1959): American handbook of Psychiatry. Basic Books, New York, pp 2098.

Arranz MJ, de Leon J (2007): Pharmacogenetics and pharmacogenomics of schizophrenia: a review of last decade of research. Mol Psychiatry 12:707-47.

Arranz MJ, Erdmann J, Kirov G, Rietschel M, Sodhi M, Albus M, Ball D, Maier W, Davies N, Franzek E, Abusaad I, Weigelt B, Murray R, Shimron-Abarbanell D, Kerwin R, Propping P, Sham P, Nothen MM, Collier DA (1997): 5-HT2A receptor and bipolar affective disorder: association studies in affected patients. Neuroscience Letters 224:95-8.

Arranz MJ, Munro J, Birkett J, Bolonna A, Mancama D, Sodhi M, Lesch KP, Meyer JF, Sham P, Collier DA, Murray RM, Kerwin RW (2000): Pharmacogenetic prediction of clozapine response. Lancet 355:16156.

Artigas F, Perez V, Alvarez E (1994): Pindolol induces a rapid improvement of depressed patients treated with serotonin reuptake inhibitors. Archives of General Psychiatry 51:248-51.

Bauer M, Whybrow PC, Angst J, Versiani M, Moller HJ (2002): World Federation of Societies of Biological Psychiatry (WFSBP) Guidelines for Biological Treatment of Unipolar Depressive Disorders, Part 1: Acute and continuation treatment of major depressive disorder. World J Biol Psychiatry 3:5-43.

BEBCG (1997): No association between bipolar disorder and alleles at a functional polymorphism in the COMT gene. Biomed European Bipolar Collaborative Group. Br J Psychiatry 170:526-8.

Benedetti F, Serretti A, Colombo C, Barbini B, Lorenzi C, Campori E, Smeraldi E (2003): Influence of CLOCK gene polymorphism on circadian mood fluctuation and illness recurrence in bipolar depression. Am J Med Genet 123B:23-6.

Bocchetta A, Piccardi MP, Palmas MA, Chillotti C, Oi A, Del Zompo M (1999): Family-based association study between bipolar disorder and DRD2, DRD4, DAT, and SERT in Sardinia. American Jouranl of Medical Genetics 88:522-6.

Bonnier B, Gorwood P, Hamon M, Sarfati Y, Boni C, Hardy-Bayle MC (2002): Association of 5-HT(2A) receptor gene polymorphism with major affective disorders: the case of a subgroup of bipolar disorder with low suicide risk. Biol Psychiatry 51:762-5.

Bradley SL, Dodelzon K, Sandhu HK, Philibert RA (2005): Relationship of serotonin transporter gene polymorphisms and haplotypes to mRNA transcription. Am J Med Genet B Neuropsychiatr Genet 136:58-61.

Breen G, Prata D, Osborne S, Munro J, Sinclair M, Li T, Staddon S, Dempster D, Sainz R, Arroyo B, Kerwin RW, St Clair D, Collier D (2006): Association of the dysbindin gene with bipolar affective disorder. Am J Psychiatry 163:1636-8.

Burdick KE, Funke B, Goldberg JF, Bates JA, Jaeger J, Kucherlapati R, Malhotra AK (2007): COMT genotype increases risk for bipolar I disorder and influences neurocognitive performance. Bipolar Disord 9:3706.

Caspi A, Sugden K, Moffitt TE, Taylor A, Craig IW, Harrington H, McClay J, Mill J, Martin J, Braithwaite A, Poulton R (2003): Influence of life stress on depression: moderation by a polymorphism in the 5-HTT gene. Science 301:386-9. 
Chee IS, Lee SW, Kim JL, Wang SK, Shin YO, Shin SC, Lee YH, Hwang HM, Lim MR (2001): 5-HT2A receptor gene promoter polymorphism $-1438 \mathrm{~A} / \mathrm{G}$ and bipolar disorder. Psychiatr Genet 11:111-4.

Chen YS, Akula N, Detera-Wadleigh SD, Schulze TG, Thomas J, Potash JB, DePaulo JR, McInnis MG, Cox NJ, McMahon FJ (2004): Findings in an independent sample support an association between bipolar affective disorder and the G72/G30 locus on chromosome 13q33. Mol Psychiatry 9:87-92; image 5.

Cho HJ, Meira-Lima I, Cordeiro Q, Michelon L, Sham P, Vallada H, Collier DA (2005): Population-based and family-based studies on the serotonin transporter gene polymorphisms and bipolar disorder: a systematic review and meta-analysis. Mol Psychiatry 12:12.

Cichon S, Nothen MM, Erdmann J, Propping P (1994): Detection of four polymorphic sites in the human dopamine D1 receptor gene (DRD1). Hum Mol Genet 3:209.

Cichon S, Nothen MM, Stober G, Schroers R, Albus M, Maier W, Rietschel M, Korner J, Weigelt B, Franzek E, Wildenauer D, Fimmers R, Propping P (1996): Systematic screening for mutations in the 5'-regulatory region of the human dopamine D1 receptor (DRD1) gene in patients with schizophrenia and bipolar affective disorder. Am J Med Genet 67:424-8.

Craddock N, Dave S, Greening J (2001): Association studies of bipolar disorder. Bipolar Disord 3:284-98.

Cramer JA, Rosenheck R (1998): Compliance with medication regimens for mental and physical disorders. Psychiatr Serv 49:196-201.

Das Gupta R, Guest JF (2002): Annual cost of bipolar disorder to UK society. Br J Psychiatry 180:227-233.

De Luca V, Mueller DJ, Tharmalingam S, King N, Kennedy JL (2004): Analysis of the novel TPH2 gene in bipolar disorder and suicidality. Mol Psychiatry 9:896-7.

Devon RS, Anderson S, Teague PW, Burgess P, Kipari TM, Semple CA, Millar JK, Muir WJ, Murray V, Pelosi AJ, Blackwood DH, Porteous DJ (2001): Identification of polymorphisms within Disrupted in Schizophrenia 1 and Disrupted in Schizophrenia 2, and an investigation of their association with schizophrenia and bipolar affective disorder. Psychiatr Genet 11:71-8.

Dmitrzak-Weglarz M, Rybakowski JK, Slopien A, Czerski PM, Leszczynska-Rodziewicz A, Kapelski P, Kaczmarkiewicz-Fass M, Hauser J (2006): Dopamine receptor D1 gene -48A/G polymorphism is associated with bipolar illness but not with schizophrenia in a Polish population. Neuropsychobiology 53:46-50.

Drago A, Ronchi DD, Serretti A (2007): 5-HT1A gene variants and psychiatric disorders: a review of current literature and selection of SNPs for future studies. Int J Neuropsychopharmacol:1-21.

Egan MF, Goldberg TE, Kolachana BS, Callicott JH, Mazzanti CM, Straub RE, Goldman D, Weinberger DR (2001): Effect of COMT Val108/158 Met genotype on frontal lobe function and risk for schizophrenia. Proc Natl Acad Sci U S A 98:6917-22.

Egeland JA, Gerhard DS, Pauls DL, Sussex JN, Kidd KK, Allen CR, Hostetter AM (1987): Bipolar affective disorders linked to markers on chromosome 11. Nature 325:783-787.

Ehlers CL (1995): Chaos and complexity. Can it help us to understand mood and behavior? Arch Gen Psychiatry 52:960-4.

Entsuah AR, Huang H, Thase ME (2001): Response and remission rates in different subpopulations with major depressive disorder administered venlafaxine, selective serotonin reuptake inhibitors, or placebo. J Clin Psychiatry 62:869-77.

Etain B, Rousseva A, Roy I, Henry C, Malafosse A, Buresi C, Preisig M, Rayah F, Leboyer M, Bellivier F (2004): Lack of association between 5HT2A receptor gene haplotype, bipolar disorder and its clinical subtypes in a West European sample. Am J Med Genet B Neuropsychiatr Genet 129:29-33.

Fallin MD, Lasseter VK, Avramopoulos D, Nicodemus KK, Wolyniec PS, McGrath JA, Steel G, Nestadt G, Liang K-Y, Huganir RL, Valle D, Pulver AE (2005): Bipolar I Disorder and Schizophrenia: A 440Single-Nucleotide Polymorphism Screen of 64 Candidate Genes among Ashkenazi Jewish Case-Parent Trios. Am J Hum Genet 77:918-936.

Faraone S, Tsuang M, Tsuang D (1999): Genetics of mental disorders. The Guilford Press, New York.

Flint J, Munafo MR (2006): The endophenotype concept in psychiatric genetics. Psychol Med:1-18.

Funke B, Malhotra AK, Finn CT, Plocik AM, Lake SL, Lencz T, DeRosse P, Kane JM, Kucherlapati R (2005): COMT genetic variation confers risk for psychotic and affective disorders: a case control study. Behav Brain Funct 1:19.

Furlong RA, Ho L, Rubinsztein JS, Walsh C, Paykel ES, Rubinsztein DC (1999): Analysis of the monoamine oxidase A (MAOA) gene in bipolar affective disorder by association studies, meta-analyses, and sequencing of the promotor. American Journal of Medical Genetics 88:398-406.

Furlong RA, Ho L, Walsh C, Rubinsztein JS, Jain S, Paykel ES, Easton DF, Rubinsztein DC (1998): Analysis and meta-analysis of two serotonin transporter gene polymorphisms in bipolar and unipolar affective disorders. American Journal of Medical Genetics 81:58-63.

Geller B, Badner JA, Tillman R, Christian SL, Bolhofner K, Cook EH, Jr. (2004): Linkage disequilibrium of the 
brain-derived neurotrophic factor Val66Met polymorphism in children with a prepubertal and early adolescent bipolar disorder phenotype. Am J Psychiatry 161:1698-700.

Georgieva L, Dimitrova A, Nikolov I, Koleva S, Tsvetkova R, Owen MJ, Toncheva D, Kirov G (2002): Dopamine transporter gene (DAT1) VNTR polymorphism in major psychiatric disorders: family-based association study in the Bulgarian population. Acta Psychiatr Scand 105:396-399.

Gomez-Casero E, Perez de Castro I, Saiz-Ruiz J, Llinares C, Fernandez-Piqueras J (1996): No association between particular DRD3 and DAT gene polymorphisms and manic-depressive illness in a Spanish sample. Psychiatric Genetics 6:209-12.

Green EK, Raybould R, Macgregor S, Gordon-Smith K, Heron J, Hyde S, Grozeva D, Hamshere M, Williams N, Owen MJ, O'Donovan MC, Jones L, Jones I, Kirov G, Craddock N (2005): Operation of the schizophrenia susceptibility gene, neuregulin 1, across traditional diagnostic boundaries to increase risk for bipolar disorder. Arch Gen Psychiatry 62:642-8.

Green EK, Raybould R, Macgregor S, Hyde S, Young AH, O'Donovan MC, Owen MJ, Kirov G, Jones L, Jones I, Craddock N (2006): Genetic variation of brain-derived neurotrophic factor (BDNF) in bipolar disorder: case-control study of over 3000 individuals from the UK. Br J Psychiatry 188:21-5.

Greenwood TA, Alexander M, Keck PE, McElroy S, Sadovnick AD, Remick RA, Kelsoe JR (2001): Evidence for linkage disequilibrium between the dopamine transporter and bipolar disorder. Am J Med Genet 105:145-51.

Greenwood TA, Schork NJ, Eskin E, Kelsoe JR (2006): Identification of additional variants within the human dopamine transporter gene provides further evidence for an association with bipolar disorder in two independent samples. Mol Psychiatry 11:125-33, 115.

Gutierrez B, Arias B, Gasto C, Catalan R, Papiol S, Pintor L, Fananas L (2004): Association analysis between a functional polymorphism in the monoamine oxidase A gene promoter and severe mood disorders. Psychiatr Genet 14:203-8.

Gutierrez B, Bertranpetit J, Collier D, Arranz MJ, Valles V, Guillamat R, Van Os J, Fananas L (1997a): Genetic variation of the 5-HT2A receptor gene and bipolar affective disorder. Human Genetics 100:582-584.

Gutierrez B, Bertranpetit J, Guillamat R, Valles V, Arranz MJ, Kerwin R, Fananas L (1997b): Association analysis of the catechol O-methyltransferase gene and bipolar affective disorder. Am J Psychiatry 154:113-5.

Halpern CT, Kaestle CE, Guo G, Hallfors DD (2007): Gene-environment contributions to young adult sexual partnering. Arch Sex Behav 36:543-54.

Ham BJ, Lee BC, Paik JW, Kang RH, Choi MJ, Choi IG, Lee MS (2007): Association between the tryptophan hydroxylase-1 gene A218C polymorphism and citalopram antidepressant response in a Korean population. Prog Neuropsychopharmacol Biol Psychiatry 31:104-7.

Ham BJ, Lee MS, Lee HJ, Kang RH, Han CS, Choi MJ, Lee SH, Ryu SH (2005): No association between the tryptophan hydroxylase gene polymorphism and major depressive disorders and antidepressant response in a Korean population. Psychiatr Genet 15:299-301.

Harvey M, Gagne B, Labbe M, Barden N (2007): Polymorphisms in the neuronal isoform of tryptophan hydroxylase 2 are associated with bipolar disorder in French Canadian pedigrees. Psychiatr Genet $17: 17-22$.

Harvey M, Shink E, Tremblay M, Gagne B, Raymond C, Labbe M, Walther DJ, Bader M, Barden N (2004): Support for the involvement of TPH2 gene in affective disorders. Mol Psychiatry 9:980-1.

Hasler G, Drevets WC, Gould TD, Gottesman, II, Manji HK (2006): Toward constructing an endophenotype strategy for bipolar disorders. Biol Psychiatry 60:93-105.

Hattori E, Liu C, Badner JA, Bonner TI, Christian SL, Maheshwari M, Detera-Wadleigh SD, Gibbs RA, Gershon ES (2003): Polymorphisms at the G72/G30 gene locus, on 13q33, are associated with bipolar disorder in two independent pedigree series. Am J Hum Genet 72:1131-40.

Heiden A, Schussler P, Itzlinger U, Leisch F, Scharfetter J, Gebhardt C, Fuchs K, Willeit M, Nilsson L, MillerReiter E, Stompe T, Meszaros K, Sieghart W, Hornik K, Kasper S, Aschauer HN (2000): Association studies of candidate genes in bipolar disorders. Neuropsychobiology 42 Suppl 1:18-21.

Hickman M, Cairns J (2003): The Centenary of the One-Gene One-Enzyme Hypothesis. Genetics 163:839-841.

Hodgkinson CA, Goldman D, Jaeger J, Persaud S, Kane JM, Lipsky RH, Malhotra AK (2004): Disrupted in Schizophrenia 1 (DISC1): Association with Schizophrenia, Schizoaffective Disorder, and Bipolar Disorder. Am J Hum Genet 75:5.

Holliday R (2006): Epigenetics: a historical overview. Epigenetics 1:76-80.

Hong CJ, Chen TJ, Yu YW, Tsai SJ (2006): Response to fluoxetine and serotonin 1A receptor (C-1019G) polymorphism in Taiwan Chinese major depressive disorder. Pharmacogenomics J 6:27-33.

Hong CJ, Yu YW, Lin CH, Tsai SJ (2003): An association study of a brain-derived neurotrophic factor Val66Met polymorphism and clozapine response of schizophrenic patients. Neurosci Lett 349:206-8. 
Hughes HB, Biehl JP, Jones AP, Schmidt LH (1954): Metabolism of isoniazid in man as related to the occurrence of peripheral neuritis. Am Rev Tuberc 70:266-73.

Huxley A (1932): Brave New World. Harper and Brothers, New York.

Jacobs N, Kenis G, Peeters F, Derom C, Vlietinck R, van Os J (2006): Stress-related negative affectivity and genetically altered serotonin transporter function: evidence of synergism in shaping risk of depression. Arch Gen Psychiatry 63:989-96.

Jensen S, Plaetke R, Holik J, Hoff M, O'Connell P, Reimherr F, Wender P, Zhou QY, Civelli O, Litt M, et al. (1992): Linkage analysis of the D1 dopamine receptor gene and manic depression in six families. Hum Hered 42:269-75.

Johansson C, Jansson M, Linner L, Yuan Q-P, Pedersen NL, Blackwood D, Barden N, Kelsoe J, Schalling M (2001): Genetics of affective disorders. European Neuropsychopharmacology 11:385-394.

Joo EJ, Lee KY, Jeong SH, Chang JS, Ahn YM, Koo YJ, Kim YS (2007): Dysbindin gene variants are associated with bipolar I disorder in a Korean population. Neurosci Lett 418:272-5.

Joyce PR, Mulder RT, Luty SE, McKenzie JM, Miller AL, Rogers GR, Kennedy MA (2003): Age-dependent antidepressant pharmacogenomics: polymorphisms of the serotonin transporter and G protein beta3 subunit as predictors of response to fluoxetine and nortriptyline. Int J Neuropsychopharmacol 6:33946.

Kalow W, Gunn DR (1957): The relation between dose of succinylcholine and duration of apnea in man. J Pharmacol Exp Ther 120:203-214.

Kanazawa T, Glatt SJ, Kia-Keating B, Yoneda H, Tsuang MT (2007): Meta-analysis reveals no association of the Val66Met polymorphism of brain-derived neurotrophic factor with either schizophrenia or bipolar disorder. Psychiatr Genet 17:165-70.

Kang RH, Hahn SW, Choi MJ, Lee MS (2007): Relationship between G-protein beta-3 subunit C825T polymorphism and mirtazapine responses in Korean patients with major depression. Neuropsychobiology 56:1-5.

Kato M, Wakeno M, Okugawa G, Fukuda T, Azuma J, Kinoshita T, Serretti A (2008a): No Association of TPH1 218A/C Polymorphism with Treatment Response and Intolerance to SSRIs in Japanese Patients with Major Depression. Neuropsychobiology 56:167-171.

Kato M, Wakeno M, Okugawa G, Fukuda T, Takekita Y, Hosoi Y, Azuma J, Kinoshita T, Serretti A (2008b): Antidepressant response and intolerance to SSRI is not influenced by G-protein beta3 subunit gene C825T polymorphism in Japanese major depressive patients. Prog Neuropsychopharmacol Biol Psychiatry.

Kato T (2007): Molecular genetics of bipolar disorder and depression. Psychiatry Clin Neurosci 61:3-19.

Katzenberg D, Young T, Finn L, Lin L, King DP, Takahashi JS, Mignot E (1998): A CLOCK polymorphism associated with human diurnal preference. Sleep 21:569-576.

Keikhaee MR, Fadai F, Sargolzaee MR, Javanbakht A, Najmabadi H, Ohadi M (2005): Association analysis of the dopamine transporter (DAT1)-67A/T polymorphism in bipolar disorder. Am J Med Genet B Neuropsychiatr Genet 135:47-9.

Kelsoe JR, Ginns EI, Egeland EA, Gerhard DS, Goldstein AM, Bale SJ, Pauls DL, Long RT, Kidd KK, Conte G, Housman DE, Paul SM (1989): Re-evaluation of the linkage relationship between chromosome 11p loci and the gene for bipolar affective disorder in the Old Order Amish. Nature 342:238-343.

Kendler KS (2005): "A gene for...": the nature of gene action in psychiatric disorders. Am J Psychiatry 162:1243-52.

Kendler KS (2006): Reflections on the relationship between psychiatric genetics and psychiatric nosology. Am J Psychiatry 163:1138-46.

Kendler KS, Gardner CO, Jr. (1998): Boundaries of major depression: an evaluation of DSM-IV criteria. Am J Psychiatry 155:172-7.

Kendler KS, Greenspan RJ (2006): The nature of genetic influences on behavior: lessons from "simpler" organisms. Am J Psychiatry 163:1683-94.

Kessler RC, Chiu WT, Demler O, Merikangas KR, Walters EE (2005): Prevalence, severity, and comorbidity of 12-month DSM-IV disorders in the National Comorbidity Survey Replication. Arch Gen Psychiatry 62:617-27.

Kirchheiner J, Brosen K, Dahl ML, Gram LF, Kasper S, Roots I, Sjoqvist F, Spina E, Brockmoller J (2001): CYP2D6 and CYP2C19 genotype-based dose recommendations for antidepressants: a first step towards subpopulation-specific dosages. Acta Psychiatr Scand 104:173-92.

Krawczak M, Trefilov A, Berard J, Bercovitch F, Kessler M, Sauermann U, Croucher P, Nurnberg P, Widdig A, Schmidtke J (2005): Male reproductive timing in Rhesus macaques is influenced by the 5HTTLPR promoter polymorphism of the serotonin transporter gene. Biol Reprod 72:1109-13.

Kremeyer B, Herzberg I, Garcia J, Kerr E, Duque C, Parra V, Vega J, Lopez C, Palacio C, Bedoya G, Ospina J, 
Ruiz-Linares A (2006): Transmission distortion of BDNF variants to bipolar disorder type I patients from a south american population isolate(,). Am J Med Genet B Neuropsychiatr Genet 141:435-9.

Kuhs H, Schlake HP, Rolf LH, Rudolf GA (1992): Relationship between parameters of serotonin transport and antidepressant plasma levels or therapeutic response in depressive patients treated with paroxetine and amitriptyline. Acta Psychiatr Scand 85:364-9.

Kunugi H, Iijima Y, Tatsumi M, Yoshida M, Hashimoto R, Kato T, Sakamoto K, Fukunaga T, Inada T, Suzuki T, Iwata N, Ozaki N, Yamada K, Yoshikawa T (2004): No association between the Val66Met polymorphism of the brain-derived neurotrophic factor gene and bipolar disorder in a Japanese population: a multicenter study. Biol Psychiatry 56:376-8.

Kunugi H, Ishida S, Kato T, Tatsumi M, Sakai T, Hattori M, Hirose T, Nanko S (1999): A functional polymorphism in the promoter region of monoamine oxidase-A gene and mood disorders. Mol Psychiatry 4:393-5.

Kunugi H, Vallada HP, Hoda F, Kirov G, Gill M, Aitchison KJ, Ball D, Arranz MJ, Murray RM, Collier DA (1997): No evidence for an association of affective disorders with high- or low-activity allele of catechol-o-methyltransferase gene. Biol Psychiatry 42:282-5.

Lachman HM, Kelsoe J, Moreno L, Katz S, Papolos DF (1997): Lack of association of catechol-Omethyltransferase (COMT) functional polymorphism in bipolar affective disorder. Psychiatr Genet 7:13-7.

Lasky-Su JA, Faraone SV, Glatt SJ, Tsuang MT (2005): Meta-analysis of the association between two polymorphisms in the serotonin transporter gene and affective disorders. Am J Med Genet B Neuropsychiatr Genet 133:110-5.

Lee HJ, Cha JH, Ham BJ, Han CS, Kim YK, Lee SH, Ryu SH, Kang RH, Choi MJ, Lee MS (2004): Association between a G-protein beta3 subunit gene polymorphism and the symptomatology and treatment responses of major depressive disorders. Pharmacogenomics J 4:29-33.

Lemonde S, Du L, Bakish D, Hrdina P, Albert PR (2004): Association of the C(1019)G 5-HT1A functional promoter polymorphism with antidepressant response. Int J Neuropsychopharmacol 7:501-506.

Lenox RH, Gould TD, Manji HK (2002): Endophenotypes in bipolar disorder. Am J Med Genet 114:391-406.

Lesch KP, Bengel D, Heils A, Sabol SZ, Greenberg BD, Petri S, Benjamin J, Muller CR, Hamer DH, Murphy DL (1996): Association of anxiety-related traits with a polymorphism in the serotonin transporter gene regulatory region. Science 274:1527-31.

Levin GM, Bowles TM, Ehret MJ, Langaee T, Tan JY, Johnson JA, Millard WJ (2007): Assessment of Human Serotonin 1A Receptor Polymorphisms and SSRI Responsiveness. Mol Diagn Ther 11:155-60.

Levinson DF (2006): The genetics of depression: a review. Biol Psychiatry 60:84-92.

Li T, Vallada H, Curtis D, Arranz M, Xu K, Cai G, Deng H, Liu J, Murray R, Liu X, Collier DA (1997): Catechol-O-methyltransferase Val158Met polymorphism: frequency analysis in Han Chinese subjects and allelic association of the low activity allele with bipolar affective disorder. Pharmacogenetics 7:349-53.

Lin SC, Jiang SD, Wu XD, Qian YP, Wang DX, Tang GM, Gu NF (2000): Association analysis between mood disorder and monoamine oxidase gene. American Journal of Medical Genetics 96:12-14.

Lin YM, Yang HC, Lai TJ, Fann CS, Sun HS (2003): Receptor mediated effect of serotonergic transmission in patients with bipolar affective disorder. J Med Genet 40:781-6.

Lohoff FW, Sander T, Ferraro TN, Dahl JP, Gallinat J, Berrettini WH (2005): Confirmation of association between the Val66Met polymorphism in the brain-derived neurotrophic factor (BDNF) gene and bipolar I disorder. Am J Med Genet B Neuropsychiatr Genet 139:51-3.

Lopez VA, Detera-Wadleigh S, Cardona I, Kassem L, McMahon FJ (2007): Nested association between genetic variation in tryptophan hydroxylase II, bipolar affective disorder, and suicide attempts. Biol Psychiatry 61:181-6.

Maeda K, Nwulia E, Chang J, Balkissoon R, Ishizuka K, Chen H, Zandi P, McInnis MG, Sawa A (2006): Differential expression of disrupted-in-schizophrenia (DISC1) in bipolar disorder. Biol Psychiatry 60:929-35.

Malhotra AK, Murphy GM, Jr., Kennedy JL (2004): Pharmacogenetics of psychotropic drug response. Am J Psychiatry 161:780-96.

Mann JJ, Currier D, Murphy L, Huang YY, Galfalvy H, Brent D, Greenhill L, Oquendo M (2007): No association between a TPH2 promoter polymorphism and mood disorders or monoamine turnover. J Affect Disord.

Masand PS (2003): Tolerability and adherence issues in antidepressant therapy. Clin Ther 25:2289-304.

McGuffin P, Owen MJ, Gottesman II (2004): Psychiatric Genetics and Genomics. Oxford University Press, USA, pp 1-504.

Mitchell AJ (2006): Two-week delay in onset of action of antidepressants: new evidence. Br J Psychiatry 
188:105-6.

Mitchell P, Selbie L, Waters B, Donald J, Vivero C, Tully M, Shine J (1992): Exclusion of close linkage of bipolar disorder to the dopamine D1 and D2 receptor gene markers. Journal of Affective Disorder 25:112.

Moncrieff J, Kirsch I (2005): Efficacy of antidepressants in adults. BMJ 331:551-557.

Muller DJ, de Luca V, Sicard T, King N, Strauss J, Kennedy JL (2006): Brain-derived neurotrophic factor (BDNF) gene and rapid-cycling bipolar disorder: family-based association study. Br J Psychiatry 189:317-23.

Muller DJ, Serretti A, Sicard T, Tharmalingam S, King N, Artioli P, Mandelli L, Lorenzi C, Kennedy JL (2007): Further evidence of MAO-A gene variants associated with bipolar disorder. Am J Med Genet B Neuropsychiatr Genet 144:37-40.

Mundo E (2006): Neurobiology of dynamic psychotherapy: an integration possible? J Am Acad Psychoanal Dyn Psychiatry 34:679-91.

Mynett-Johnson LA, Murphy VE, Claffey E, Shields DC, McKeon P (1998): Preliminary evidence of an association between bipolar disorder in females and the catechol-O-methyltransferase gene. Psychiatr Genet 8:221-5.

Nakamura K, Hasegawa H (2007): Developmental role of tryptophan hydroxylase in the nervous system. Mol Neurobiol 35:45-54.

Nakamura K, Sugawara Y, Sawabe K, Ohashi A, Tsurui H, Xiu Y, Ohtsuji M, Lin QS, Nishimura H, Hasegawa H, Hirose S (2006): Late developmental stage-specific role of tryptophan hydroxylase 1 in brain serotonin levels. J Neurosci 26:530-4.

Nakata K, Ujike H, Sakai A, Uchida N, Nomura A, Imamura T, Katsu T, Tanaka Y, Hamamura T, Kuroda S (2003): Association study of the brain-derived neurotrophic factor (BDNF) gene with bipolar disorder. Neurosci Lett 337:17-20.

Neves FS, Silveira G, Romano-Silva MA, Malloy-Diniz L, Ferreira AA, De Marco L, Correa H (2007): Is the 5HTTLPR polymorphism associated with bipolar disorder or with suicidal behavior of bipolar disorder patients? Am J Med Genet B Neuropsychiatr Genet.

Neves-Pereira M, Cheung JK, Pasdar A, Zhang F, Breen G, Yates P, Sinclair M, Crombie C, Walker N, St Clair DM (2005): BDNF gene is a risk factor for schizophrenia in a Scottish population. Mol Psychiatry 10:208-12.

Neves-Pereira M, Mundo E, Muglia P, King N, Macciardi F, Kennedy JL (2002): The brain-derived neurotrophic factor gene confers susceptibility to bipolar disorder: evidence from a family-based association study. Am J Hum Genet 71:651-5.

Ni X, Trakalo JM, Mundo E, Lee L, Parikh S, Kennedy JL (2002a): Family-based association study of the serotonin-2A receptor gene (5-HT2A) and bipolar disorder. Neuromolecular Med 2:251-9.

Ni X, Trakalo JM, Mundo E, Macciardi FM, Parikh S, Lee L, Kennedy JL (2002b): Linkage disequilibrium between dopamine D1 receptor gene (DRD1) and bipolar disorder. Biol Psychiatry 52:1144-50.

Niccol A (1997): GATTACA. Columbia Pictures, USA, pp $101 \mathrm{~min}$.

Nierenberg AA (2003): Predictors of response to antidepressants general principals and clinical implications. Psychiatr Clin North Am 26:345-352.

Normann C, Horn M, Hummel B, Grunze H, Walden J (2004): Paroxetine in major depression: correlating plasma concentrations and clinical response. Pharmacopsychiatry 37:134-8.

Nöthen M, Erdmann J, Körner J, Lanczik M, Fritze J, Fimmers R, Grandy D, O’Dowd B, Propping P (1992): Lack of association between dopamine D1 and D2 receptor genes and bipolar affective disorder. Am J Psych 149:199-201.

Ohadi M, Keikhaee MR, Javanbakht A, Sargolzaee MR, Robabeh M, Najmabadi H (2007): Gender dimorphism in the DAT1 -67 T-allele homozygosity and predisposition to bipolar disorder. Brain Res.

Ohara K, Nagai M, Tani K, Tsukamoto T, Suzuki Y (1998): Polymorphism in the promoter region of the alpha 2A adrenergic receptor gene and mood disorders. Neuroreport 9:1291-4.

Okada T, Hashimoto R, Numakawa T, Iijima Y, Kosuga A, Tatsumi M, Kamijima K, Kato T, Kunugi H (2006): A complex polymorphic region in the brain-derived neurotrophic factor (BDNF) gene confers susceptibility to bipolar disorder and affects transcriptional activity. Mol Psychiatry 11:695-703.

O'Reilly RL, Bogue L, Singh SM (1994): Pharmacogenetic response to antidepressants in a multicase family with affective disorder. Biol Psychiatry 36:467-71.

Oswald P, Souery D, Mendlewicz J (2004): Molecular genetics of affective disorders. Prog Neuropsychopharmacol Biol Psychiatry 28:865-77.

Pae CU, Serretti A, Mandelli L, Yu HS, Patkar AA, Lee CU, Lee SJ, Jun TY, Lee C, Paik IH, Kim JJ (2006): Effect of 5-haplotype of dysbindin gene (DTNBP1) polymorphisms for the susceptibility to bipolar I disorder. Am J Med Genet B Neuropsychiatr Genet. 
Pae CU, Serretti A, Mandelli L, Yu HS, Patkar AA, Lee CU, Lee SJ, Jun TY, Lee C, Paik IH, Kim JJ (2007): Effect of 5-haplotype of dysbindin gene (DTNBP1) polymorphisms for the susceptibility to bipolar I disorder. Am J Med Genet B Neuropsychiatr Genet 144:701-3.

Parsey RV, Olvet DM, Oquendo MA, Huang YY, Ogden RT, Mann JJ (2006): Higher 5-HT(1A) Receptor Binding Potential During a Major Depressive Episode Predicts Poor Treatment Response: Preliminary Data from a Naturalistic Study. Neuropsychopharmacology 31:1745-9.

Perez V, Gilaberte I, Faries D, Alvarez E, Artigas F (1997): Randomised, double-blind, placebo-controlled trial of pindolol in combination with fluoxetine antidepressant treatment. Lancet 349:1594-7.

Perlis RH (2007): Pharmacogenetic studies of antidepressant response: how far from the clinic? Psychiatr Clin North Am 30:125-38.

Peters EJ, Slager SL, McGrath PJ, Knowles JA, Hamilton SP (2004): Investigation of serotonin-related genes in antidepressant response. Mol Psychiatry 9:879-89.

Pincus HA, Pettit AR (2001): The societal costs of chronic major depression. J Clin Psychiatry 62 Suppl 6:5-9.

Prata DP, Breen G, Munro J, Sinclair M, Osborne S, Li T, Kerwin R, St Clair D, Collier DA (2006): Bipolar 1 disorder is not associated with the RGS4, PRODH, COMT and GRK3 genes. Psychiatr Genet 16:22930 .

Preisig M, Bellivier F, Fenton BT, Baud P, Berney A, Courtet P, Hardy P, Golaz J, Leboyer M, Mallet J, Matthey ML, Mouthon D, Neidhart E, Nosten-Bertrand M, Stadelmann-Dubuis E, Guimon J, Ferrero F, Buresi C, Malafosse A (2000): Association between bipolar disorder and monoamine oxidase A gene polymorphisms: results of a multicenter study. Am J Psychiatry 157:948-55.

Ranade SS, Mansour H, Wood J, Chowdari KV, Brar LK, Kupfer DJ, Nimgaonkar VL (2003): Linkage and association between serotonin $2 \mathrm{~A}$ receptor gene polymorphisms and bipolar I disorder. Am J Med Genet 121B:28-34.

Raybould R, Green EK, MacGregor S, Gordon-Smith K, Heron J, Hyde S, Caesar S, Nikolov I, Williams N, Jones L, O'Donovan MC, Owen MJ, Jones I, Kirov G, Craddock N (2005): Bipolar disorder and polymorphisms in the dysbindin gene (DTNBP1). Biol Psychiatry 57:696-701.

Risch N (1990): Linkage strategies for genetically complex traits:I. Multilocus models. American Journal of Medical Genetics 46:222-228.

Risch N, Botstein D (1996): A manic depressive history. Nature Genetics 12:351-353.

Rodriguez-Revenga L, Mila M, Rosenberg C, Lamb A, Lee C (2007): Structural variation in the human genome: the impact of copy number variants on clinical diagnosis. Genet Med 9:600-6.

Roiser JP, Muller U, Clark L, Sahakian BJ (2007): The effects of acute tryptophan depletion and serotonin transporter polymorphism on emotional processing in memory and attention. Int $\mathrm{J}$ Neuropsychopharmacol 10:449.461.

Rotondo A, Mazzanti C, Dell'Osso L, Rucci P, Sullivan P, Bouanani S, Gonnelli C, Goldman D, Cassano GB (2002): Catechol o-methyltransferase, serotonin transporter, and tryptophan hydroxylase gene polymorphisms in bipolar disorder patients with and without comorbid panic disorder. Am J Psychiatry 159:23-9.

Sartorius N (2001): The economic and social burden of depression. J Clin Psychiatry 62 Suppl 15:8-11.

Savoye C, Laurent C, Amadeo S, Gheysen F, Leboyer M, Lejeune J, Zarifian E, Mallet J (1998): No association between dopamine D1, D2, and D3 receptor genes and manic-depressive illness. Biol Psychiatry 44:644-7.

Schumacher J, Jamra RA, Becker T, Ohlraun S, Klopp N, Binder EB, Schulze TG, Deschner M, Schmal C, Hofels S, Zobel A, Illig T, Propping P, Holsboer F, Rietschel M, Nothen MM, Cichon S (2005): Evidence for a relationship between genetic variants at the brain-derived neurotrophic factor (BDNF) locus and major depression. Biol Psychiatry 58:307-14.

Schumacher J, Jamra RA, Freudenberg J, Becker T, Ohlraun S, Otte AC, Tullius M, Kovalenko S, Bogaert AV, Maier W, Rietschel M, Propping P, Nothen MM, Cichon S (2004): Examination of G72 and D-aminoacid oxidase as genetic risk factors for schizophrenia and bipolar affective disorder. Mol Psychiatry 9:203-7.

Serretti A, Artioli P, Lorenzi C, Pirovano A, Tubazio V, Zanardi R (2004): The C(-1019)G polymorphism of the 5-HT1A gene promoter and antidepressant response in mood disorders: preliminary findings. Int J Neuropsychopharmacol 7:453-460.

Serretti A, Benedetti F, Mandelli L, Calati R, Caneva B, Lorenzi C, Fontana V, Colombo C, Smeraldi E (2008): Association between GSK-3ß -50T/C polymorphism and personality and psychotic symptoms in Mood Disorders. Psychiatry Res. 158:132-140.

Serretti A, Benedetti F, Mandelli L, Lorenzi C, Pirovano A, Colombo C, Smeraldi E (2003a): Genetic dissection of psychopathological symptoms: Insomnia in mood disorders and CLOCK gene polymorphism. Am J Med Genet 121B:39-43. 
Serretti A, Calati R, Ferrari B, De Ronchi D (2007a): Personality and Genetics. Current Psychiatry Reviews 3:147-159.

Serretti A, Calati R, Mandelli L, De Ronchi D (2006a): Serotonin transporter gene variants and behaviour: a comprehensive review. Current Drug Targets 7:1659-1669.

Serretti A, Calati R, Oasi O, De Ronchi D, Colombo C (2007b): Dissecting the determinants of depressive disorders outcome: an in depth analysis of two clinical cases. Ann Gen Psychiatry 6:5.

Serretti A, Cavallini MC, Macciardi F, Namia C, Franchini L, Souery D, Lipp O, Bauwens F, Smeraldi E, Mendlewicz J (1999): Social adjustment and self-esteem in remitted patients with mood disorders. European Psychiatry 14:137-42.

Serretti A, Cusin C, Benedetti F, Mandelli L, Pirovano A, Zanardi R, Colombo C, Smeraldi E (2005a): Insomnia improvement during antidepressant treatment and CLOCK gene polymorphism. Am J Med Genet B Neuropsychiatr Genet 137:36-9.

Serretti A, Cusin C, Cristina S, Lorenzi C, Lilli R, Lattuada E, Grieco G, Costa A, Santorelli F, Barale F, Smeraldi E, Nappi G (2003b): Multicentre Italian family-based association study on tyrosine hydroxylase, catechol-O-methyl transferase and Wolfram syndrome 1 polymorphisms in mood disorders. Psychiatr Genet 13:121-6.

Serretti A, Drago A, De Ronchi D (2007c): HTR2A gene variants and psychiatric disorders: a review of current literature and selection of SNPs for future studies. Curr Med Chem 14:2053-2069.

Serretti A, Kato M, Kennedy JL (2007d): Pharmacogenetic studies in depression: a proposal for methodologic guidelines. Pharmacogenomics J.

Serretti A, Lorenzi C, Cusin C, Zanardi R, Lattuada E, Rossini D, Lilli R, Pirovano A, Catalano M, Smeraldi E (2003c): SSRIs antidepressant activity is influenced by Gbeta3 variants. Eur Neuropsychopharmacol 13:117-22.

Serretti A, Mandelli L, Lorenzi C, Smeraldi E (2005b): Social adjustment could be associated with the serotonin transporter gene in remitted patients with mood disorders and healthy subjects. Psychiatry Res $134: 191-4$

Serretti A, Masaki K, De Ronchi D, Kinoshita T (2007e): Meta-Analysis of Serotonin Transporter Gene Promoter Polymorphism (5-HTTLPR) association with Selective Serotonin Reuptake Inhibitor Efficacy in Depressed Patients. Molecular Psychiatry 12:247-257.

Serretti A, Olgiati P (2007): Pharmacogenetics of Major Depression: From Research to Clinical Practice. Current Medical Literature - Psychiatry 18:37-52.

Serretti A, Olgiati P, Liebman MN, Hu H, Zhang Y, Zanardi R, Colombo C, Smeraldi E (2007f): Clinical prediction of antidepressant response in mood disorders: Linear multivariate vs. neural network models. Psychiatry Res 152:223-231.

Serretti A, Rotondo A, Lorenzi C, Smeraldi E, Cassano GB (2006b): Catechol-O-methyltransferase gene variants in mood disorders in the Italian population. Psychiatr Genet 16:181-2.

Serretti A, Smeraldi E (2004): Neural network analysis in pharmacogenetics of mood disorders. BMC Med Genet 5:27.

Serretti A, Zanardi R, Cusin C, Rossini D, Lorenzi C, Smeraldi E (2001a): Tryptophan hydroxylase gene associated with paroxetine antidepressant activity. European Neuropsychopharmacology 11:375-380.

Serretti A, Zanardi R, Mandelli L, Smeraldi E, Colombo C (2007g): A neural network model for combining clinical predictors of antidepressant response in mood disorders. J Affect Disord 98:239-45.

Serretti A, Zanardi R, Rossini D, Cusin C, Lilli R, Smeraldi E (2001b): Influence of tryptophan hydroxylase and serotonin transporter genes on fluvoxamine antidepressant activity. Molecular Psychiatry 6:586-592.

Severino G, Congiu D, Serreli C, De Lisa R, Chillotti C, Del Zompo M, Piccardi MP (2005): A48G polymorphism in the D1 receptor genes associated with bipolar I disorder. Am J Med Genet B Neuropsychiatr Genet 134:37-8.

Shifman S, Bronstein M, Sternfeld M, Pisante A, Weizman A, Reznik I, Spivak B, Grisaru N, Karp L, Schiffer R, Kotler M, Strous RD, Swartz-Vanetik M, Knobler HY, Shinar E, Yakir B, Zak NB, Darvasi A (2004): COMT: a common susceptibility gene in bipolar disorder and schizophrenia. Am J Med Genet B Neuropsychiatr Genet 128:61-4.

Skibinska M, Hauser J, Czerski PM, Leszczynska-Rodziewicz A, Kosmowska M, Kapelski P, Slopien A, Zakrzewska M, Rybakowski JK (2004): Association analysis of brain-derived neurotrophic factor (BDNF) gene Val66Met polymorphism in schizophrenia and bipolar affective disorder. World J Biol Psychiatry 5:215-20.

Sklar P, Gabriel SB, McInnis MG, Bennett P, Lim YM, Tsan G, Schaffner S, Kirov G, Jones I, Owen M, Craddock N, DePaulo JR, Lander ES (2002): Family-based association study of 76 candidate genes in bipolar disorder: BDNF is a potential risk locus. Brain-derived neutrophic factor. Mol Psychiatry 7:579-93. 
Smeraldi E, Zanardi R, Benedetti F, Dibella D, Perez J, Catalano M (1998): Polymorphism Within the Promoter of the Serotonin Transporter Gene and Antidepressant Efficacy of Fluvoxamine. Molecular Psychiatry 3:508-511.

Snyder LH (1931): Inherited taste deficiency. Science 74:151-152.

Souery D, Lipp O, Mahieu B, Mendelbaum K, De Martelaer V, Van Broeckhoven C, Mendlewicz J (1996): Association study of bipolar disorder with candidate genes involved in catecholamine neurotransmission: DRD2, DRD3, DAT1, and TH genes. American Journal of Medical Genetics 67:551-5.

Stahl S (1994): 5HT1A receptors and pharmacotherapy. Is serotonin receptor down-regulation linked to the mechanism of action of antidepressant drugs? Psychopharmacol Bull 30:39-43.

Stober G, Sprandel J, Schmidt F, Faul T, Jabs B, Knapp M (2006): Association study of 5'-UTR polymorphisms of the human dopamine transporter gene with manic depression. Bipolar Disord 8:490-5.

Strauss J, Barr CL, George CJ, King N, Shaikh S, Devlin B, Kovacs M, Kennedy JL (2004): Association study of brain-derived neurotrophic factor in adults with a history of childhood onset mood disorder. Am J Med Genet B Neuropsychiatr Genet 131:16-9.

Syagailo YV, Stober G, Grassle M, Reimer E, Knapp M, Jungkunz G, Okladnova O, Meyer J, Lesch KP (2001): Association analysis of the functional monoamine oxidase A gene promoter polymorphism in psychiatric disorders. Am J Med Genet 105:168-71.

Szaz TS (1973): The Second Sin. Anchor/Doubleday, Garden City, NY.

Takahashi H, Yoshida K, Ito K, Sato K, Kamata M, Higuchi H, Shimizu T, Inoue K, Tezuka T, Suzuki T, Ohkubo T, Sugawara K (2002): No association between the serotonergic polymorphisms and incidence of nausea induced by fluvoxamine treatment. Eur Neuropsychopharmacol 12:477-81.

Thomson PA, Christoforou A, Morris SW, Adie E, Pickard BS, Porteous DJ, Muir WJ, Blackwood DH, Evans KL (2007): Association of Neuregulin 1 with schizophrenia and bipolar disorder in a second cohort from the Scottish population. Mol Psychiatry 12:94-104.

Thomson PA, Wray NR, Millar JK, Evans KL, Hellard SL, Condie A, Muir WJ, Blackwood DH, Porteous DJ (2005): Association between the TRAX/DISC locus and both bipolar disorder and schizophrenia in the Scottish population. Mol Psychiatry 10:657-68.

Tsuang M, Faraone S (1990): The genetics of mood disorders. The Johns Hopkins University Press, Baltimore, pp 1-31.

Ustun TB, Ayuso-Mateos JL, Chatterji S, Mathers C, Murray CJ (2004): Global burden of depressive disorders in the year 2000. Br J Psychiatry 184:393-403.

Van Den Bogaert A, Sleegers K, De Zutter S, Heyrman L, Norrback KF, Adolfsson R, Van Broeckhoven C, Del-Favero J (2006a): Association of brain-specific tryptophan hydroxylase, TPH2, with unipolar and bipolar disorder in a Northern Swedish, isolated population. Arch Gen Psychiatry 63:1103-10.

Van Den Bogaert A, Sleegers K, De Zutter S, Heyrman L, Norrback KF, Adolfsson R, Van Broeckhoven C, Del-Favero J (2006b): No allelic association or interaction of three known functional polymorphisms with bipolar disorder in a northern Swedish isolated population. Psychiatr Genet 16:209-12.

Venter JC, Adams MD, Myers EW, Li PW, Mural RJ, Sutton GG, Smith HO, Yandell M, Evans CA, Holt RA, Gocayne JD, Amanatides P, Ballew RM, Huson DH, Wortman JR, Zhang Q, Kodira CD, Zheng XH, Chen L, Skupski M, Subramanian G, Thomas PD, Zhang J, Gabor Miklos GL, Nelson C, Broder S, Clark AG, Nadeau J, McKusick VA, Zinder N, Levine AJ, Roberts RJ, Simon M, Slayman C, Hunkapiller M, Bolanos R, Delcher A, Dew I, Fasulo D, Flanigan M, Florea L, Halpern A, Hannenhalli S, Kravitz S, Levy S, Mobarry C, Reinert K, Remington K, Abu-Threideh J, et al (2001): The sequence of the human genome. Science 291:1304-51.

Vincent JB, Masellis M, Lawrence J, Choi V, Gurling HM, Parikh SV, Kennedy JL (1999): Genetic association analysis of serotonin system genes in bipolar affective disorder. American Journal of Psychiatry $156: 136-8$.

Vogel F (1959): Moderne problem der humangenetik. Ergeb Inn Med U Kinderheilk:52-125.

Waldman ID, Robinson BF, Feigon SA (1997): Linkage disequilibrium between the dopamine transporter gene (DAT1) and bipolar disorder: extending the transmission disequilibrium test (TDT) to examine genetic heterogeneity. Genet Epidemiol 14:699-704.

Walss-Bass C, Raventos H, Montero AP, Armas R, Dassori A, Contreras S, Liu W, Medina R, Levinson DF, Pereira M, Leach RJ, Almasy L, Escamilla MA (2006): Association analyses of the neuregulin 1 gene with schizophrenia and manic psychosis in a Hispanic population. Acta Psychiatr Scand 113:314-21.

Weber WW (1997): Pharmacogenetics. Oxford University Press, New York.

Wellcome Trust CCC (2007): Genome-wide association study of 14,000 cases of seven common diseases and 3,000 shared controls. Nature 447:661-78.

Wilkie MJ, Smith D, Reid IC, Day RK, Matthews K, Wolf CR, Blackwood D, Smith G (2007): A splice site 
polymorphism in the G-protein beta subunit influences antidepressant efficacy in depression. Pharmacogenet Genomics 17:207-15.

Williams NM, Green EK, Macgregor S, Dwyer S, Norton N, Williams H, Raybould R, Grozeva D, Hamshere M, Zammit S, Jones L, Cardno A, Kirov G, Jones I, O'Donovan MC, Owen MJ, Craddock N (2006): Variation at the DAOA/G30 locus influences susceptibility to major mood episodes but not psychosis in schizophrenia and bipolar disorder. Arch Gen Psychiatry 63:366-73.

Wittchen H-U, Jacobi F (2005): Size and burden of mental disorders in Europe--a critical review and appraisal of 27 studies. European Neuropsychopharmacology 15:357-376.

Woyshville MJ, Lackamp JM, Eisengart JA, Gilliland JA (1999): On the meaning and measurement of affective instability: clues from chaos theory. Biol Psychiatry 45:261-9.

Yoshida K, Naito S, Takahashi H, Sato K, Ito K, Kamata M, Higuchi H, Shimizu T, Itoh K, Inoue K, Tezuka T, Suzuki T, Ohkubo T, Sugawara K, Otani K (2002): Monoamine oxidase: A gene polymorphism, tryptophan hydroxylase gene polymorphism and antidepressant response to fluvoxamine in Japanese patients with major depressive disorder. Prog Neuropsychopharmacol Biol Psychiatry 26:1279-83.

Yu YW, Tsai SJ, Liou YJ, Hong CJ, Chen TJ (2006): Association study of two serotonin 1A receptor gene polymorphisms and fluoxetine treatment response in Chinese major depressive disorders. Eur Neuropsychopharmacol.

Zill P, Baghai TC, Zwanzger P, Schule C, Minov C, Riedel M, Neumeier K, Rupprecht R, Bondy B (2000): Evidence for an association between a G-protein beta3-gene variant with depression and response to antidepressant treatment. Neuroreport 11:1893-7. 
Summary and concluding remarks

Mood disorders are the most common severe adult psychiatric disorders. Genetic factors are important as well as environmental ones. During the last decades a number of liability genes have been identified but the full understanding of the genetic contribution is still far to be obtained. The focus on more specific aspects could be a better strategy. Pharmacogenetics, that is the study of gene variants influencing drug response, is one of these aspects and the starting point of the papers reviewed in this thesis.

The newly reported contributions of three gene variants on antidepressant response is the subject of the chapters two to four followed by the first attempt to create a neural network analysis of gene interaction in antidepressant response. The sixth and seventh chapters report the first investigation of a specific effect of a gene (CLOCK) on mood disorder insomnia and antidepressant response. The eight chapter further develops the concept of pharmacogenetics suggesting that gene variants exert their influence through a much more complex range of effects on the whole human behavior. In order to investigate also the possible environmental influences, the ninth chapter focused on the possible clinical factors influencing antidepressant response that should be considered in future studies. The tenth chapter summarizes available knowledge through the first meta analysis ever of the most important gene for antidepressant response (HTTLPR) and finally the eleventh chapter is the first application of the new concept that genes influence a wide range of effects, with the example of GSK-3beta gene variants.

The path of the reported research line starting from pharmacogenetics leads to a more comprehensive analysis of the effect of gene variants on human behavior. But genetic susceptibility will never be deterministic, it will never be possible to provide each person with a certainty of what it will happen, but it will be possible only to furnish a percentage of increase or reduction compared to the general population. Moreover, the detailed knowledge of all possible effects of genetic susceptibility can never create individuals of A or B series any psychological genetically determined trait also has positive aspects as well as negative ones - but only profiles characterized by specific risks more or less marked in each subject. Genetic knowledge will allow to possibly modulate the environment in order to minimize the negative impact of the individual genetic profile. This could also lead to a personalized medicine but also to a deeper knowledge of genetic influences on humans. 
Samenvatting en conclusies

Stemmingsstoornissen zijn de meest voorkomende zware psychiatrische stoornissen bij volwassenen. Zowel genetische factoren als omgevingsfactoren spelen een belangrijke rol. Gedurende de laatste decennia is een aantal risicogenen geïdentificeerd, maar er is nog lang geen sprake van een totaalbeeld van de genetische bijdrage. Een betere strategie zou kunnen zijn om de nadruk te leggen op meer specifieke aspecten. Eén van deze aspecten is de farmacogenetica, de discipline die onderzoekt hoe genvarianten de reactie op medicatie beïnvloeden. De farmacogenetica is het uitgangspunt van de papers die in deze thesis worden besproken.

Hoofdstuk twee $\mathrm{t} / \mathrm{m}$ vier gaan over de recent ontdekte invloed van drie genvarianten op de reactie op antidepressiva. Daarop volgt de eerste poging tot een neurale netwerkanalyse van de interactie tussen genen bij de reactie op antidepressiva. In hoofdstuk zes en zeven wordt verslag uitgebracht over het eerste onderzoek naar het effect van een specifiek gen (CLOCK) op slapeloosheid ten gevolge van stemmingsstoornissen en op de reactie op antidepressiva. Hoofdstuk acht gaat dieper in op het concept van de farmacogenetica en hier wordt besproken of de invloed van genvarianten op het volledige menselijke gedrag veel complexer is dan gedacht. Om ook de mogelijke invloed vanuit de omgeving te kunnen onderzoeken, ligt de nadruk in hoofdstuk negen vooral op de mogelijke klinische factoren die de reactie op antidepressiva beïnvloeden en die in de toekomst meer aandacht moeten krijgen. In hoofdstuk tien wordt de beschikbare kennis samengevat aan de hand van de eerste meta-analyse ooit van het belangrijkste gen in verband met de reactie op antidepressiva (HTTLPR). Ten slotte wordt in het elfde hoofdstuk voor het eerst het nieuwe idee toegepast dat genen een groot aantal effecten beïnvloeden, met als voorbeeld varianten van het gen GSK-3beta.

Het onderzoekspad begint bij farmacogenetica en leidt naar een uitgebreidere analyse van het effect van genvarianten op menselijk gedrag. Genetische vatbaarheid zal echter nooit deterministisch zijn. Het zal nooit mogelijk zijn om elk individu met zekerheid te zeggen wat er gaat gebeuren. Het zal enkel mogelijk worden een hoger of lager kanspercentage te verschaffen in vergelijking met de rest van de bevolking. Gedetailleerde kennis van alle mogelijke invloeden van genetische vatbaarheid kan bovendien nooit worden gebruikt om individuen onder te verdelen in een categorie A of B: elk genetisch bepaald psychologisch kenmerk heeft zowel positieve als negatieve eigenschappen. Er kunnen enkel profielen worden gecreëerd waarbij bepaalde risico's per individu meer of minder aanwezig zijn. Dankzij genetische kennis wordt het misschien mogelijk de omgeving zo te manipuleren dat de negatieve impact van het genetische profiel wordt geminimaliseerd. Dit kan niet alleen leiden tot gepersonaliseerde medicatie, maar ook tot een beter begrip van genetische invloeden op mensen. 
Acknowledgements

A first thank to Maastricht University for giving me the opportunity to obtain my doctoral degree and in particular, Professor Griez, for his kindness and accessibility. I also thank Leni Noteborn for her help and kindness. Thanks to all my past supervisors, Prof. Conte at Catholic University, Rome for making me love psychiatry, Prof. Smeraldi at Ospedale S. Raffaele, Vita-Salute University, Milan, for giving me the opportunity to grow professionally in the years we have worked together. Prof. De Ronchi for believing in me and for allowing me to have a fruitful scientific activity.

A particular thank to all my collaborators that worked all really hard and efficiently. In chronological order: Cristina Cusin, never tired, Enrico Lattuada, with unvaluable clinical skills, Laura Mandelli, still working in my group with exceptional enthusiasm and scientific skill, Paola Artioli, always postponing herself to the duty, Cristina Lorenzi, leading the laboratory at S. Raffaele with constant effort, Raffaella Calati, a precious 'bridge' between biology and psychology, Antonio Drago, recently joining our team with uncommon scientific skill and enthusiasm. Also I would like to mention Paolo Olgiati, Masaki Kato and all the others that, even for a short time, joined our team.

A thank for all patients who taught me a lot and participated with enthusiasm in all our studies.

A final thank to my father, who, with sacrifice, allowed my career development. 


\section{Curriculum Vitae}

Alessandro Serretti, born in 1966 in Senigallia, Italy, MD in 1991 (mark 110/110 with honours, Catholic University, Rome, Italy), Specialization in Psychiatry (1996 - mark 70/70 with honours, Milan University).

Since 1999 to 2006 Director of the Unit of Genetics in Mood Disorders, Dept. of Psychiatry, IRCCS Ospedale S. Raffaele, Milan.

2001-2008 Professor of Statistical Genetics at University Vita-Salute, IRCCS Ospedale S. Raffaele, Milan.

2006-present Associate Professor of Psychiatry (Ricercatore) at Bologna University, Bologna, Italy (main position).

Author of more than 190 scientific papers in peer reviewed journals and 272 presentations in National and International congresses. Reviewer and member of the editorial board for a number of journals and funding agencies. Principal Investigator in various national and international scientific collaborative projects. Coordinator of a research unit active in genetic and clinical studies of major psychoses. 